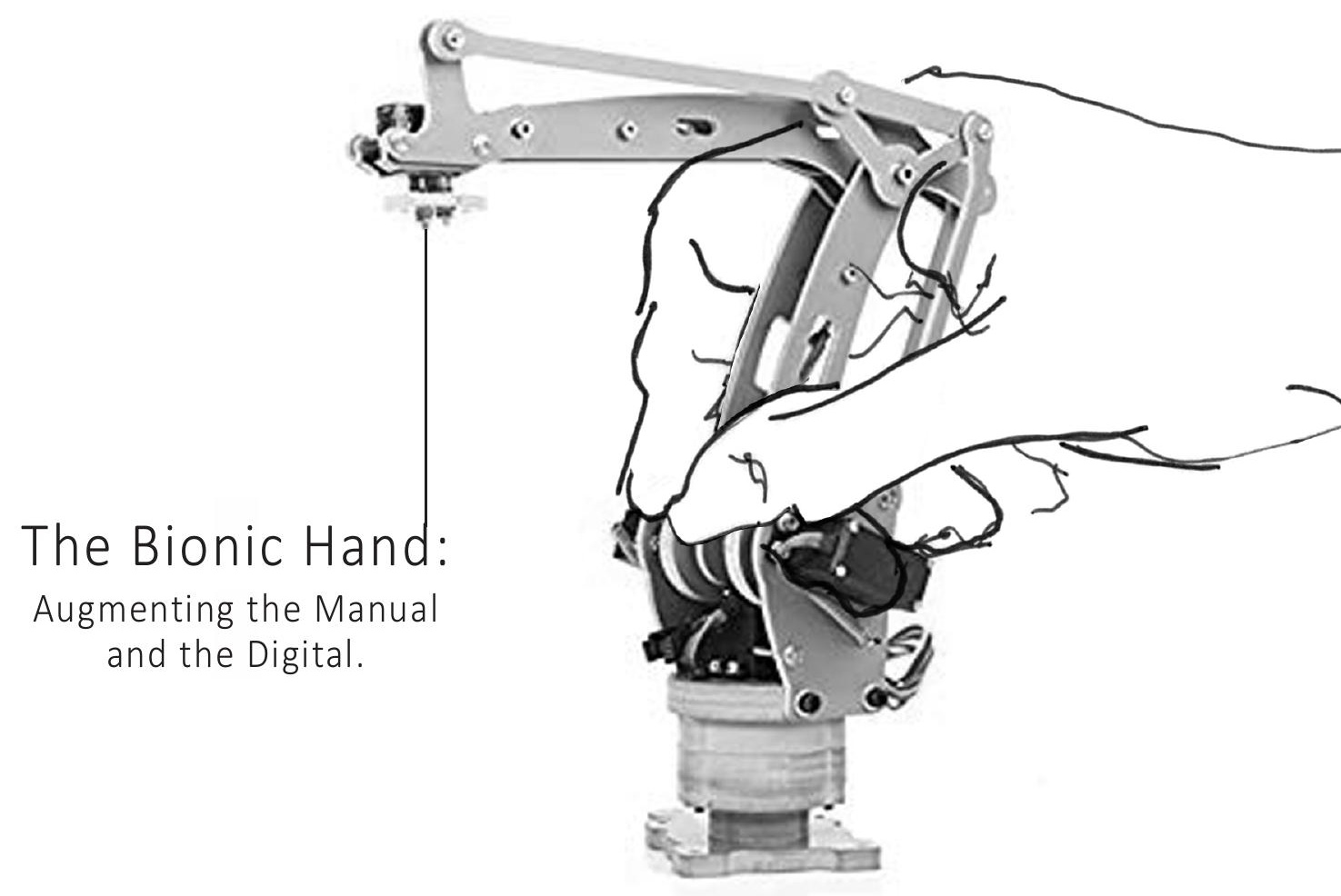


Sarah Davie

A 120-point research portfolio submitted to Victoria University of Wellington in partial fulfilment of the requirements for the degree of Masters of Architecture (Professional).

ictoria University of Wellington 


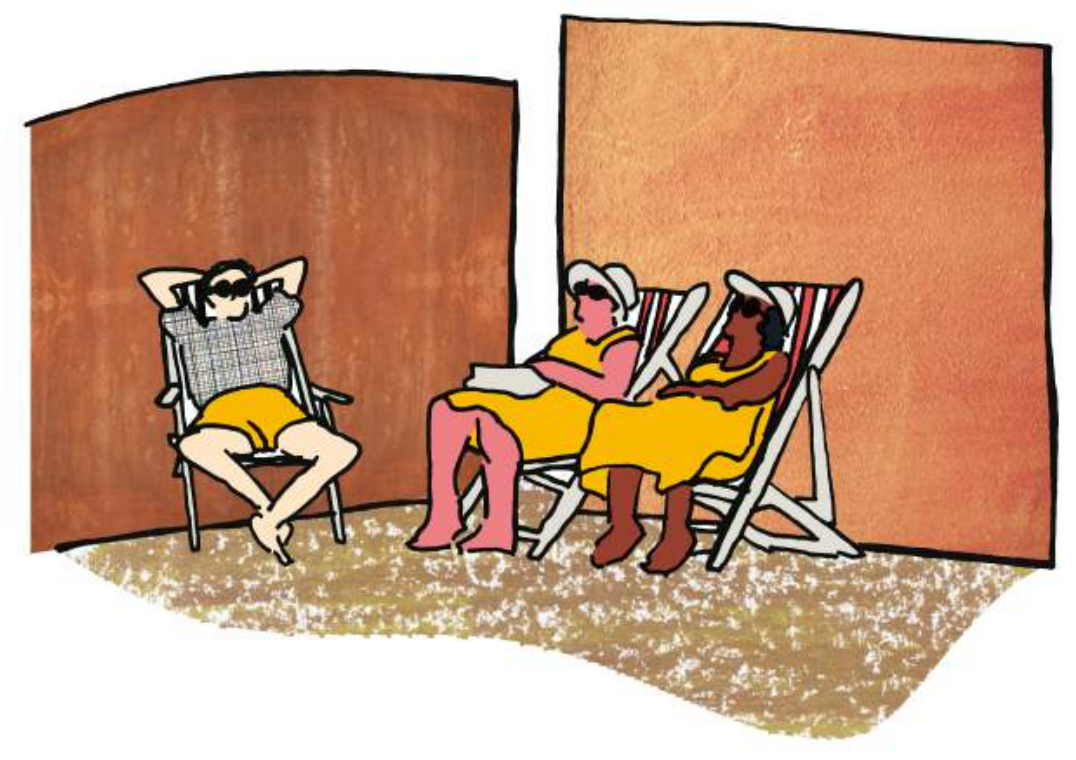

Thank you:

To my supervisor Dr Sam Kebbell for your knowledge, insight, and

To my friends on campus for being so talented and pushing me to work hard

To my friends off campus for sticking around.

But mainly to my parents, and Katherine, Justin and Abby for putting up with it all. 
The tension between the hand and machine is currently at the core of one of architecture's biggest debates. Pallasmaa and the firm Kieran thith a significant following.

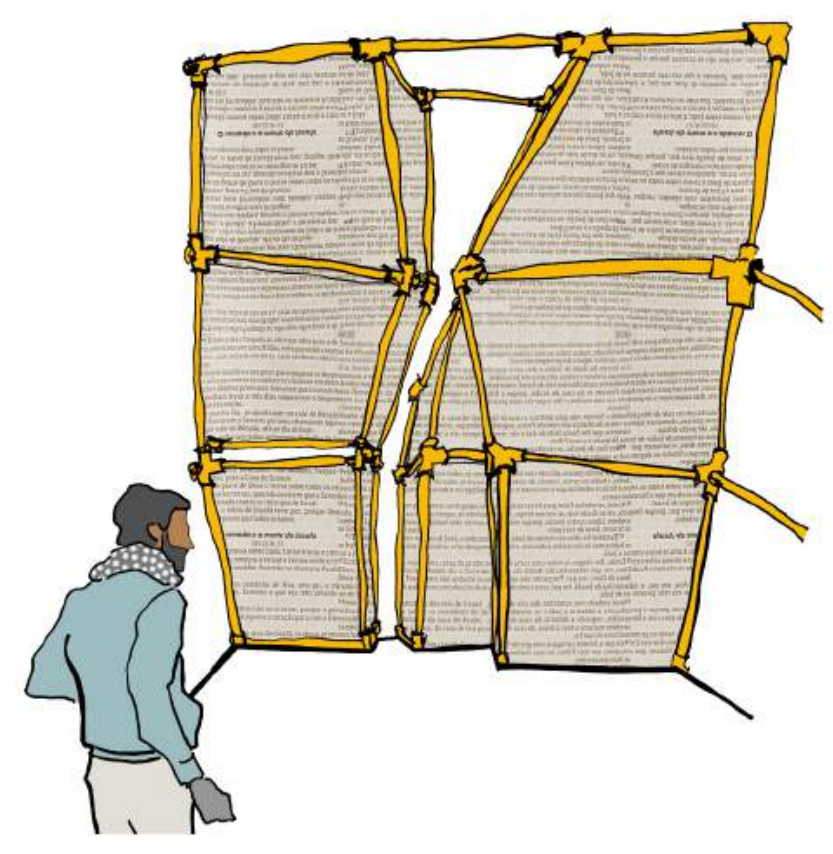

Kieran Timberlake, who designed Loblolly House, use digital design and construction methods to discover new construction techniques for a globalised world. The capacity of parametric software, 3D printing, They are opening the possibilities of new sculptural forms, more efficient construction processes, and alternative forms of detailing and ornamentation.

In contrast, Pallasmaa uses 'the thinking hand' to draw out intimacy: nooks, irregularities, material richness, and handcraft that invite the user into a closer relationship with architecture. Hand drawing and hand making are crucial to Pallasmaa's goals: intimacy exists in both the design process and the final form of architecture.

The design process is not as divisive as famous pillars at each end of the spectrum inply. In this work, I explore. how can rnigrging technologies and 'the thinking hand' complement each other? And how might the 'bionic hand' inform both intimacy and efficiency?

I explored this through designing a six-unit housing project in the Wellington suburb of Hataitai. The site is next to Roger Walker's maze ugh hand and digital processes

My main intention was to document a design process that integrates hand and digital techniques, showing one way an exchange between them could occur. I almed to combine efficiency and intimacy, throus exploring digital and hand techniques. This resulted in findings of architecture, the design's place in the context of New Zealand suburia and its place in the discipline. 

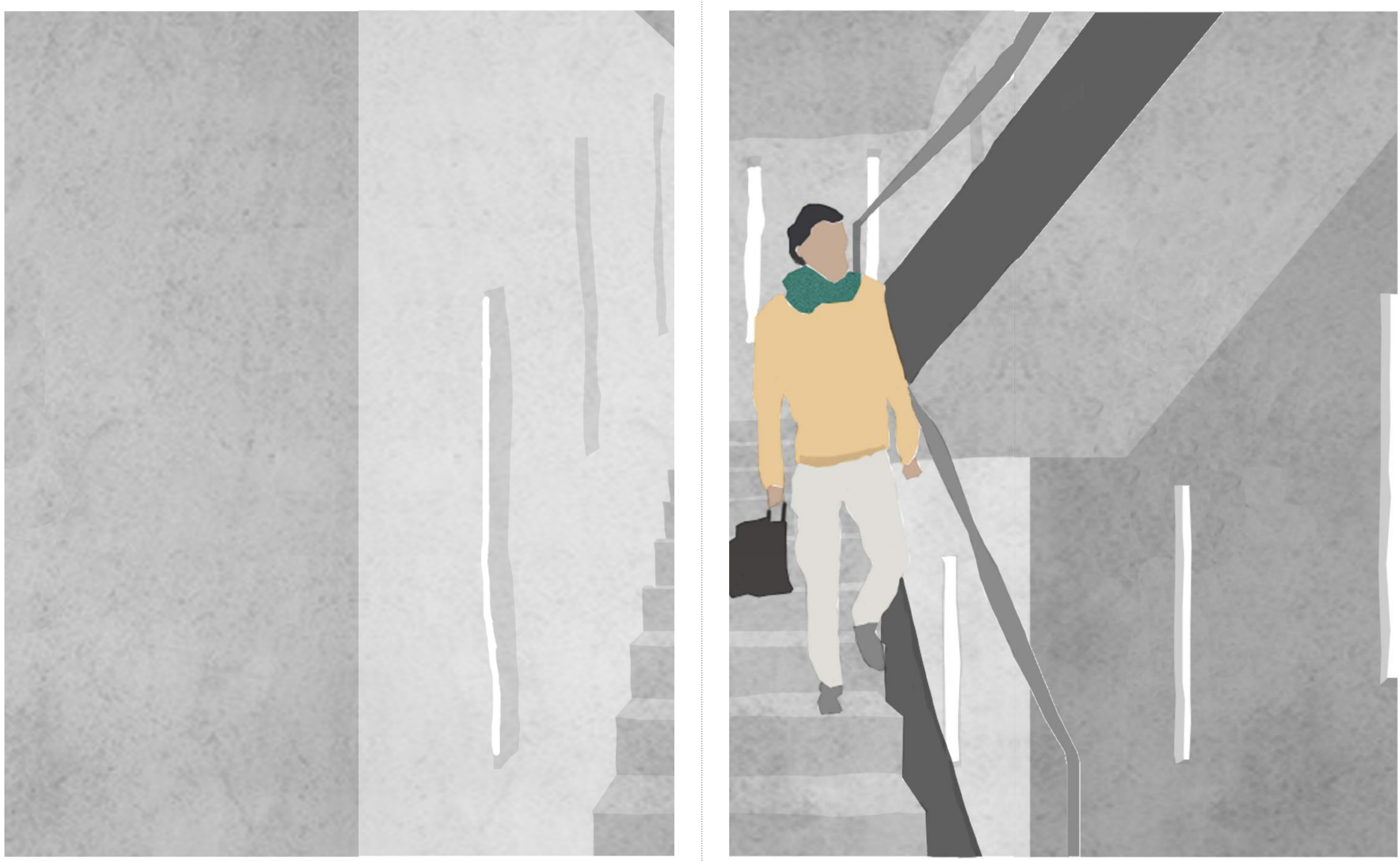


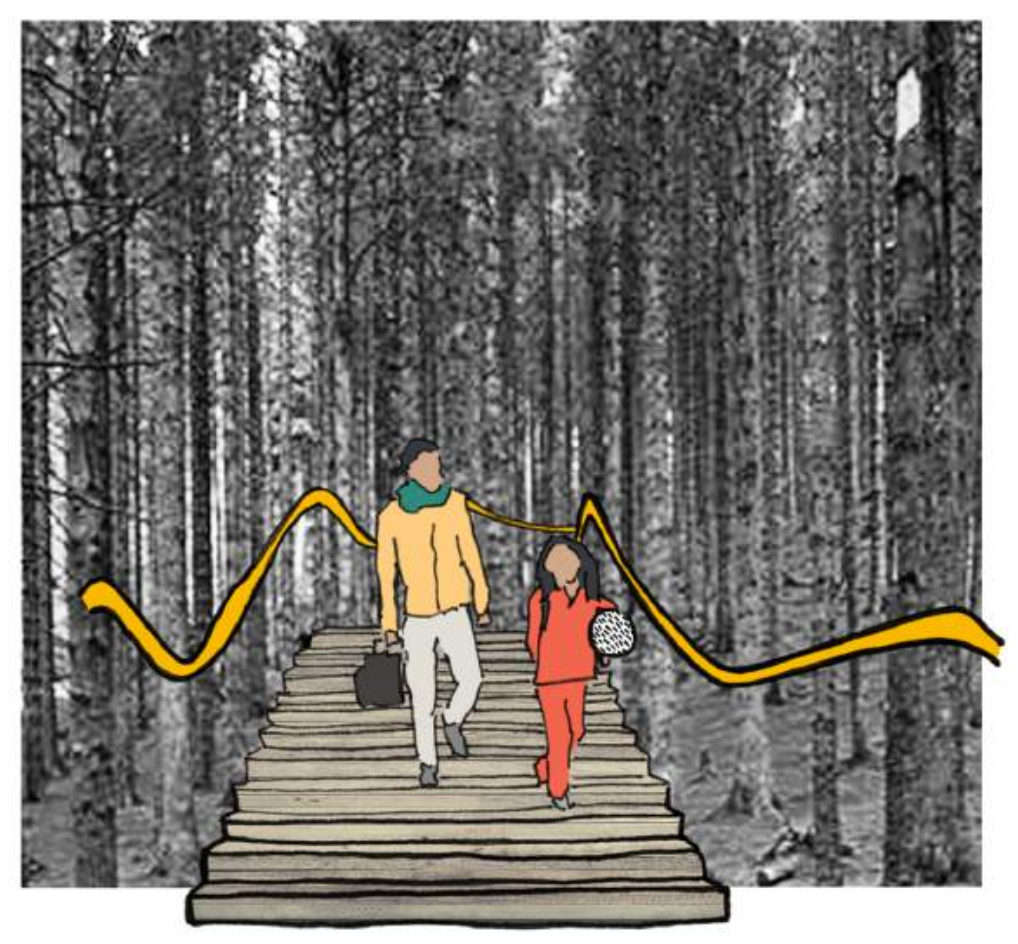

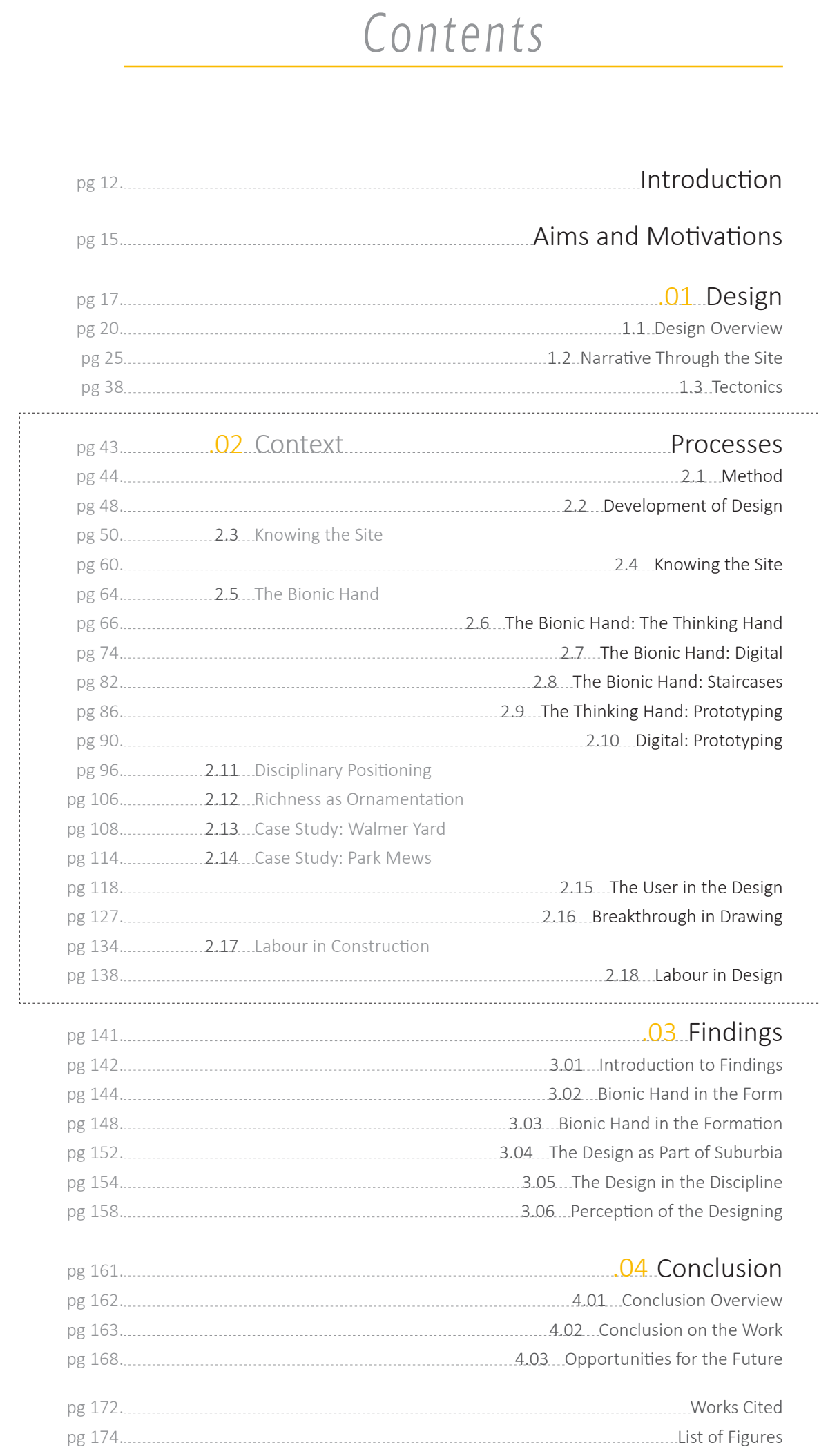


The bionic hand is a process of working (the formation of architecture), and an approach to building (the form of architecture).

It combines:

Firstly, the thinking hand. This is the direct connection of brain to arm to tool for drawing and modelling to create intimate space, and in construction, to create hand crafted, materially rich space.

Secondly digital tools: which allow a more efficient design proces through digital programmes augmenting manual techniques, and digital fabrication in construction decreases the labour associated with irregular design.

I have explored this in a suburban context through a six-unit housing project in Hataital. The research stream is investigating the

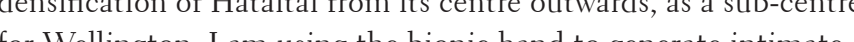
for Wellington. I am using the bionic hand to generate intimate architecture, with moments of interest and spaces to dwell and inhabit.

The design of intimacy comes through complexity in the building The site is adjacent to Park Mews, a building that contrasts the otherwise low-density stand alone dwellings of the area. Park Mews is a

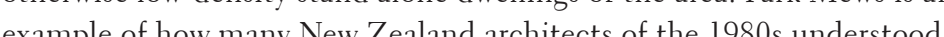
'complexity' and 'irreguly'

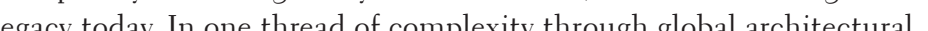

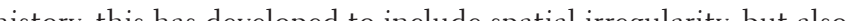
complexity and intimacy thro coft and

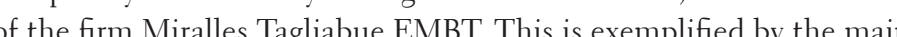

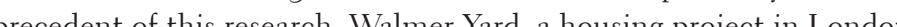
by Peter Salter.

position my research within this thread of history, using the bionic hand to achieve it. I also draw on Peggy Deamer's writing around the high levels of labour involved in both the design and construction progress the understanding of complexity to address this.
I mainly designed through two orbiting processes.

1. Orbiting between hand processes and parametric digital models to augment the drawing and make it more efficient for testing.

2. I switched between perspective drawing of moments and planning and form of the full scheme aggregating the moments together. This used physical drawing to generate irregular imaginary worlds and the intimacy of the experience within them.

Discoveries within each side of the bionic hand, both in designing and prototyping pushed the research and understanding of this way of working forward.

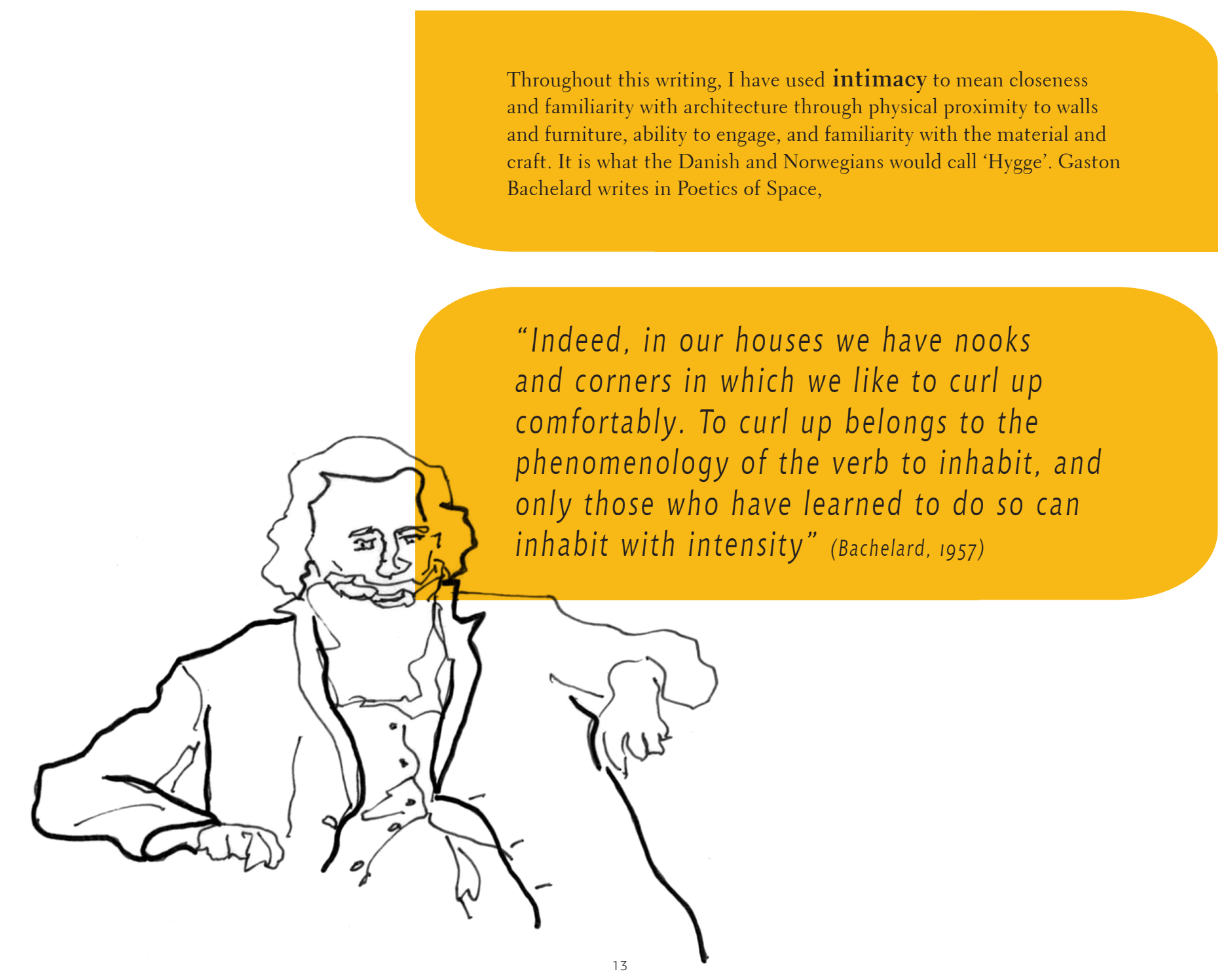




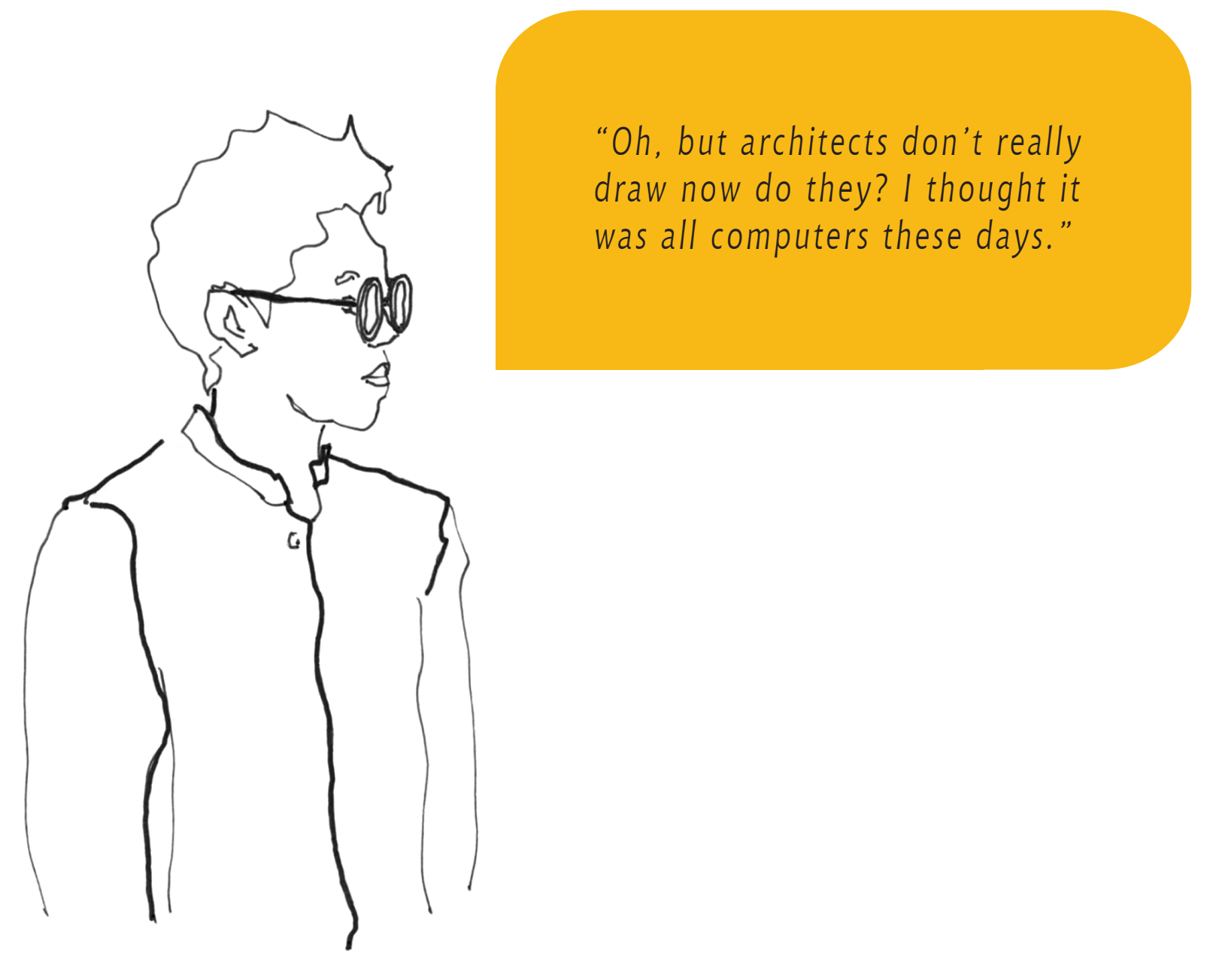

\section{Aims and Motivations}

This was said to me by a friend during the year.

It is a common misconception outside of the discipline. A false dichotomy. This tension within my own process was the motivation of this research

Thinking and creating imaginary spaces through drawing has been fundamental to my design process throughout my architectural education. To speak of only 'drawing with computers' does not begin to touch on the capabilities digital tools provide us. These are advancing capabilities designers must embrace. However, the value of hand drawing should not be disregarded in the digital age. My research question is:

How can emerging technologies and 'the thinking hand' augment each other in the design and construction of intimate architecture?

The key aims in this research are:

1. To contribute to the body of knowledge of how design process works. The specific aim in this project is to document a process of digital and hand techniques augmenting each other-

2. To use drawing to generate intimate, familiar spaces through complexity in space, craft and material,

3. To use digital tools to mitigate the high levels of labour (in both the form and formation of architecture) associated with this style of bespoke design.

4. Designing a suburban architecture to engage with a densified street front

The objective of the final design is to be an example of the bionic hand form of architecture.

The objective of the documented design process is one example of the bionic hand in the formation of architecture.

Overall this project addresses both these aspects of architecture, the form (the constructed building) and formation (the design process) of an intimate architecture. 


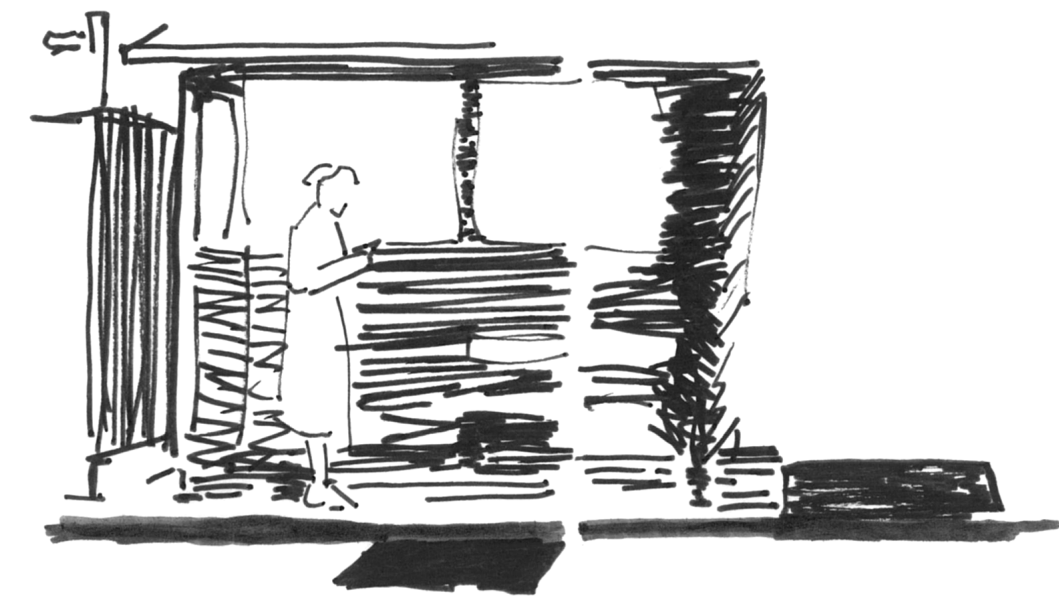



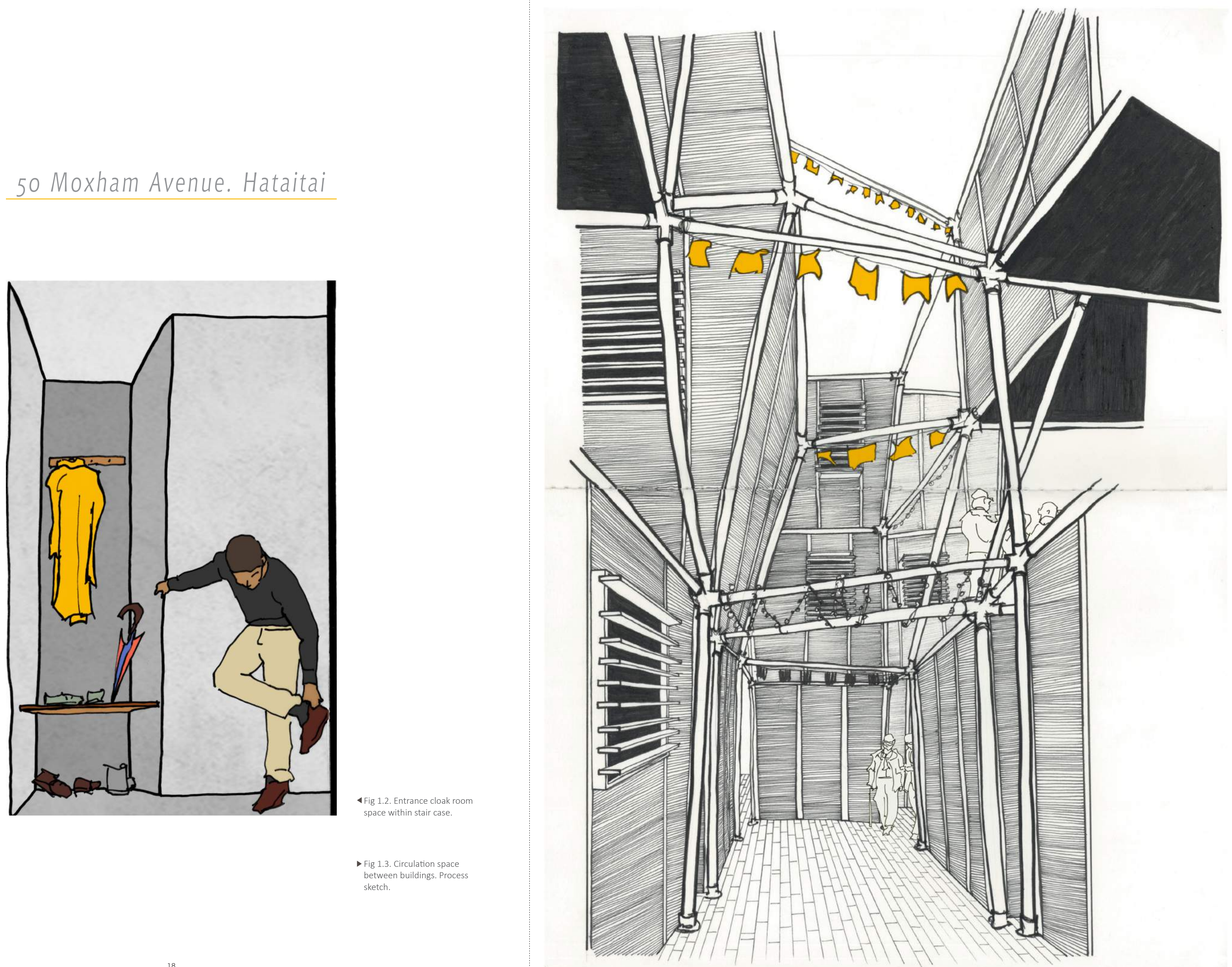


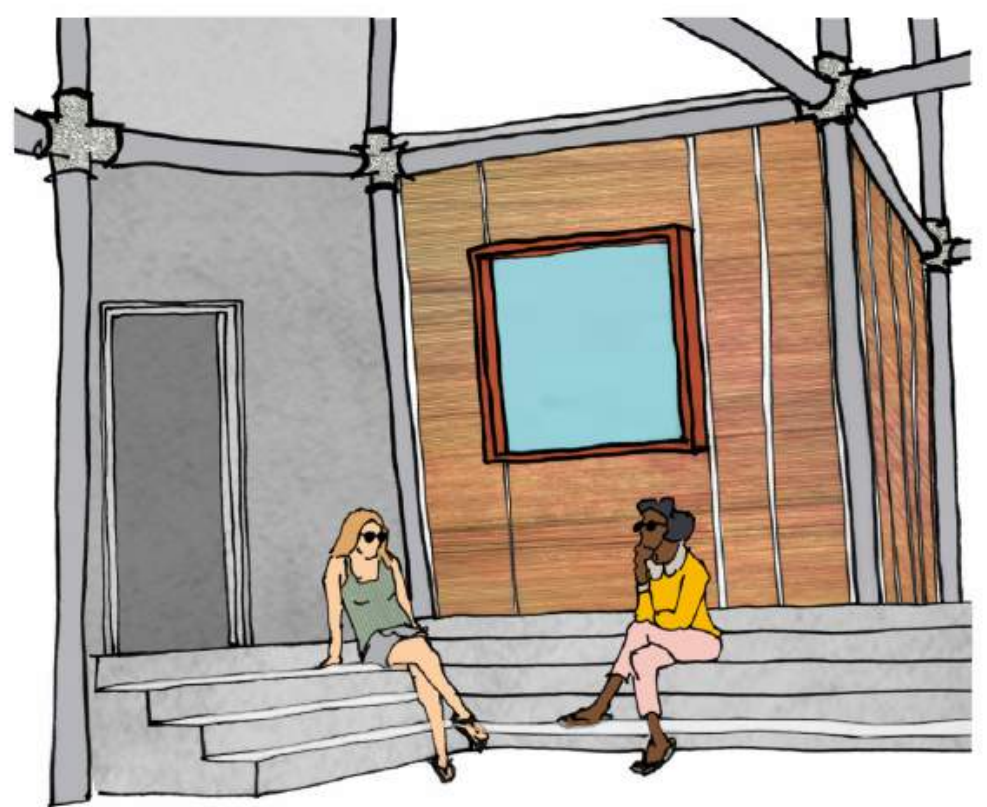

A Fig 1.4. 'Stoop' space for socialising between houses.

Fig 1.5 shows the design is six houses within one site, and within one as a structure to the houses within. Each house spans three storeys,

including a private baleony on the first floor. The conterete staircases sit amongst the steel structure but are self-supporting. Their weight and solidity contrasts the lightness of the exoskeleton on the site. They are six pillars of the building with irregularly planned and formed houses wrapping themselves around them
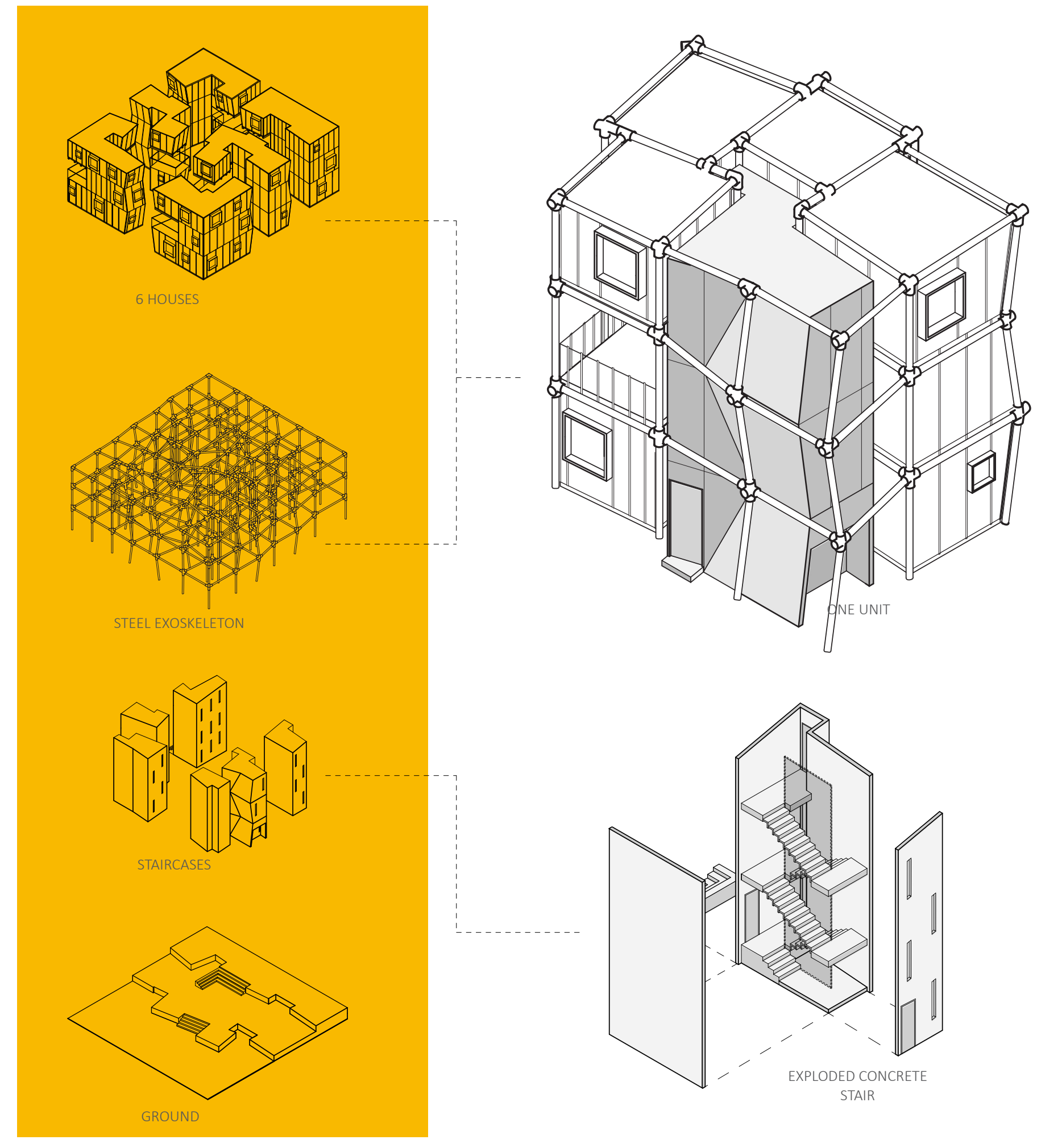

Fig 1.5. Tectonics of the six houses 

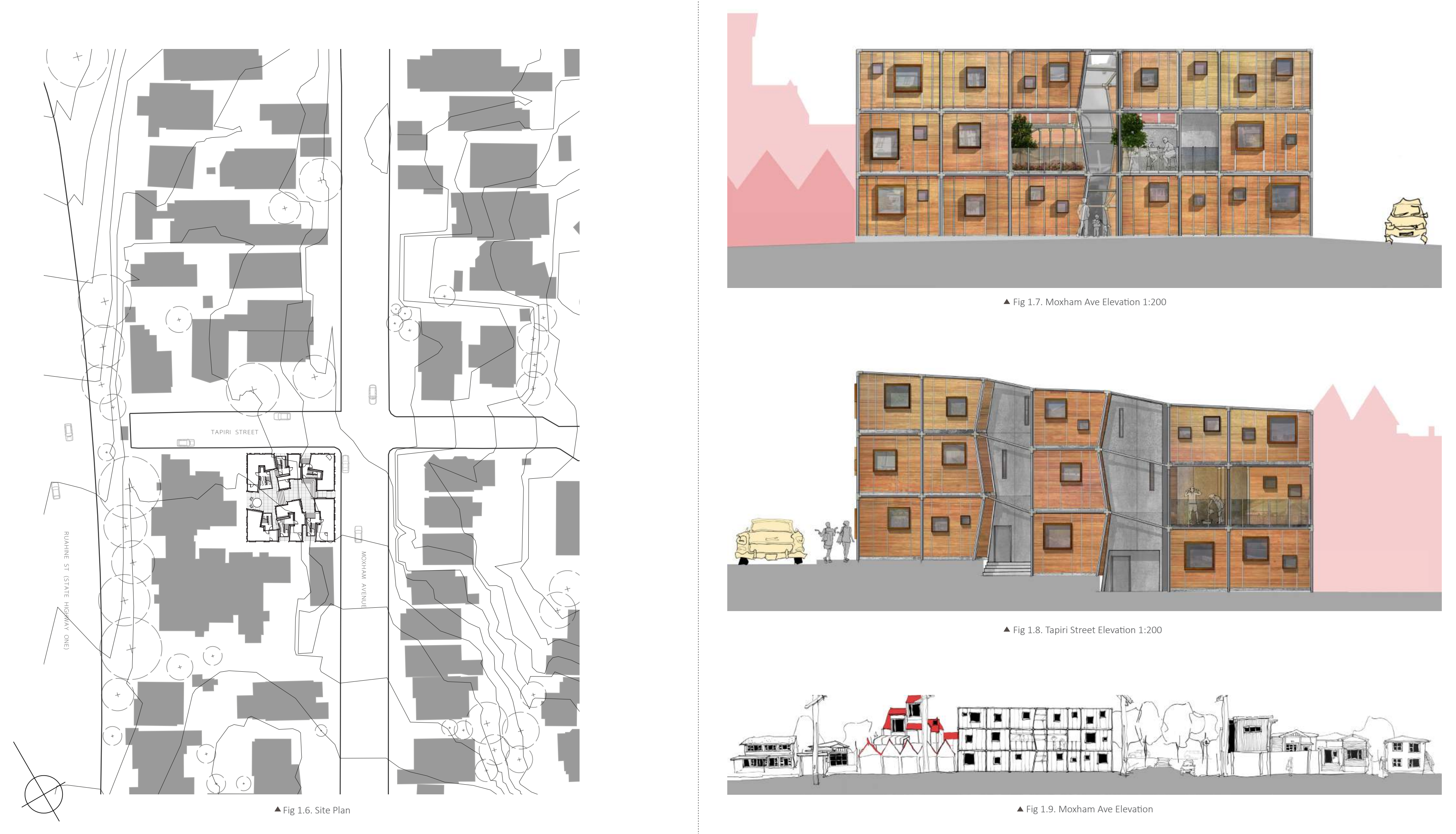

A Fig 1.8. Tapiri Street Elevation 1:200

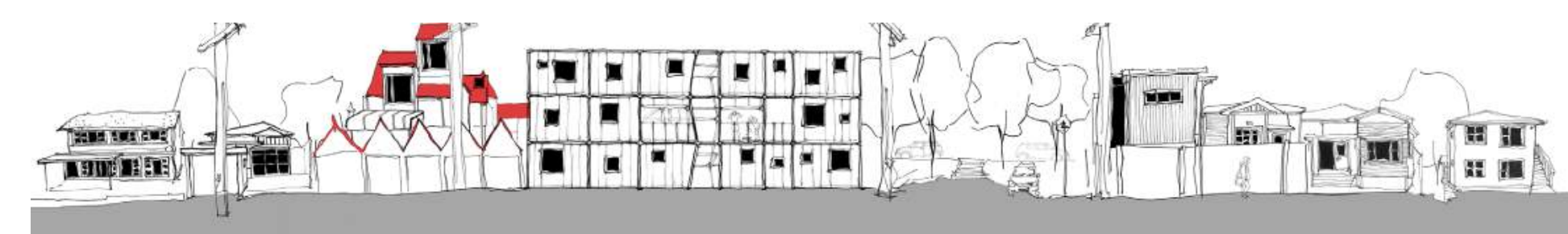




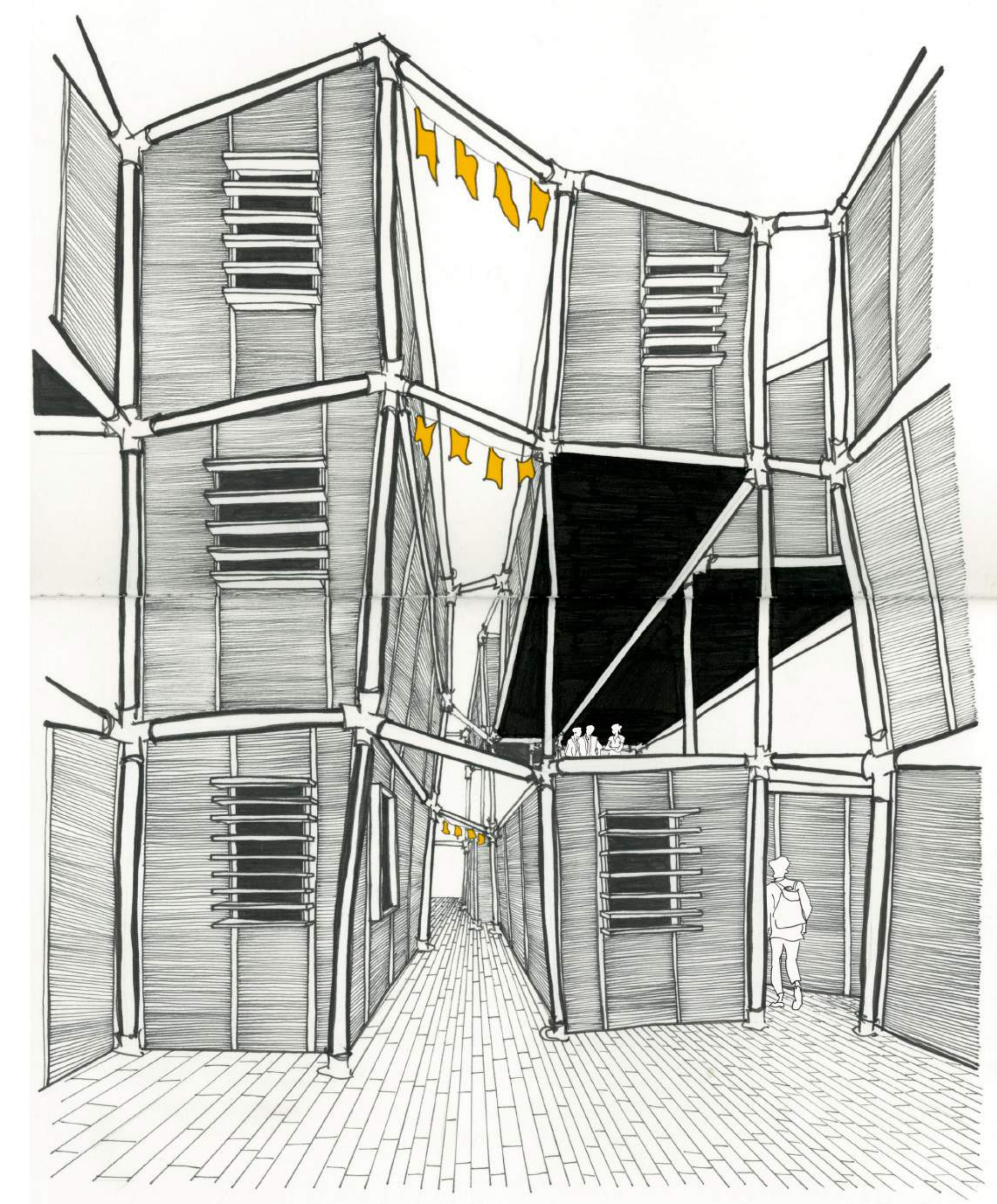

Narrative Through the Site

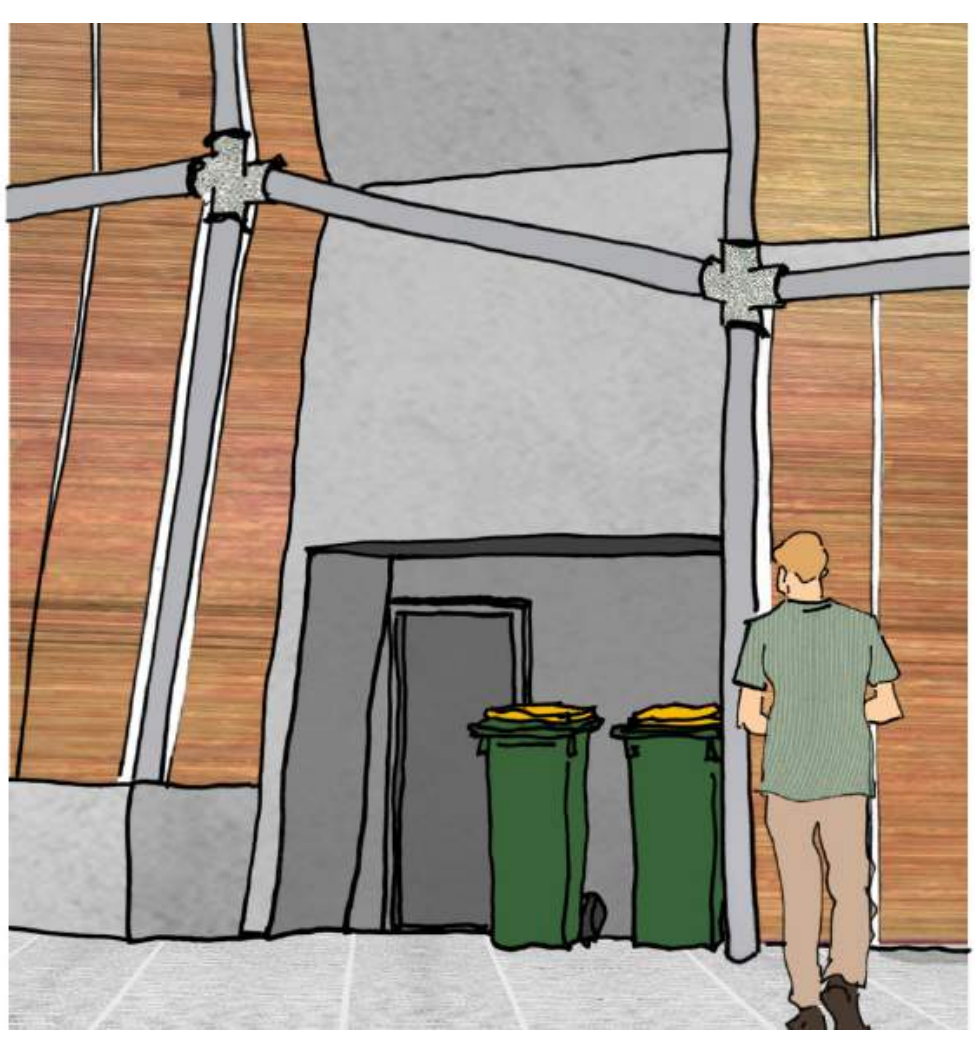

The main entrance to the site comes off Moxham Ave, a key street

leading to the Hataitai Town centre. A straight façade abutting

the footpath breaks into a kinked slit of an entrance, hinting at the

complexity of form behind the Euclidian front (shown in fig 1.7).

Fig 1.10 shows upon entrance exoskeleton beams criss-cross over the

circulation spaces, walls lean over the walker, and corners poke out

leaving nooks aside them. Stairs along the central axis drop down the site's contours, for both circulation and sitting (fig 1.4). Unique paths off the different levels lead to each house.

As seen on the ground floor plan on the following page the main entrance to each house is through the staircase, which acts as storage and a cloakroom. A second entrance/exit and utility space, drawn above,

$\triangle$ Fig 1.11. Second entrance Tapiri St. Provides bin and utility space.

4 Fig 1.10. Circulation space sketch

h staircase leads off site. The concrete textures

of the stairs act as a threshold to the warm dwelling spaces through the

next door. The ground floor contains a bathroom and laundry, but the

door opens into a kithen, each bespoke in lay ont. A living area comes

off the kitchen and dining space enclosed by richly crafted bamboo

lined walls, shelving, a sloped wall for leaning against, and inbuilt

furniture to fit the irregular angles. 

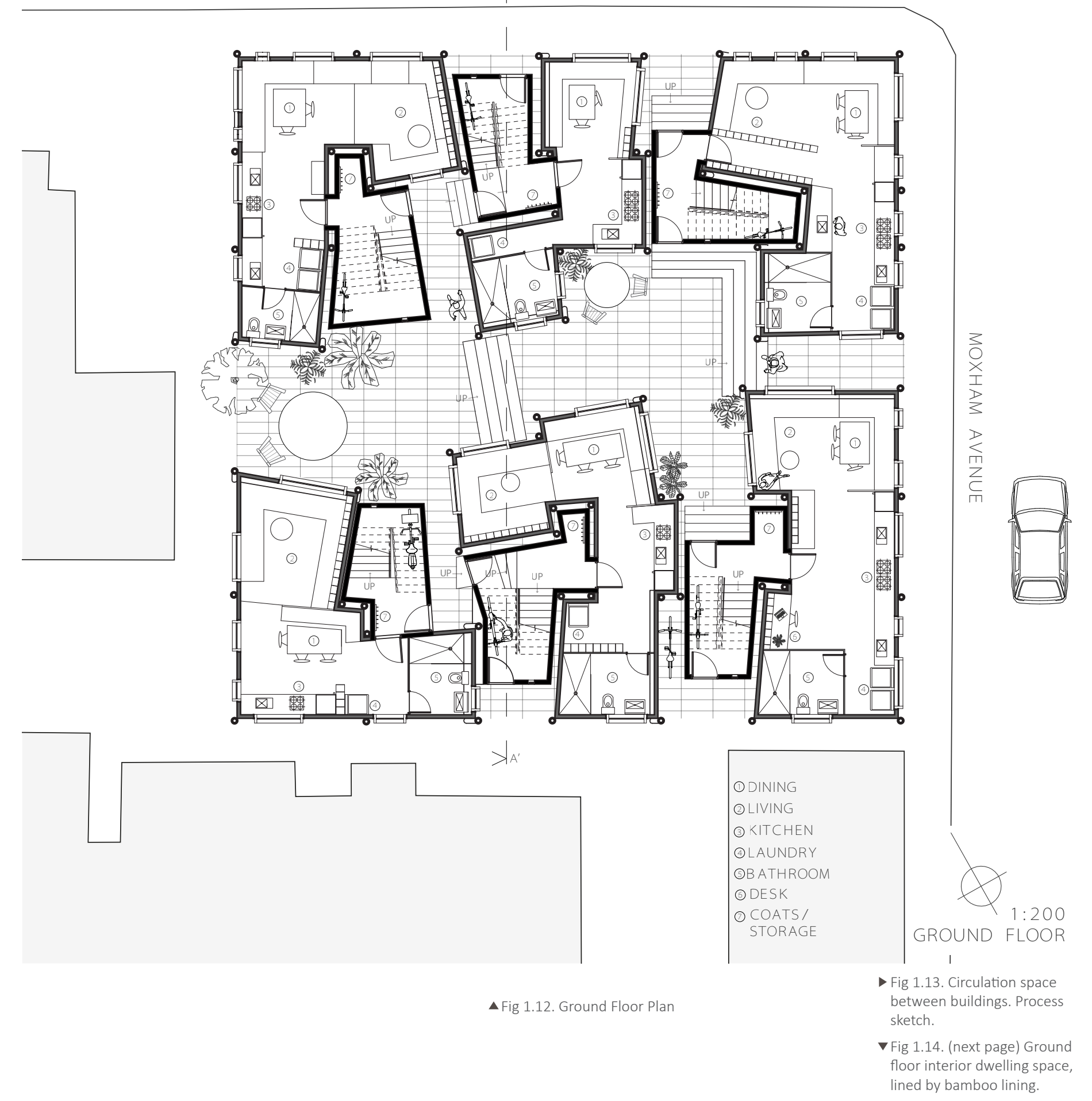

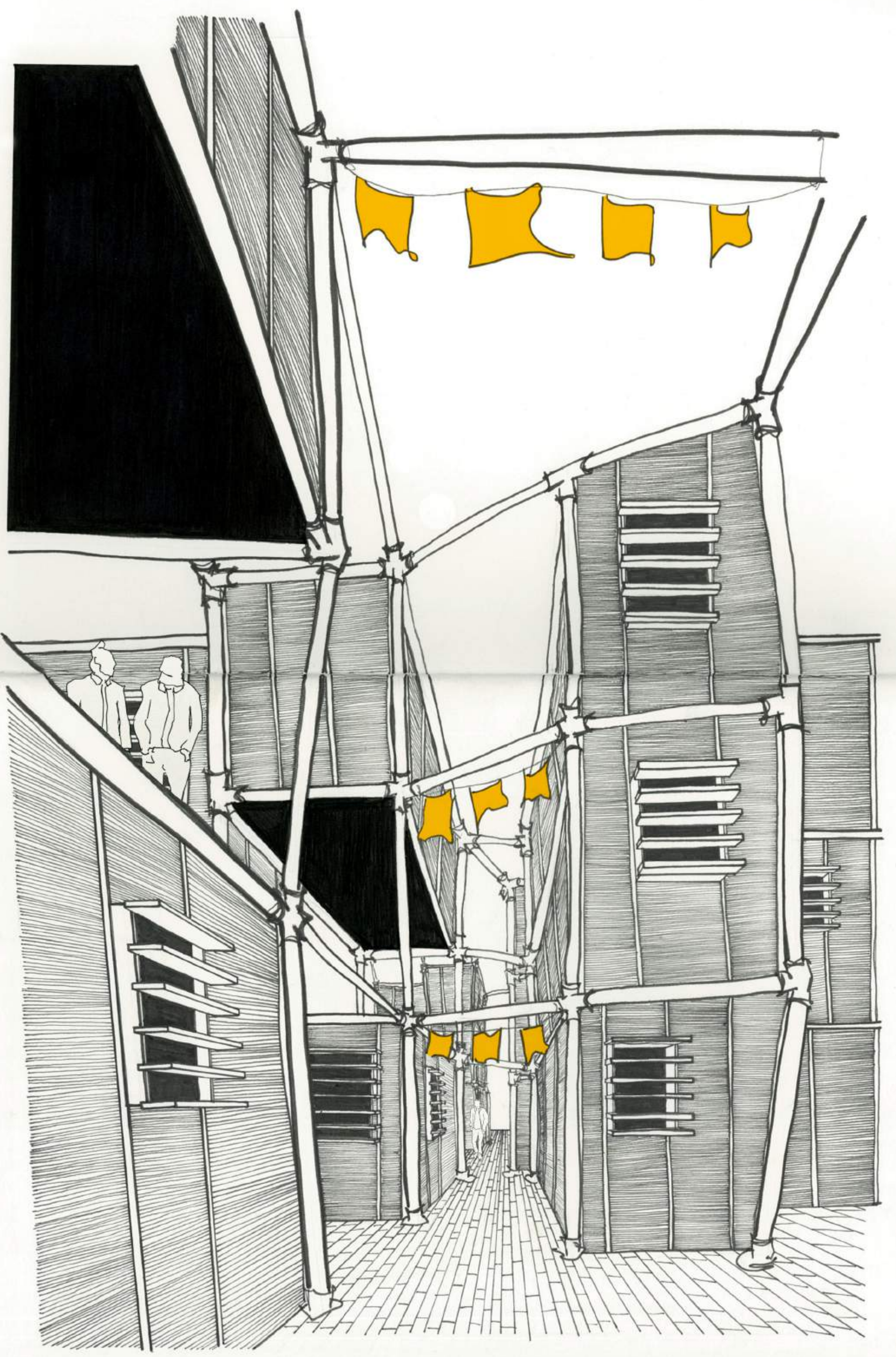





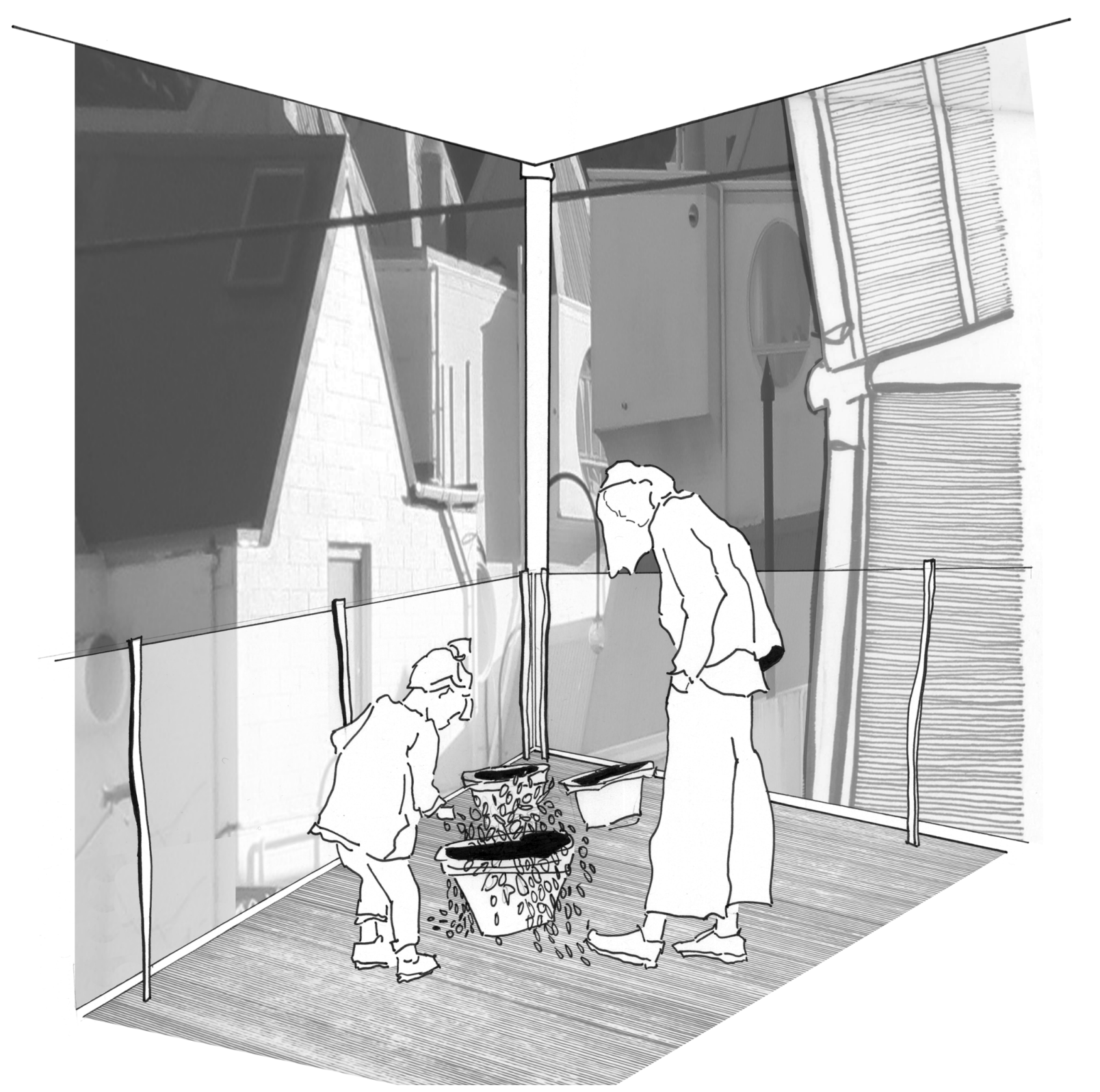

Level one provides the main living spaces. The interior of these also takes on the characteristics of rich material and inbuit finture to

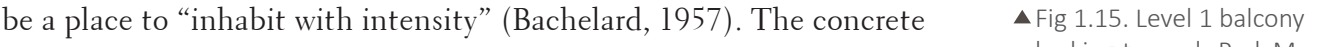
staircase diversifies the material palette as a threshold between the levels. On the first floor is an open balcony looking over the maze of structural members below, out to Hataitai or back to Park Mews (as shown above).

V Fig 1.17. (next page) Level one balcony and interior dwelling area.
APIRI |STREET

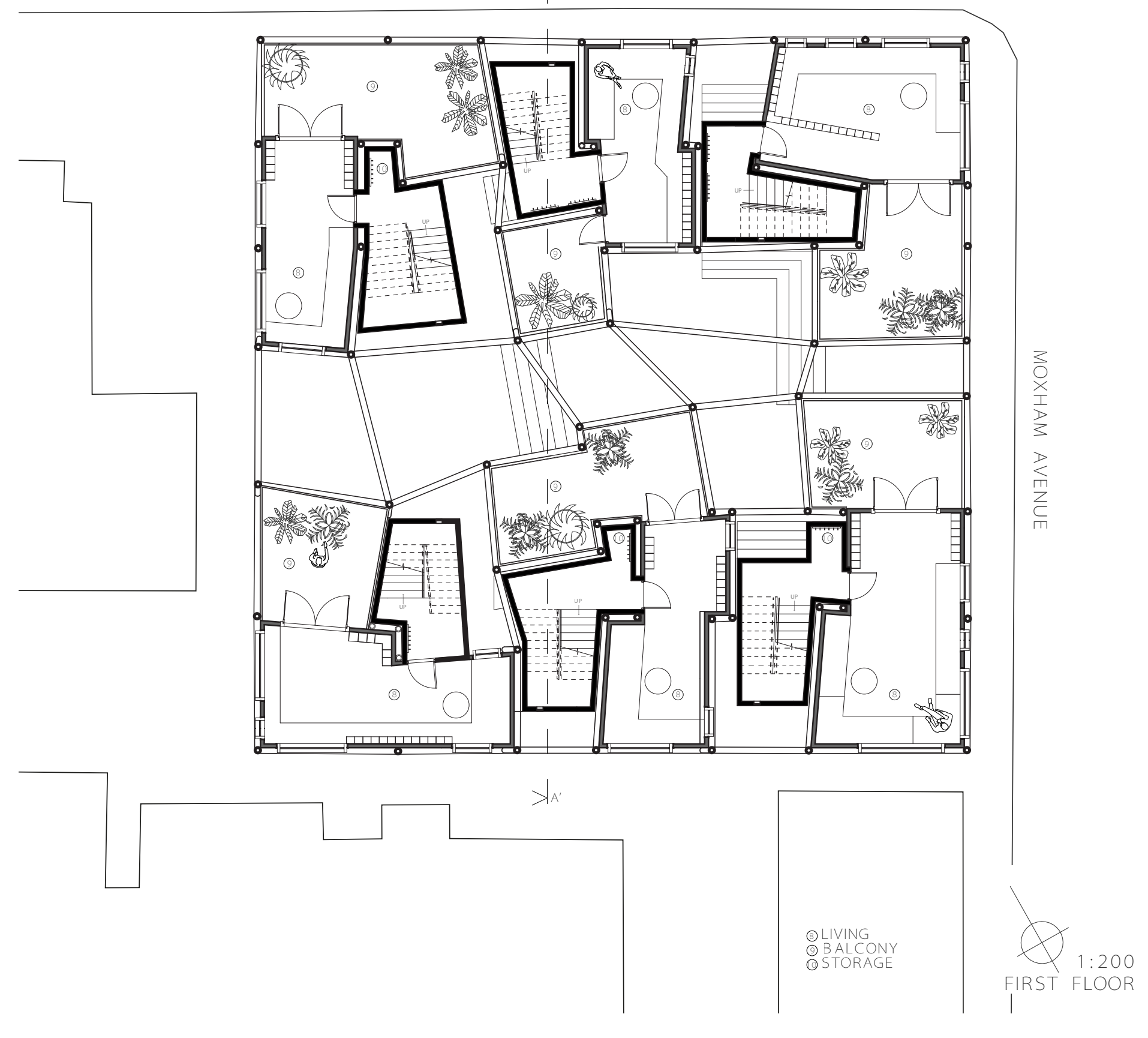




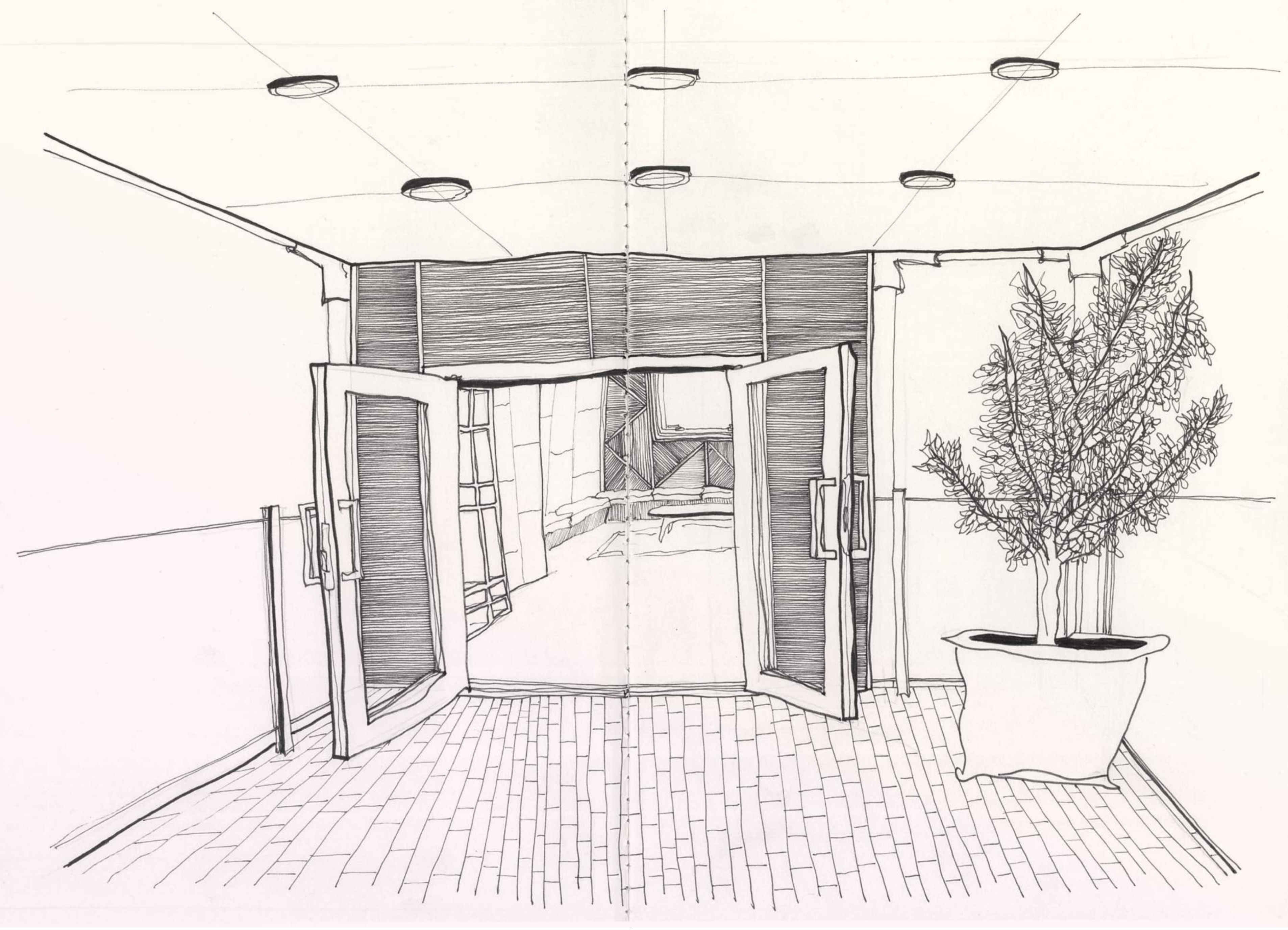




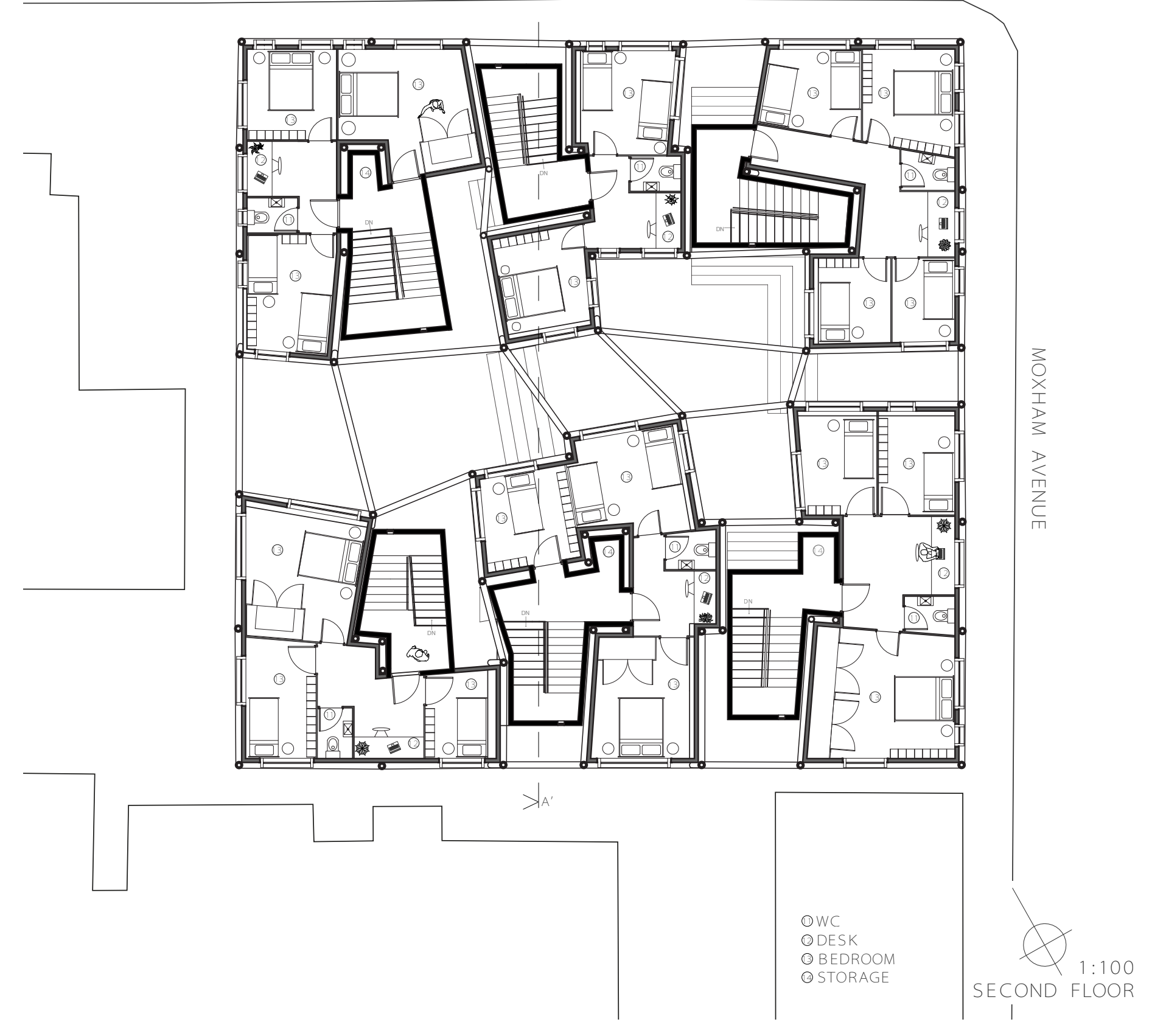

The top floor maintains irregular angles and sloping walls of the other

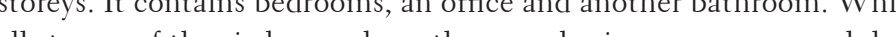
has a unique arrangement due to the irregularity of the planning.

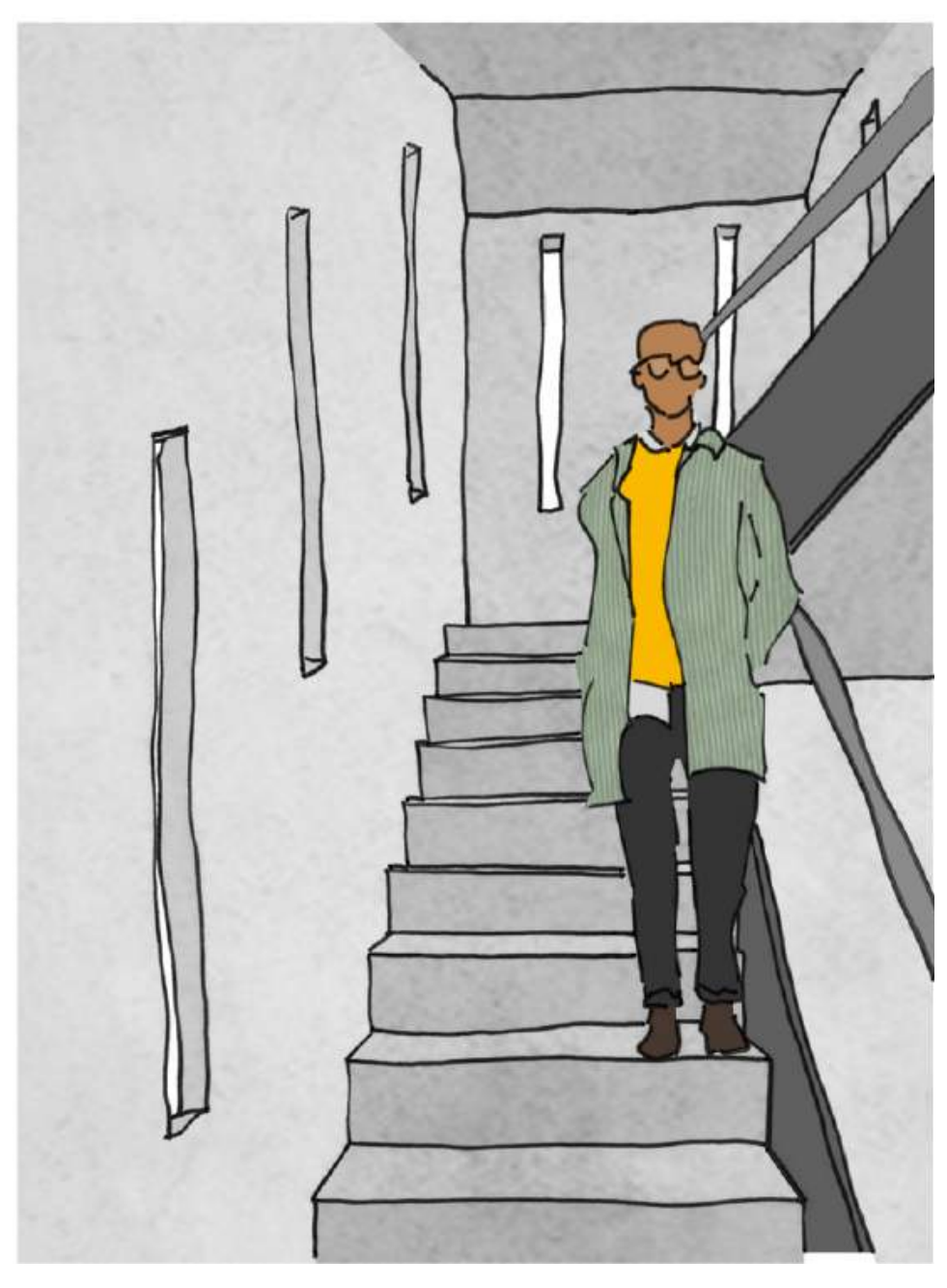



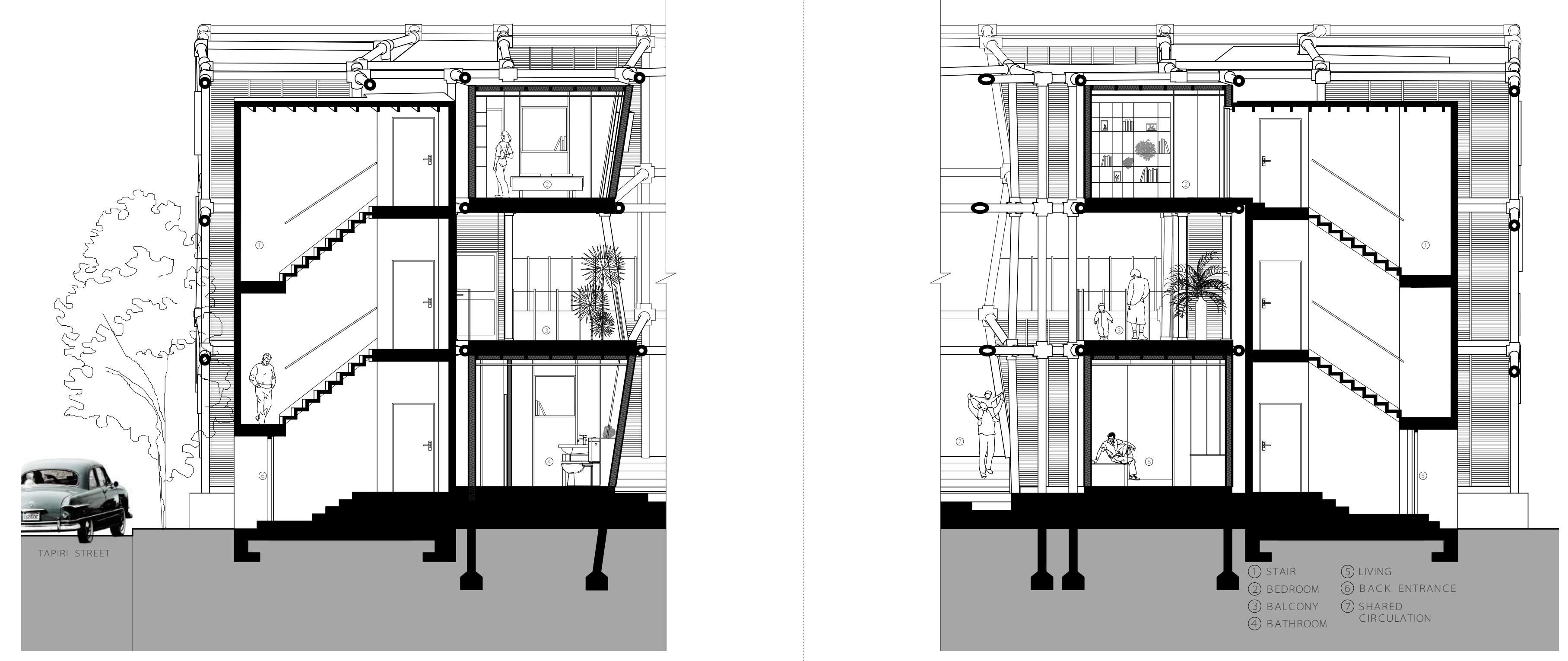


\section{Tectonics}
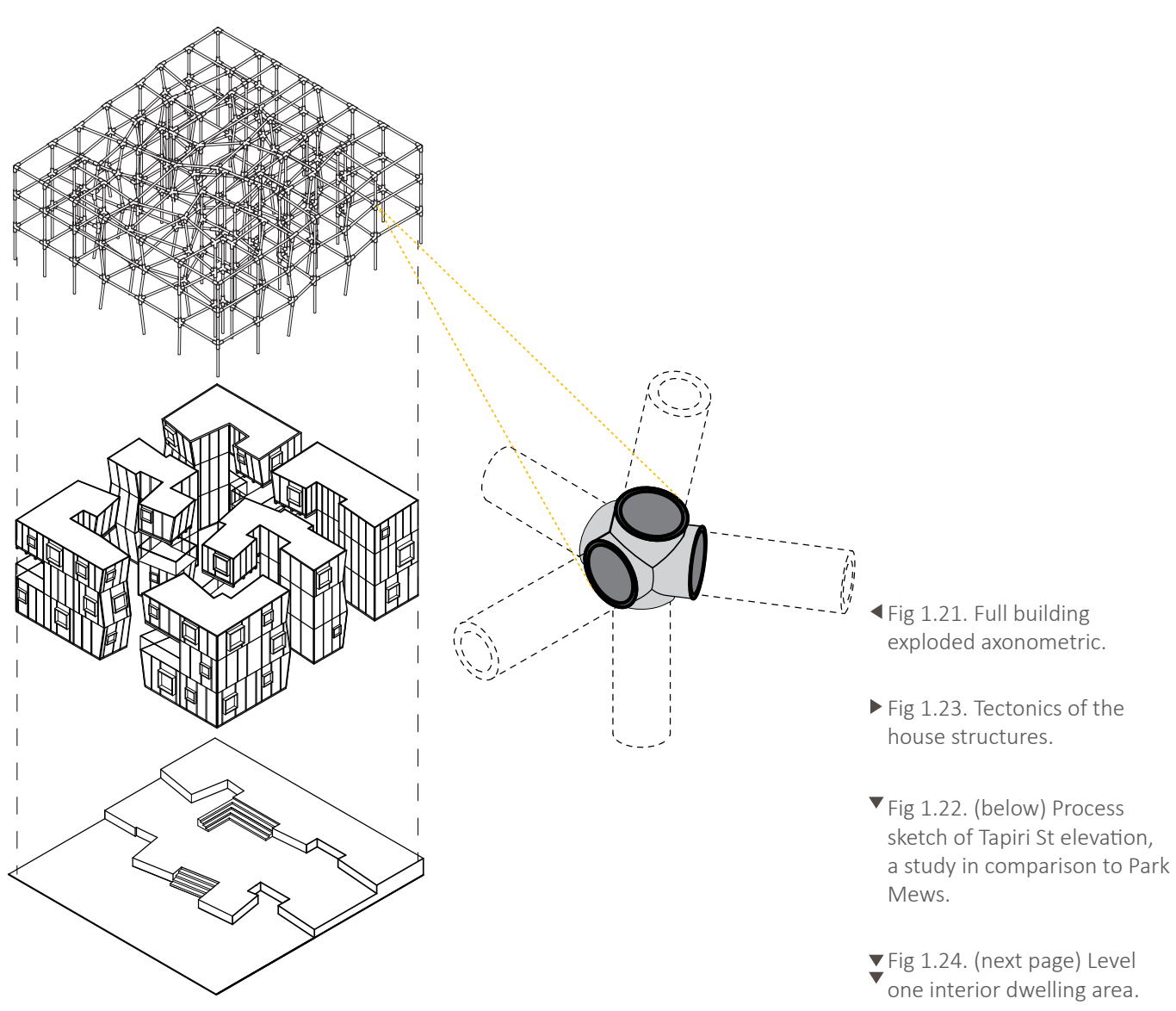

The exoskeleton system provides the structure for the building. Because the nodes and the structural system provide the irregular angles, corners and lengths, all other construction systems only have to fit into and around it, not accommodate the irregularity themselves. Ribs attaching to the structure and floor slabs make up the walls. These hold the windows insulation and claddings, including the hand crafted bamboo interior linings. The exoskeleton takes the structural responsibility off the walls allowing them to angle creating spatial intimacy.

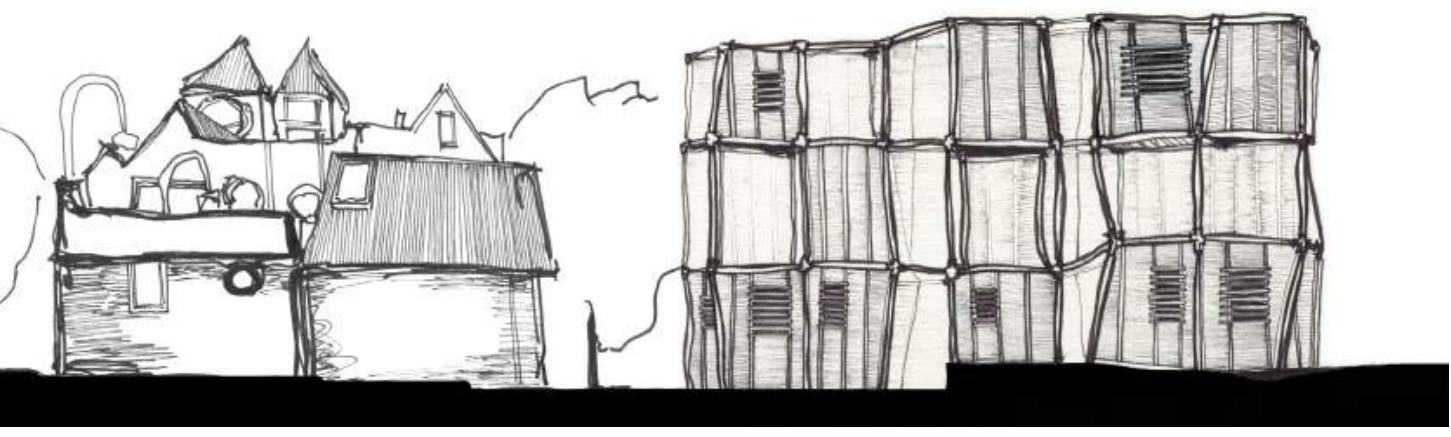

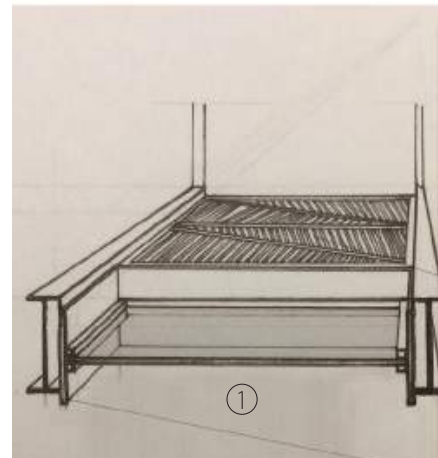
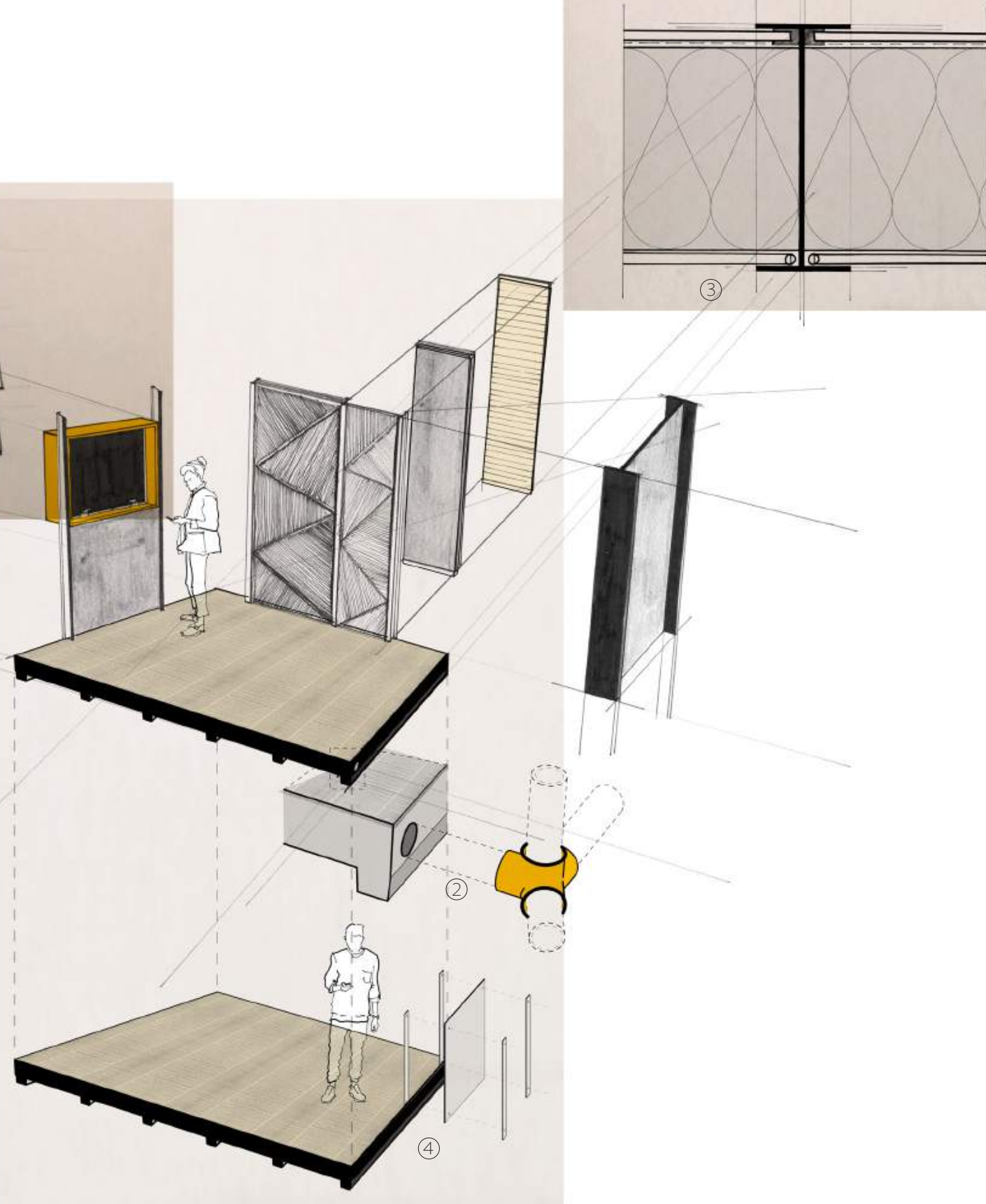

(1) Wooden box window detail. 3) Exterior cladding- insulation- exterior
cladding. Held together by the ribs.

(4) Balustrade to floor slab bolted detail. Beam through floor slab 


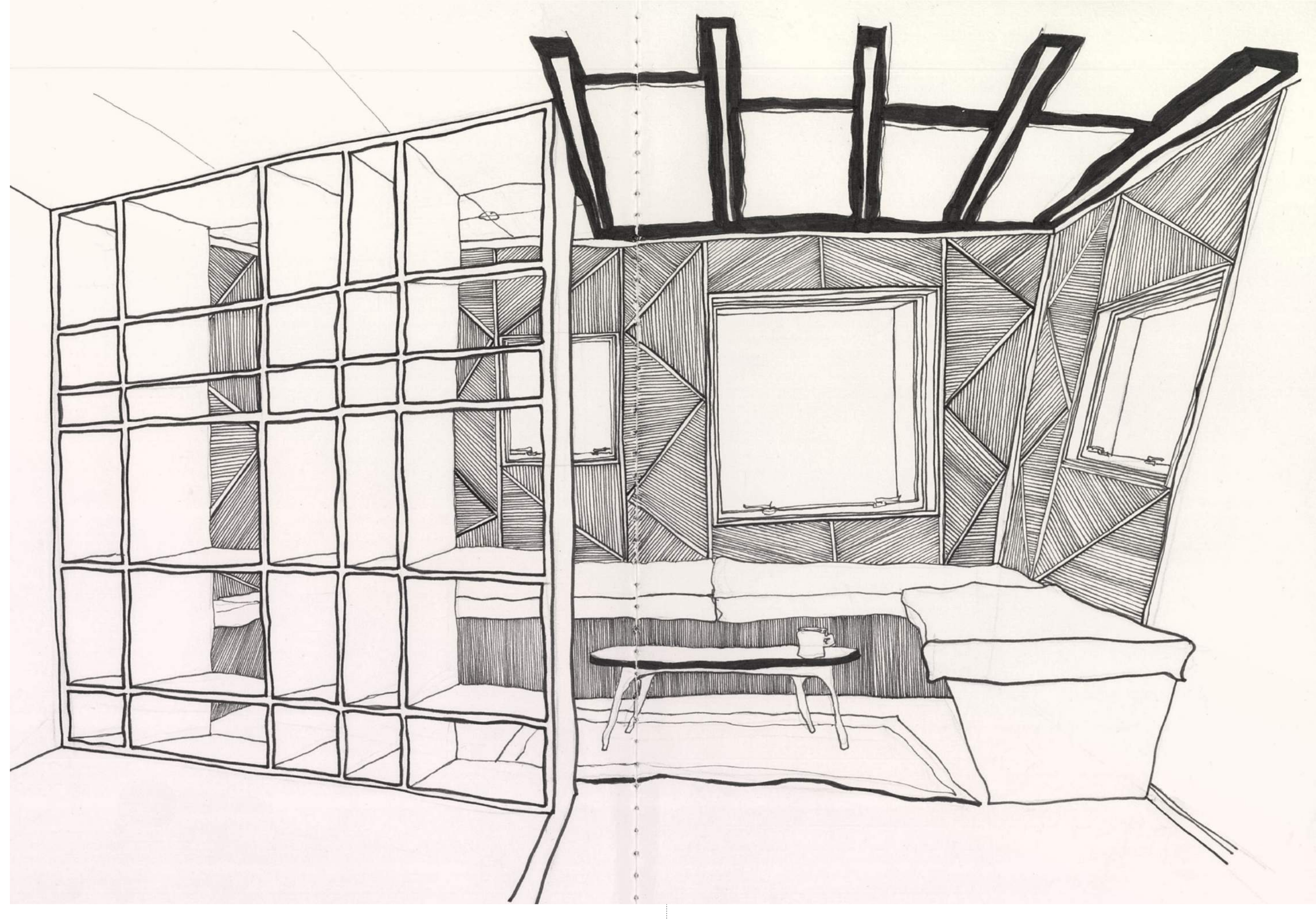




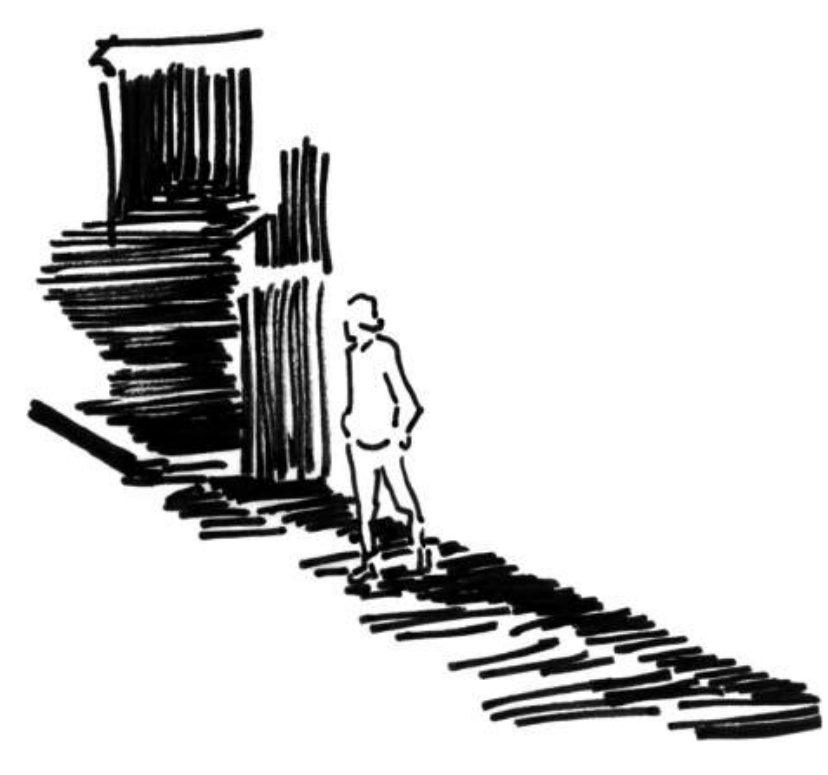

Context and Processes 02 . 
The design method is diagrammed and explained through annotation on the following pages.

As design led research, early work sparked my understanding of my own process. I was continually further enlightened by critical reflection of that all of my work fits within. Processes fit either on the hand side, on the digita side. However the nost valuable and effcient work when the two sides agnentedeach other.

The design process began with an analysis of Hataitai as a whole, and of my original site (Hataitai Park). Alongside this, I was developing concepts for that site through the brain to pen connection of the thinking hand. It was critical analysis of these drawings that uncovered a tendency toward the complex geometries in design. This discovery raised Peter Salter's Walmer Yard as a key precedent.

This reflection, along with the site analysis led to the final site choice. The site is adjacent to a case study (page 114), Roger Walker's icon of irregularity, Park Mews.

From further critical analysis of these drawings came the understanding

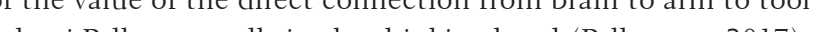

uhani Pallas tha cllb it, the thilking hand (Pallasman, 2017).

A plan designed through the thinking hand led to the development of a parametric script, which gave me a wire frame base for drawing formal, material, structural and tectonic tests over. This, in conjunction with photoshop drawing editing, was the point of understanding of the value of digital tools as a side of the bionic hand, bringing efficiency to the design process.

A main way I used the thinking hand was cartooning human eye level, perspective moments of the building, as I was designing it, such as in fig 2.2. A change in perception of my project developed into more detailed drawings to push my designing forward.

The final stages on the design method are annotated on the diagram on the following pages.

"The bionic hand" was my design method that included all of these processes, using the strengths of both the hand and digital sides. My process was at its strongest when I used the strengths of each side in

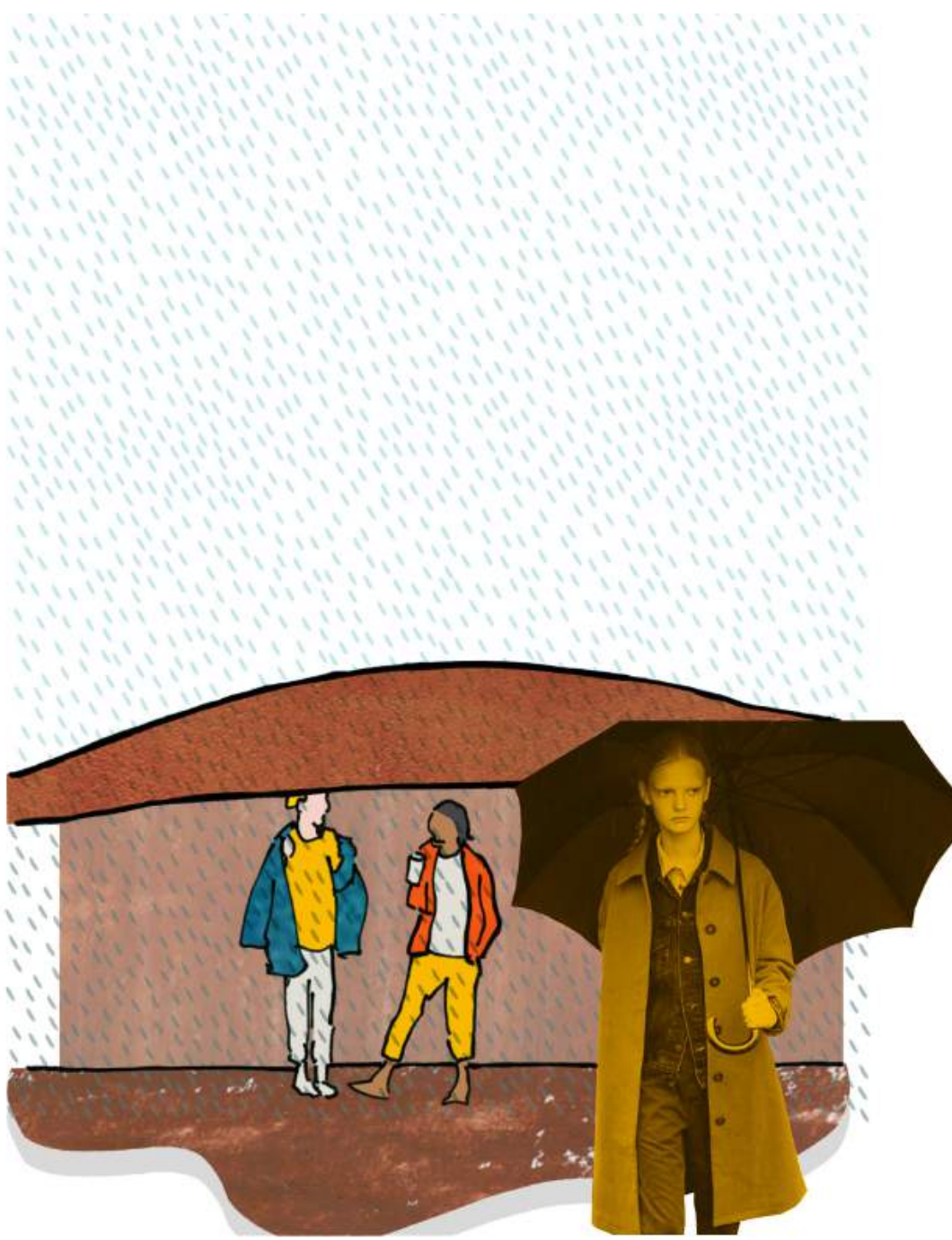

The rest of this chapter is a broken down analysis of the contexts my work fits within, and relevant literature and case studies. These contexts are: the site, the bionic hand as a way of working, the placement in the discipline, interpretation of visual richness as ornamentation, and labour in the building's construction and design. In conjunction 


\section{동}

A main way I used the thinking hand was cartooning was designing it. A change in perception of my project developed into more detailed drawings to push $\mathrm{my}$
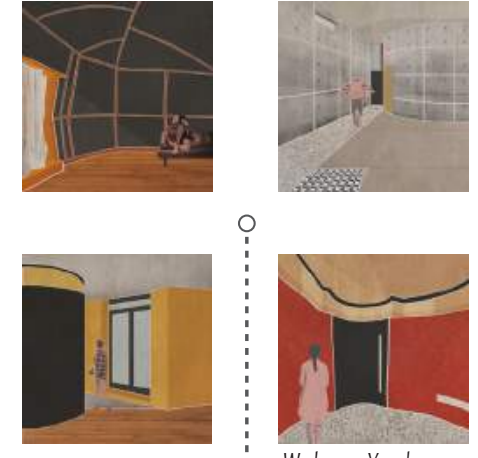

Walmer Yard
Calse Study

DESIGN METHOD

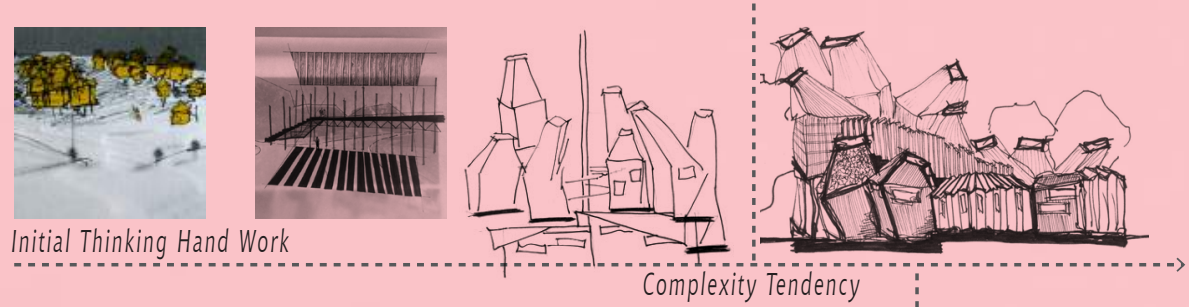

눈

$\pi$
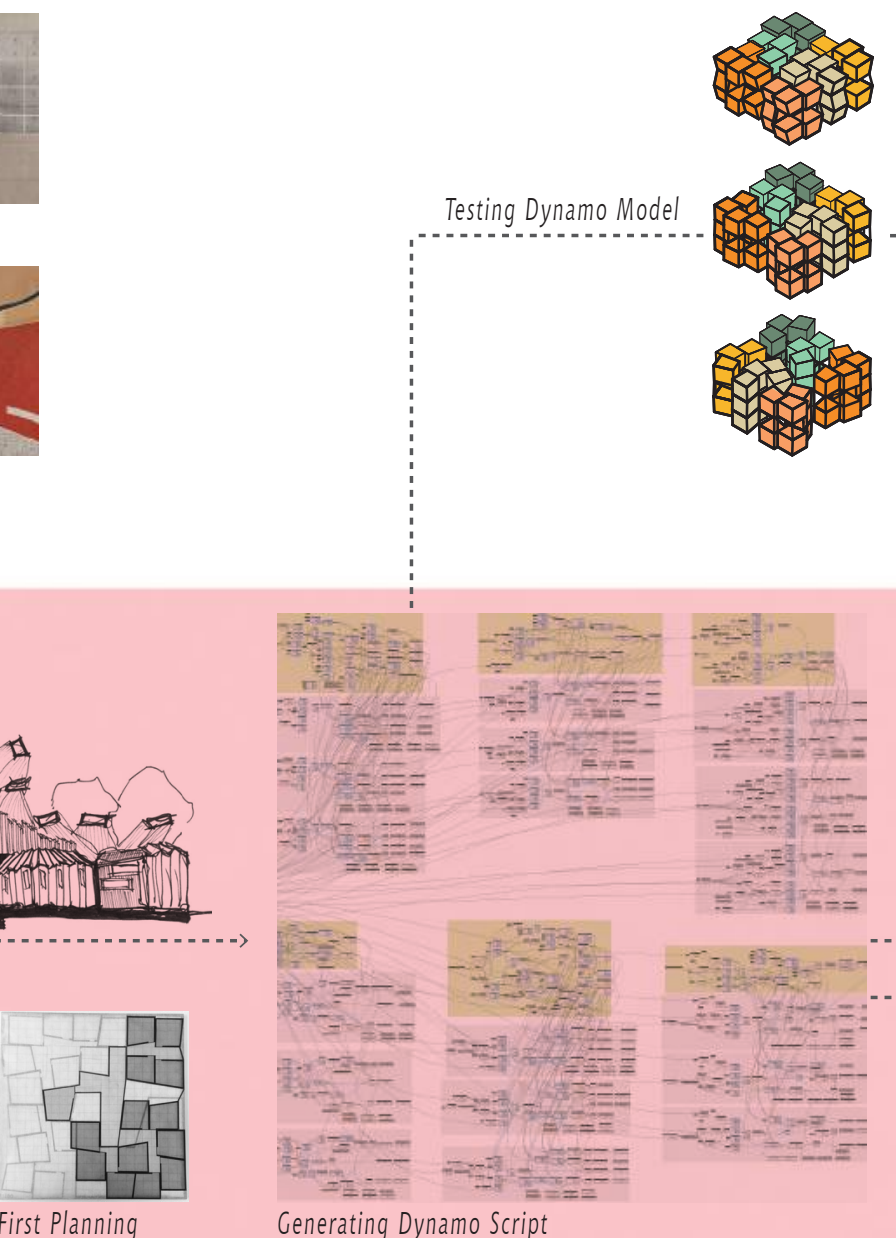

Testing Dynamo Mo

deas through drawing, I was

adding detail to a digital model,
from the original dynamo frame.
This aided planning, and became a
better base for tracing images over.

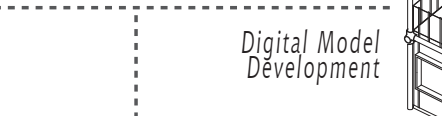

筑

final move in the design process was testing

Wh the two sides of the bionic hand came into

the built form of the building. This involved from each side. hand crafted bambo interior D.
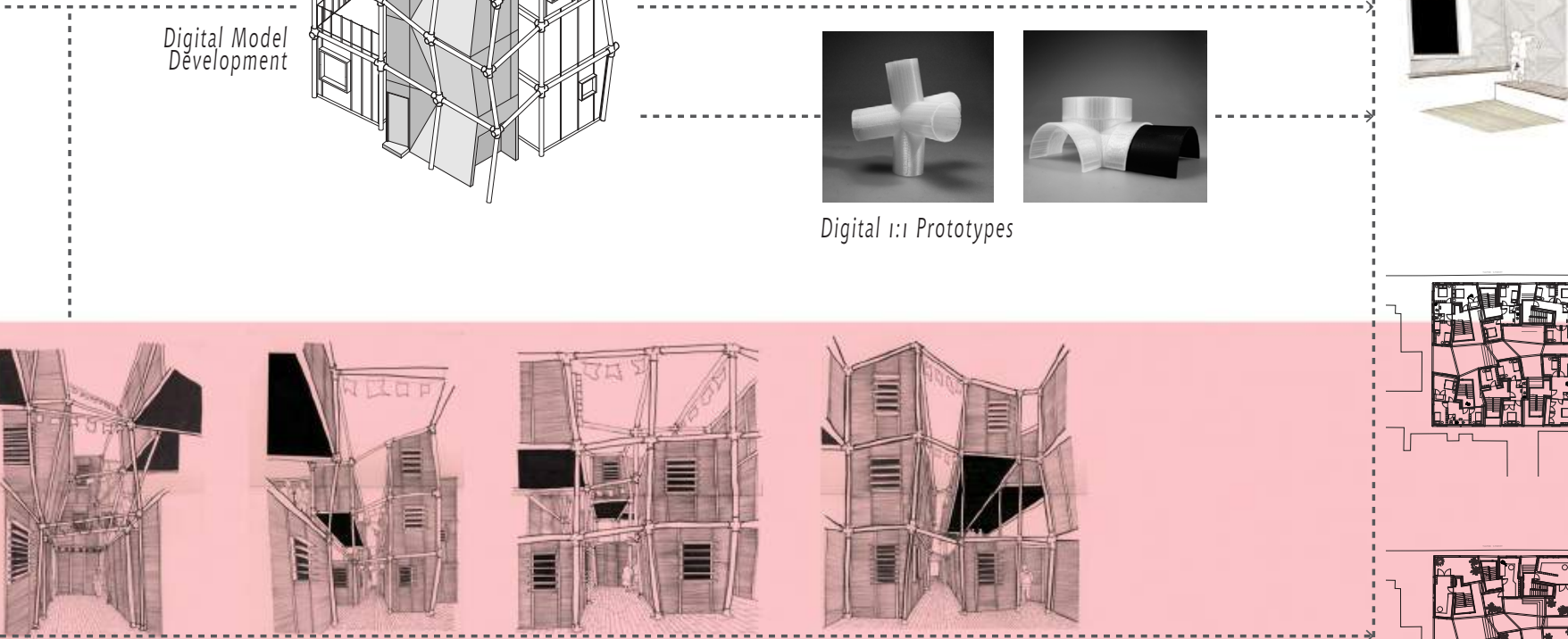

\section{E 融端}

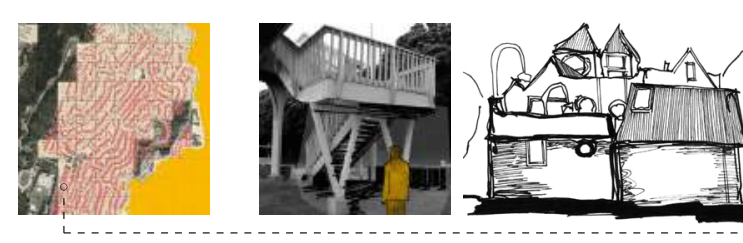

Hätàitäi Sitēe Añälysis 5.2. (1)
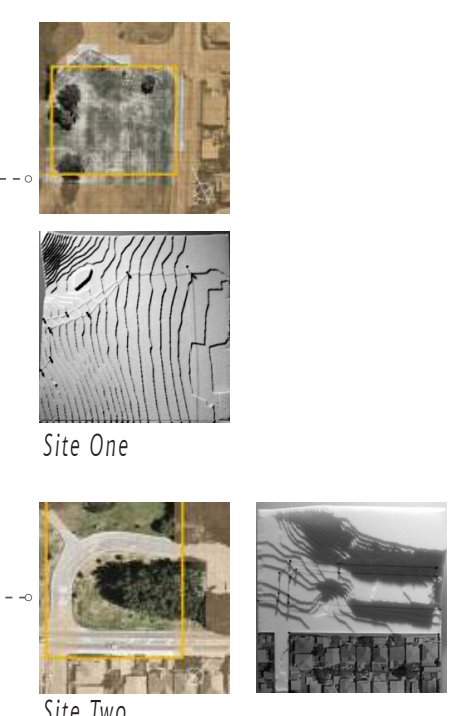

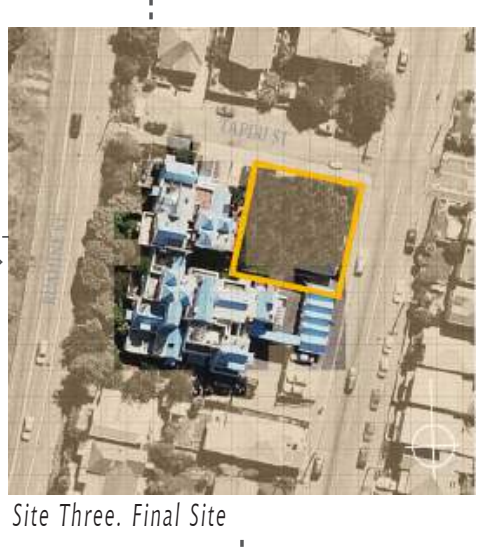

17

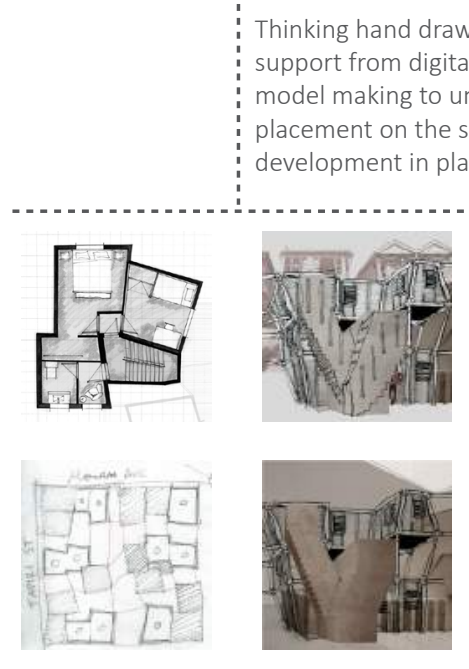

Floor Planning and Staircase Detailing
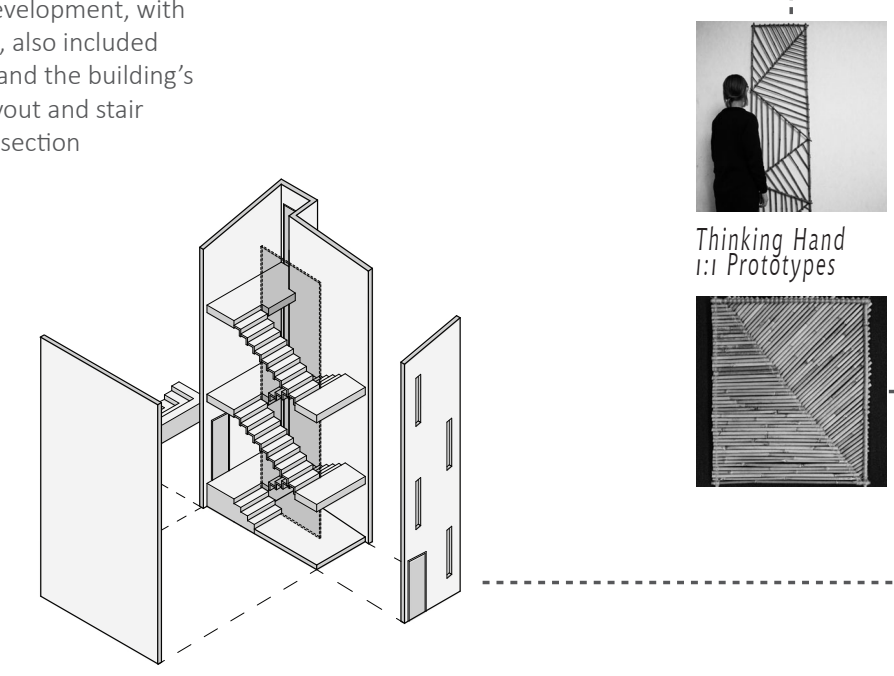

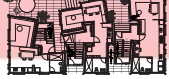

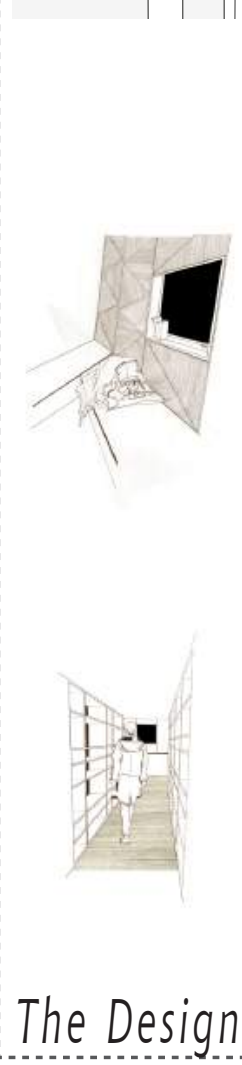




\section{Development of Design}
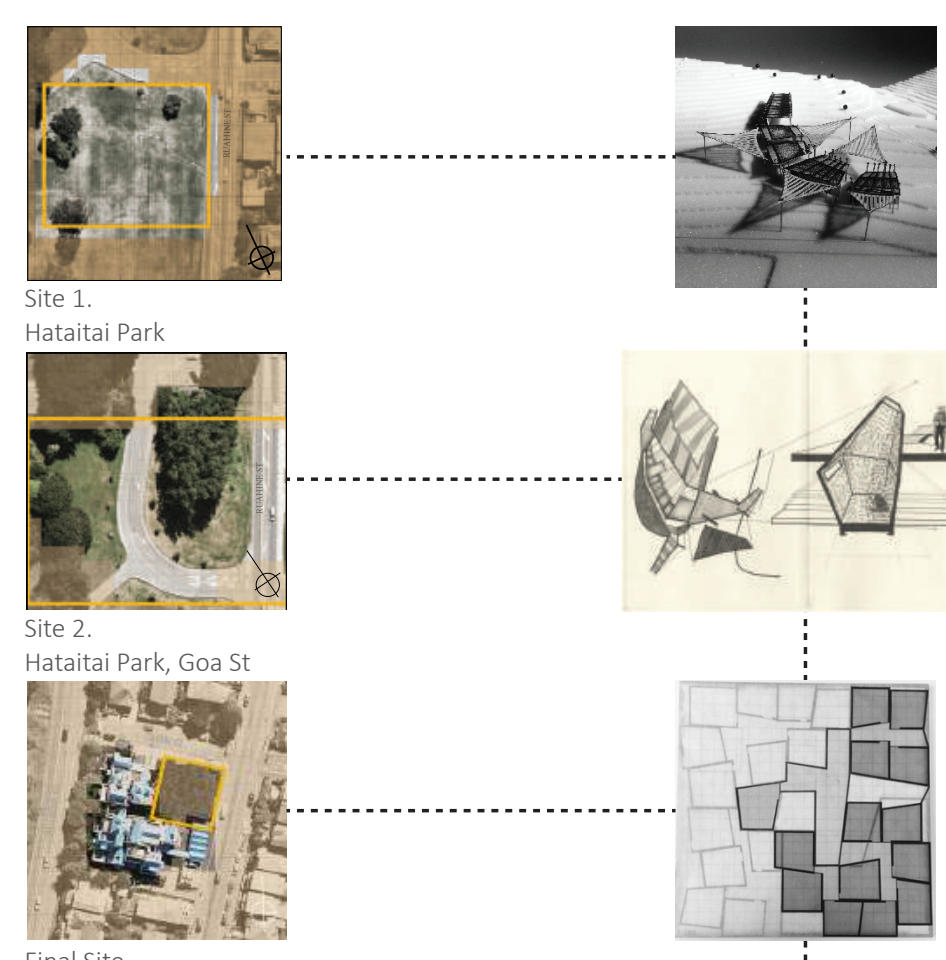

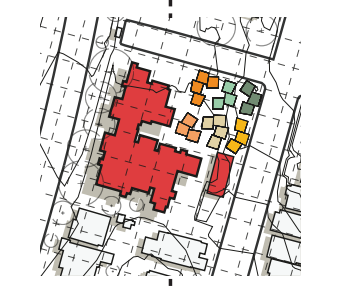

became the floor plans of six

Bringing in intimacy in material

and craft and the structural system

came in developed design.

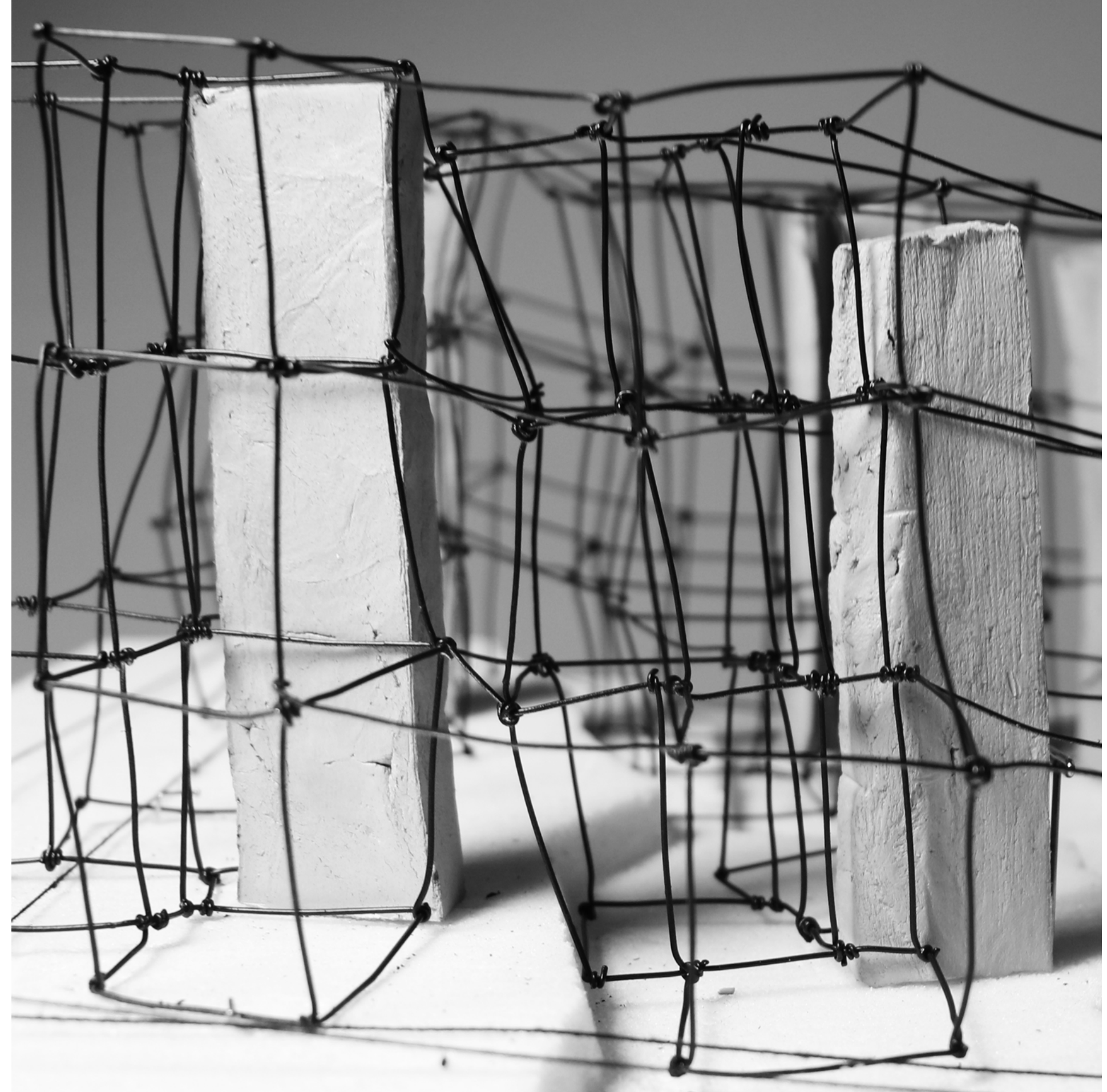




\section{Context: Knowing the Site}
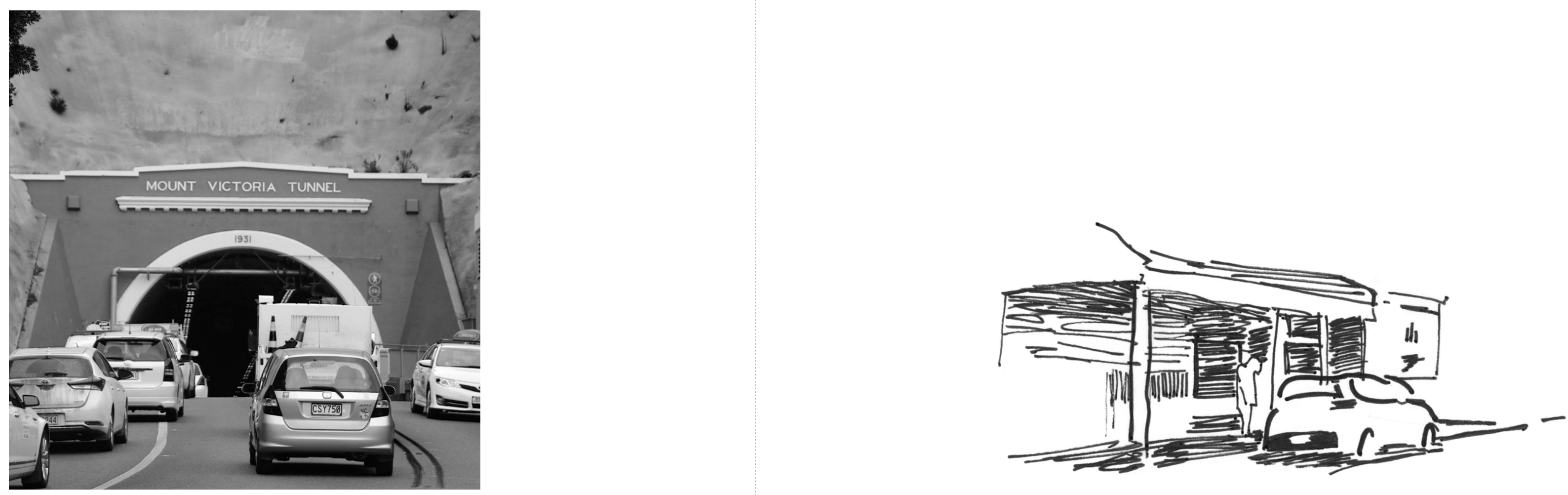

$\Delta$ Fig 2.3. Mt Victoria car tunnel. The

Hataitai is one of Wellington's eastern suburbs, directly connected to the central city by the Mount Victoria tunnel. Over the hill from the suburb of Mount Victoria's rigid grid, its roads contrastingly meander along the contours down to Evans Bay. These loops give huge, irregular locks dotted with the classic New Zealand trope: the standalone dwelling.

Buses and vehicles from the airport and other eastern suburbs passing through the tunnels to the city make Hataitai a transport hub. This is due to amplify atter the expansion of the car tunnel and motorway. This, in hand with Wellington's growh, mean Hataitai needs to densify to become an urban sub-centre of the ciry. For Wellington to achieve greater density, and thus lower carbon usage, it will be inner city suburbs the Hataitai leading the way. The reseach strean falls within is investigating this opportunity, to lower carbon use,

benefit public health, and create stronger communtios throughout the

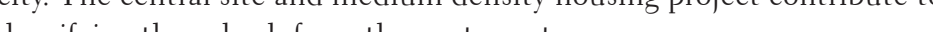
densifving the suburb from the centre out. 

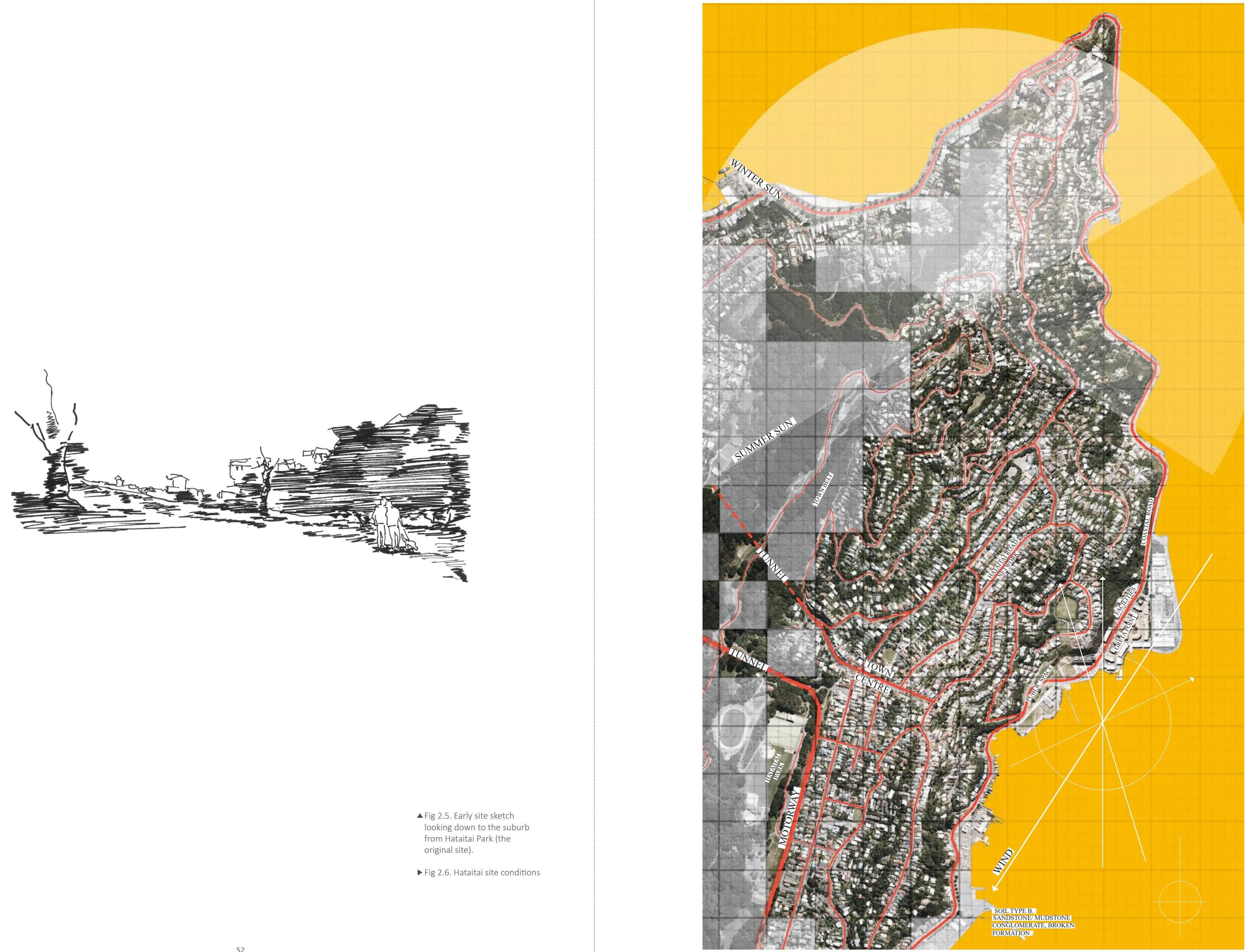


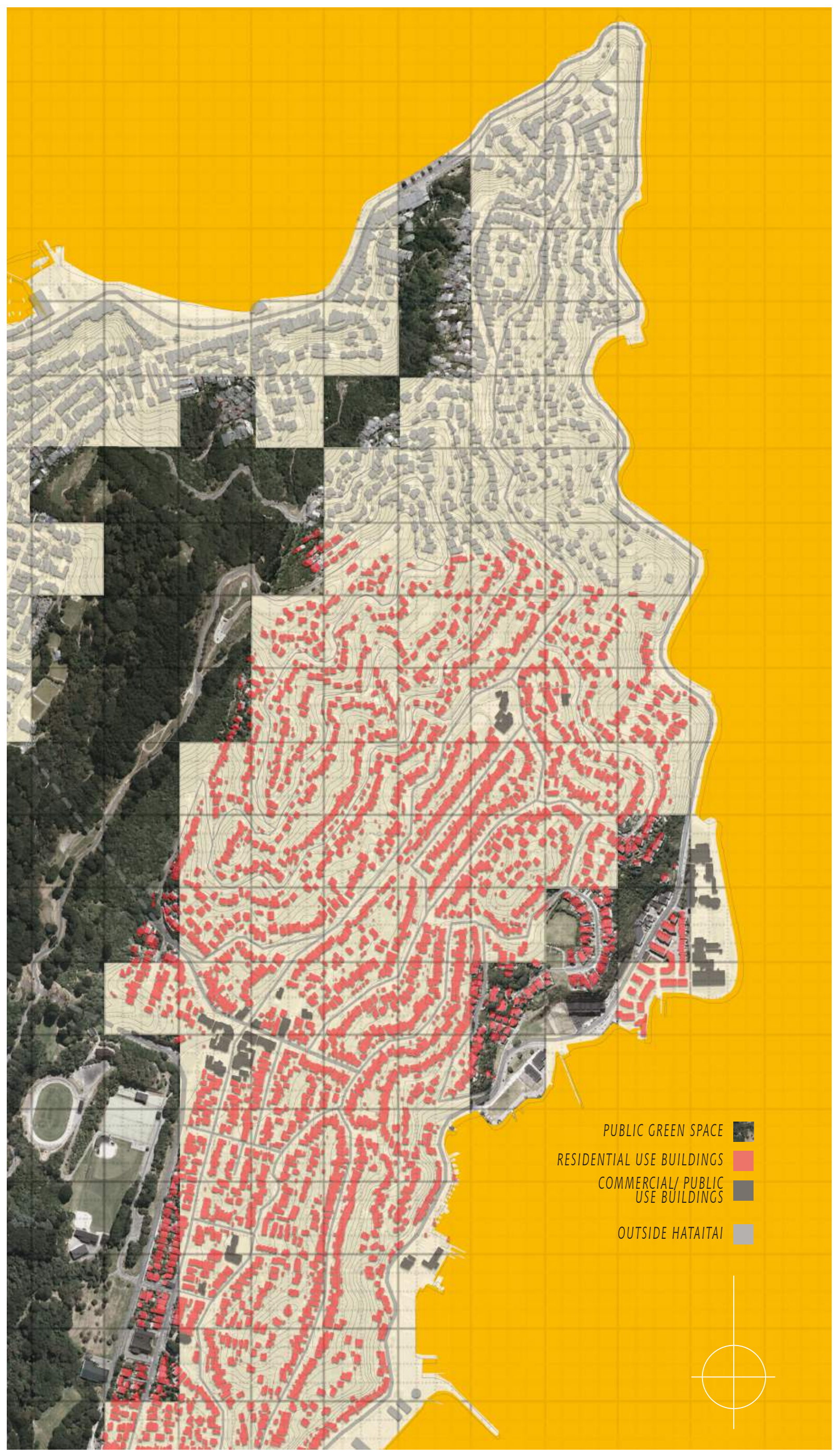

Hataitai is an example of New Zealand's attitude to suburbia and rejection of an urban realm in cities' peripheries.

As the drawn study of Raupo Street in Hataitai below exemplifies, in New Zealand's development of cities, the dominant housing type quickly became the single family, standalone dwelling. Geoffrey London writes that influence came through California's 1870s dwellings and they became cemented as the New Zealand domestic arrangement through mass state house building. European publishers exemplified standalone houses as the 'New Zealand' architecture they printed, in part securing New Zealand's perception of itself from the other side of the world. (London, 2003)

Though there are some examples of higher density in Hataitai, the concentration on the single dwelling as its own entity has largely led to a rejection of designing them collectively to create an urban realm. When writing about city evolution in Architecture and Utopic Manfredo Tafuri refers to the, "uniformity ensured by pre-constituted tormal systems (Tafuri, 1976). The arrangement of front yard, side yard, back yard, with a house in the middle presenting a garage has given us our "pre-constituted formal system." 'Porch' or 'stoop' social culture replaced with private back vard culture, means the streets show little sign of life, despite the life a few metres further back behind closed doors. Increasing density of housing and embracing the street can create a more engaging, pedestrian focussed quality of living and break the suburban landscape the current system enforces only just outside the city centre.

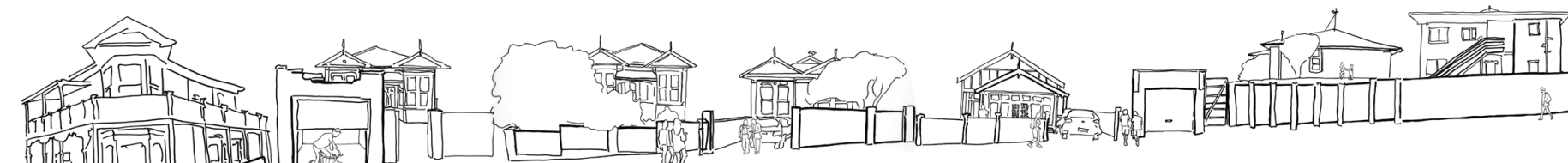

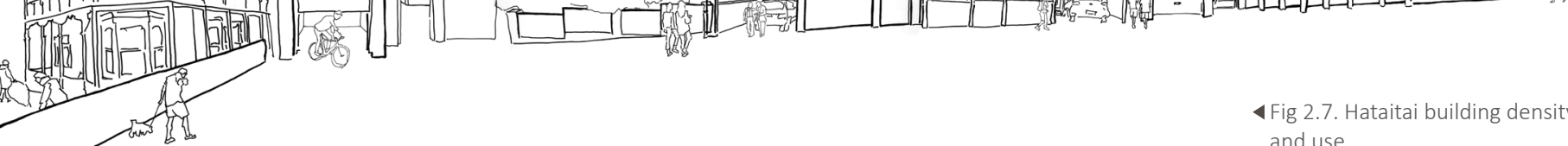
$>1$. 


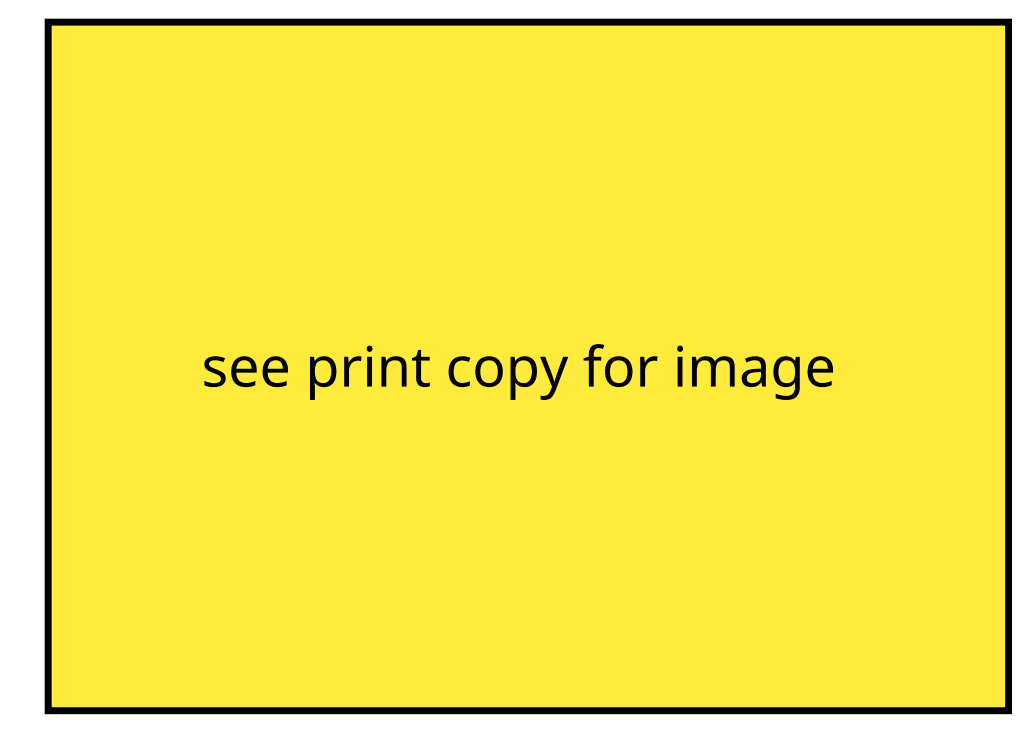




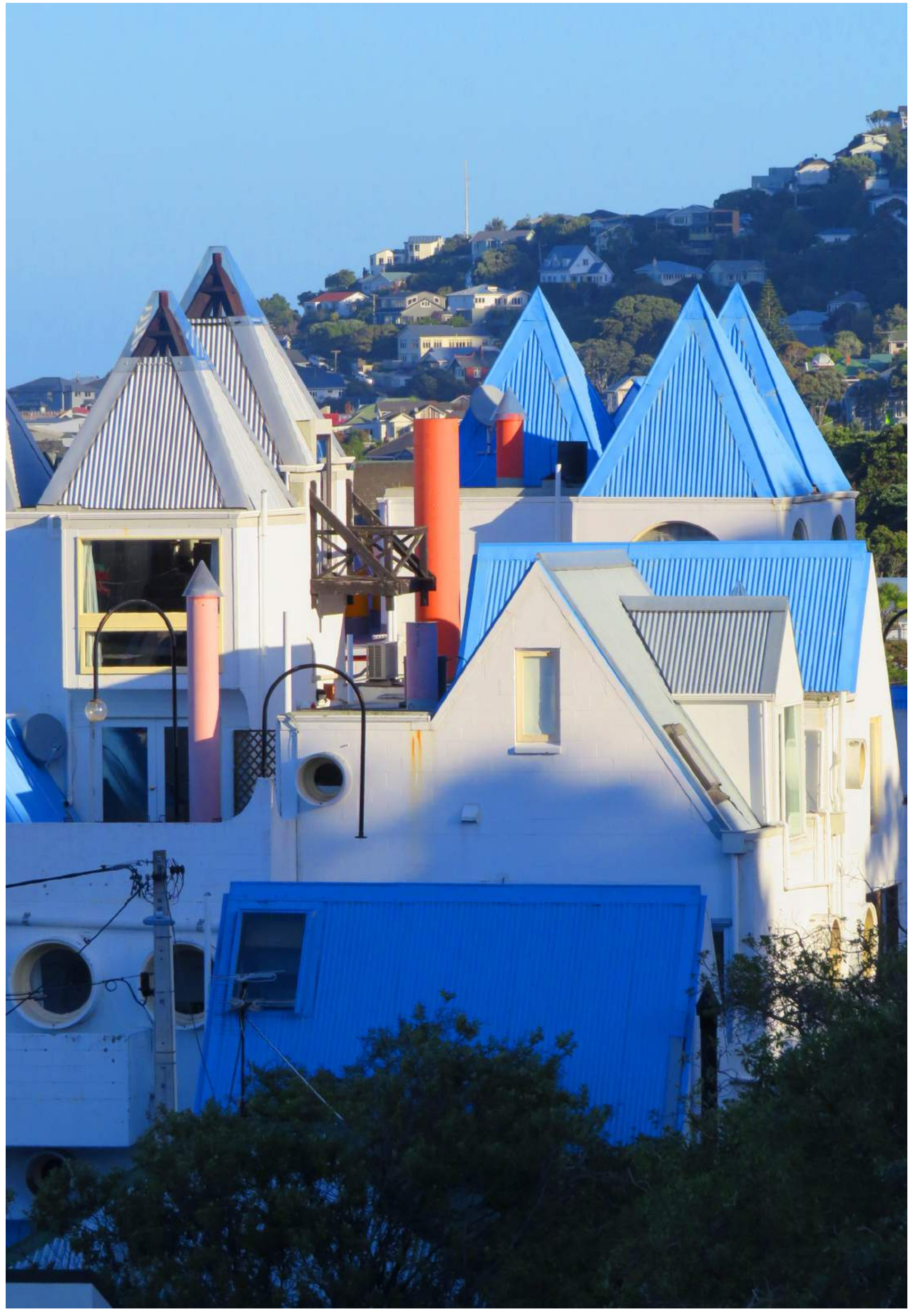

These are all symptoms of, despite being one of the most urbanised countries in the world, a preoceupation with our natural landscape, and lingness to overshadow it with the built cinvirites,

"Most New Zealand architects demonstrate their attitude to suburbia "Ny turning away from it The conventional alternative to the subub is by project the contert of the house as being landscape" (London, 2003)

When an interviewer accused Walker of using his projects to

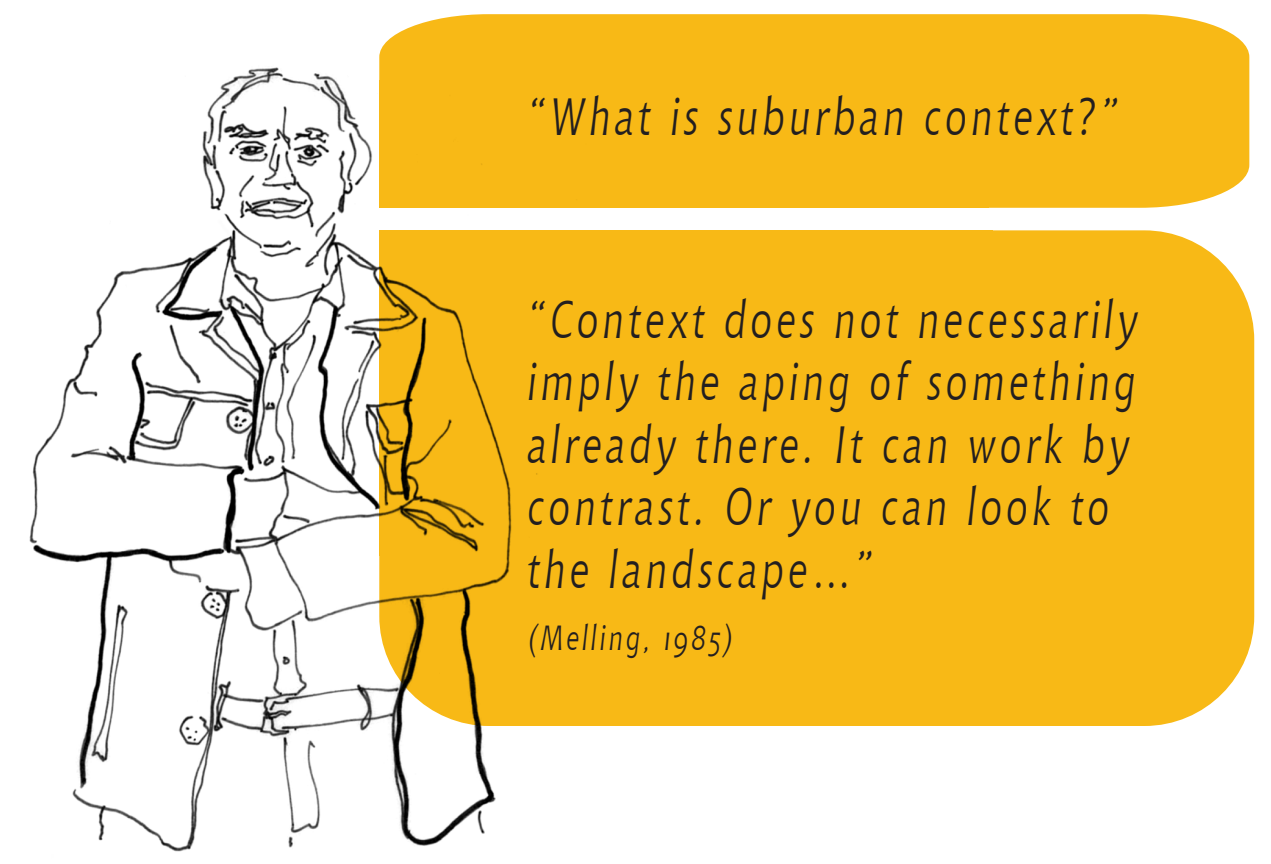

The landscape eclipses the urban realm as the appealing context, despite the nature of designing/ adding a house inherently contributing to the urbanity of the area.

Using the design to investigate densification and addressing the street front in New Zealand suburbia, as part of Hataitai's development into an urban sub-entre is how my research algigns with the Hataitai stream. However, densification for the sake of densification does not produce houses for familiarity and comfort of dwelling. The importance of using the bionic hand at the centre of this research is to design density with richness and intimacy to enjoyably inhabit. 


\section{Process: Knowing the Site}

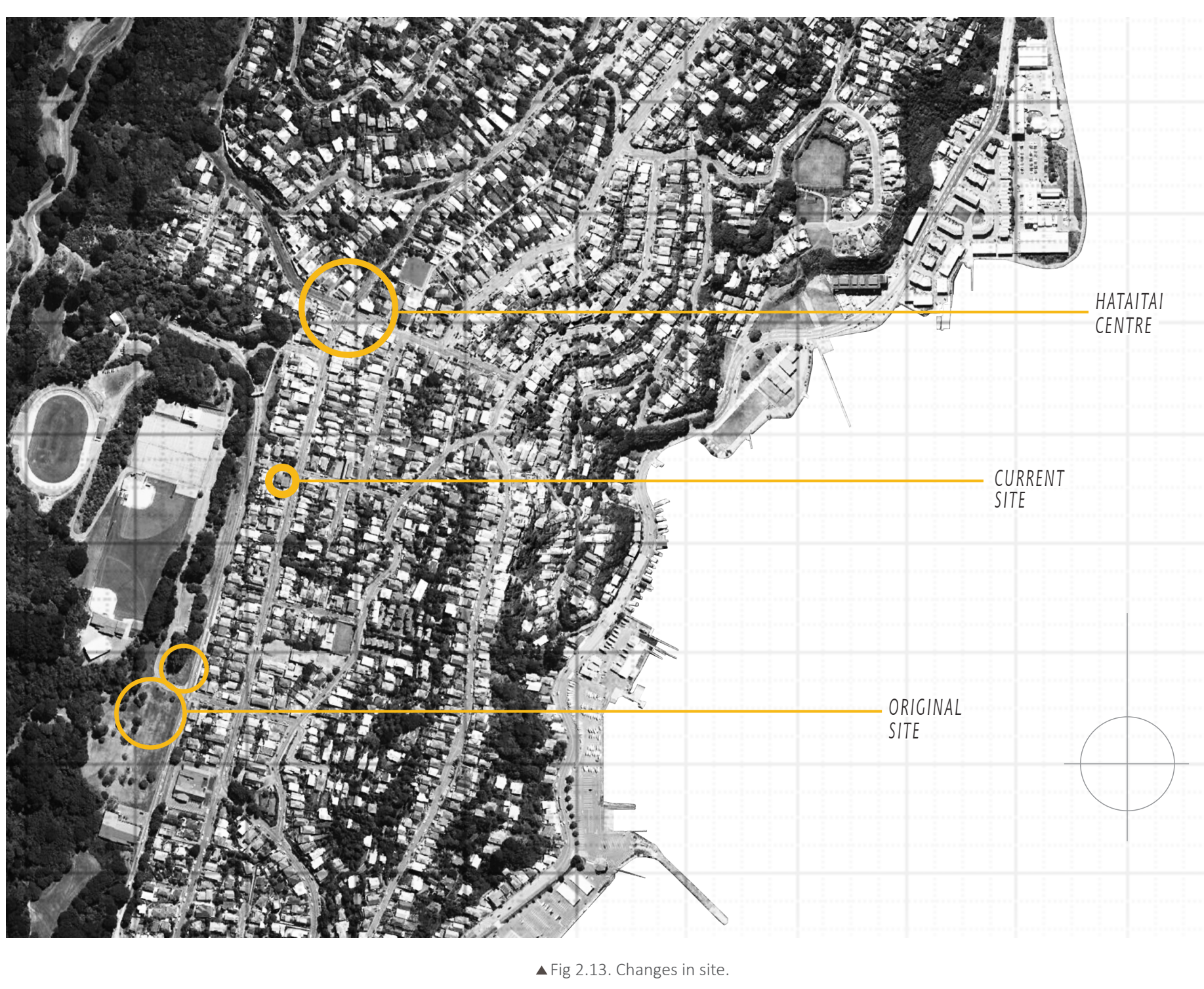

The site's proximity to the suburb's centre was key for the design to contribute to Hatatai's densifation from the centre outwards. Mnitin site selections of general green spaces changed after critical analysis of the urban nature of the work I was producing. The densified housing programme made proximity to the centre relevant, and the tendency in designing towards complexity made comparison to Park Mews inevitable. Thus, the final site is within the block of Park Mews, on the corners of Moxham Avenue and Tapiri Street.
While a full historic thread of designing complexity exists in the background (refer page 96), the recognised version in this country remains the post-modern style of Park Mews. My site within the same shown in the sketch of an early concept below.

Adjacent sites allow an easy comparison between the two projects in engagement with the street and surounding context.

The same suburban block means both projects are working with the same site and contextual conditions, with similar higher density housing programmes. Therefore, Park Mews is a strong case study for pertinent comparison in approach to complexity and construction of that complexity across time.

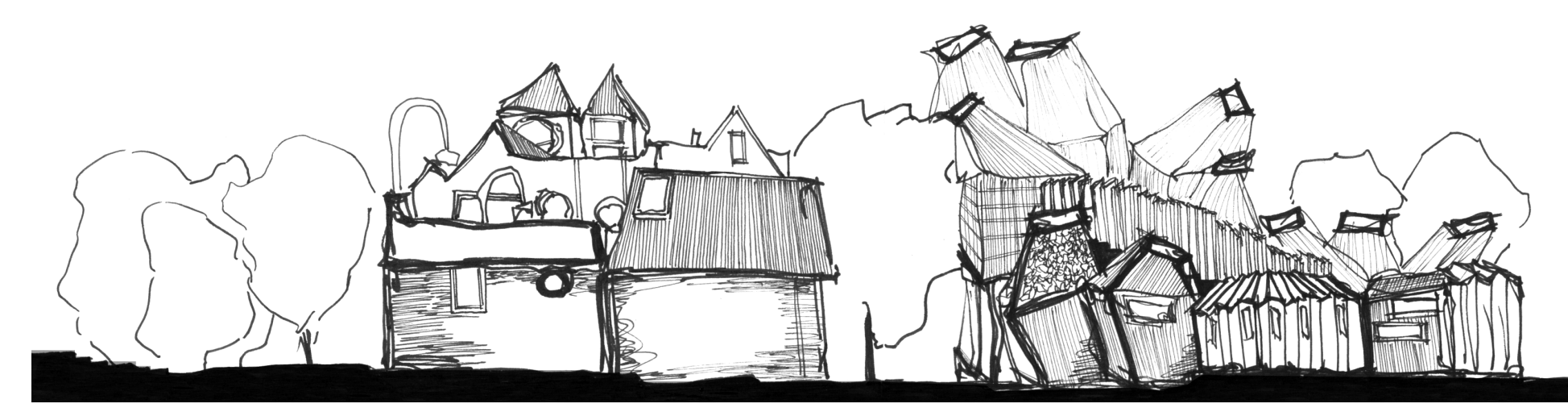

Fig 2.14. A sketch comparing an early concept
with Park Mews on the Tapiri Street elevation 

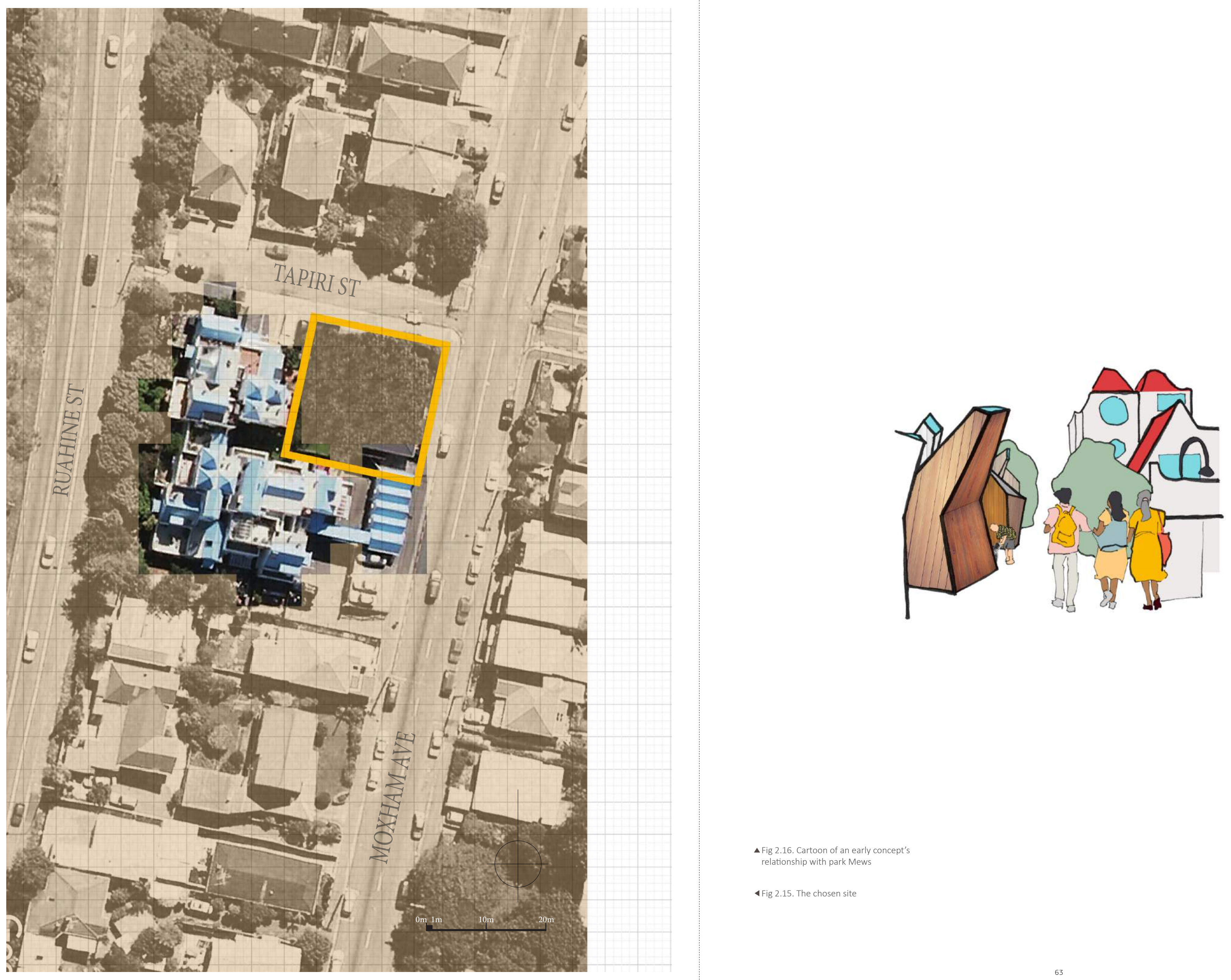
The bionic hand is a name for the way many students and practitioners are already working. It takes two sides of a false dichotomy in

architectre the hand and he digntal and combines them toward rich a hit ocion nd built outcome (form)

Pallasmaa is a key author relating to the importance of handcraft in the formation of architecture. In The Thinking Hand he writes,

"As a consequence of the mental transfer from the actuality of the drawing or the model to the reality of the project, the images with which the designer advances are not mere visual renderings; they constitute fully haptic and multi-sensory reality of imagination .

This is the way I used drawing to generate intimacy in the project. He goes on to write

"This is an intimacy that is surely difficult, if not impossible, to ( (Pallasmaa, 2017)

In this project, I have not attempted to use digital tools for this purpose. I aimed for synergy in the range of tools. I used each for their own strengths to enhance the capability of other tools. I used drawing to generate and push ideas, creating an imaginary world.

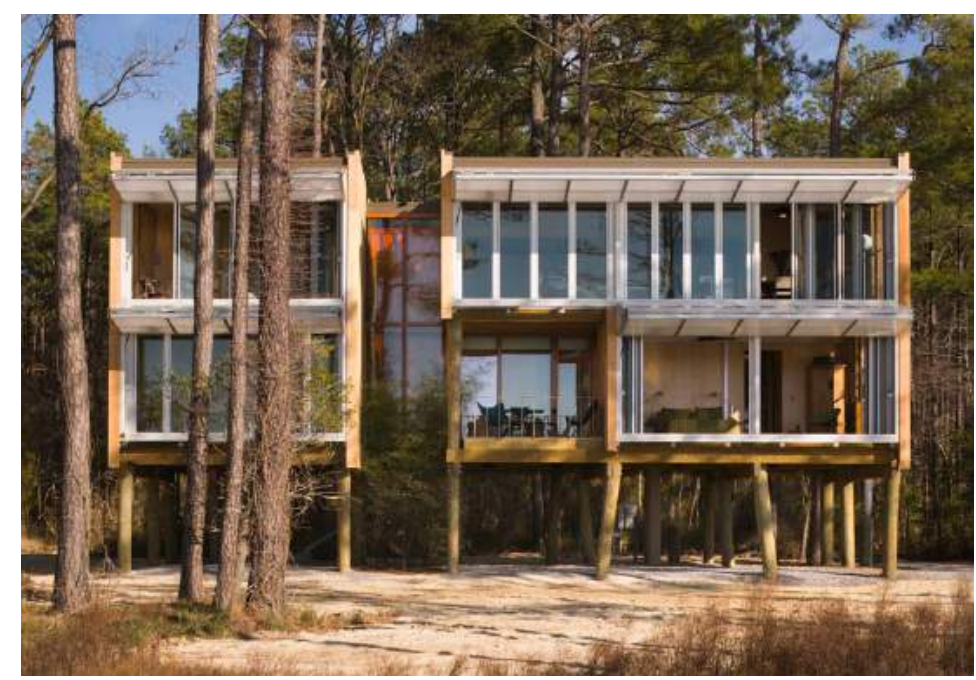

A Fig 2.17. Loblolly House
The firm Kieran Timberlake used predominantly digital tools in designing and constructing the Loblolly House. They have stated a parametic nodel design process forced collaborative design betwe parties and eliminated repetition of work increasing efficiency Pats (Kieran, 2008)

Mies Van der Rohe wrote,

"Whoever regrets that the house of the future can no longer be constructed by building craftsmen should bear in mind that the motor-car is no longer built by the wheelwright." (Conrads, 1970)

Advancing digital techniques in the building of my design aim to make the construction more efficient. Hand constructed, labour intensive materials were concentrated to moments most valuable in the project, closest to the body. Digita design tools accelerated repetitive, laborious testing in the design proces

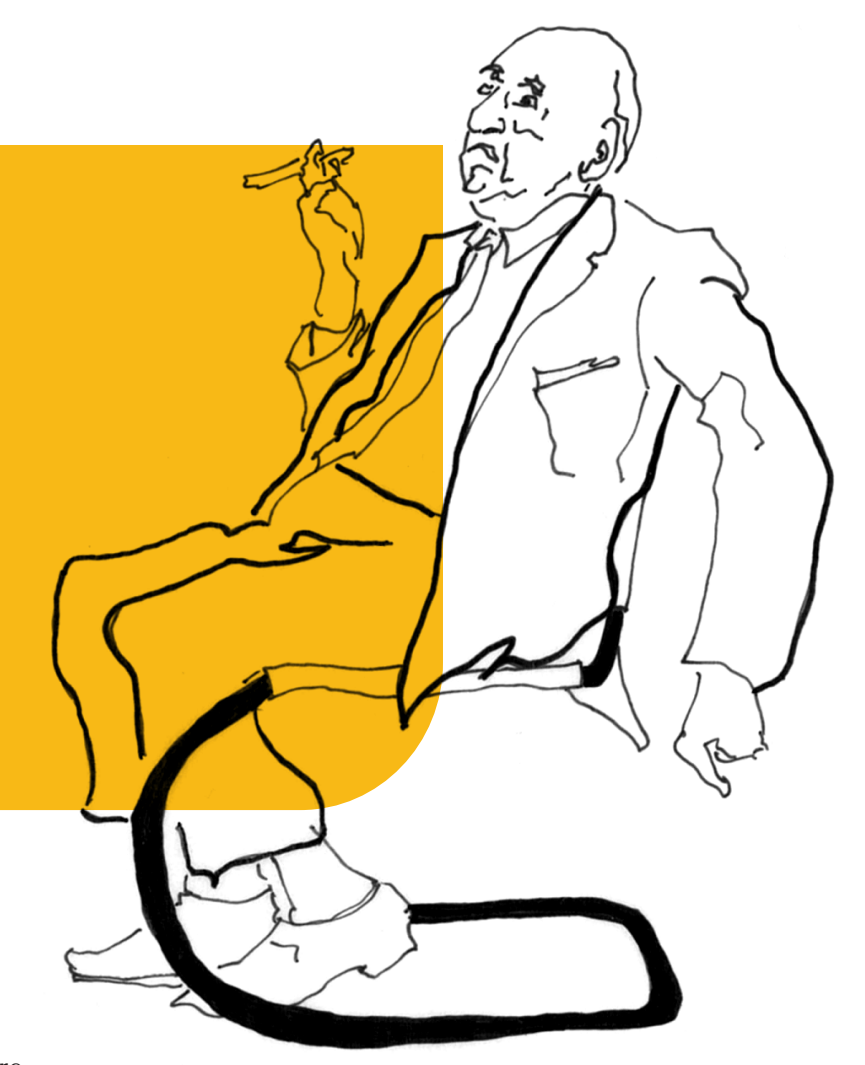


Process: The Bionic

Hand: Thinking Hand

In my work, I initially used the thinking hand for freedom of idea

without it needing to make sense to others. This occurred throug

perspective, with plan, wh section,

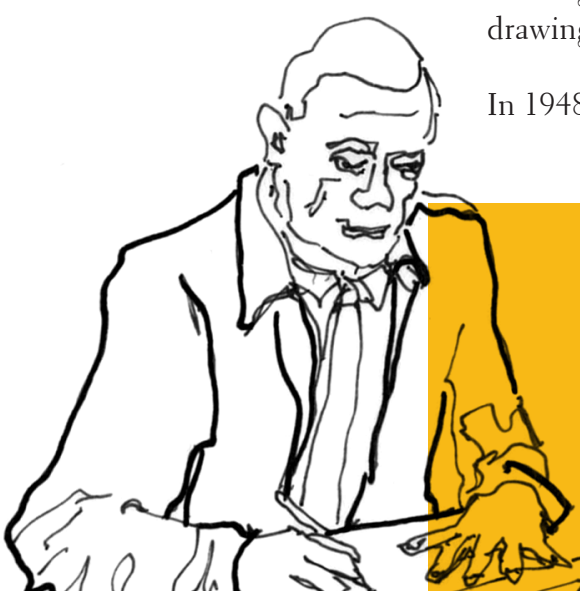
ine main idea gradually takes shape, a kind of universal substance that helps me to bring the numerous contradictory components into harmony." (Aalto \& Schildt, 1998)

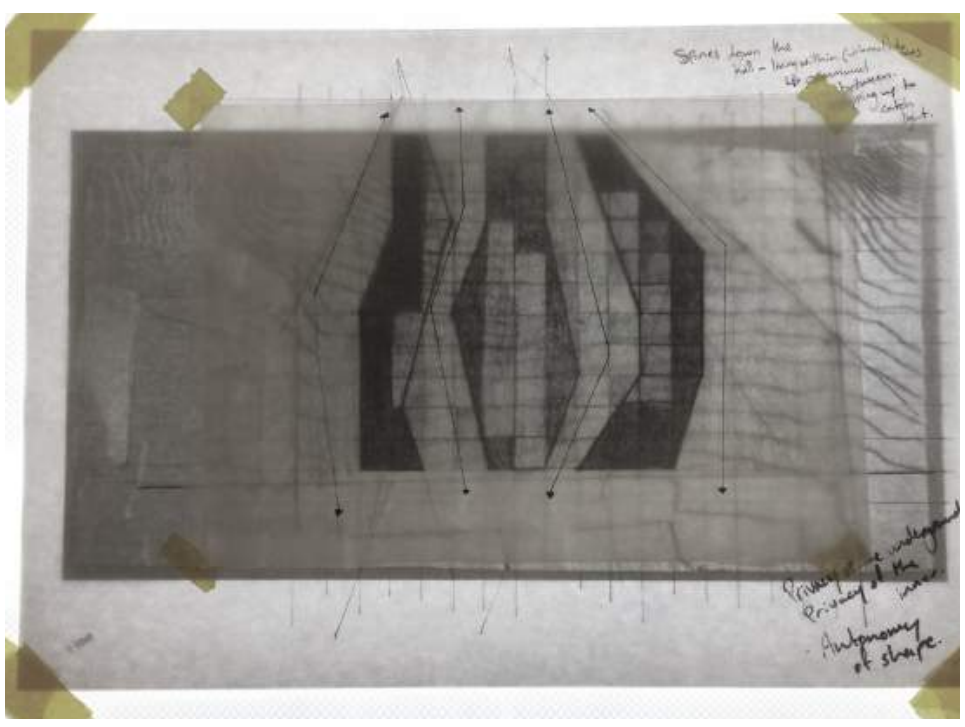

Figs 2.18-2.22. Examples concept work across the
initial sites and the final site, and compositions of
thinking hand work for comprehension by others
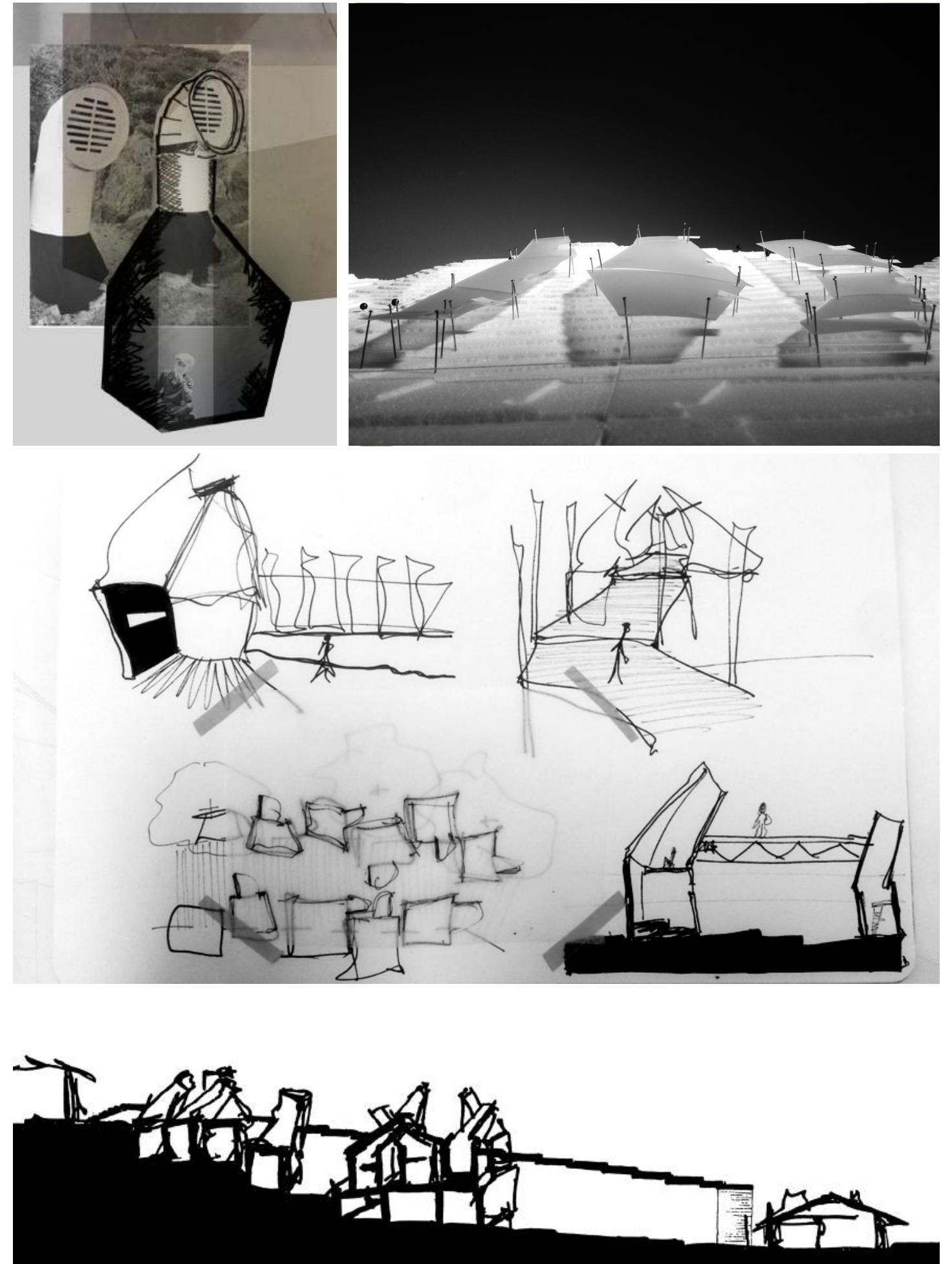

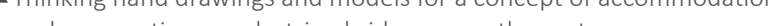



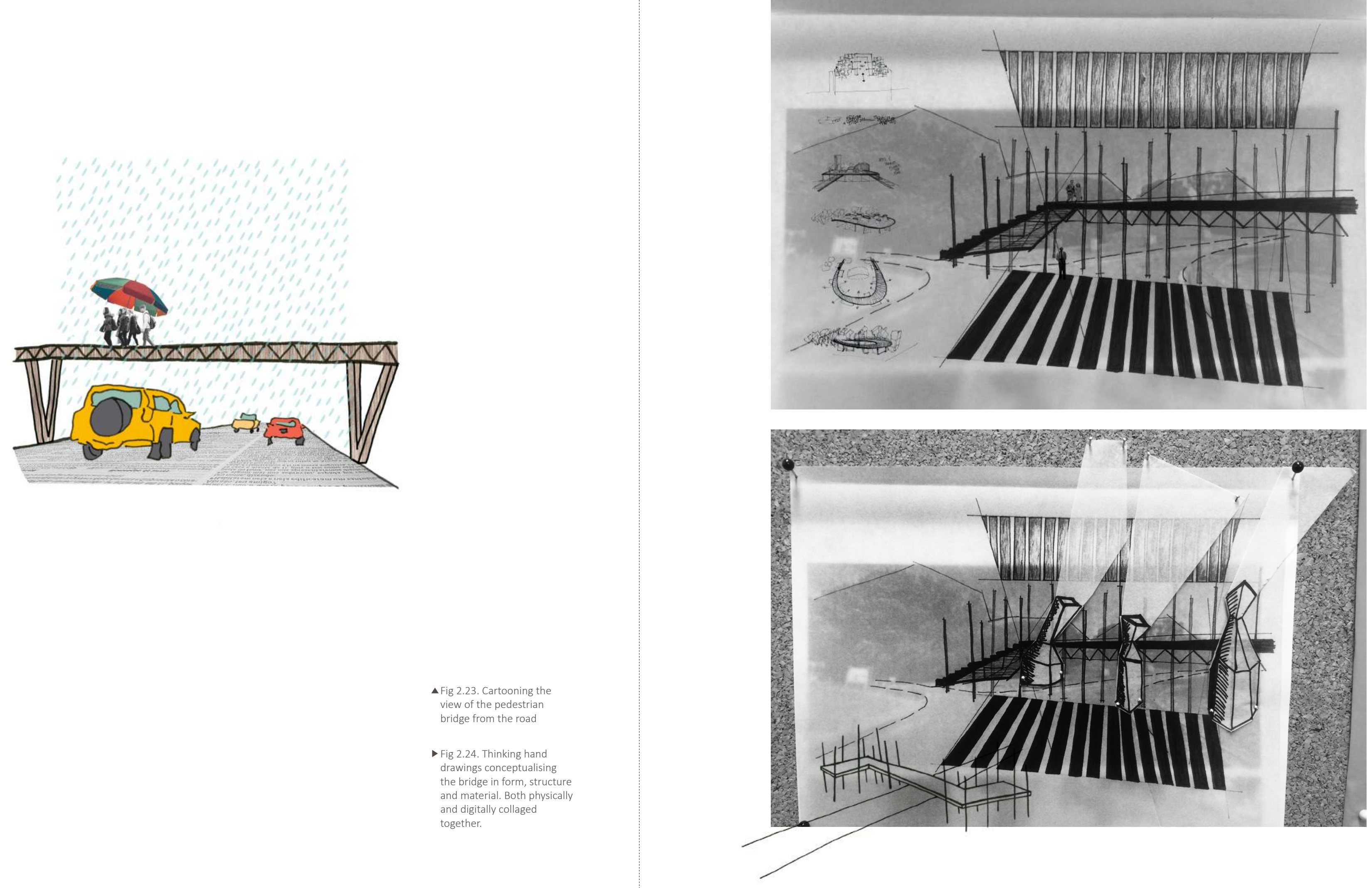

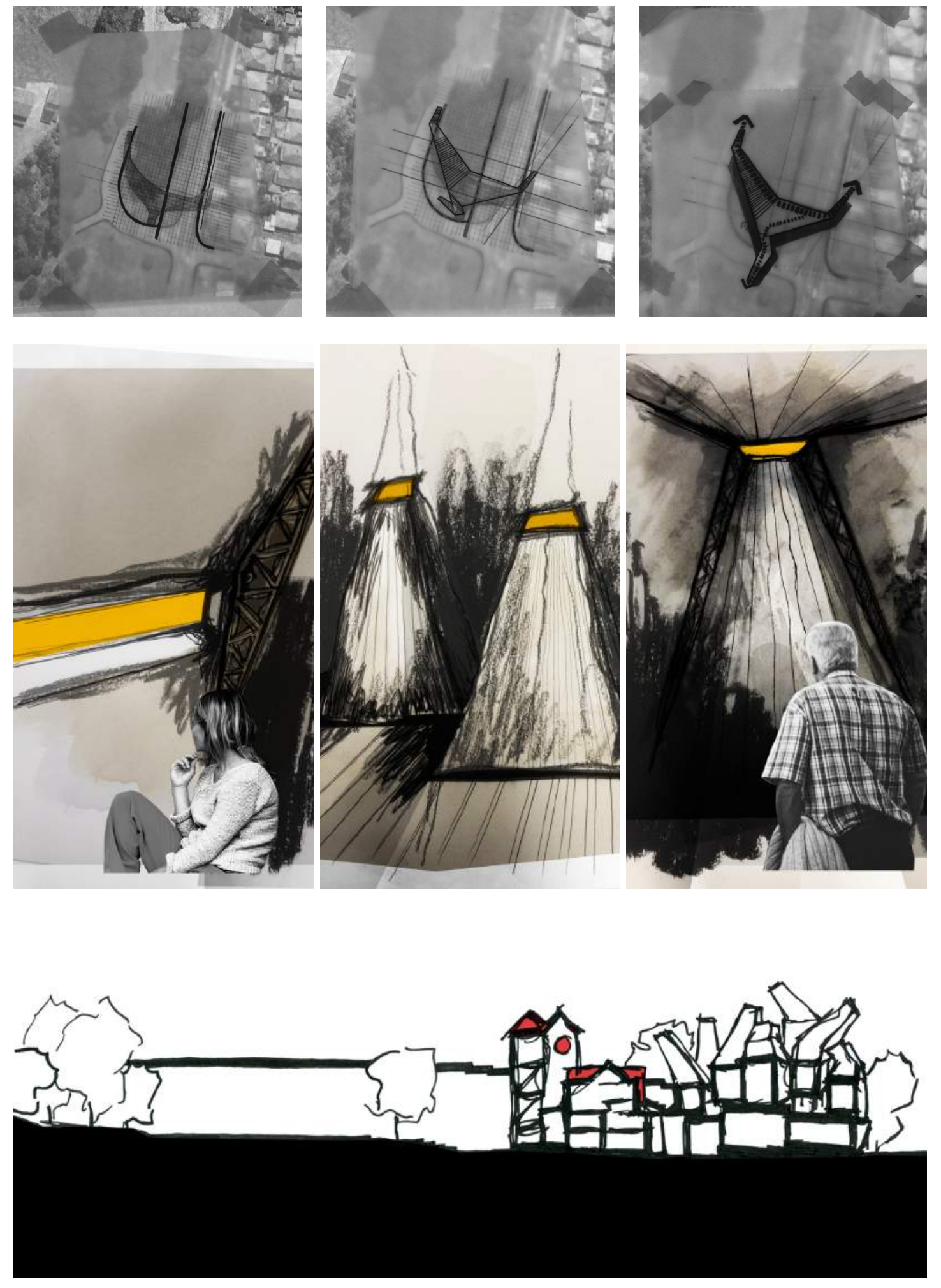

These drawings became concepts (refer page 48). Through developing

these drawings and making them morc

Fig 2.28. The concept of ccommodation pods moved from the bridge
site to the final site within the block of Park Mews. This was the concept taken context, particularly Park Mews. This was a relationship tested early through sketched sections and elevations (fig 2.28). 

Process:

The Bionic Hand: Digital

The thinking hand provided the flow of imagination to create initial ideas. I used the digital side of the bionic hand, a parametric model providing a tracing base, to make the hand drawing more efficient

(fig 2.33). This pushed the thinking hand drawings past form. Later

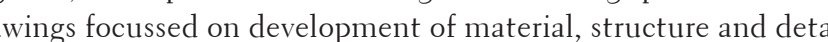
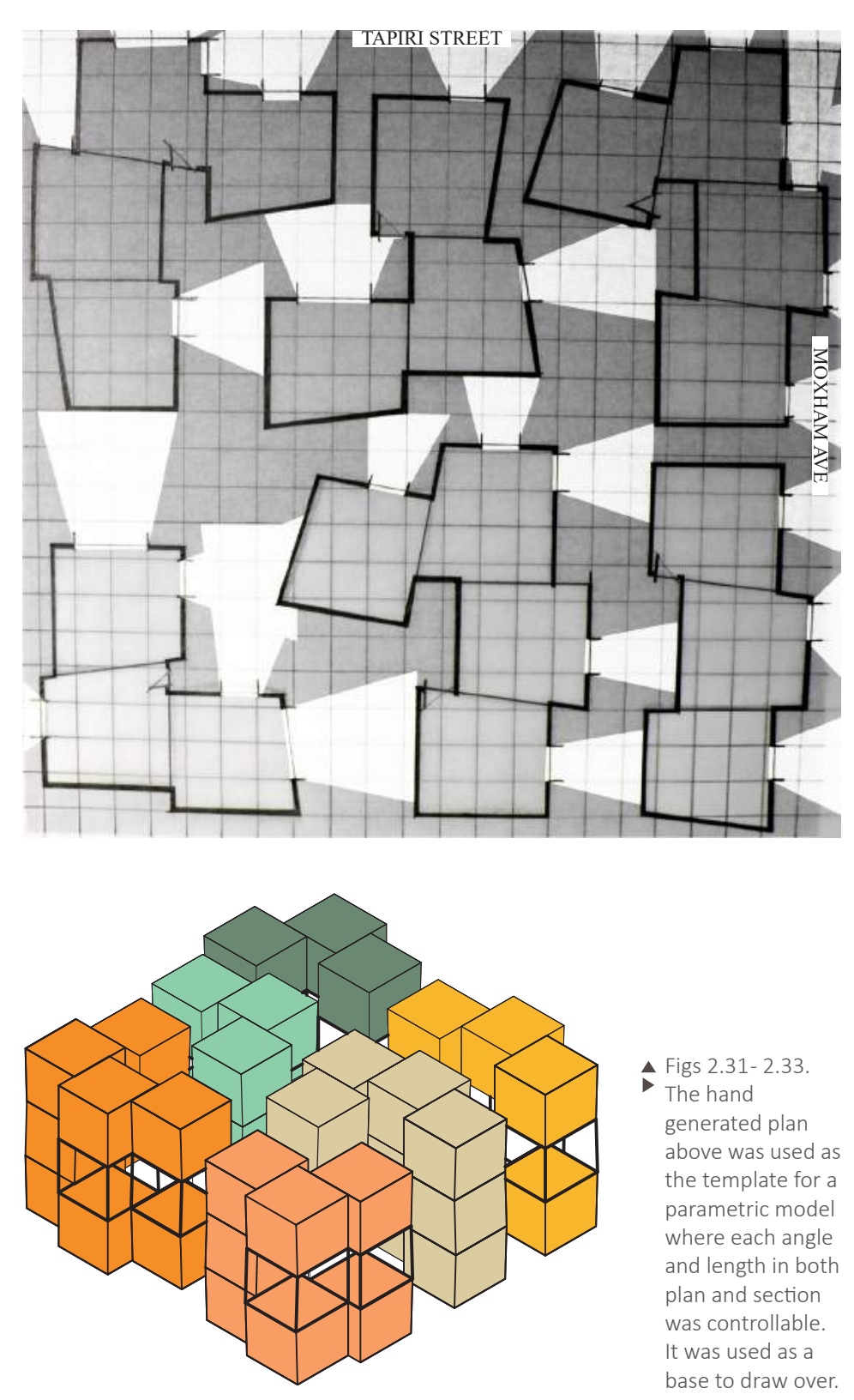

Figs 2.31-2.33.

generated plan

above was used as
the template for a

parametric model
where each angle

where each angle
and length in both

was controllable.

It was used as a
base to draw over

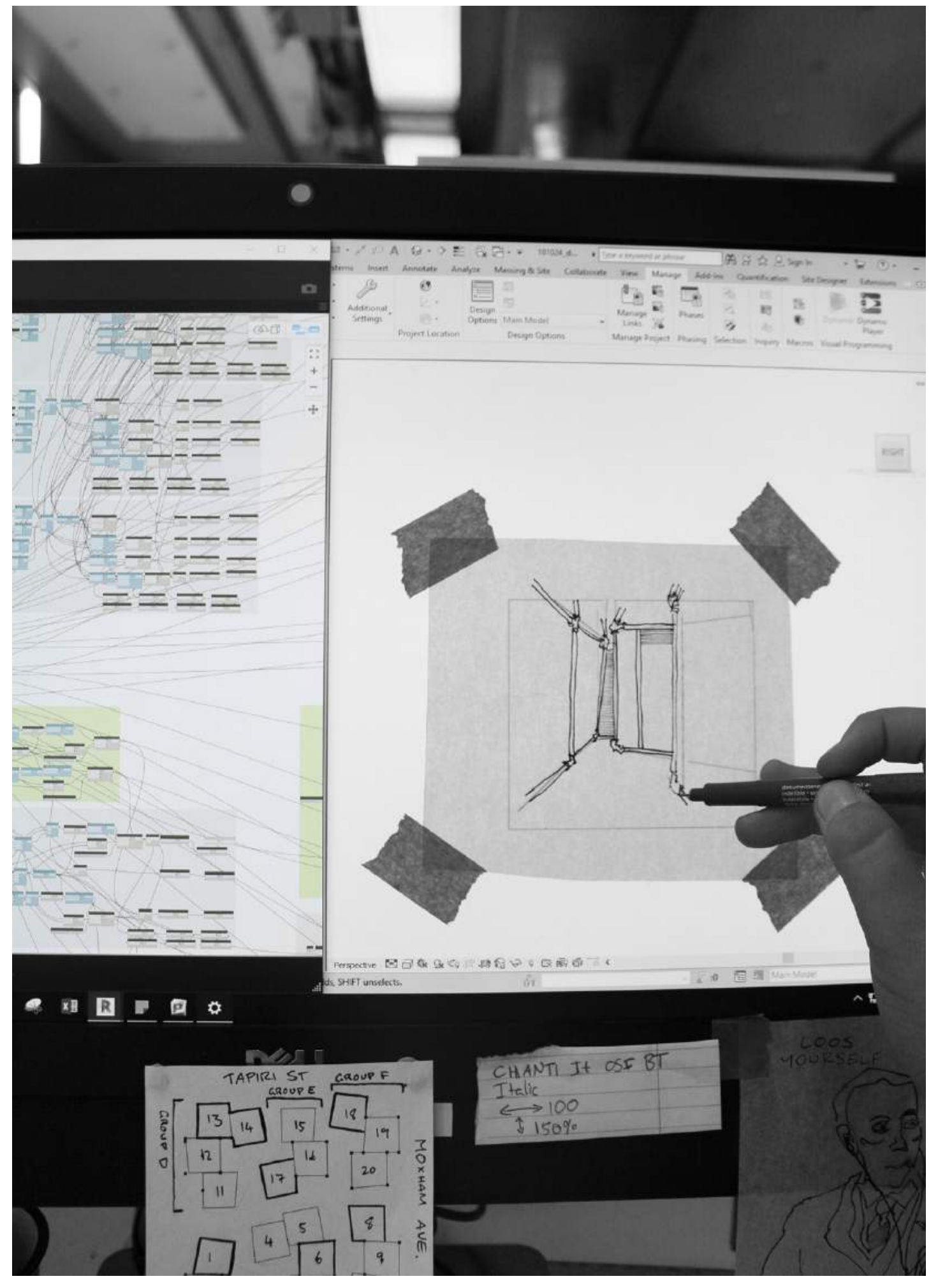



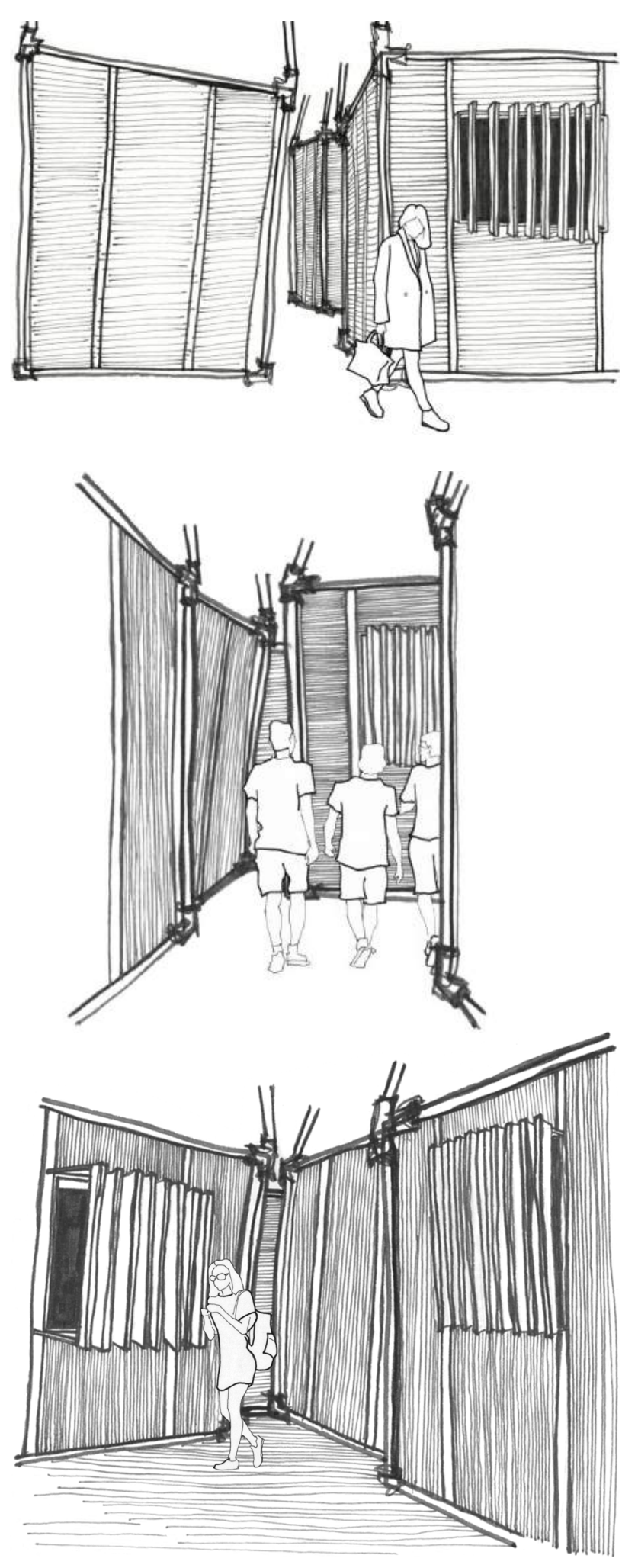

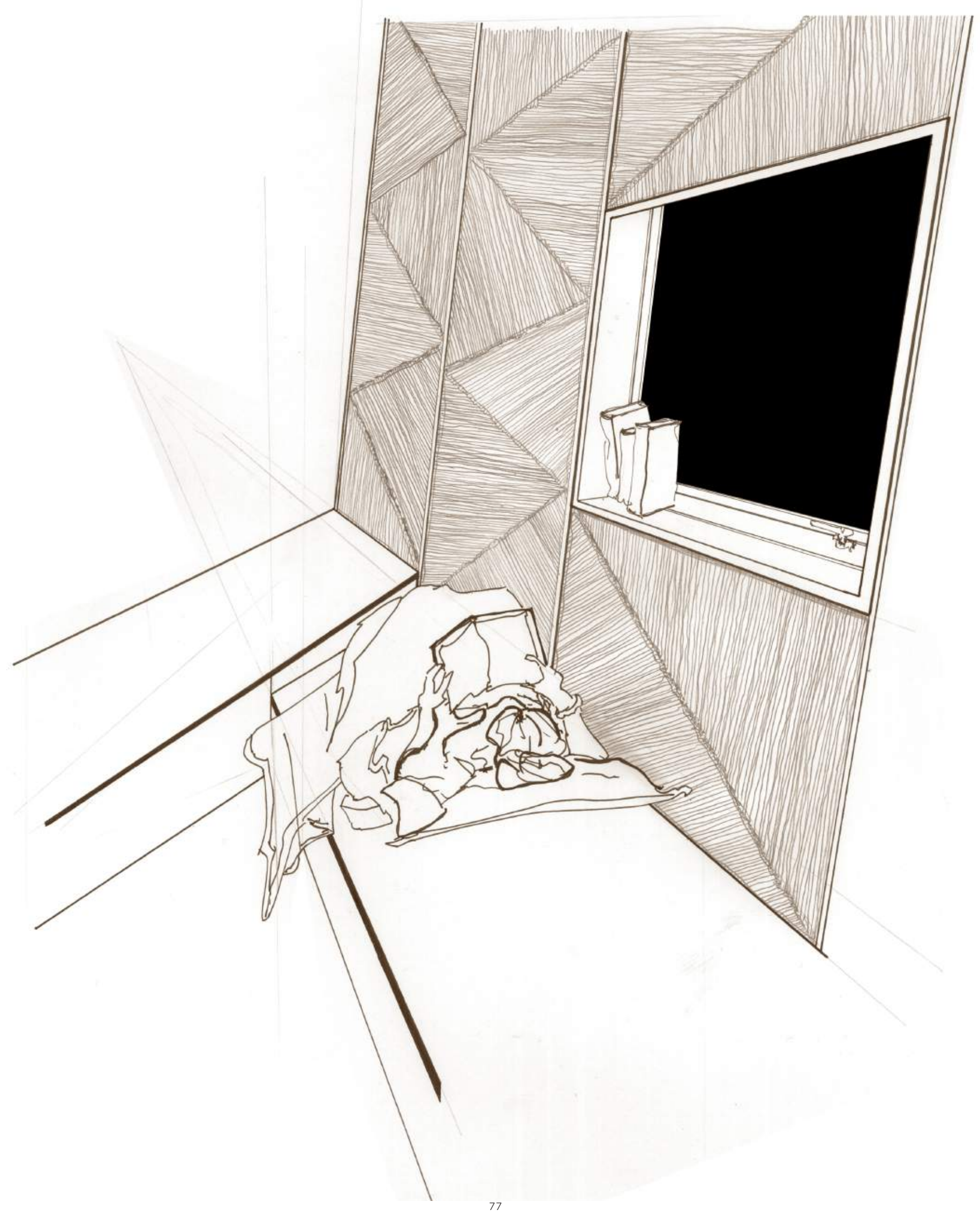



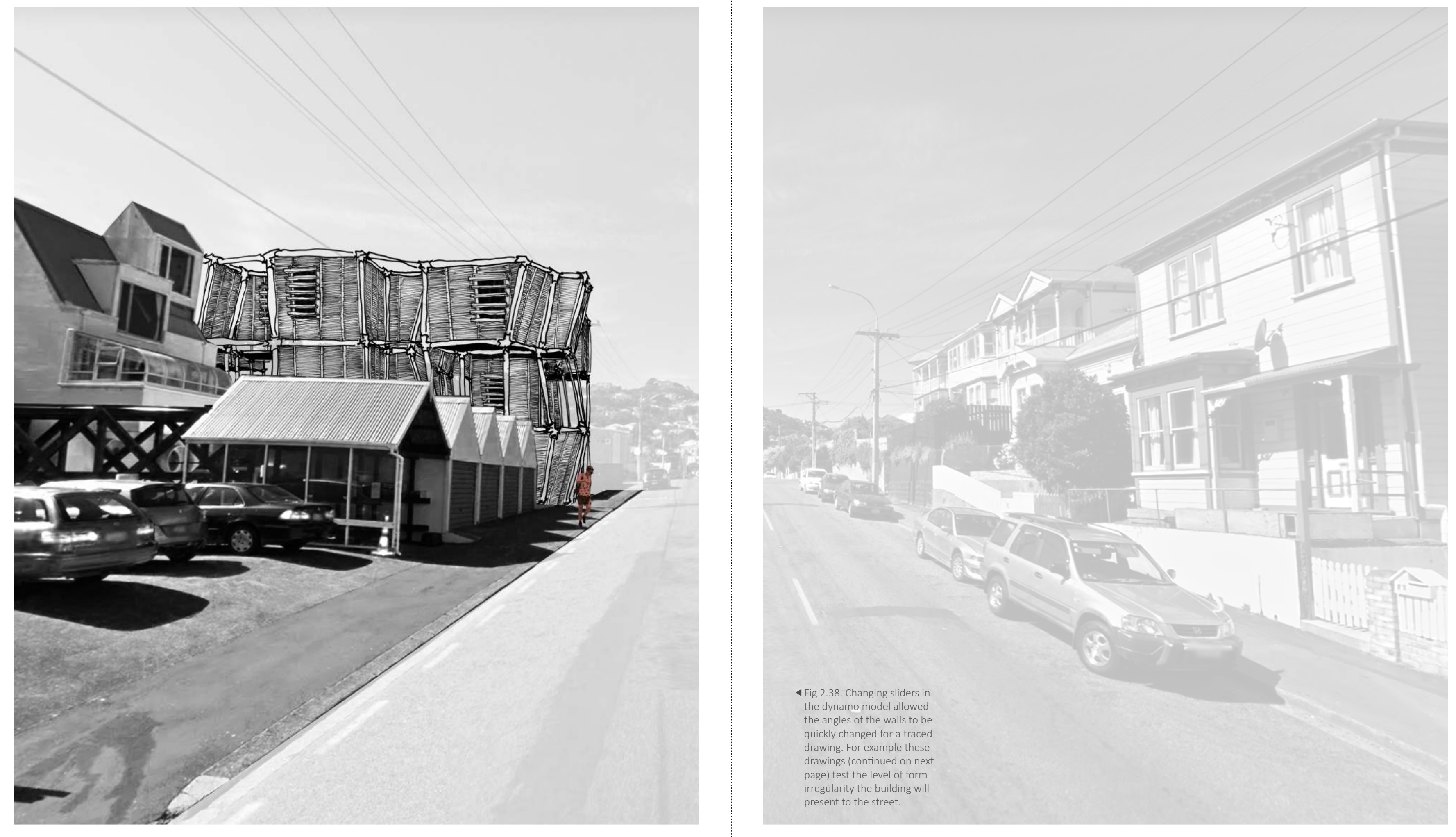

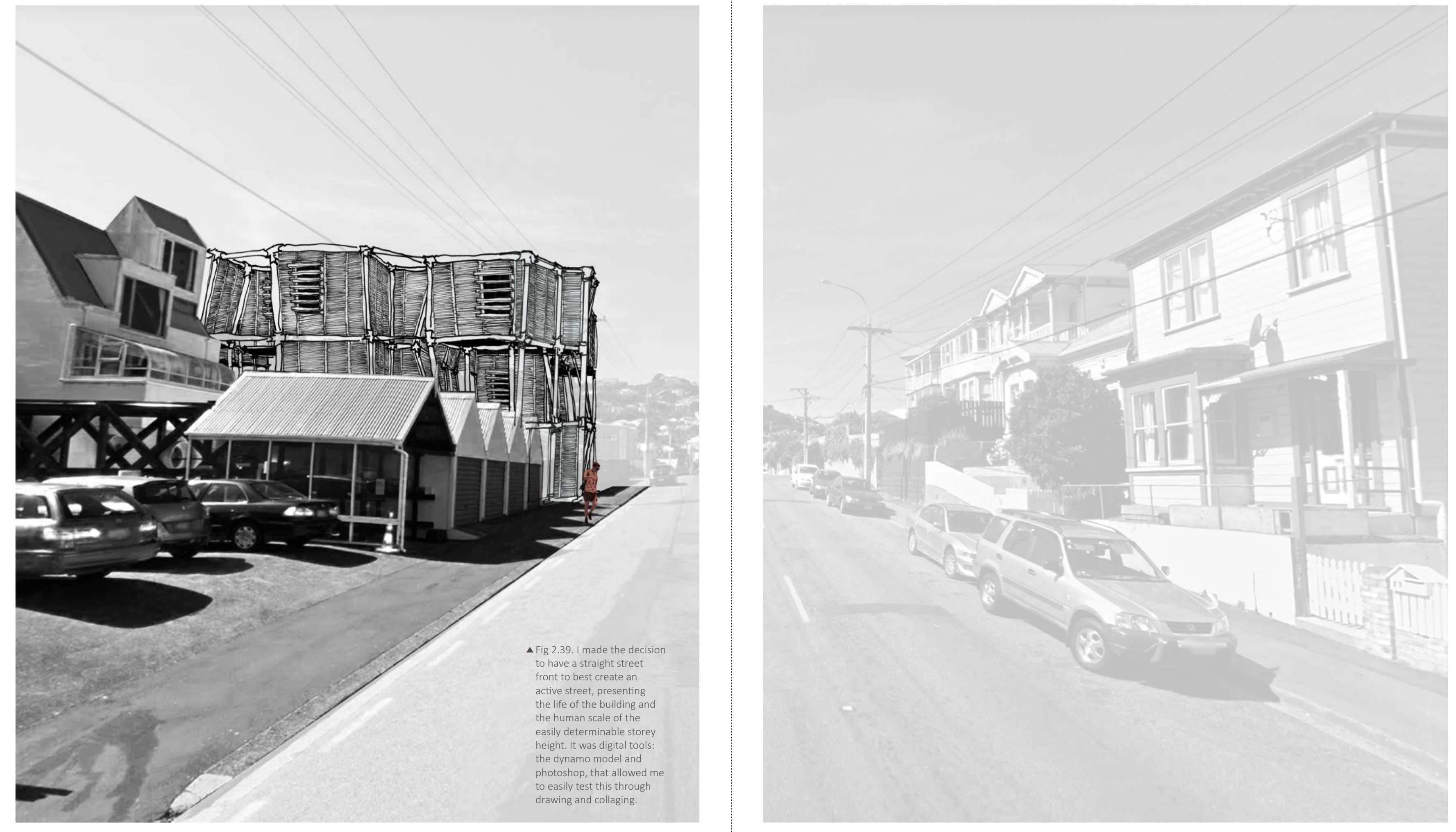


\section{Process:}

The Bionic Hand: Staircases

The process of designing the stairs neatly exemplifies a way I used the bionic hand in design.

The concept for the staircases came from evaluation of the precedent Walmer Yard. As will be discussed in depth later (page 108), Peter Salter's work embodies a contemporary version of complex design. It is building has diversity in material throughout the various spaces. This is something upon reflection, I found to be lacking in my building. The interior spaces have warm material and craft for dwelling within, and the exterior circulation has contrast between wood cladding and steel structure However these remain consistent throughout the building There was regularity in material The staircases provided an opportunity to diversify this material palette and create a threshold between the outdoors and the intimate dwelling spaces within.

As the exoskeleton sits lightly on the site, the concept for the staircases was to be weights within the building. They would seem to ground it to the site. The contrast of the stair material reflects the contrast in programme between passive dwelling spaces $T$ had been focussing on, and active circulation spaces. As artist Rachel Whiteread said,

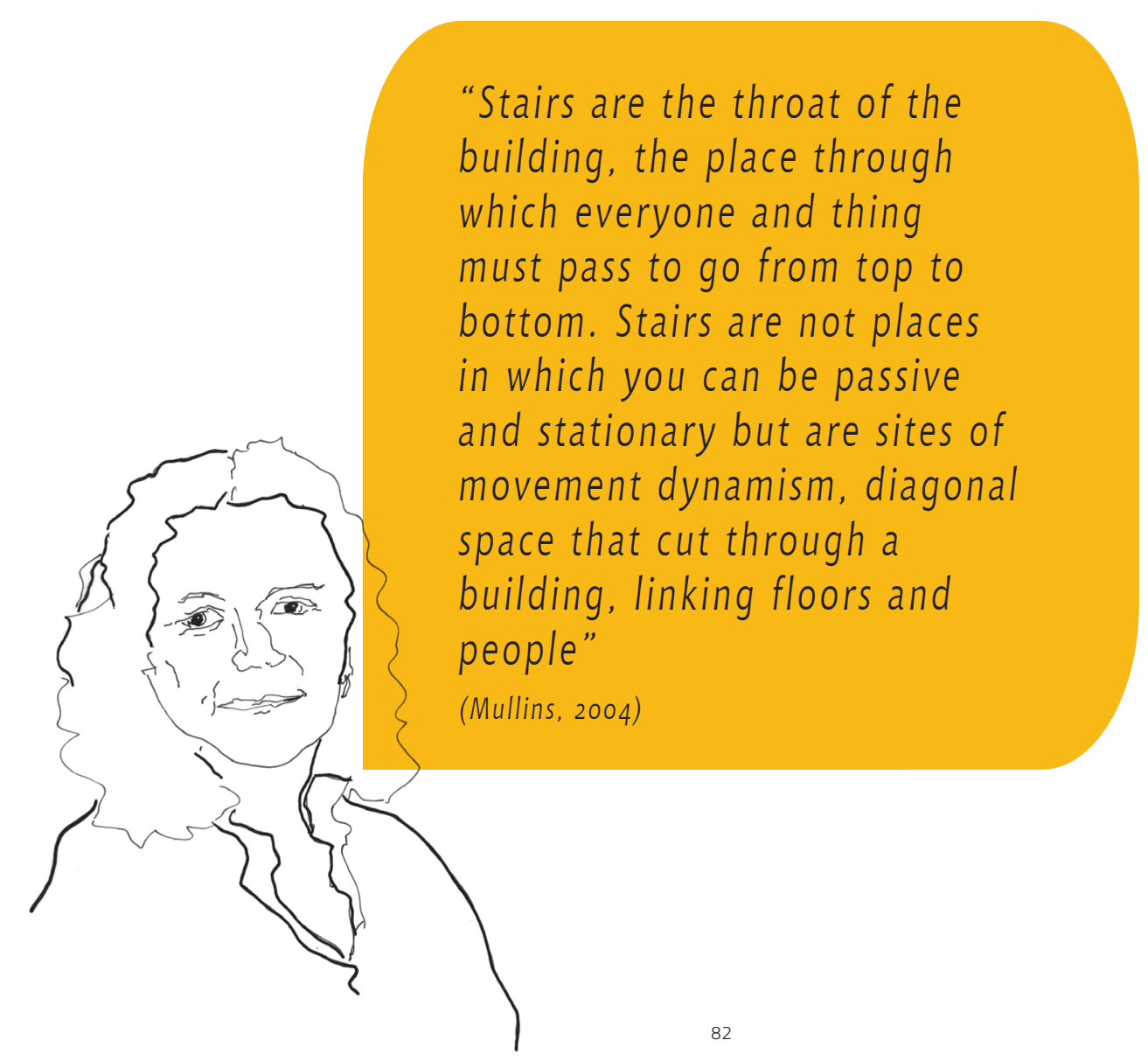

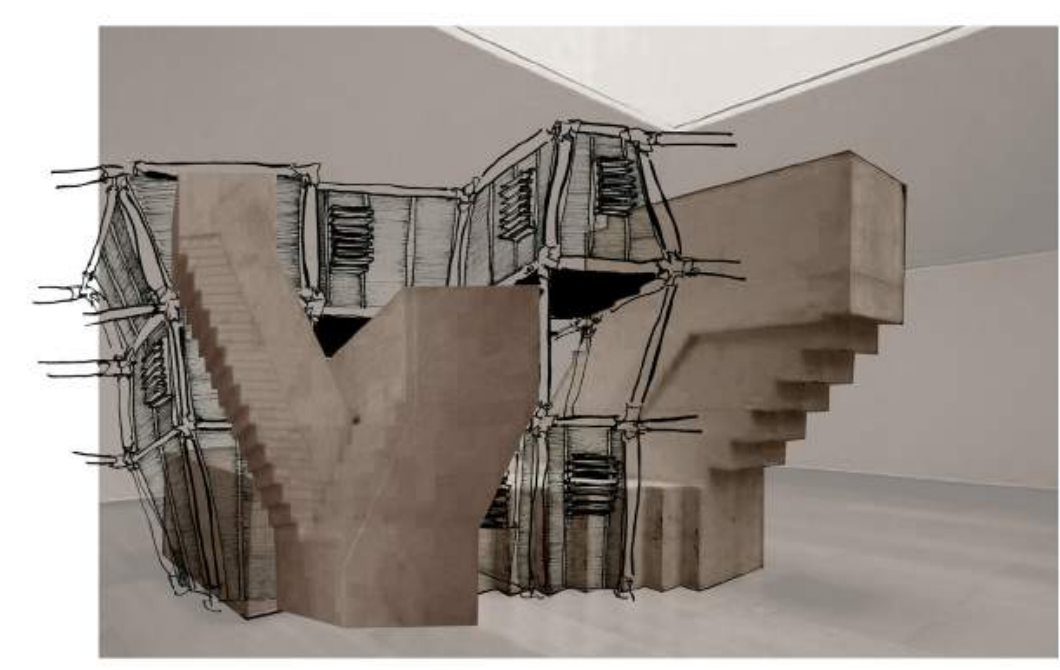

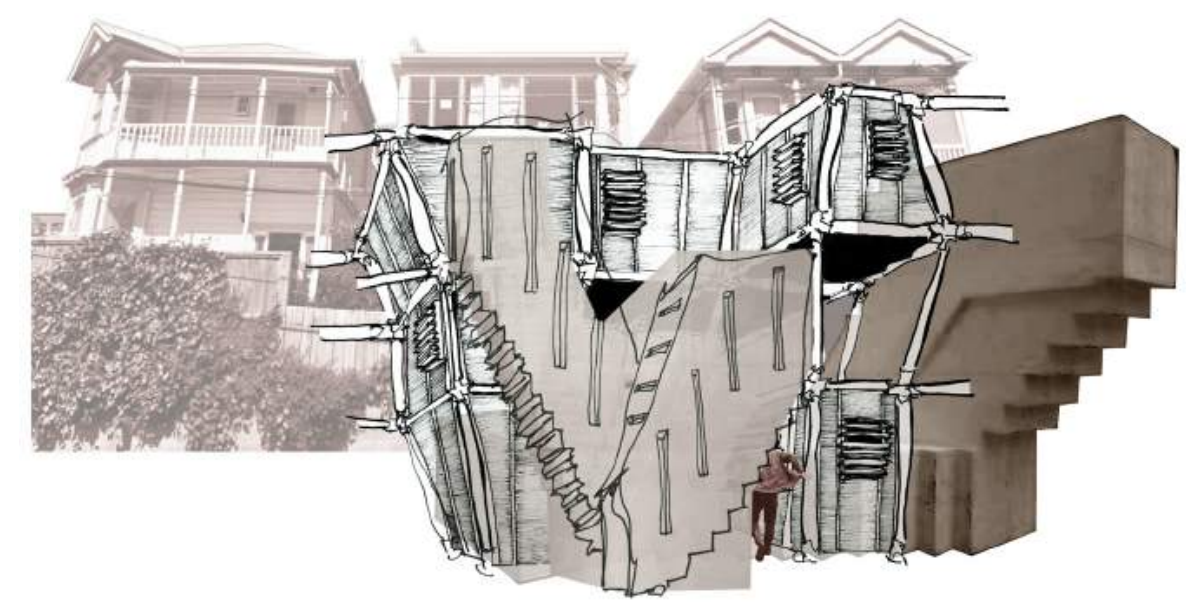

Whiteread's work casting staircases was the inspiration for the 'weighted' staircases.

I used the bionic hand to test and design these ideas. Firstly, this was through digitally collaging photos of Whiteread's work and my own drawing (fig 2.40). Tracing over the dynamo model, and the photographs of the sculptures allowed flow of imagination for how the framing and house forms could wrap around the staircases. Digital editing of those together allowed me efficiency in bringing in other tests, such as bringing in surrounding context without redrawing. 
The next step in the thinking hand designing was modelling the

concrete forms in the light frame. This showed the weight of the forms and the impact they would have on the site. This could be emphasised with the digital side of the bionic hand, by editing the photos and adding people (fig 2.41).

I also explored the impact on the site and people moving through the site through the drawing style I had already been using (fig 2.42). I

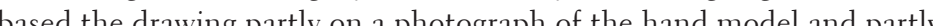
on the dy

All processes benefitted from the strengths of both sides of the bionic hand. The thinking hand to create and express ideas, and digital tools to make this way of designing more efficient.
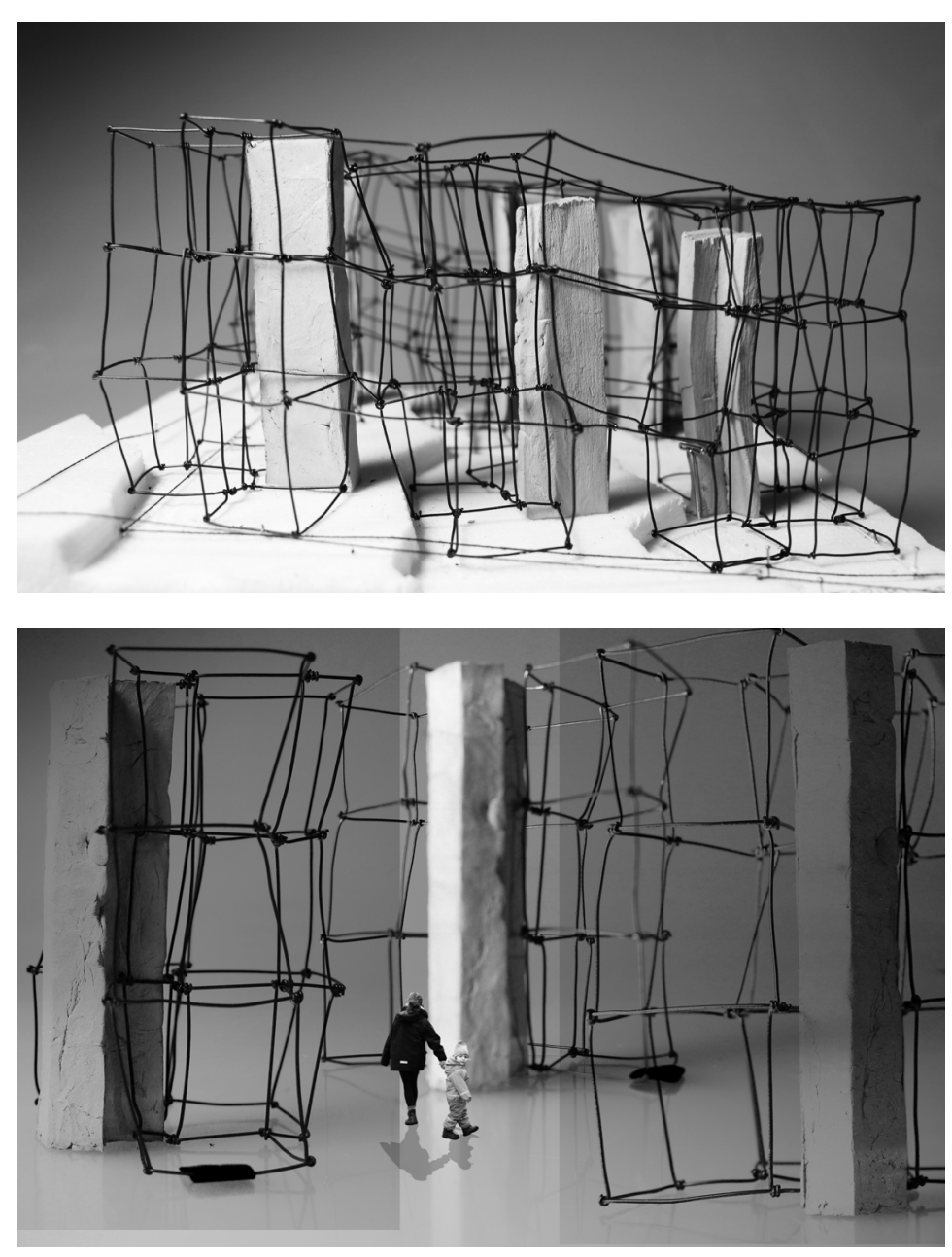

Fig 2.41. The photos of the and collaged to test the impact of the staircases.

Fig 2 42. Drawing to test the staircase from human view
amongst the exoskeleten and house forms.

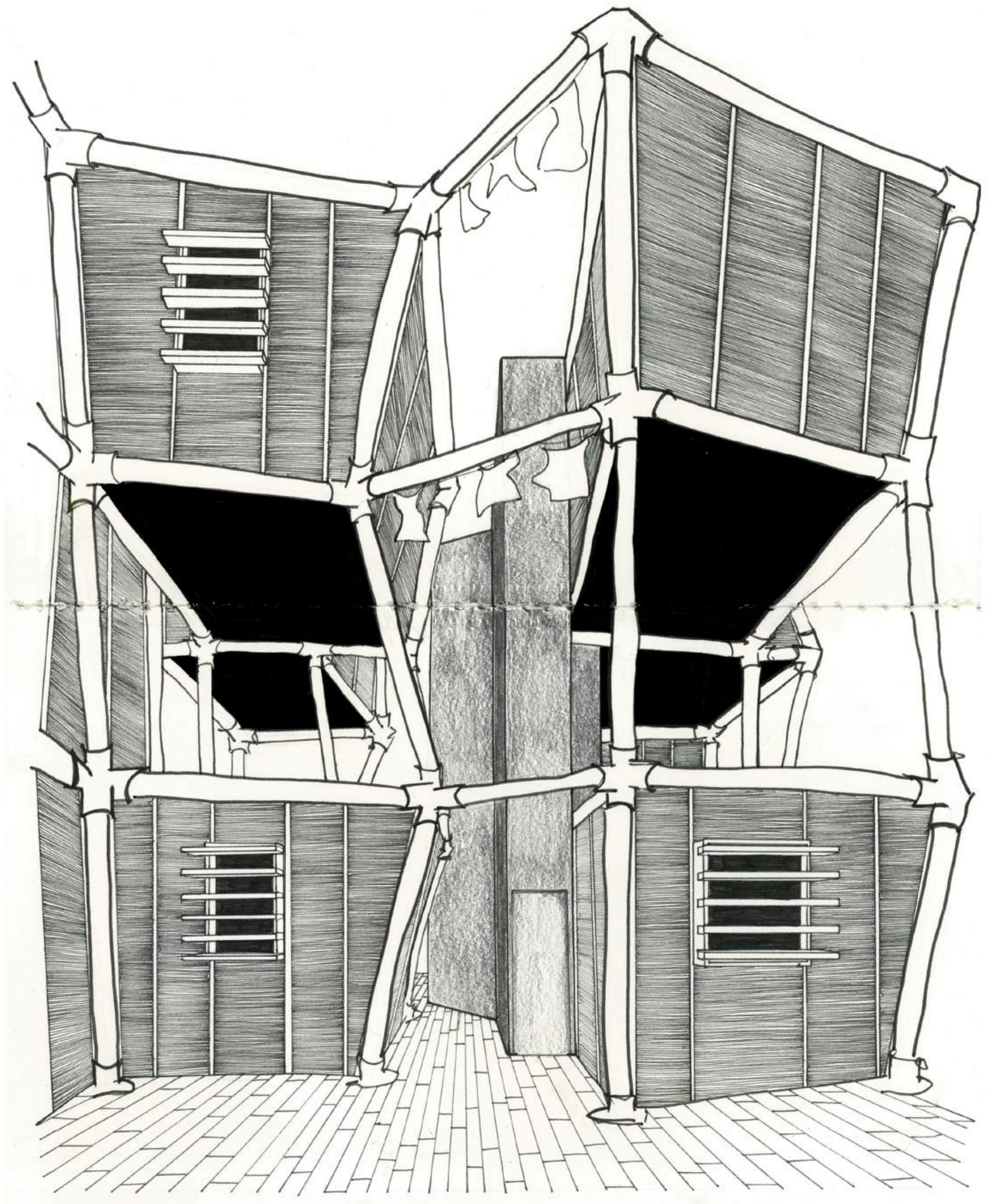


Process: Thinking Hand: Prototyping

Within the form of the relised beilding the thirking hond would come through interior maderial By drawing and prototype modelling I de thou la the d

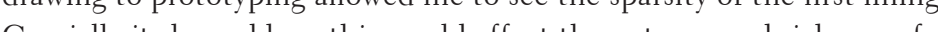

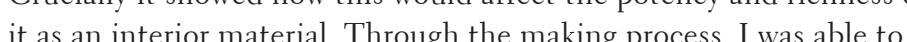

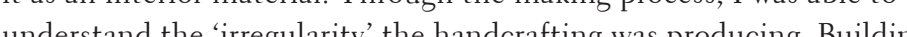
of richness to the material. This is in the same way the thinking hand can give a bespoke richness, and humanity, in drawn designing.

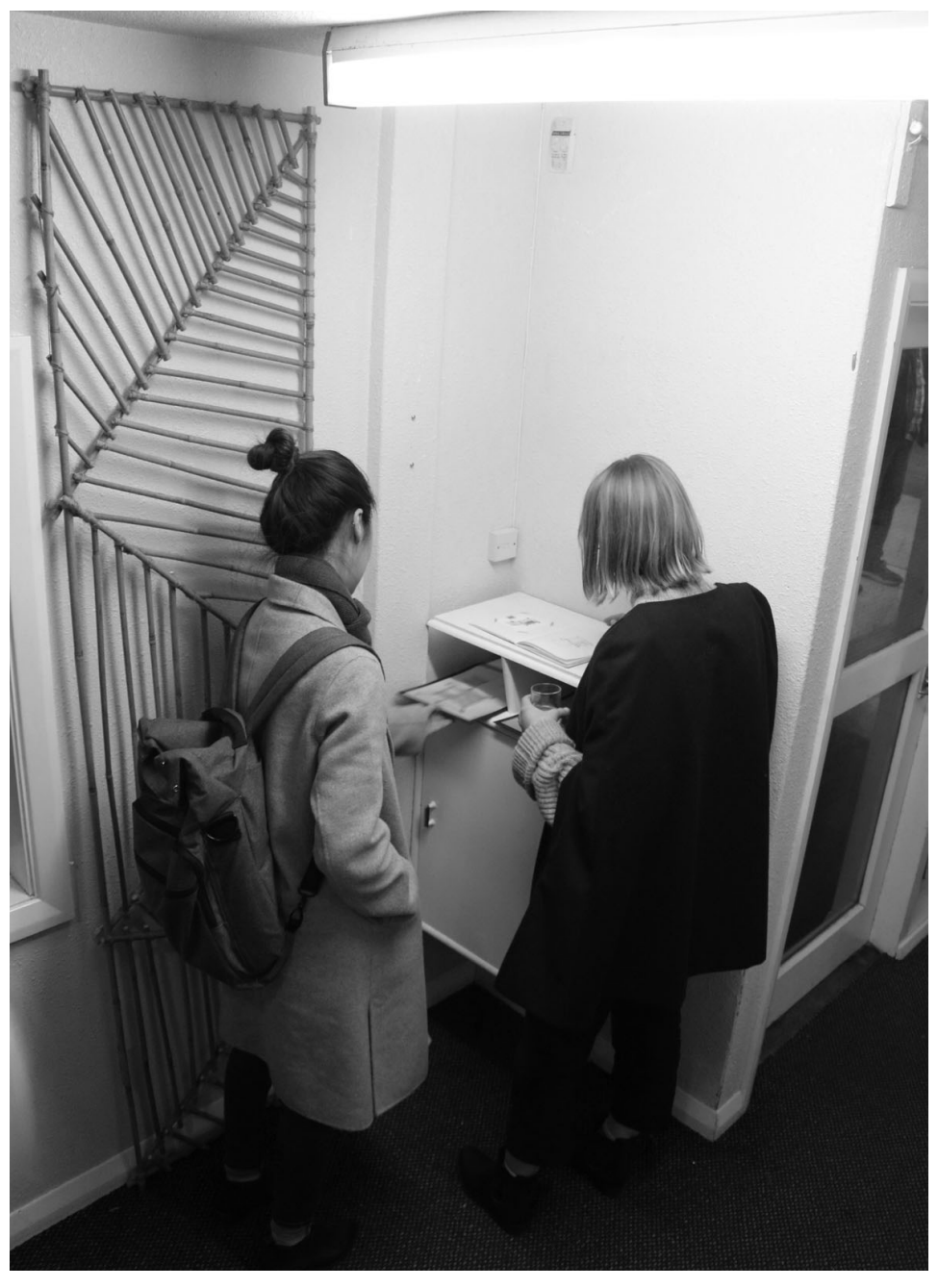

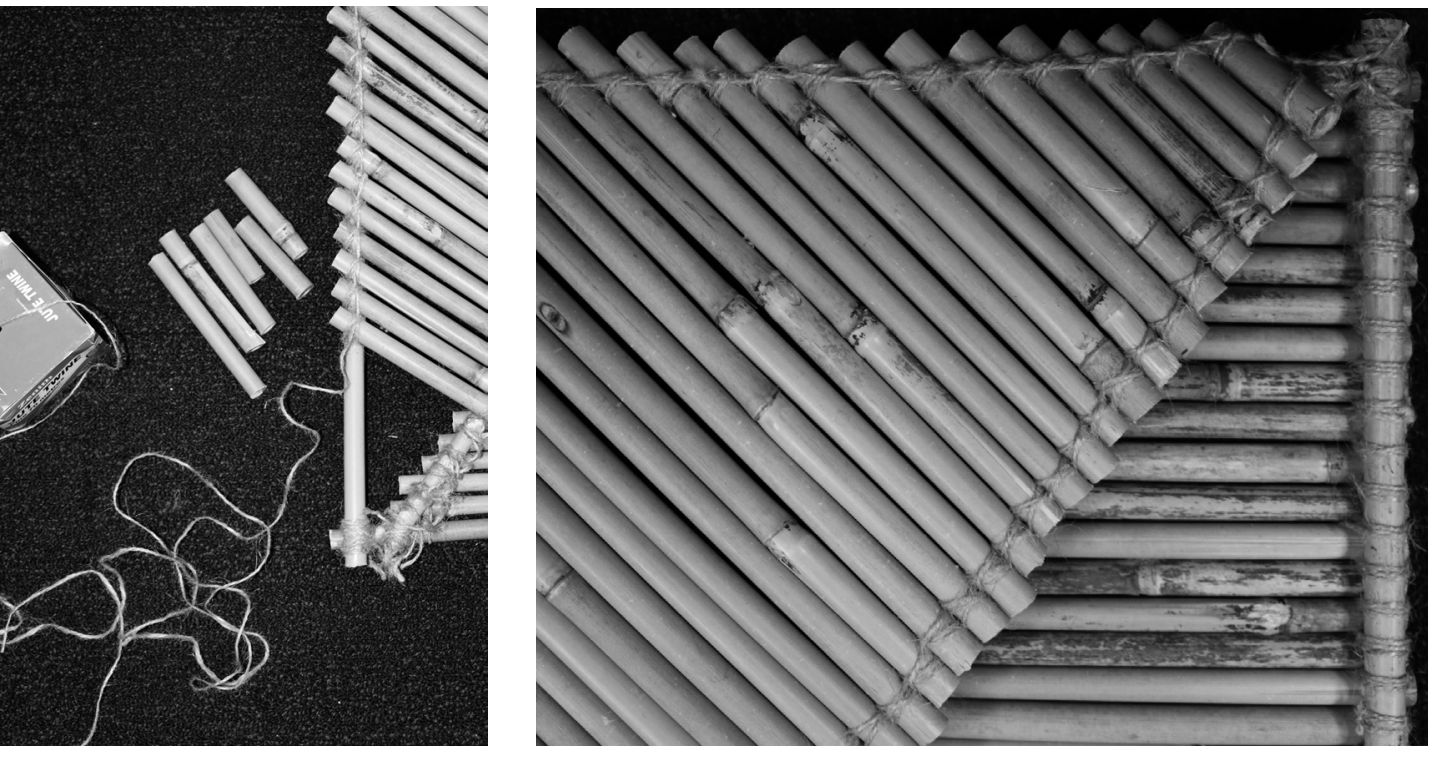
was made on site at Hataitai. When built an Hataitai. When built and
in place, the sparsity of the bamboo and thus its unsuitability as an interior
lining became apparent. - Figs 2.44-2.46. The secon prototype addressed this
sparseness to create a richer lining for dwellers to interact with.

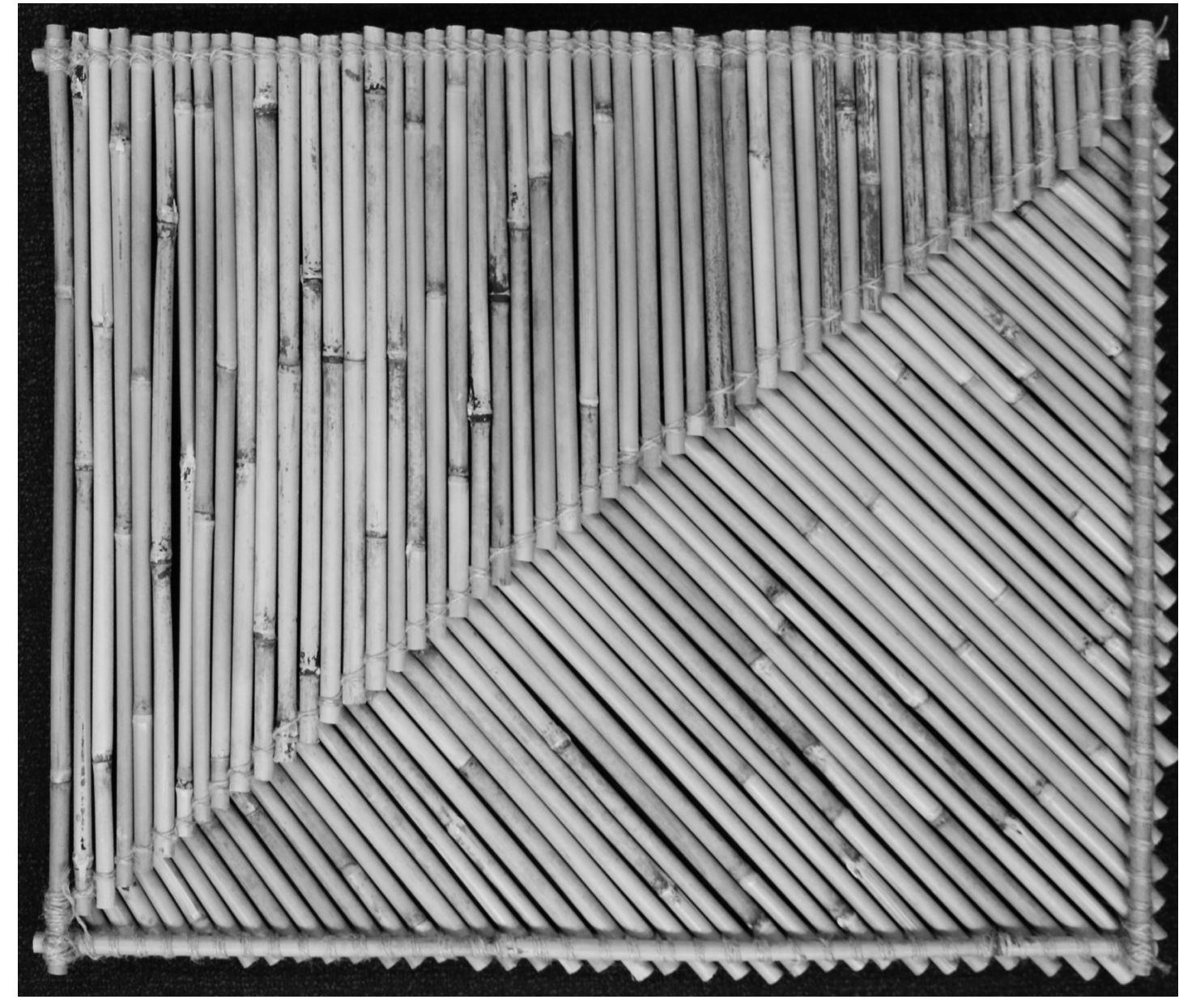


Existentialists mused on the importance of the architecture that is cons. Pallasmaa in

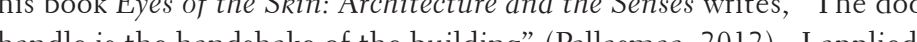
handec is the handshake of the building" (Pallasmaa, 2012). I applied this this the las

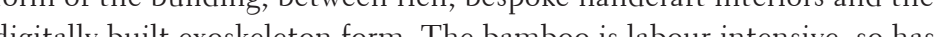
digitally built exoskeleton form. The bamboo is labor intensive, so has been limited to areas where it can create most intinacy. Lining of other spaces will be regular ling appropriate to the progra. Lite of the space.

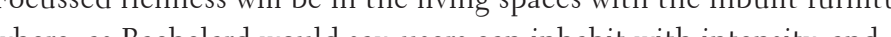
there, a Bas dis the structural frame, to mitigate exhustive levels of bespoce labs of

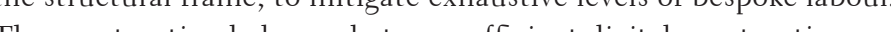
ion and

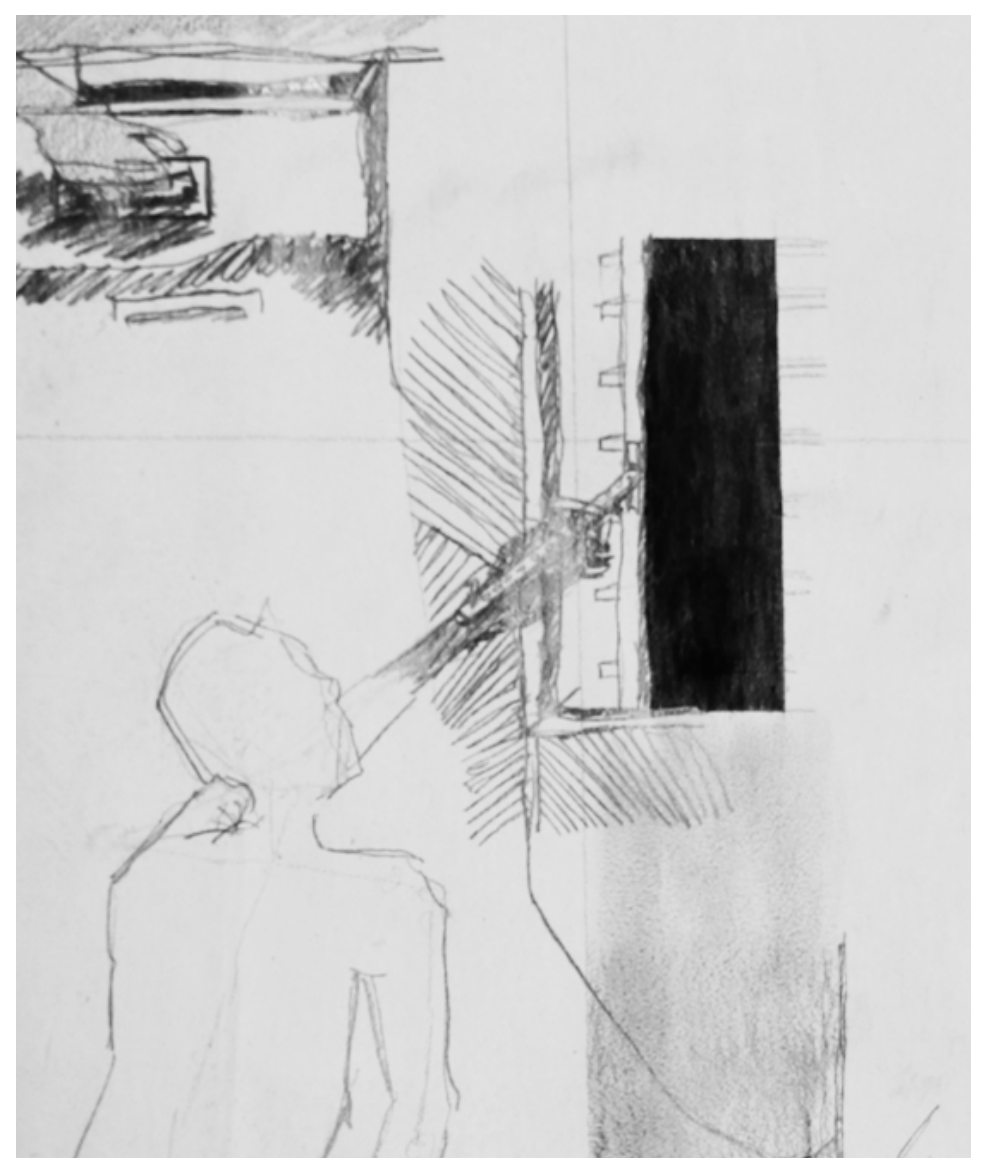

Fig 2.47. Part of a drawn study of the hand's journey around the building to understand areas mos
important to the body

Fig 2.48. A drawing of a dwelling space in the homes
where the rich material would be valuable.

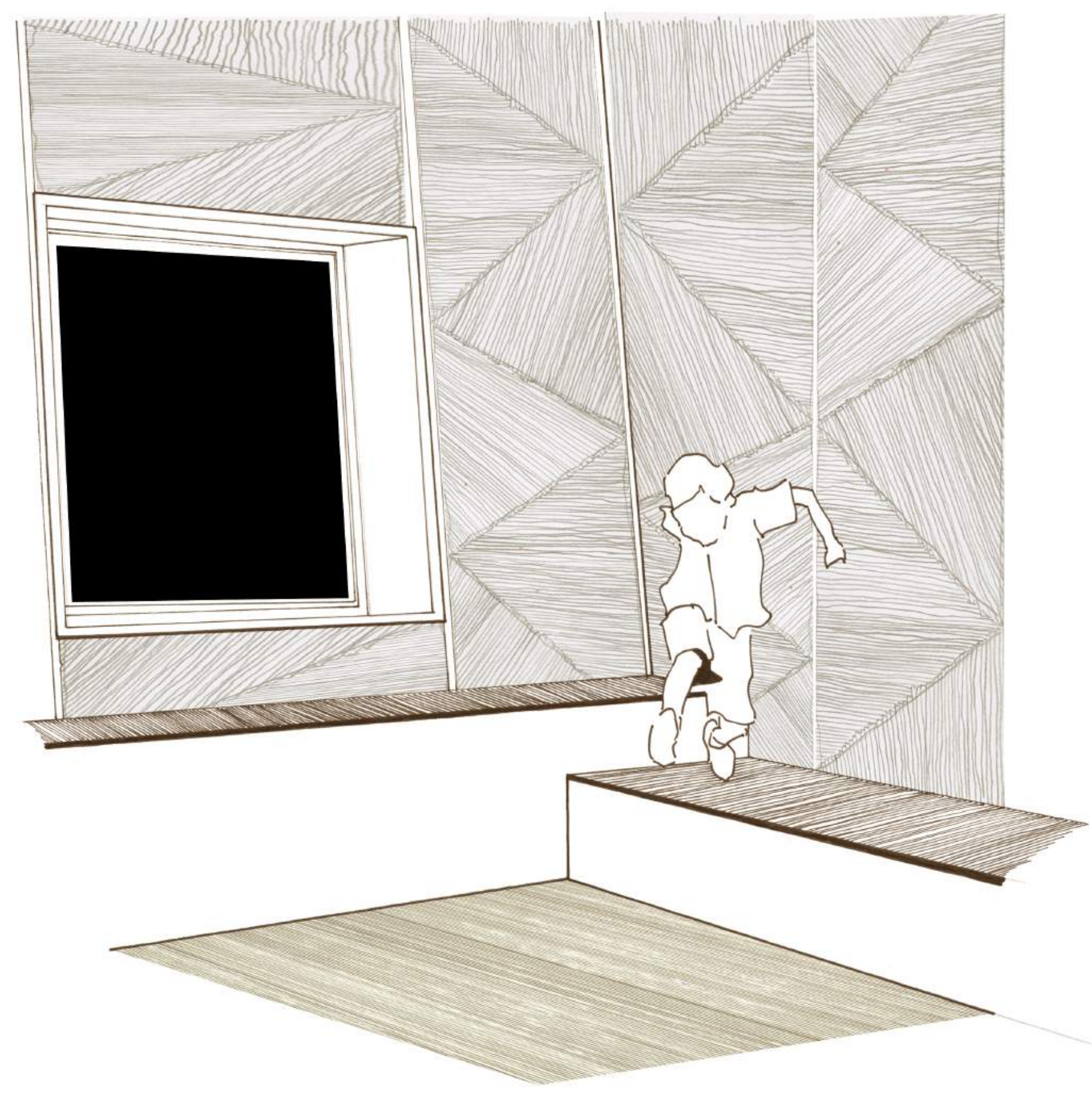


Process:

\section{Digital: Prototyping}

Changing from formation to form in the design process through prototyping was a key way to progress the digital side of the bionic

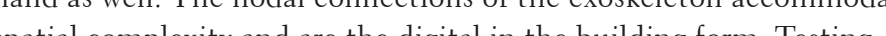
spatial complexity and are the digital in the building form. Testing collo

The intrinsically three-dimensional nature of the nodes posed difficulties in me being able to understand them through a twodimensional image, individually and as part of the overall building composition

Initial prototyping at 1:5 (fig 2.49) and the 1:1 (figs $2.50-2.51$ ) proved this difficulty. The prints of what I had originally computer modelled were laughably big and baring little similarity to what I had been drawing. Especially in their relationship to the body, despite their coherency with the architecture in the rhino model. The power of the digital tools allowed me to refine the design of the connections quickly and at real size.

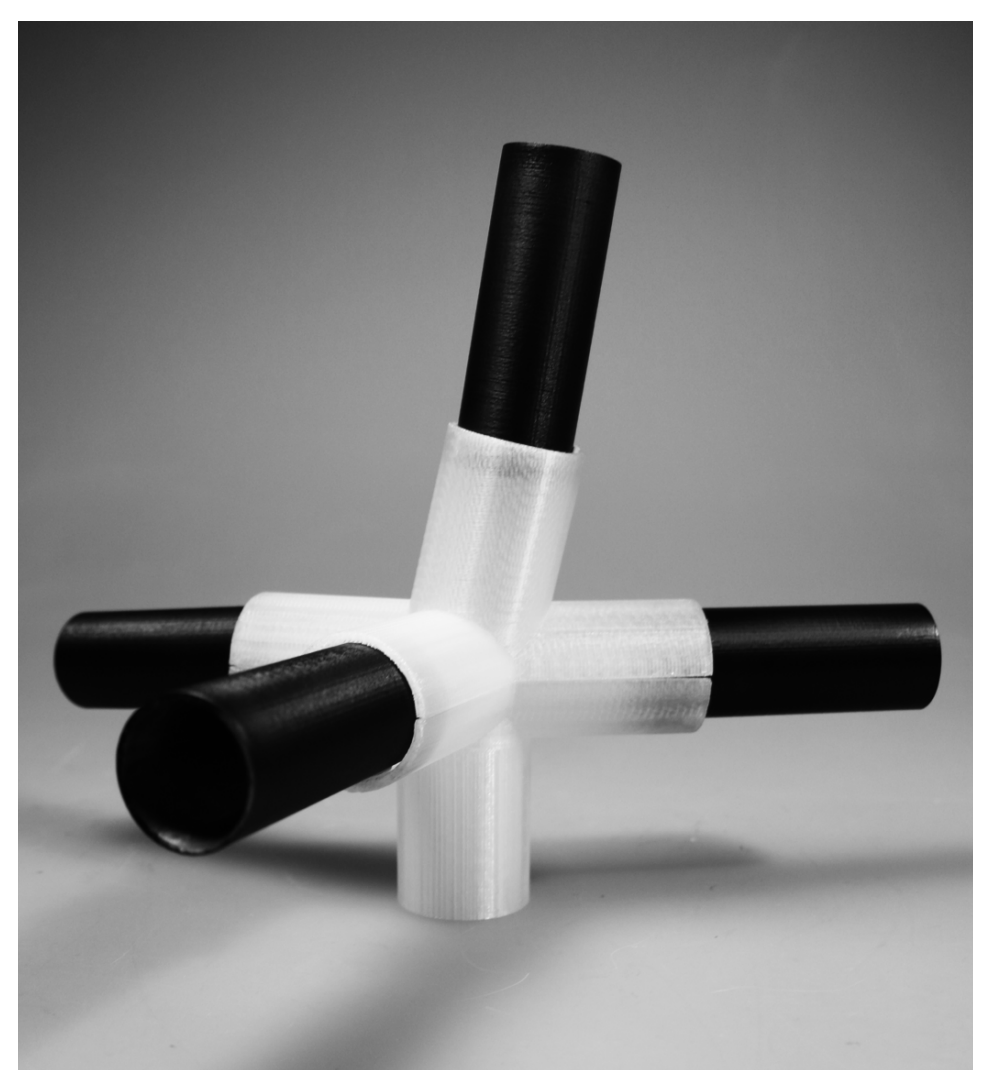

I:I prototype one

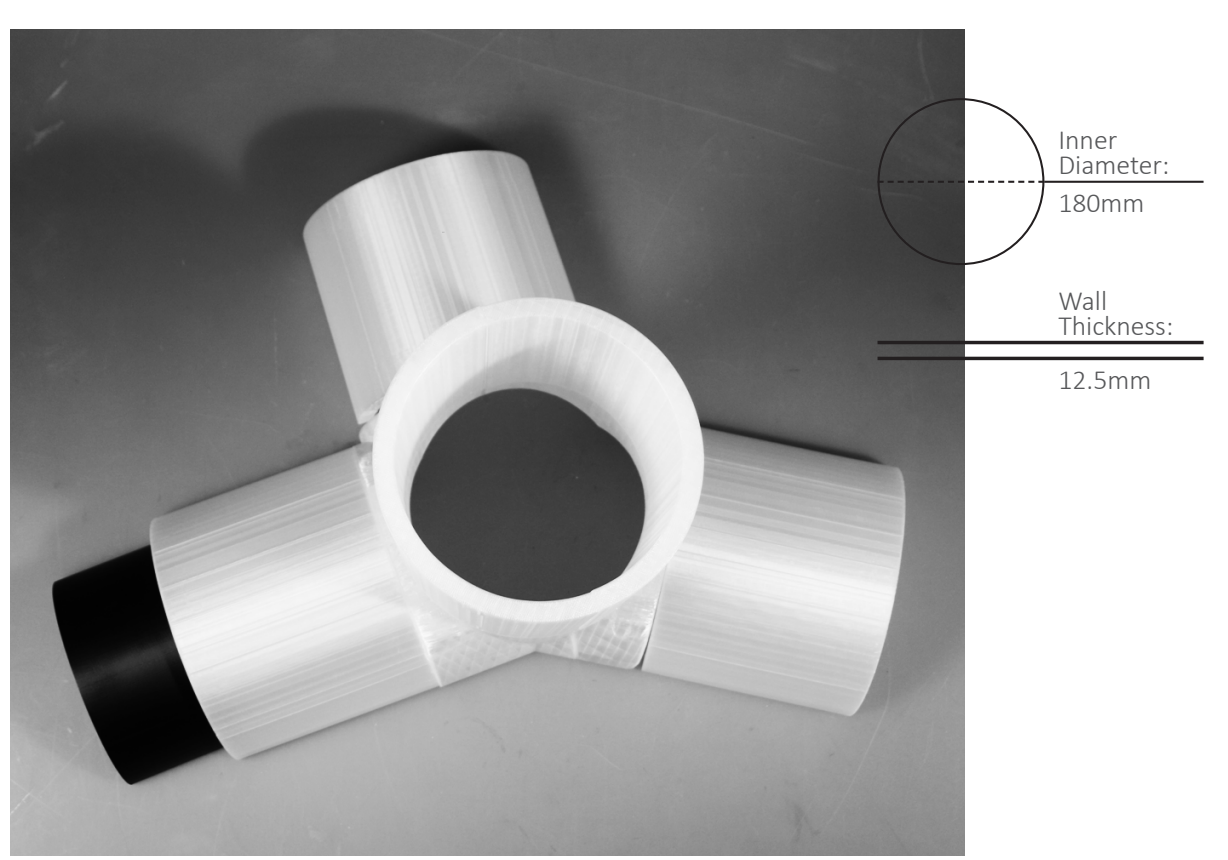

4Fig 2.49. The first 3d print prototype at 1:5 gave not scale. Using a $3 d$ printe it was equally easy to test at
$1: 1$ as at $1: 5$.

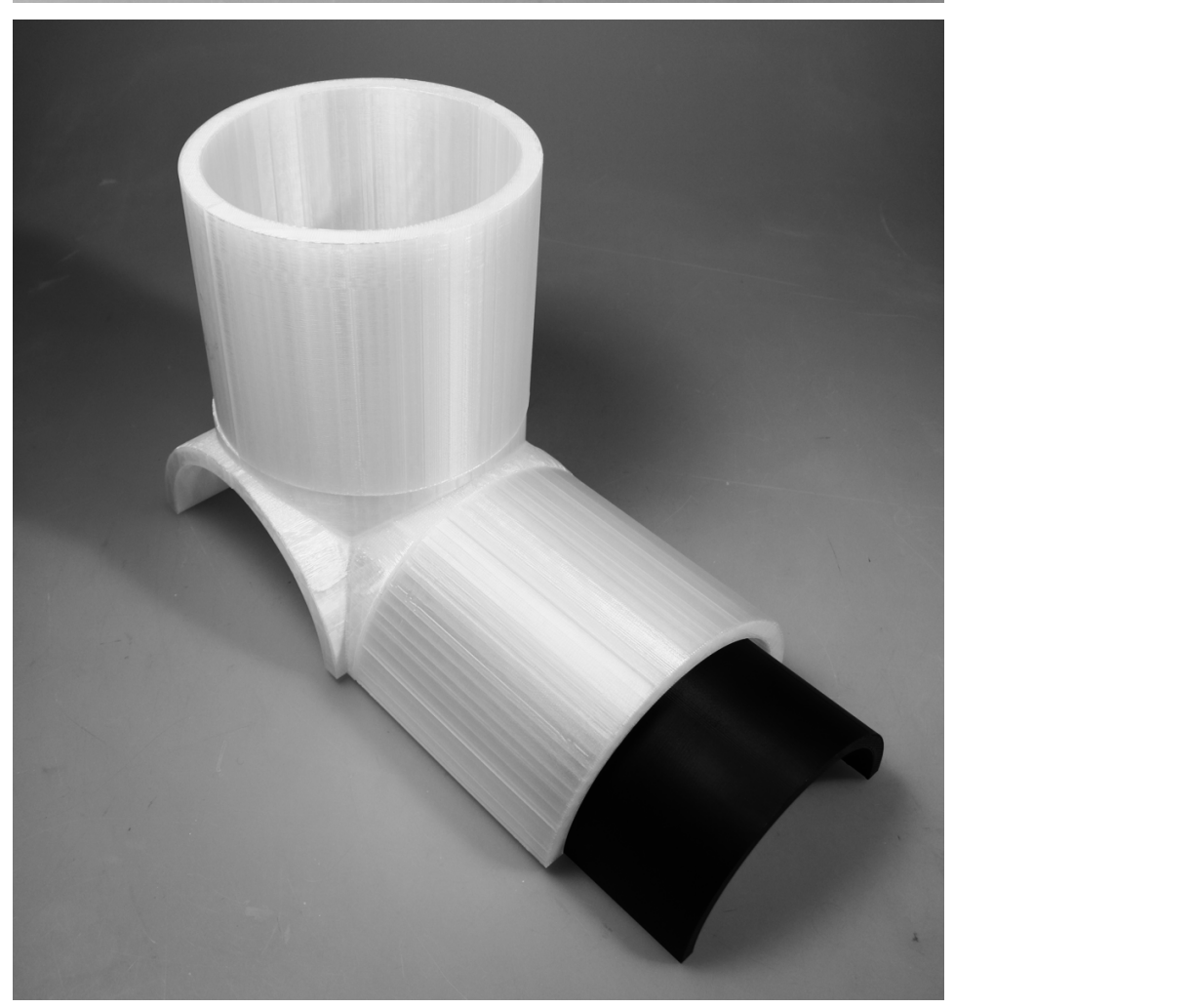


I:I prototype two
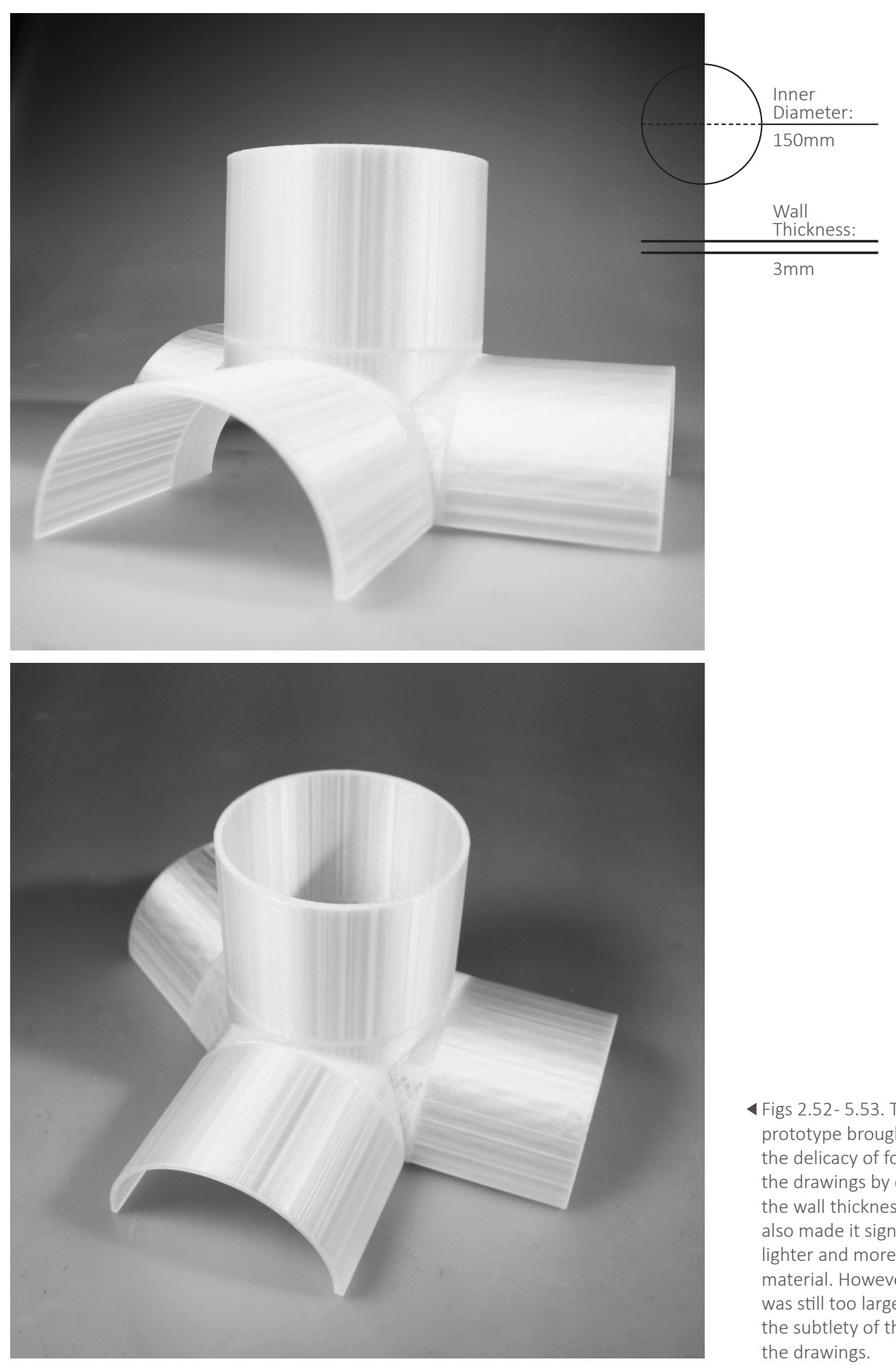

4 Figs 2.52- 5.53. The second
prototype brought back prototype brought back the drawings by decreasing the wall thickness. This also made it significantly lighter and more efficient in was still too large to have the subtlety of the nodes in the drawings
I:I final prototype

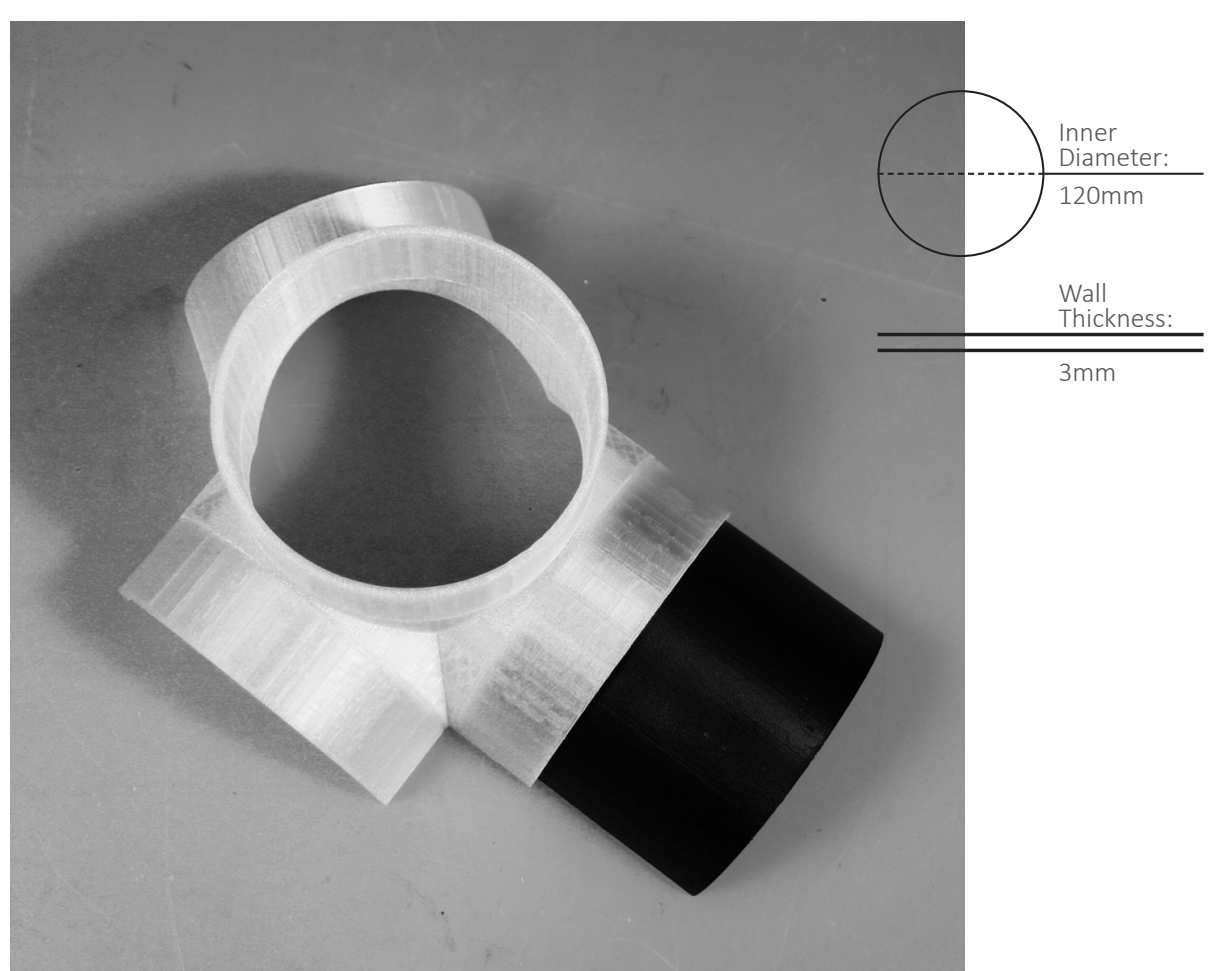

Figs 2.54- 2.55. The final delicacy of the thin walls, also changed the form by cutting down the arm length. This brought it back fitting to the steel structur poles that I had imagined through the original drawings.

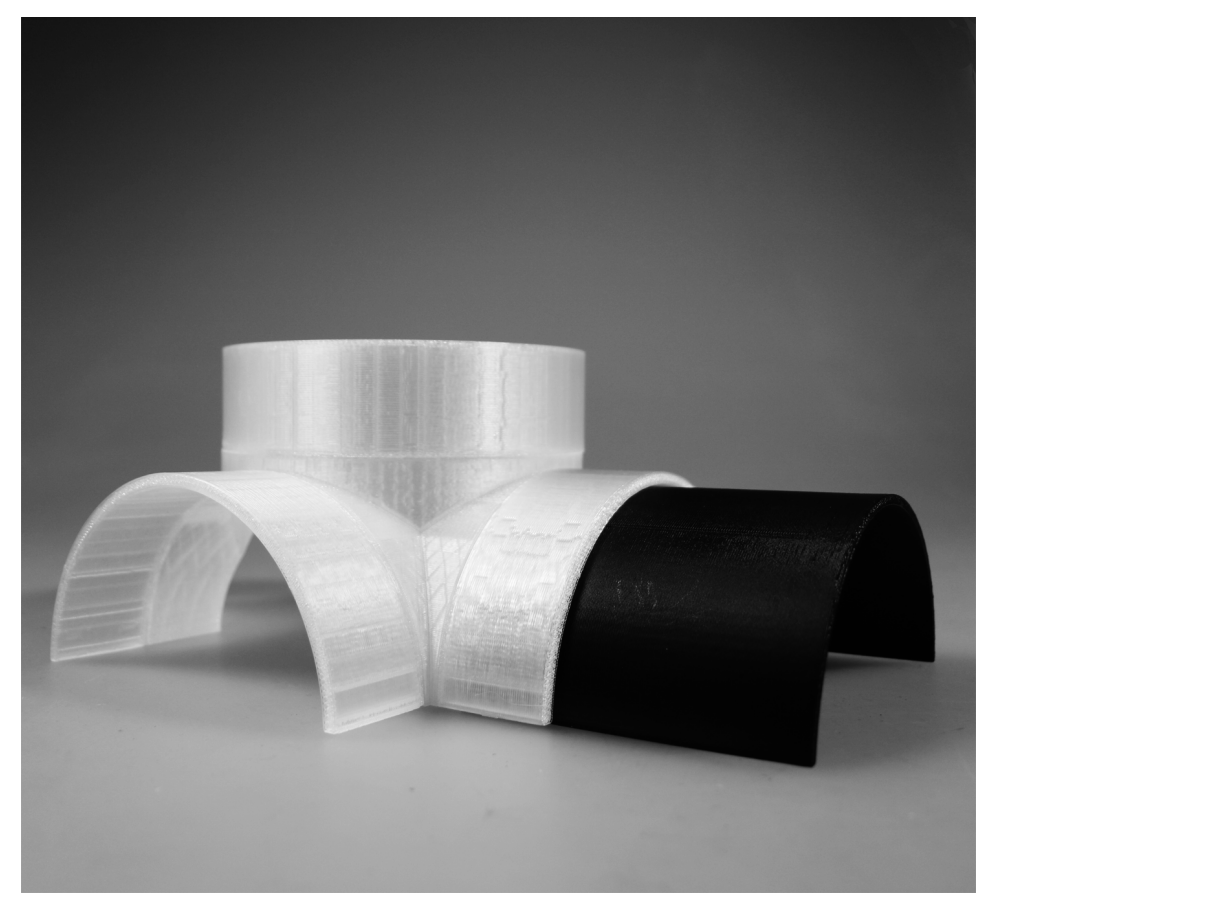




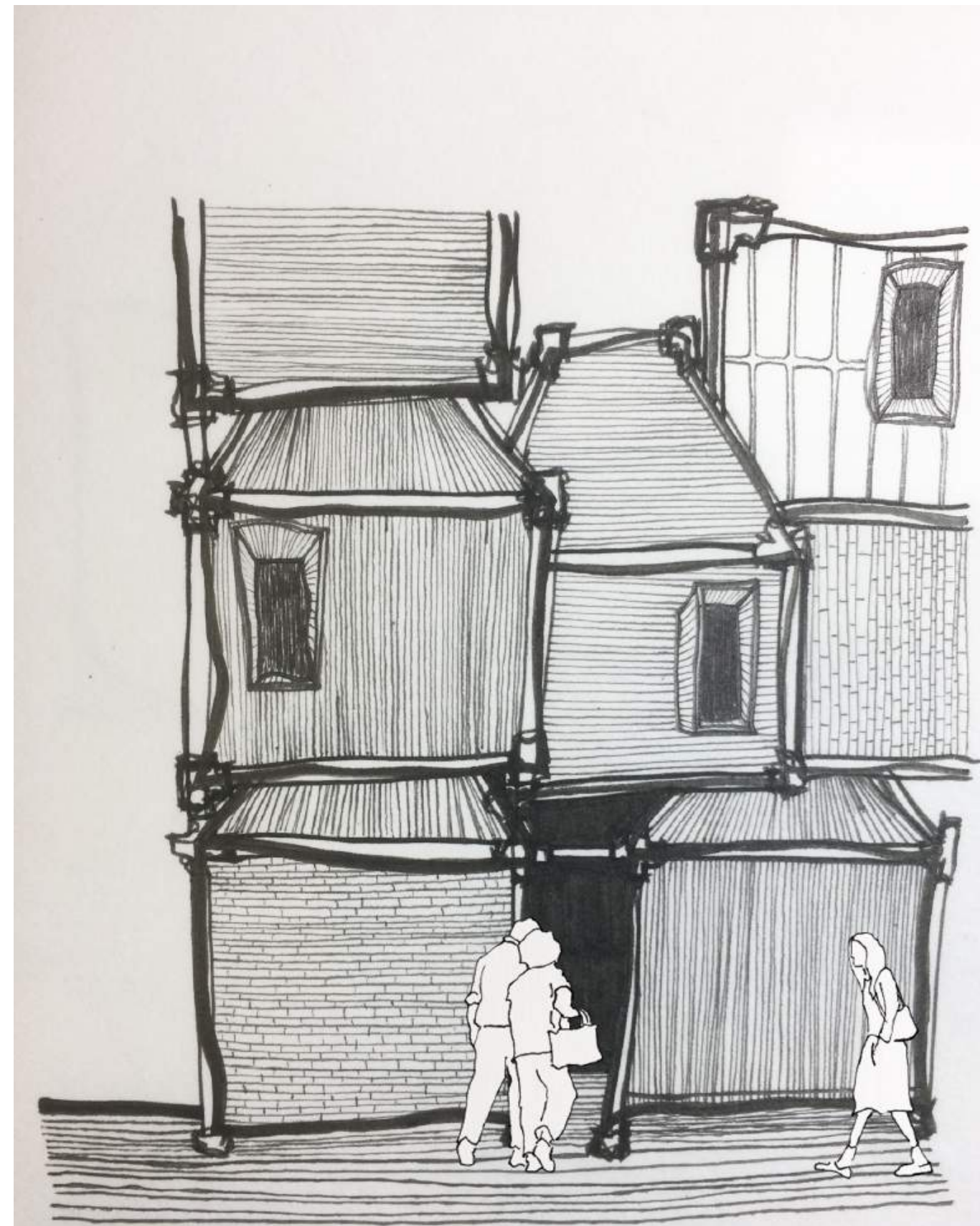

The 3D computer modelling and then offsite printing would give the "geometic and ding to in ligitaly fabricating he Loblaly Horse (Kieran, 2008). It will

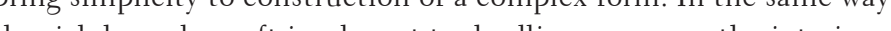
che

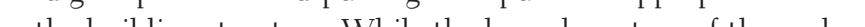
up the billing ters in giving speriatis civing intime Thus, efficient digital fabrication of generic meta is

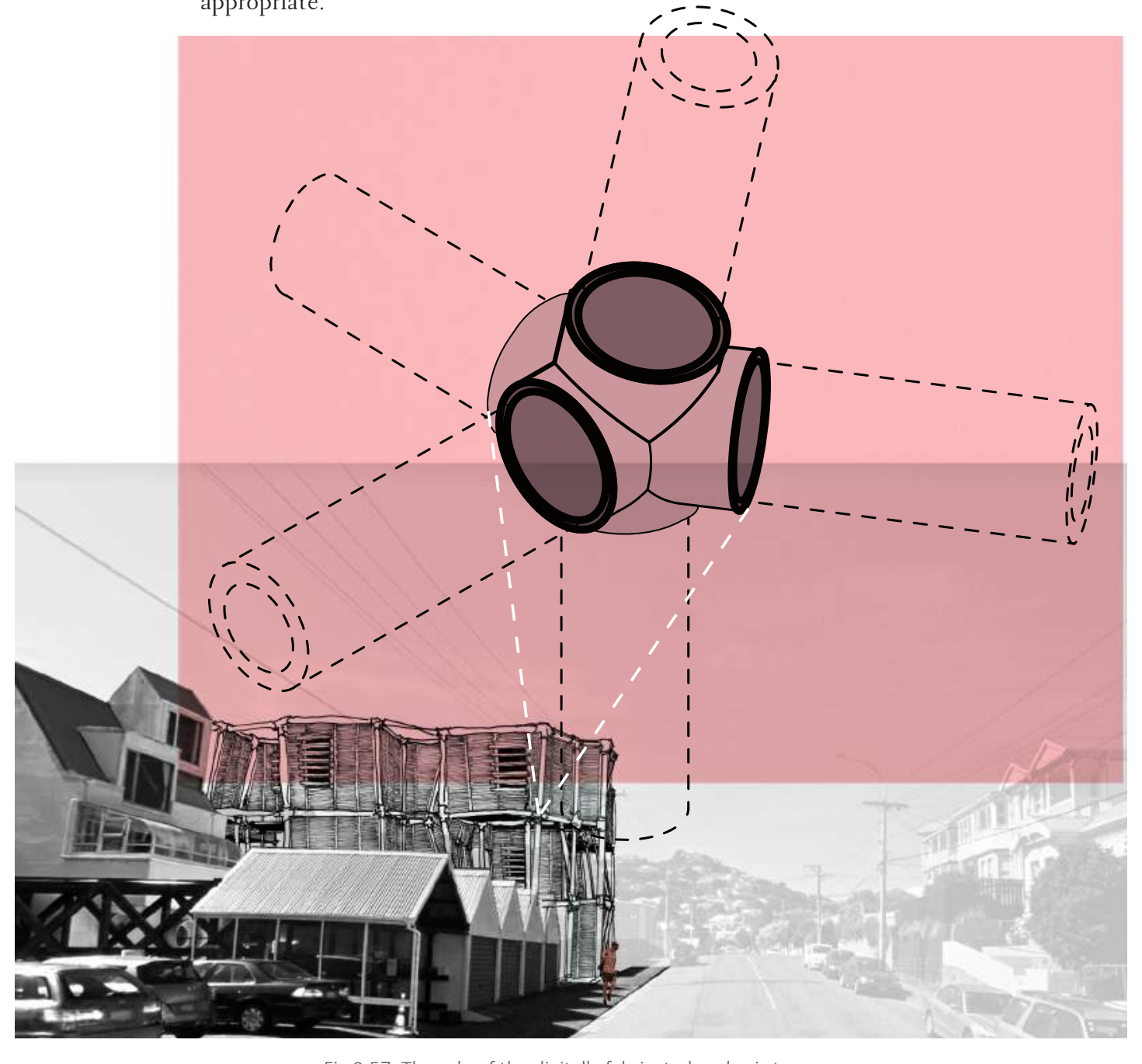

Aig 5.56. An early development drawing integrating the idea for bespoke
digitally fabricated connections into a preexisting design of aggregated forms

$\mathbf{4}$ Fig 2.57. The role of the digitally fabricated nodes is to
connect the steel exoskeleton structure of the building. 
Context:

Disciplinary Positioning

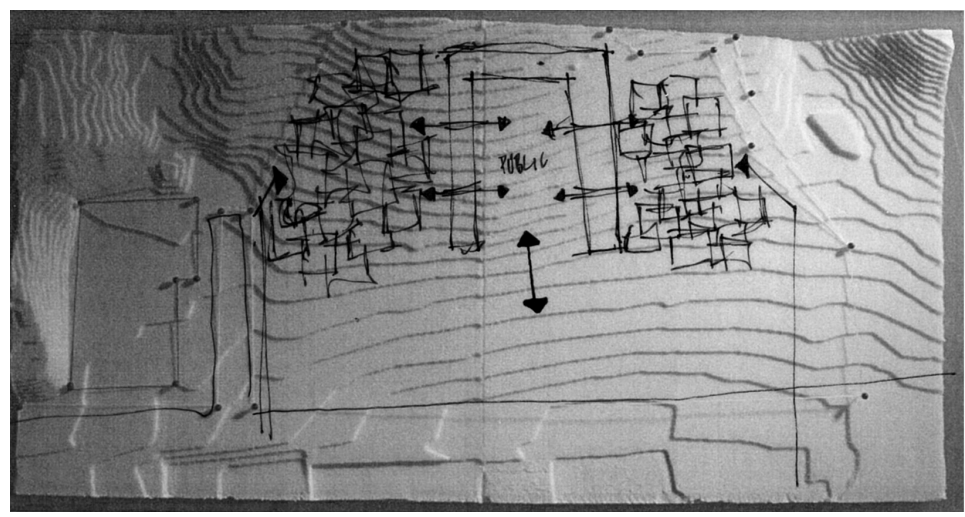

20.

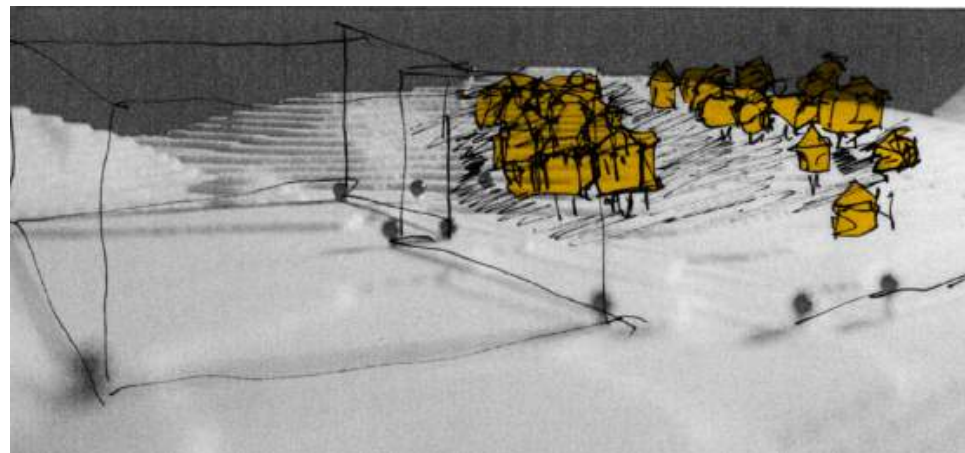

The original thinking hand drawings and models, exemplified on thi and the following pages, conceived and expressed initial ideas for a building on an early site (refer page 48). While they provoked thinking toward development of the final design, their legacy in the work was as the catalyst in understanding the design work's position within the discipline. Irregular angles and spaces I generated in plan and section were creating surprising, intimate, sporadic nooks and moments.

After critical reflection of this work, it became clear I was designing in rejection of standardised forms shapes and angles. Therefore, the position of this work is within a thread of "complex" "irregular" designing and craft in architectural history.
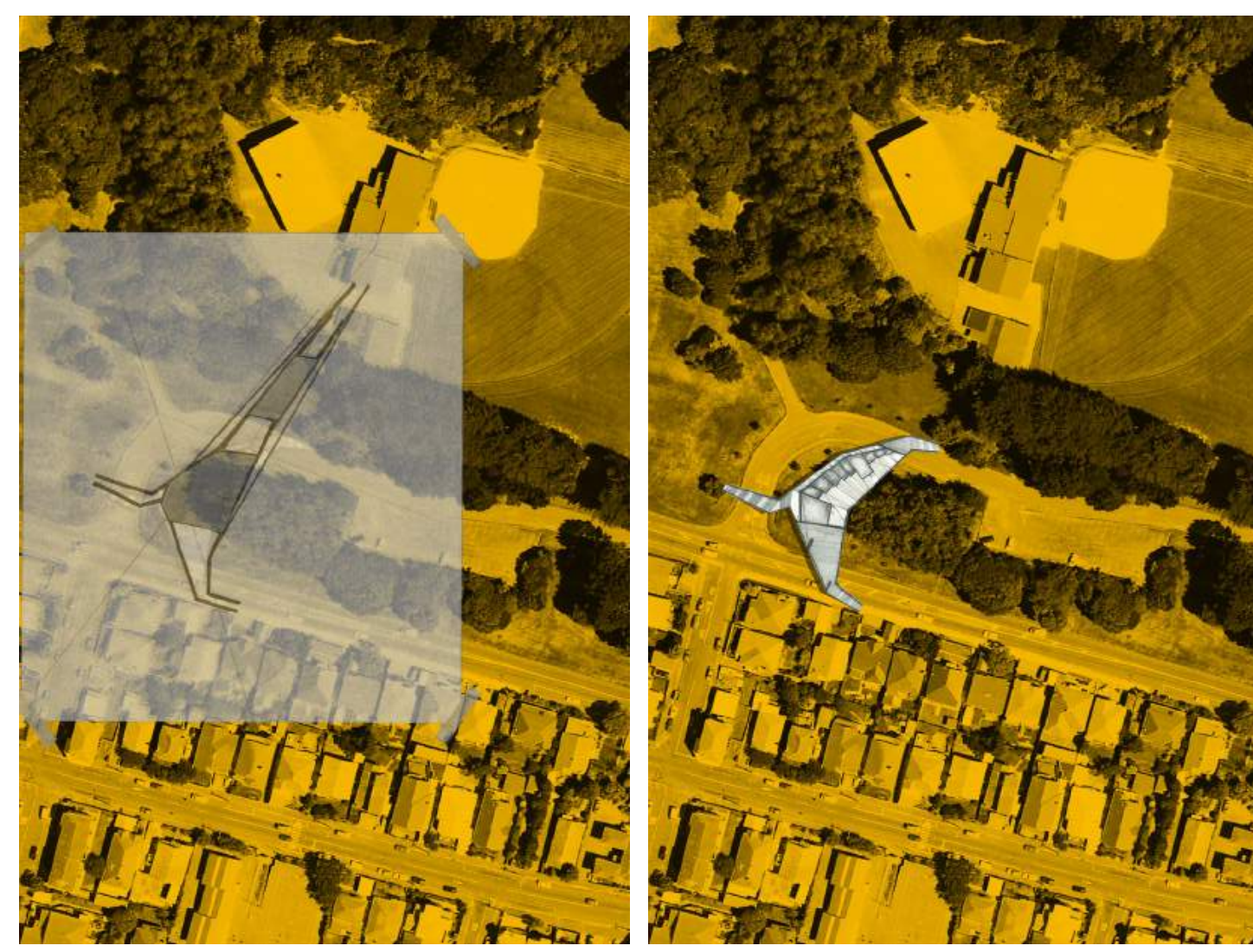

$+100100$ rutertits
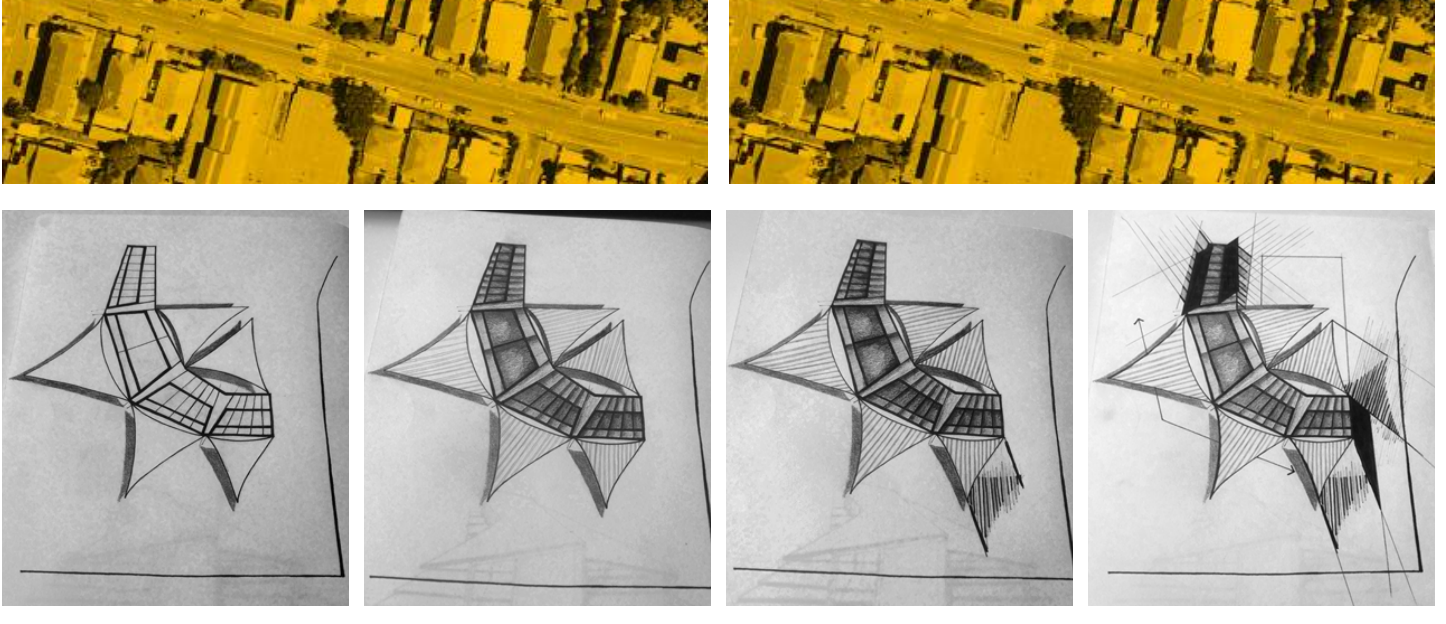

Figs 2.58- 2.69. Examples of early concepts of a single unit dwellings on a sloped shinking hand which show a tendency to irregularity and complexity. These drawings became the pod
forms of the bridge concept and then the single pod dwellings of the initial concept on the final site.

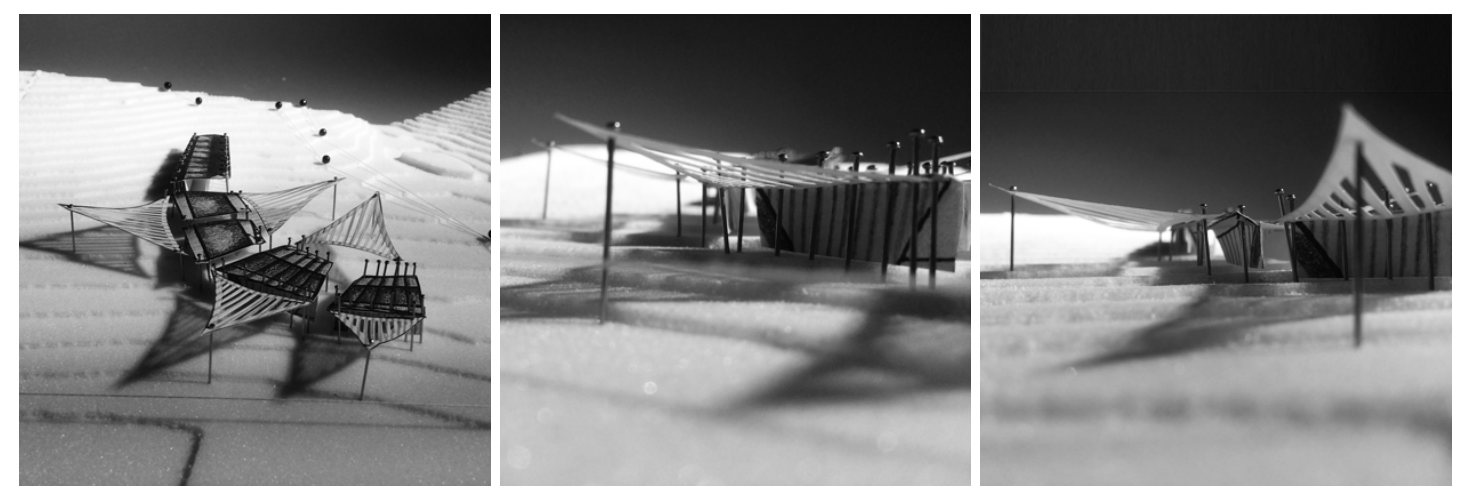



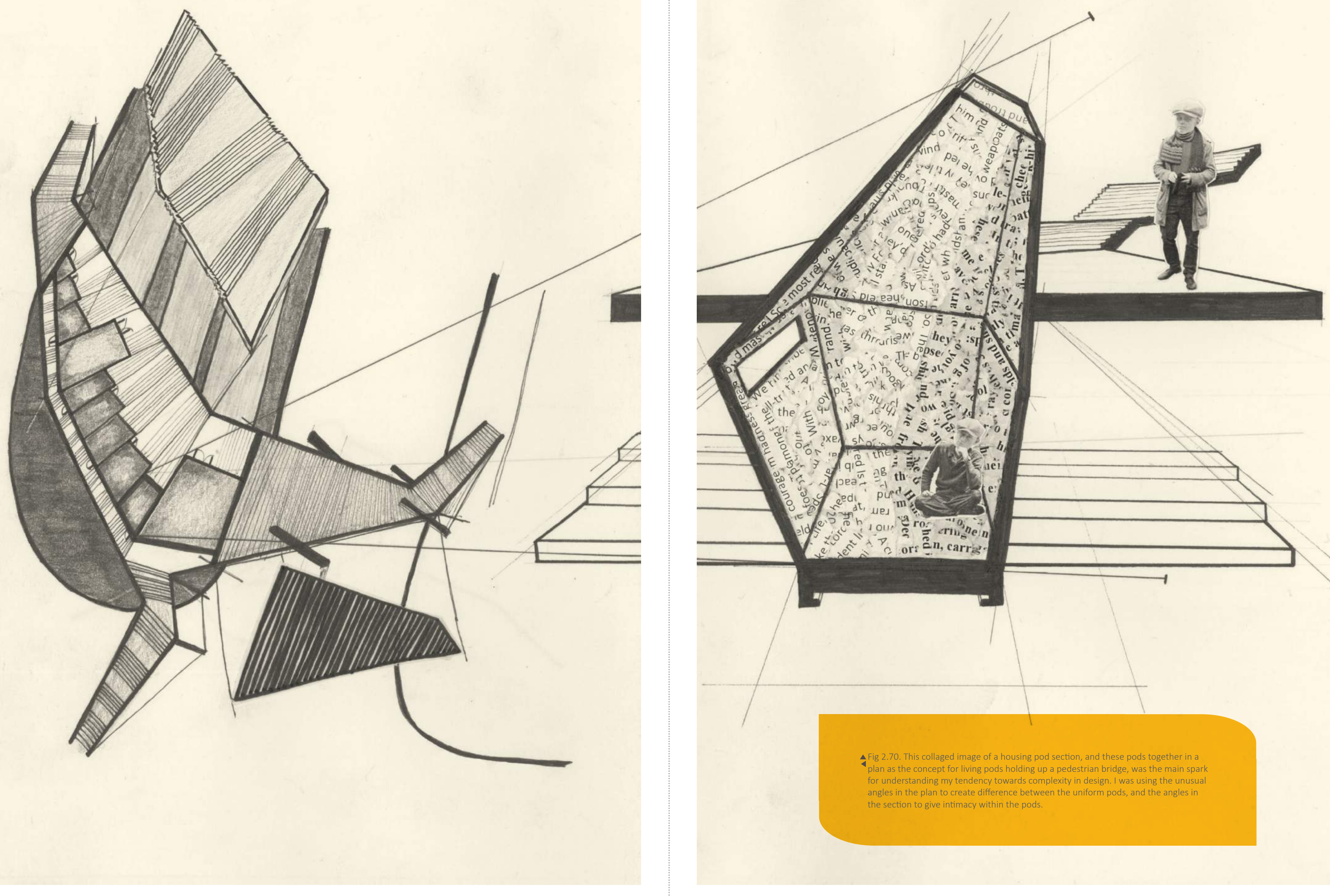
The recognisable version of 'complexity' in New Zealand architecture is the formal complexity as a version of post modernism, made famous by Roger Walker and Ian Athfield.

The word complexity in this context throws the mind to Robert Venturi

and his book Complexity and Contradiction in Architecture. Here

he expresses that complexity in architectural element and form is

reaction to the bareness of modernism.

\section{"Less is more"}

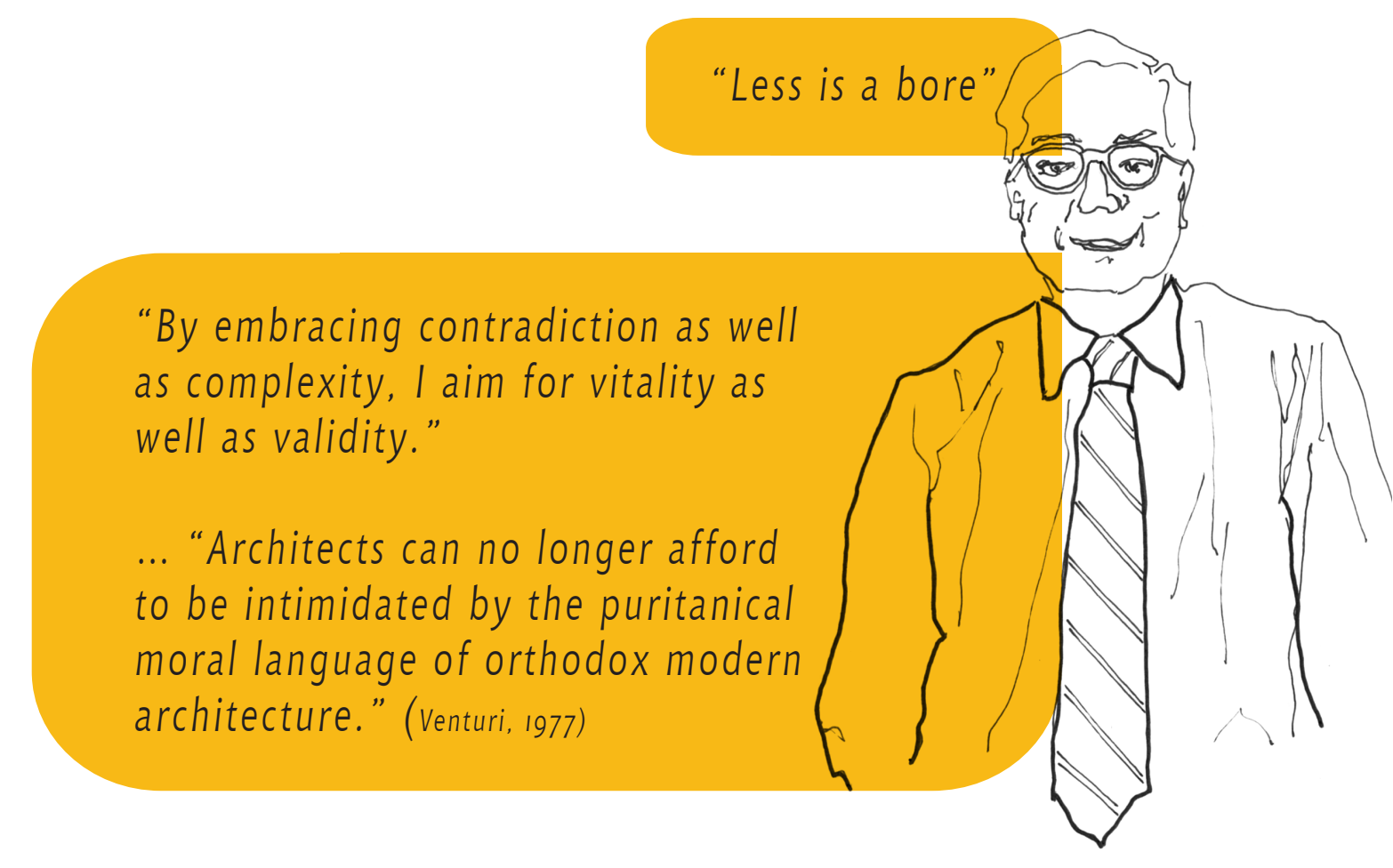

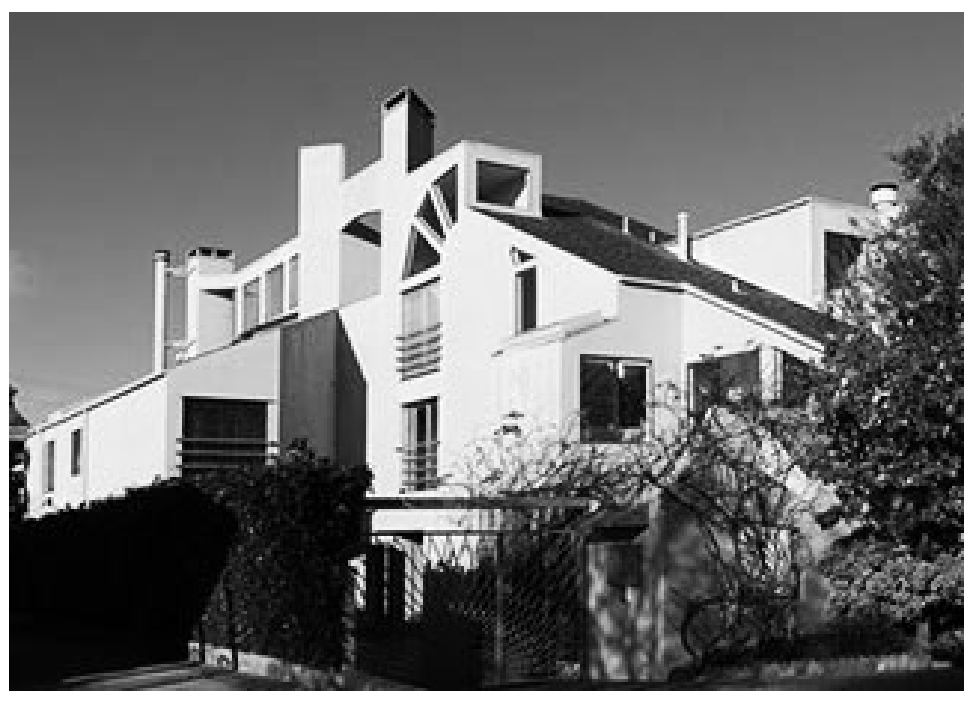

$\Delta$ Fig 2.71. Moore Rogger Hoffor

Condomonium Los Angeles completed in 1976

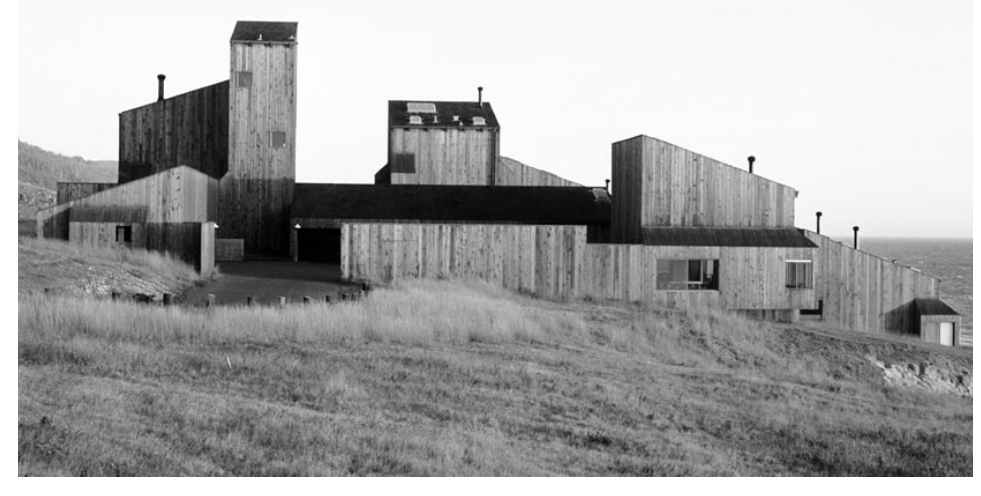

Fig 2.72. Condominium One designed by
Moore and others as MLTW. Completed 1965 .

Working at the same time, Charles Moore's version of complexity reclaimed old forms (diverging from the favoured 'box' of the modernists) and aggregated these together. While Venturi, talks in terms of form and element, Moore prioritises human understanding of the forms as space. He emphasised the importance of designing for people, their feelings, and prioritising human perception of spaces over Euclidian geometry. (Moore, 1978) 
see print copy for image

A Fig 2.73. Athfield house and offices, Kandallah.

see print copy for image

4 Fig 2.74. Buck House Te Mata Estate,
Hawke's Bay. Ian Athfield, 1980.

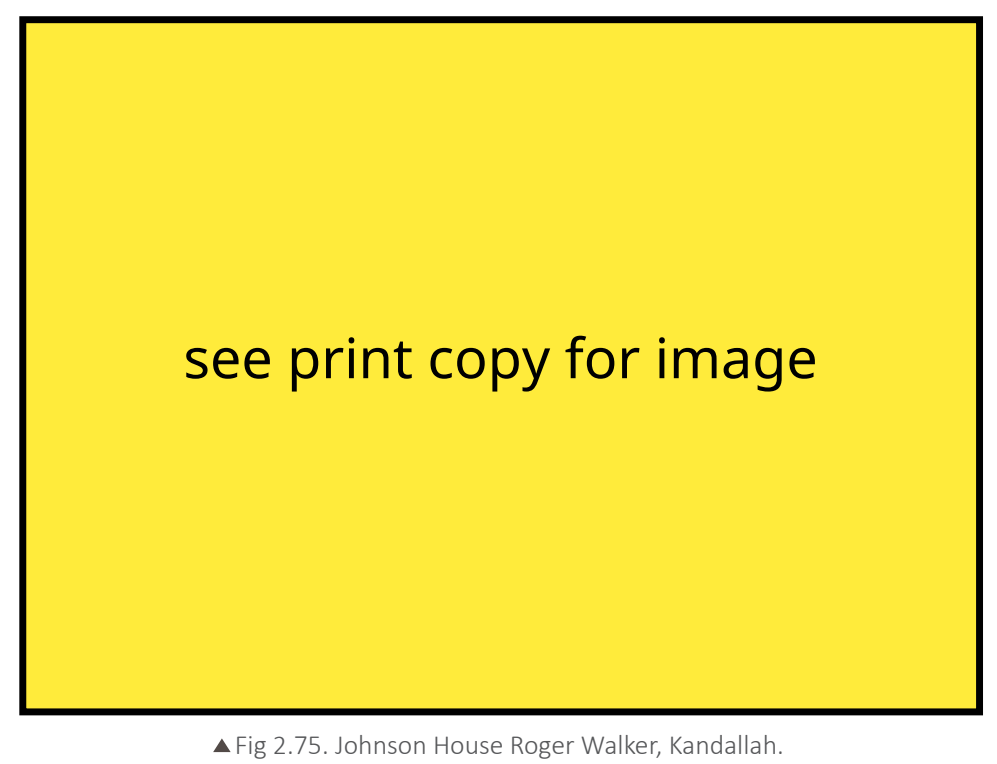

This attitude to postmodernism, mainly through Walker and Athfield, Kenn Kernohan sites the audacious work or Walker and Ath $\mathrm{Nel}$ as one of

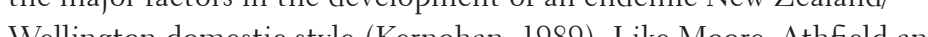
Walker used aggregated form to create site response Walker used aggregated for

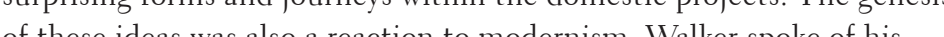
respect for the detaling in Sir Miles Whren's weder.

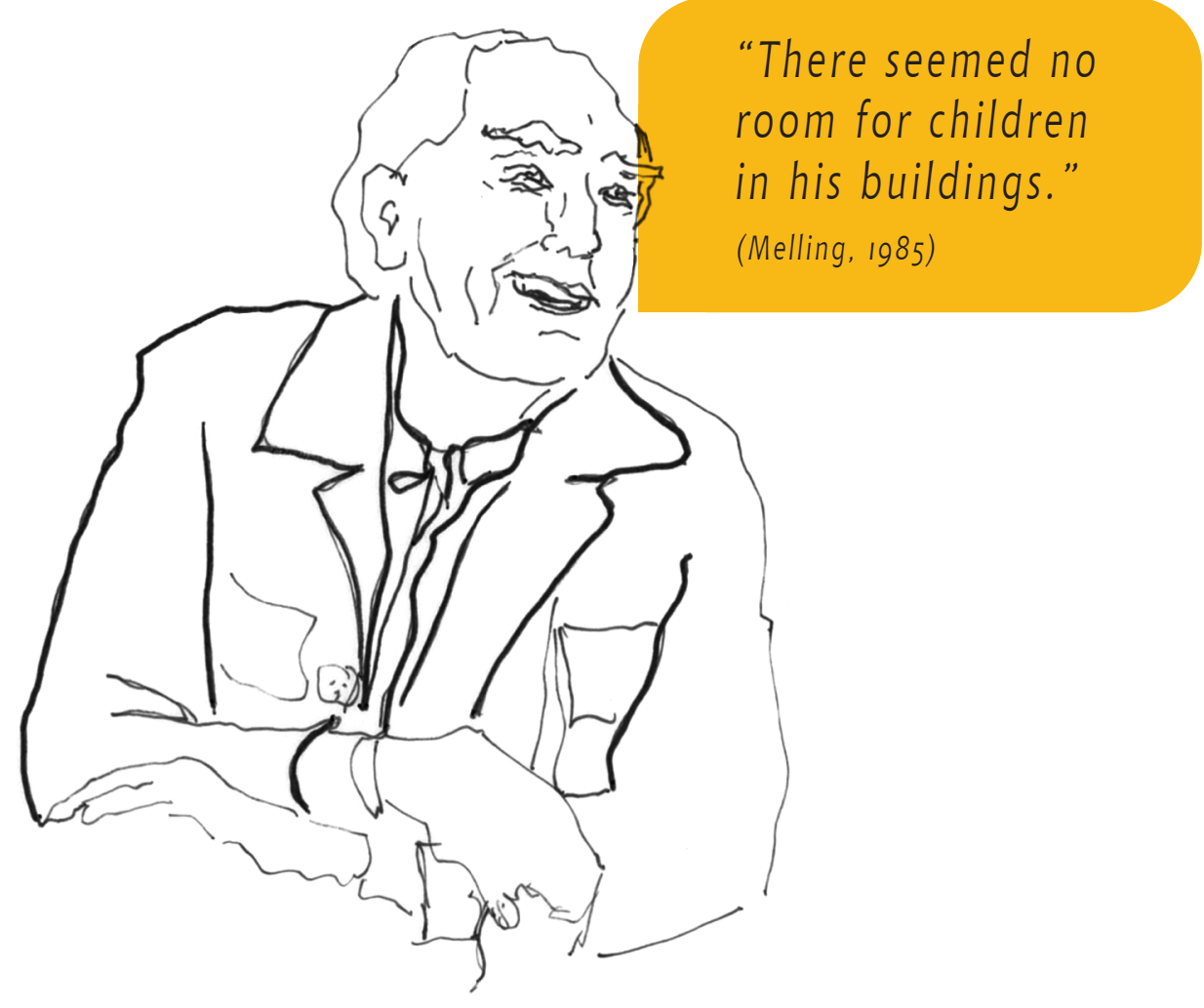

Dr Russell Walden wrote of Walker's Johnson House in a 1981 Architectural Review article, that, "the rambling house with its 48 corners clearly shows that even in this situation Walker is still strongly against the box" (Walden, 1981). The site within the block of Park Mews (a strong example of this postmodern style on a larger scale), in Hataitai was deliberately chosen for comparison between the projects. 
Outside of New Zealand, a contemporary version of complexity has developed to include craft and material intricacy and richness, as we

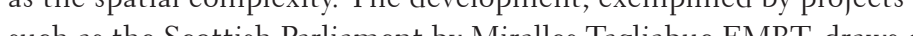

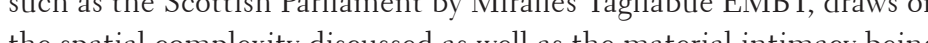
the spat sor Alvar Aalto and other existentialists (Littlejohn, 1984).

This focus on material and craft gives the spatial nooks and moments more richness and relevance to the user, bringing the spaces the

intimacy written about earlier. This is the version and thread of creating complexity in which I position my design.

A key example of this contemporary version of complexity is Peter Salter's London four-unit housing project: Walmer Yard, shown below

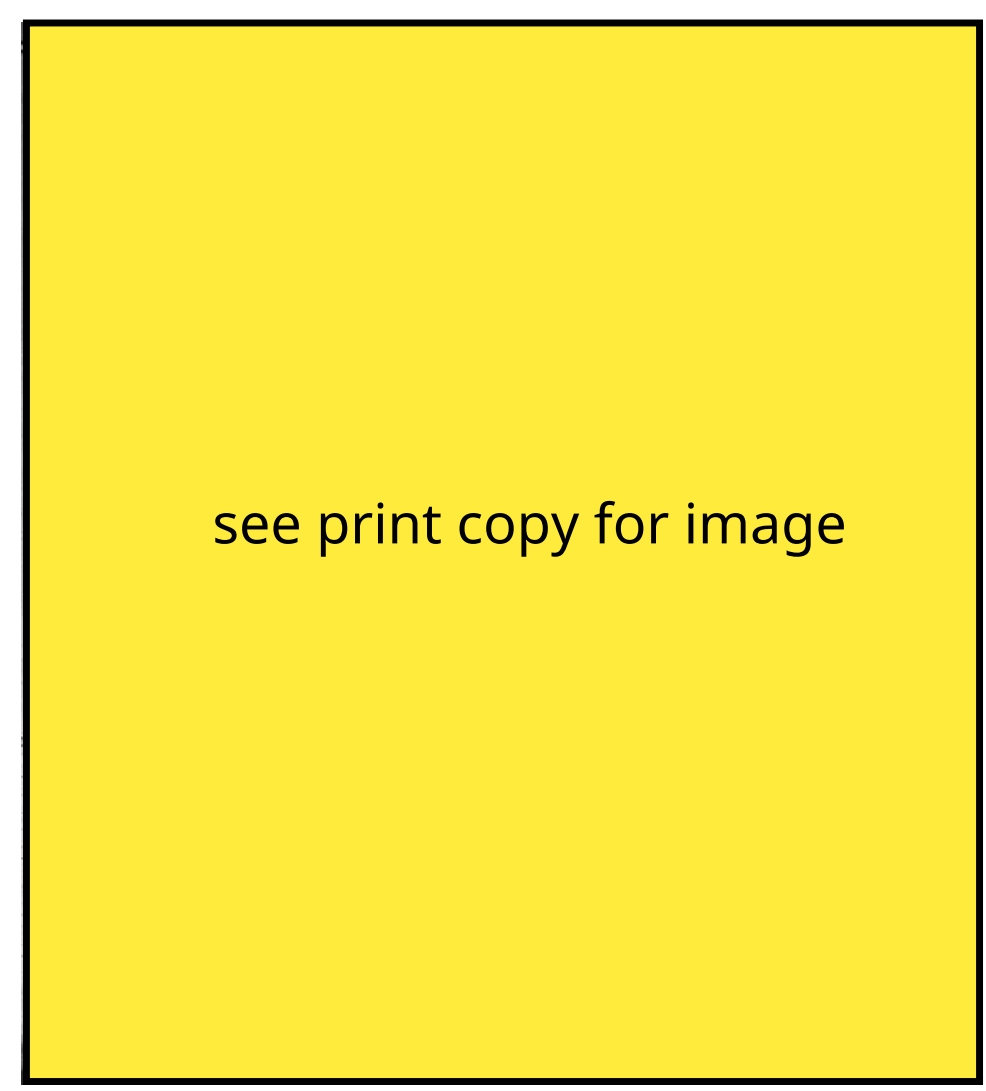

Fig 2.76. Walmer Yard's street front conceals the complex spaces and highly crafted texture combinations within the building.
Fig 2.77. A selected time line of complexity since preresulting in projects rich Walmer Yard.

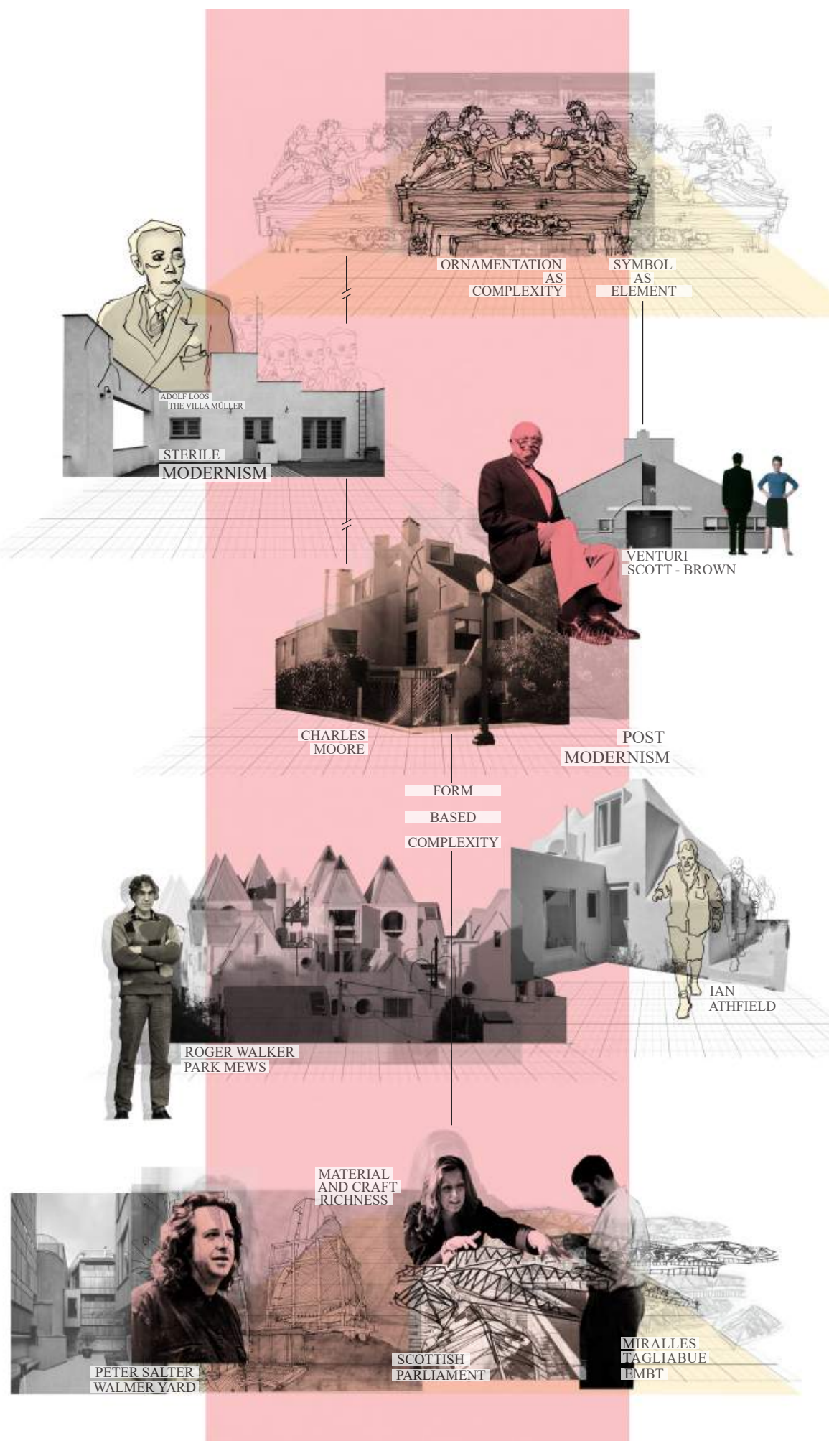


Context:

Richness as Ornamentation

In the past ornamentation could be seen as having gone out with the modernists; Adolf Loos called it a crime after all. The what some would call, cynical inclusion of it in post modernism may have been its final nail in the coffin. However, the value of visual richness remains relevant to the human experience of space.

A contemporary version of 'complexity' plays a part in a new

ornamentation A version not reliant on application to the surface as an afterthought but informing the form, material and craft to provide visual richness of their own. This is both in the building form as spectacle, and in the detail Composition of the material and craft creates ornament. In its form, it is the impact on the body providing intensity The sloping walls of my design do not add economic value, quite the opposite. However evaluating the building holistically, these irregularities give the burlding its resonance for users. The intimacy of space they create is shown in fig 2.79

In addition to the scepticism surrounding ornamentation since modernism, perception of digitally fabricated projects is that they also reject this pursult of vibrancy. Prefabrication can conjure ideas of the generic and dull. This is the power of augmenting both sides of the bionic hand. The hand, aided by the efficiency of digital tools, can stil pursue onnament. The digital can make onnament of itself. The node connections are ornaments within the external building form. The over all unusual building form creates ornament of the structure in itself, as well as the visual richness of material and craft details.

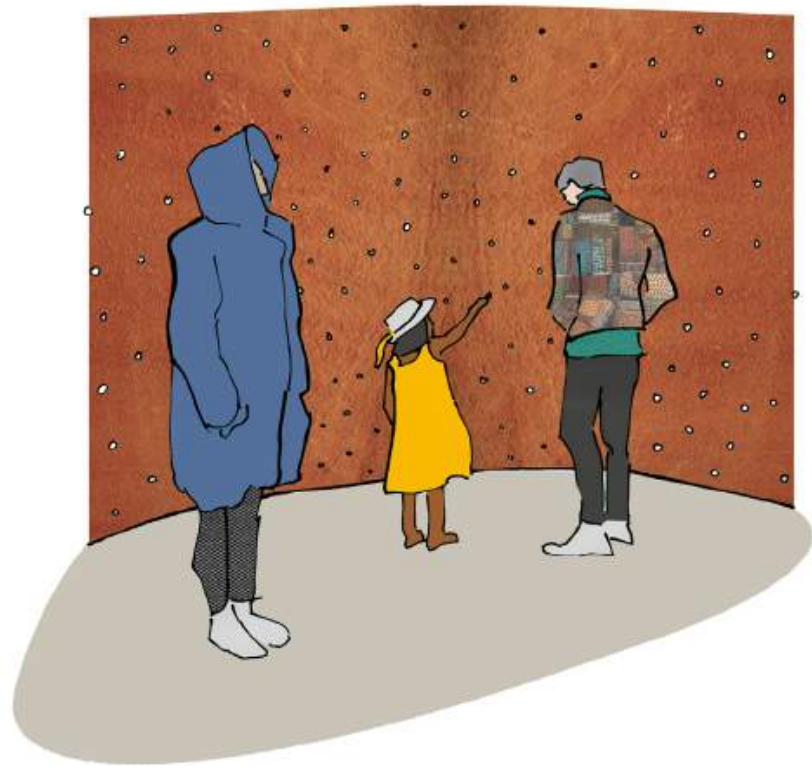

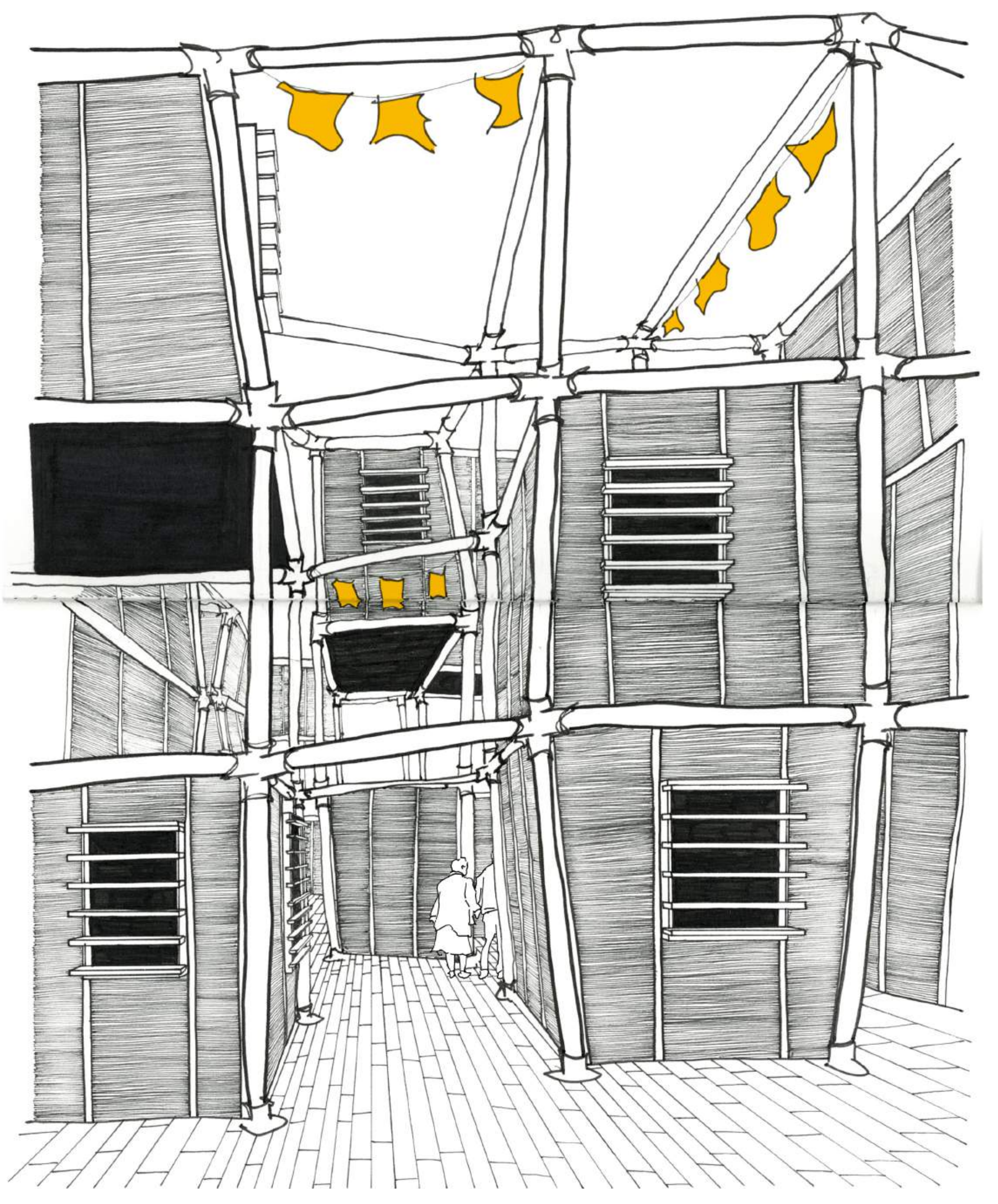

4Fig 2.78. An early
cartoon for another concept showing engagement with
textural richnes

Fig 2.79. The sloping walls, nodes and
beams as rich

ornament within the site. Dete 1 .
sketch 


\subsection{Case Study: Walmer Yard}

Walmer Yard occupies a similar size site to my project (fig 2.80). The design is four opulent, highly crafted town houses. The project is

spatially complex, creating bespoke spaces and nooks in each house

(fig 2.81). Intricately detailed and crafted together is a broad palette

of materials. The combination of these factors produces intimate and

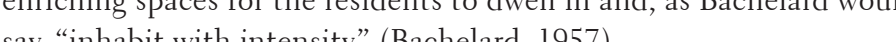

say, "inhabit with intensity" (Bachelard, 1957).

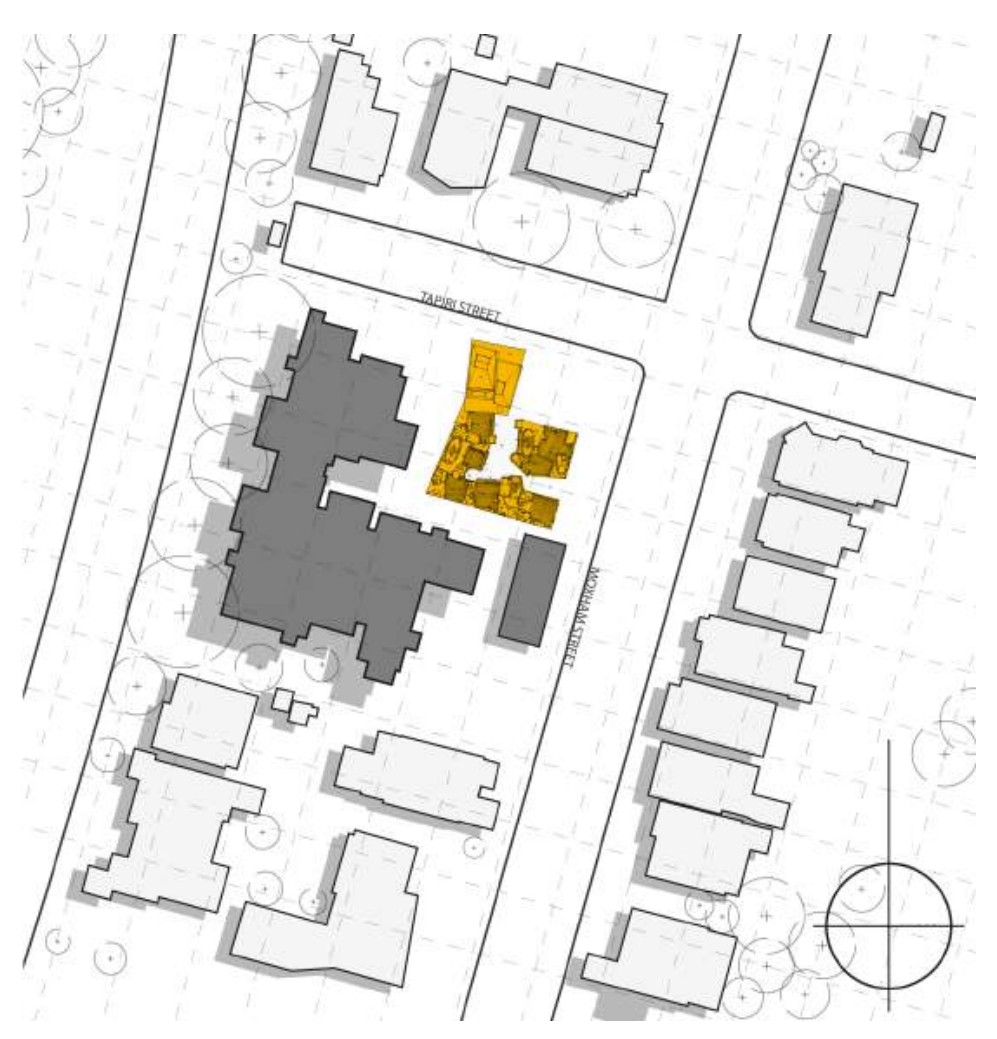

- Fig 2.82. A photograph the houses on the the diversity of form, space

Fig 2.80. Walmer Yard overlaid on to my Hataitai of site size and density between the four Walmer Yard houses, the 32 units
within Park Mews, and within Park Mews, and
surrounding stand alone surrounding stand alone
dwellings.

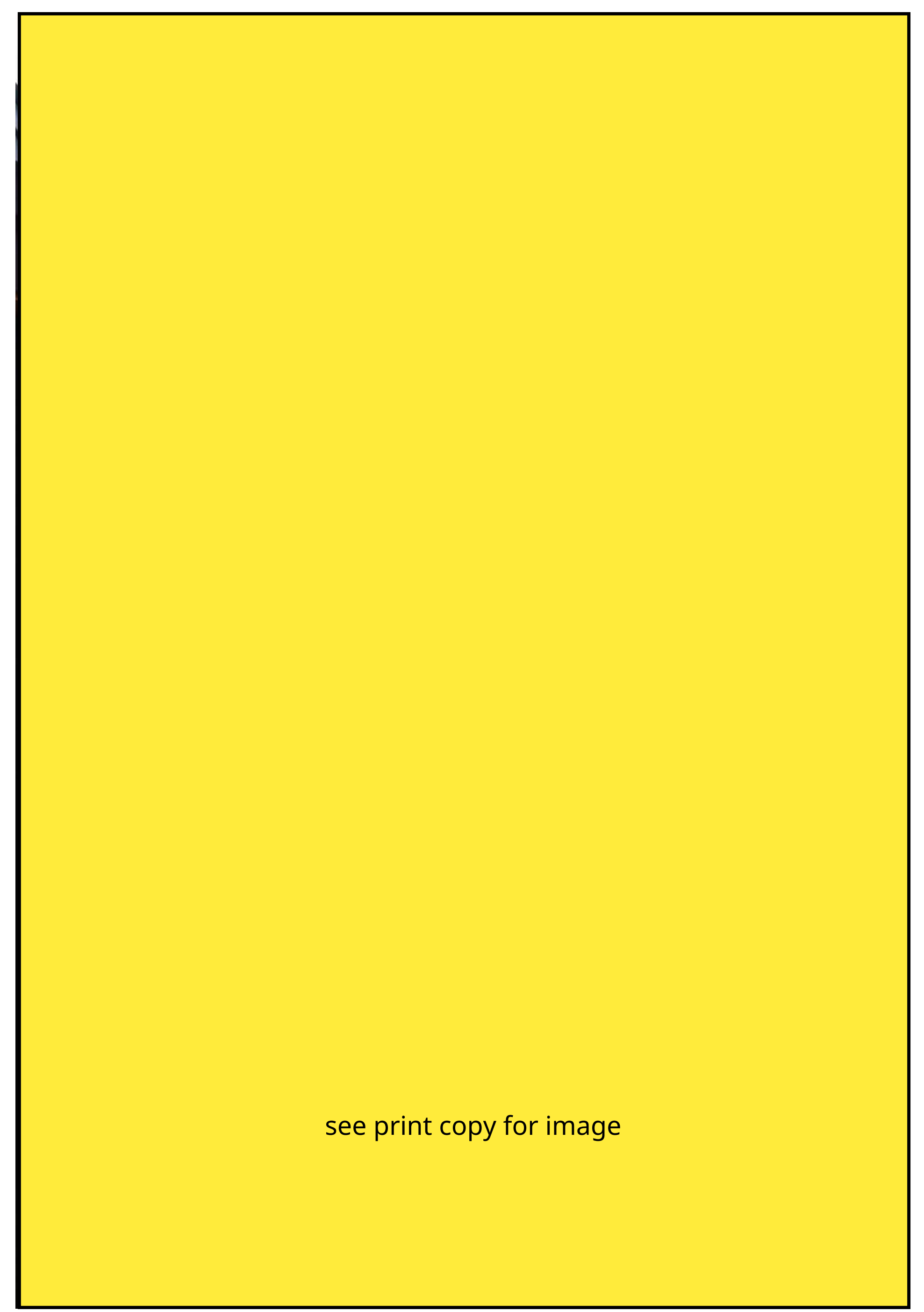




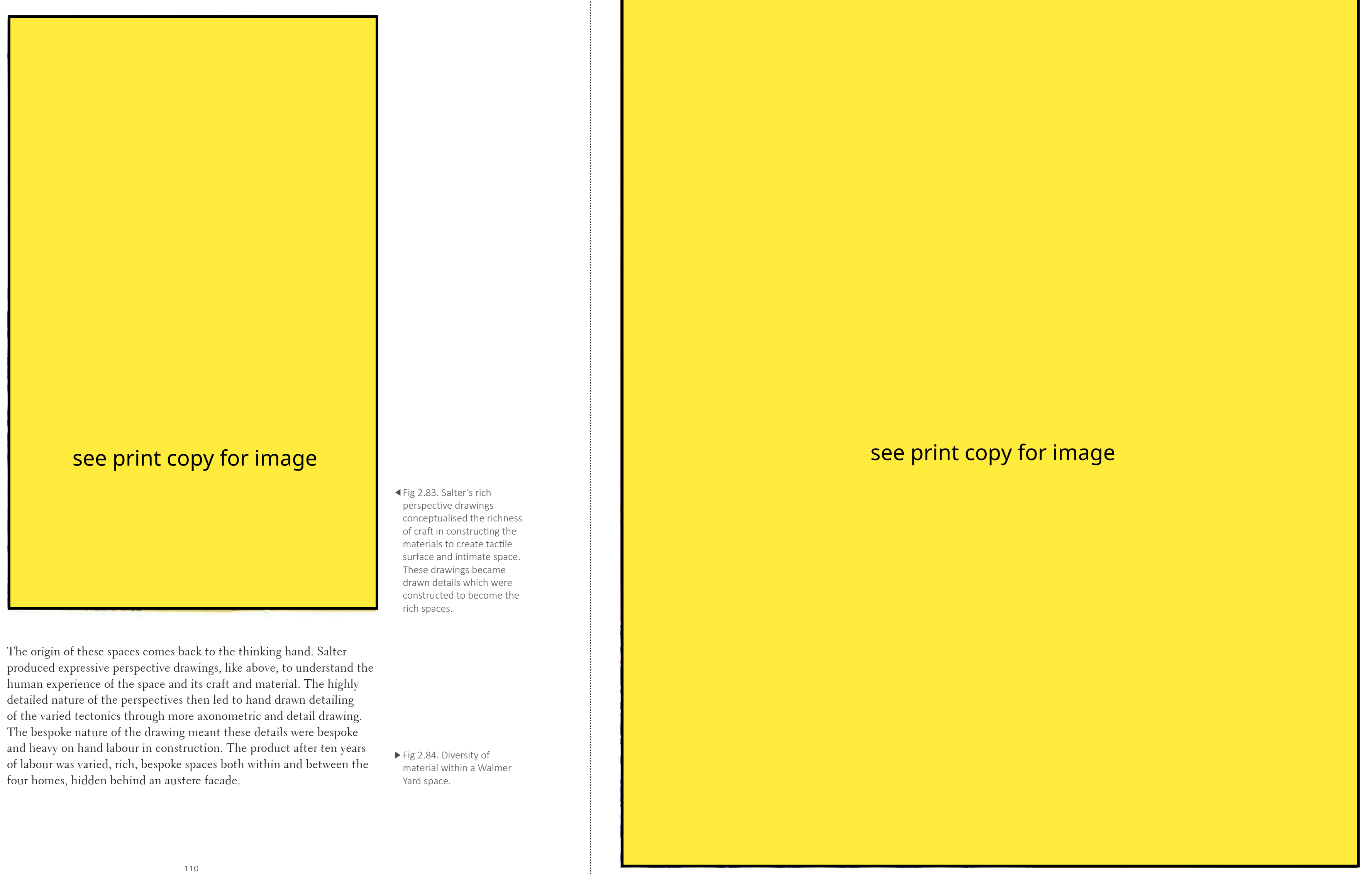



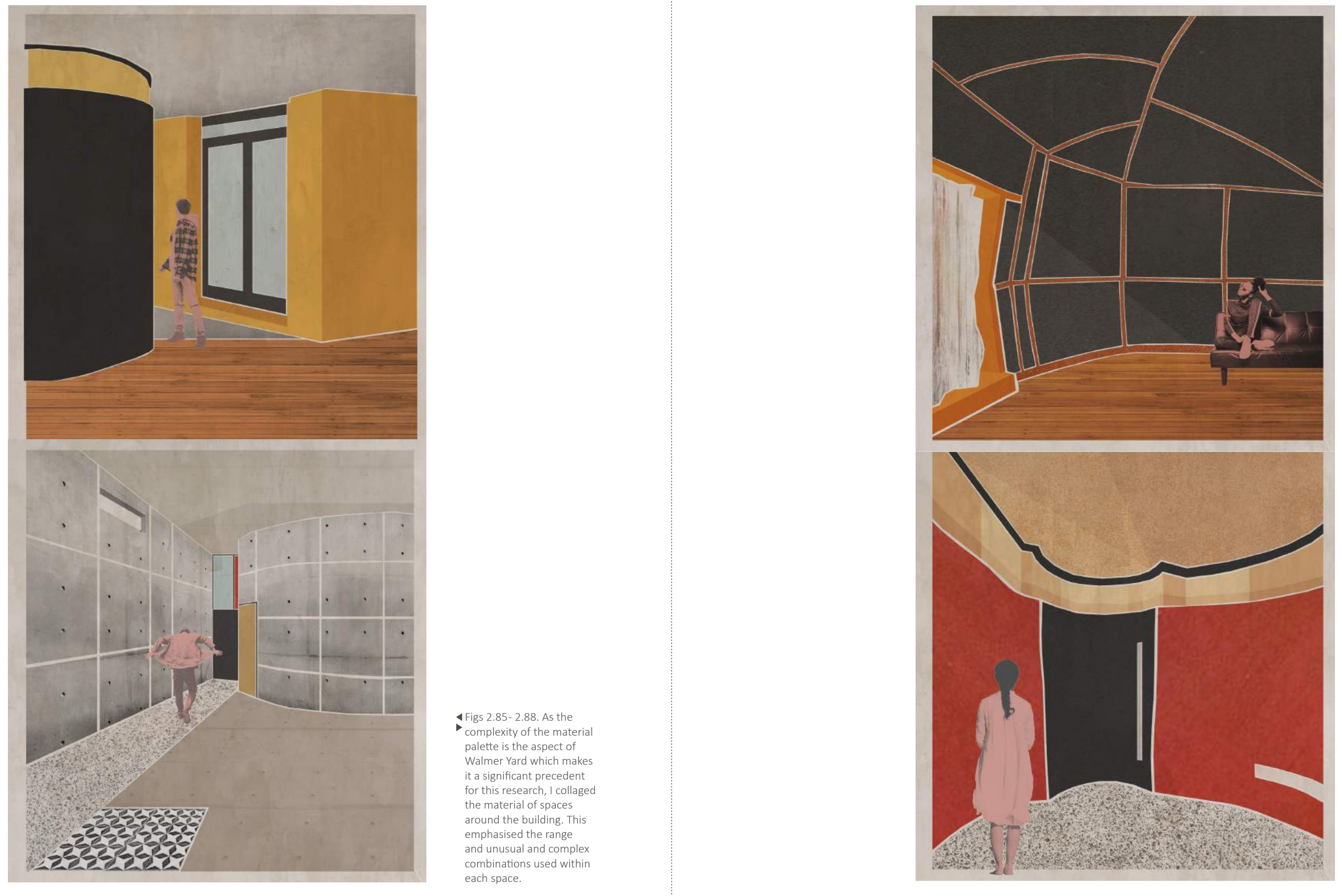

Figs $2.85-2.88$. As the
complexity of the material

palette is the aspect of

Walmer tard which makes

for this research, I collaged

around the building. This

and unusual and complex

combinations used within
each space.

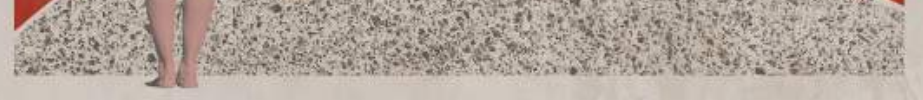


Case Study: Park Mews

As the Hataitai example of how New Zealand understands of complex architecture, I carried out a drawn case study of moments around Park Mews (figs $2.90-2.100$ ).

This study and visit confirmed the change in priorities when creating complex architecture across time. While Park Mews is spatially intricate full of surprise and variation, it is largely mono-textural. White painted concrete block dominates both interior and in between spaces. This sits in contrast to Peter Salter's work, which is willingly diverse in material and craft.

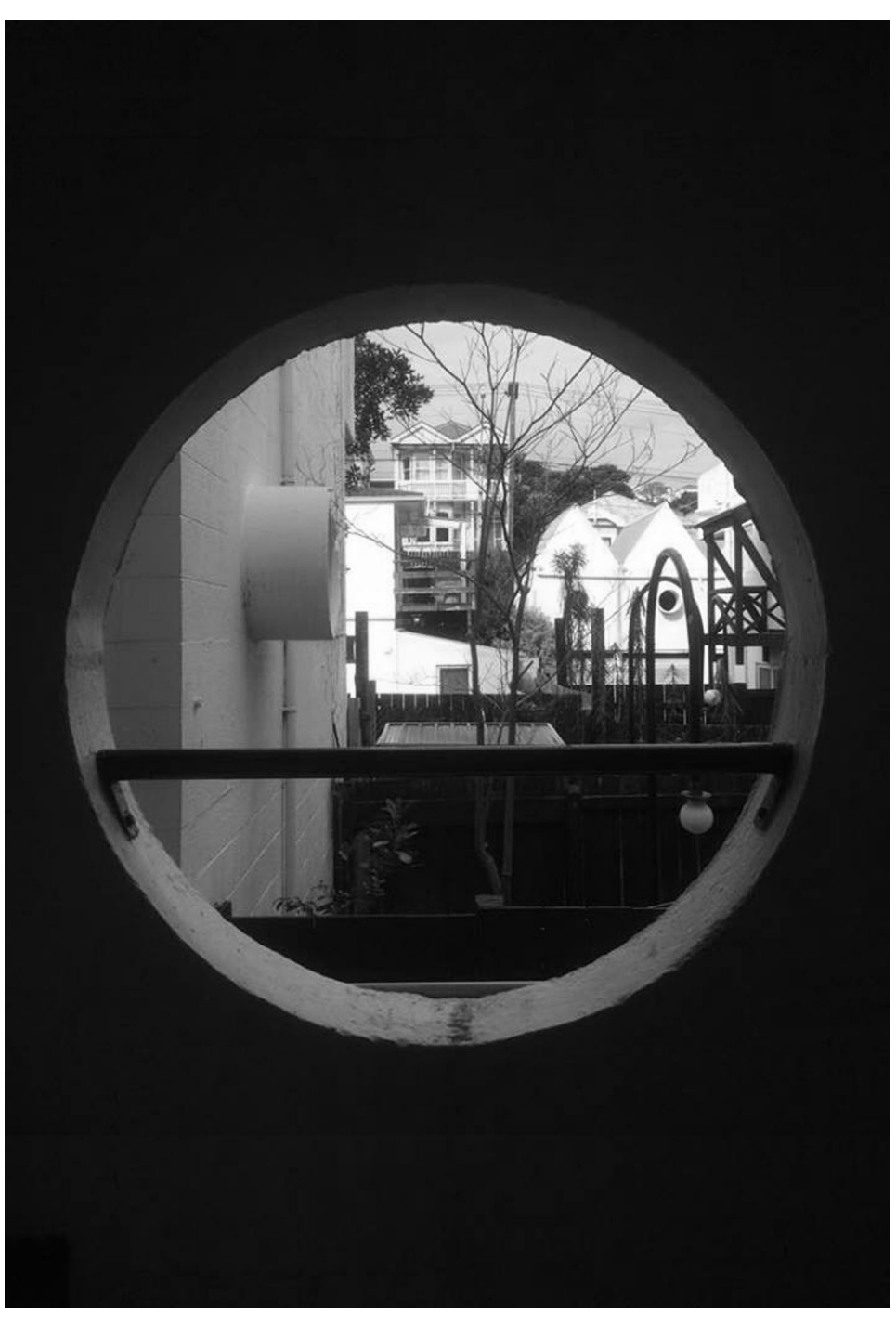

Fig 2.89. The view to
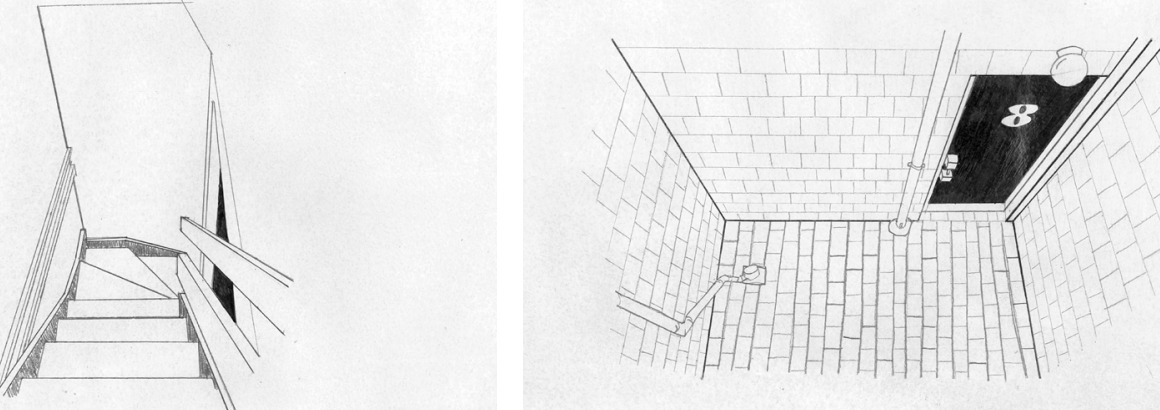

Figs 2.90-2.100.

(Continued next two pages)

As the spatial complexity

is the aspect of Park Mews
which makes it a significant

precedent for this research,

I did a series of snapshot

drawings of intimate spaces

range of these showed the

formal complexity achieved
by just 90 degree moves
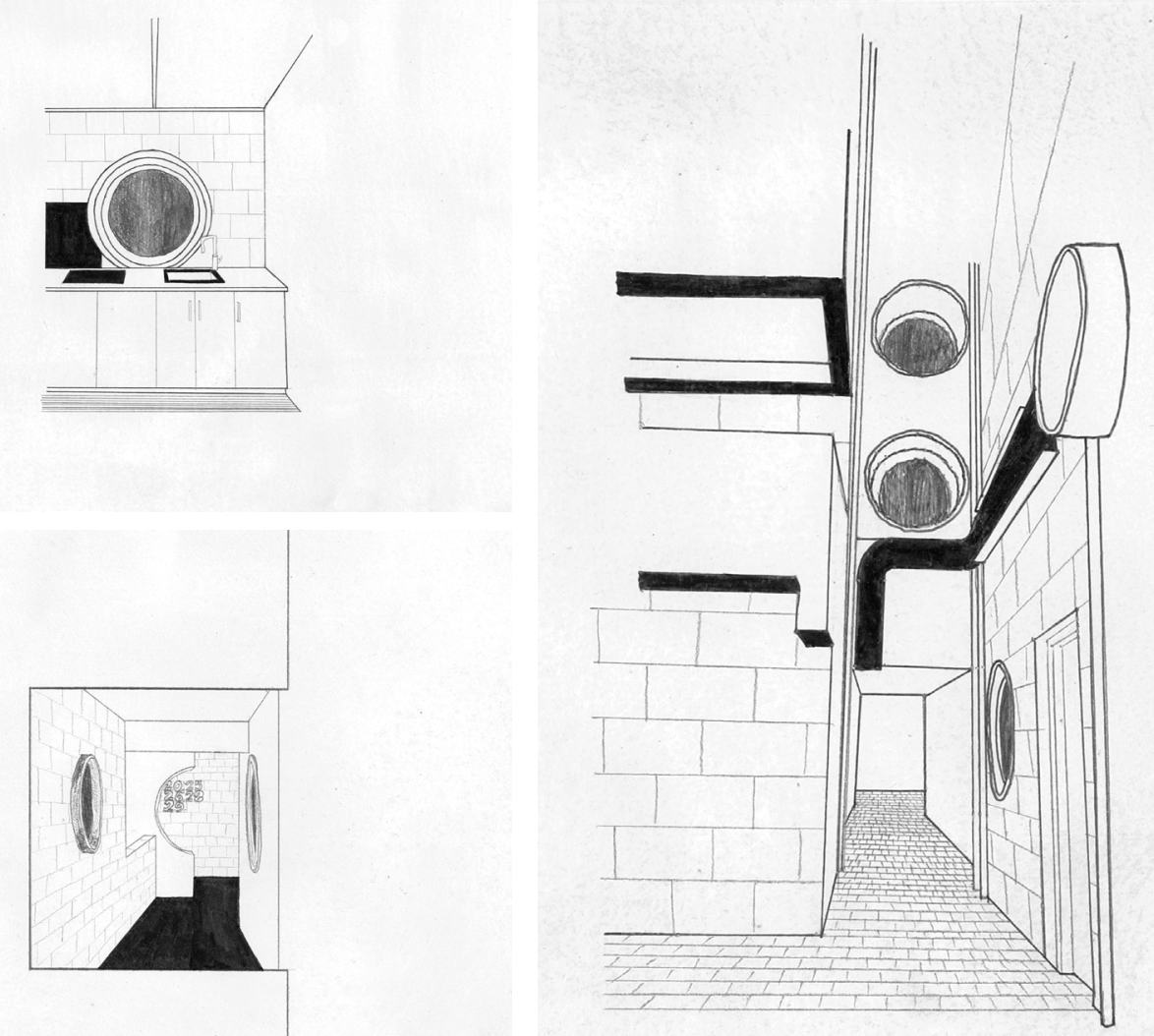

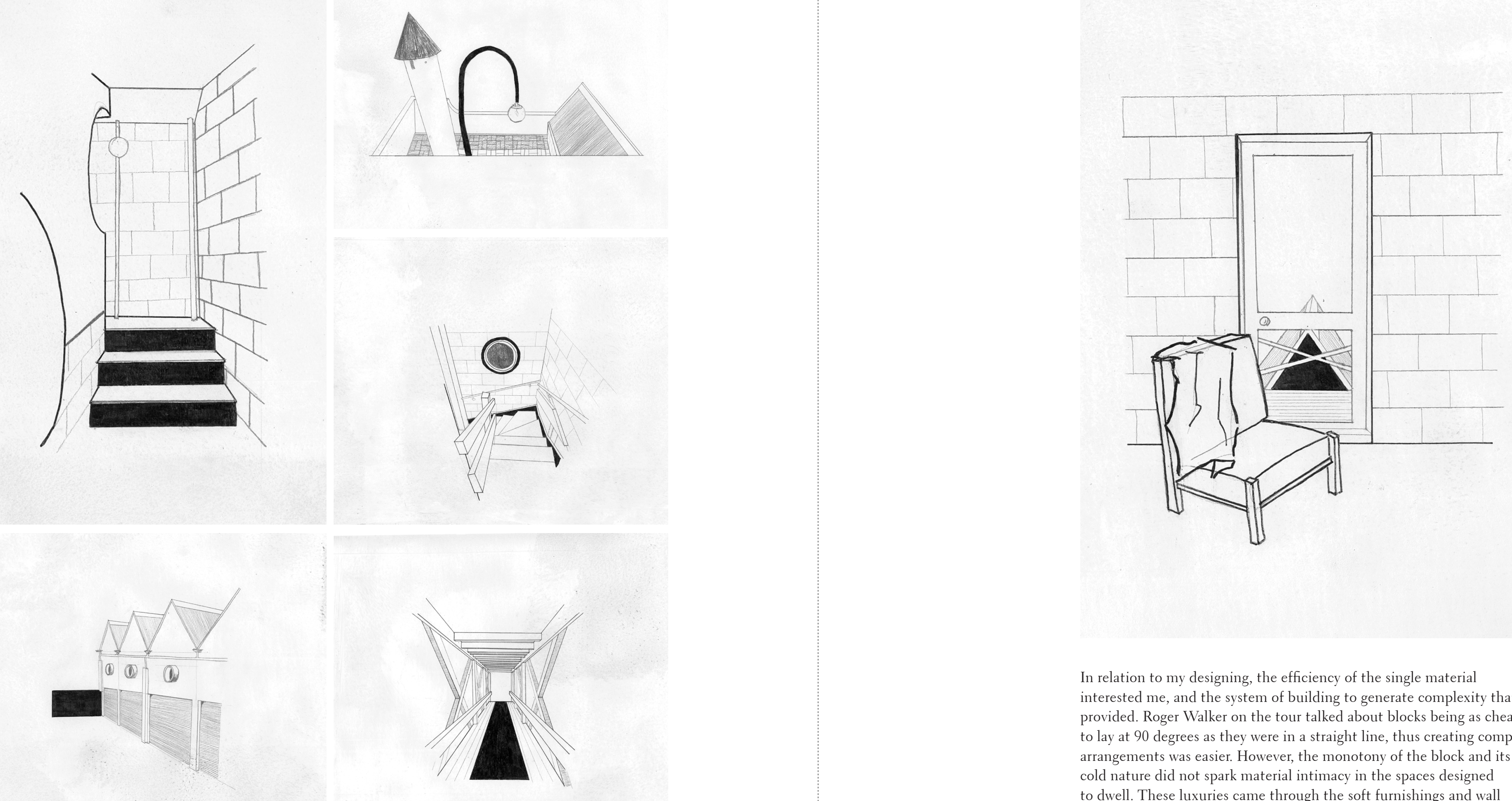

In relation to my designing, the efficiency of the single material

interested me, and the system of building to generate complexity that if provided. Roger Walker on the tour talked about blocks being as cheap to lay at 90 degrees as they were in a straight line, thus creating comple arrangements was easier. However, the monotony of the block and its cold nature did not spark material intimacy in the spaces designed to dwell. These luxuries came through the soft furnishings and wall coverings, not the architecture. 
Process:

The User in the Design

Similarly, to Moore, Athfield, Walker and Salter's focus on human understanding, personal feeling in space and moments was a driving factor in establishing the intimacy within and between the buildings. Prioritising these experiences was done by orbiting between drawing those misting as stepping out the 2.101 .

togethe. This orbiting design medhed hs dagranned hing 2.101

The thinking hand is inherently a tool of, and part of the body. I used the brain and body's subconscious understanding of space and translated this into worlds on the page.

This went through a few iterations (refer page 48). The first key breakthrough was the development of a pod form; this related to the development of closeness, privacy and intimacy. This initiated as part of a scheme from an earlier site, but carried over to the Park Mews site as a starting point for bringing these snapshot cartoons together.

On the final site, it became a series of a repeating shape with the irregular angles in plan and section to create these nooks for dwelling in and intense spaces between the buildings (fig 2.102). With walls sloping away or over you, and voids for balconies and light.

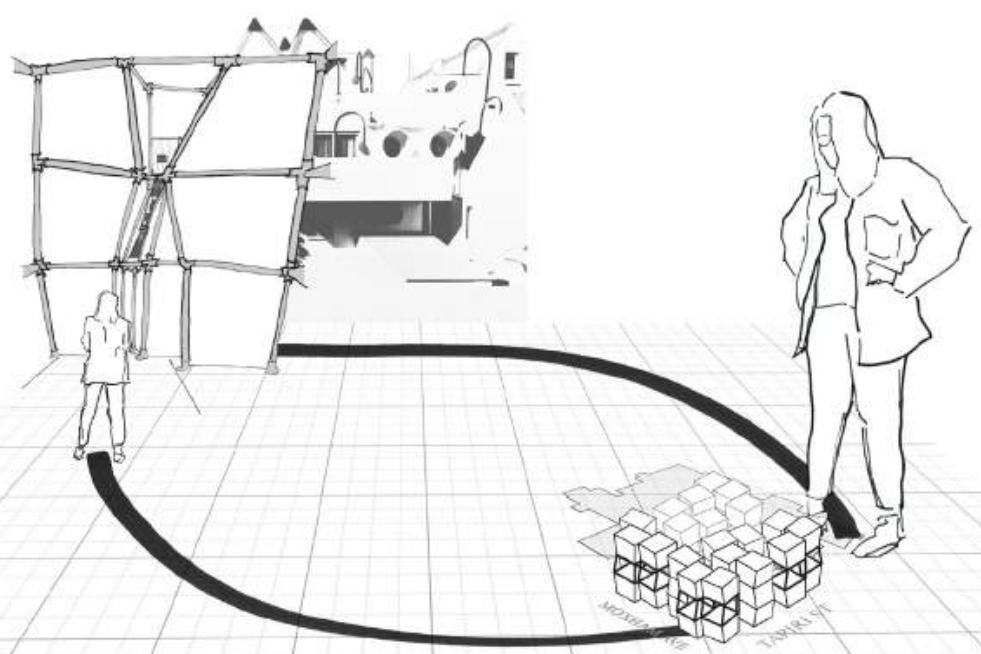

Fig 2.101. Designing through a human perspective within the site and seeing
the scheme as a whole allowed me to understand the human experience.

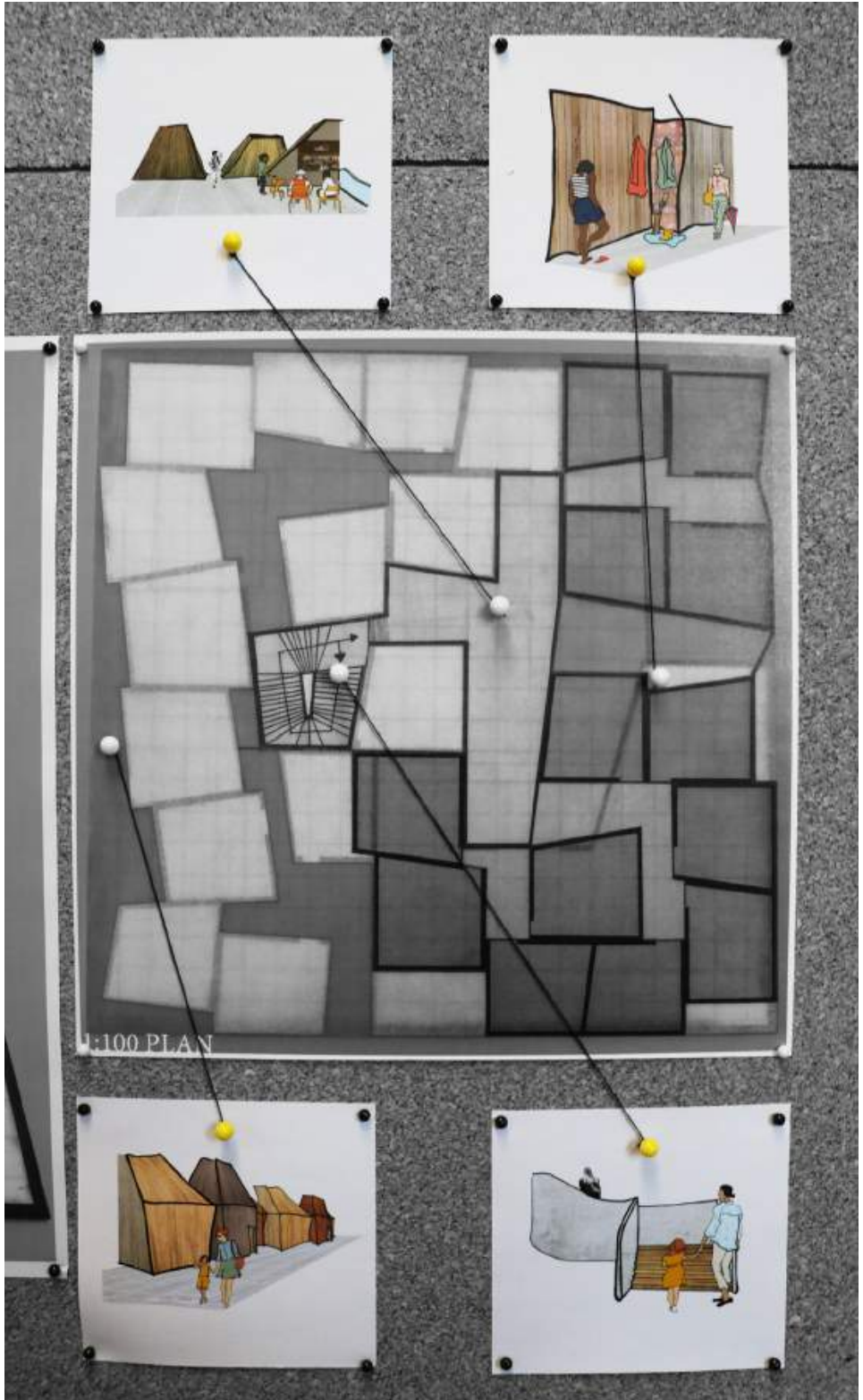

A Fig 2.102. Each cartoon is a perspective snapshot of a moment within the

Fig 2.103. (Next page) The cartoons were a way of working that spanned relate to the final scheme, but reflect moments other concepts or development ideas along the way. 
.

Wh

战

Dis

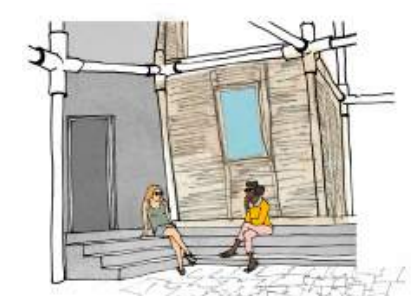

4
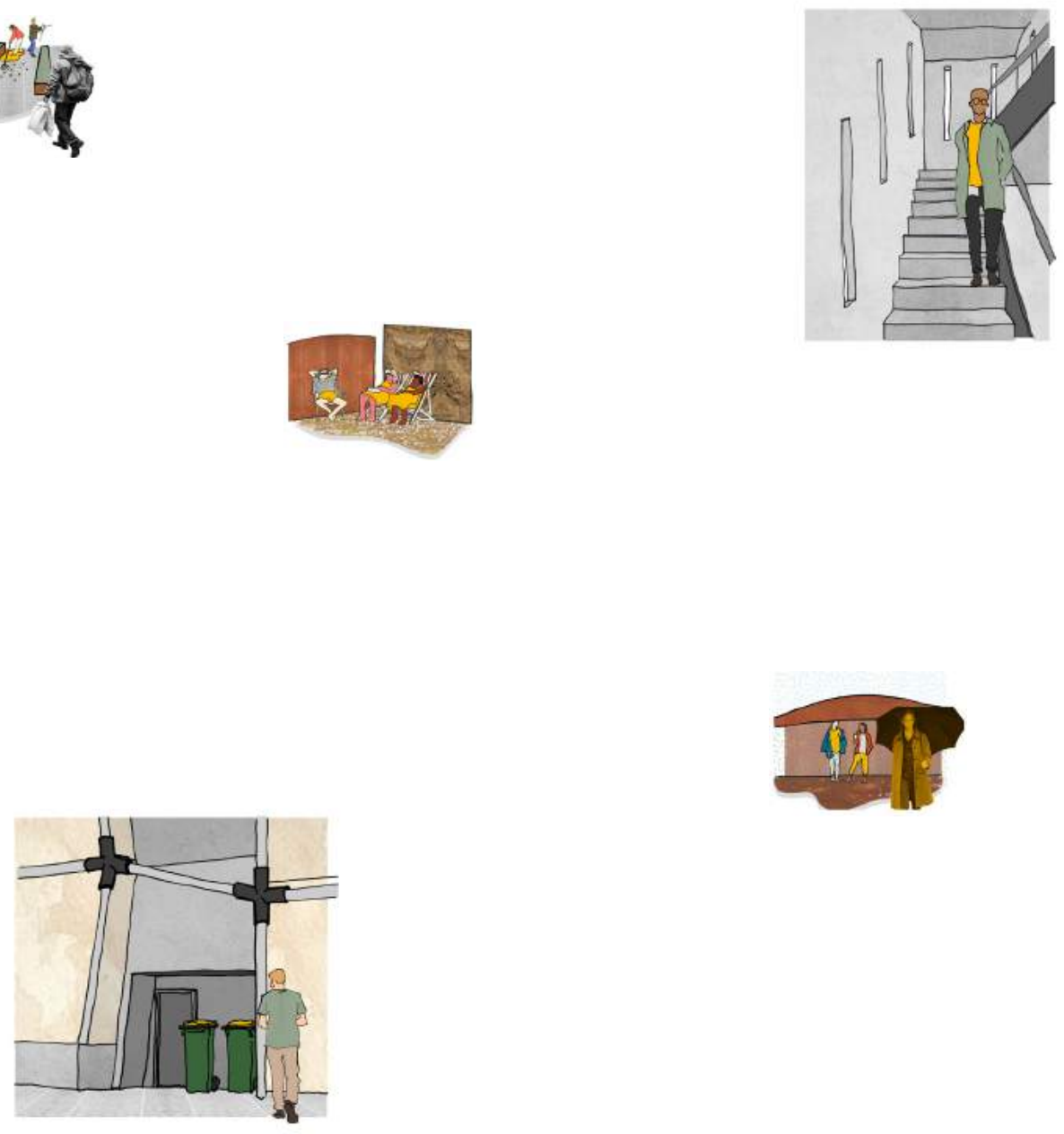

anp

4.69
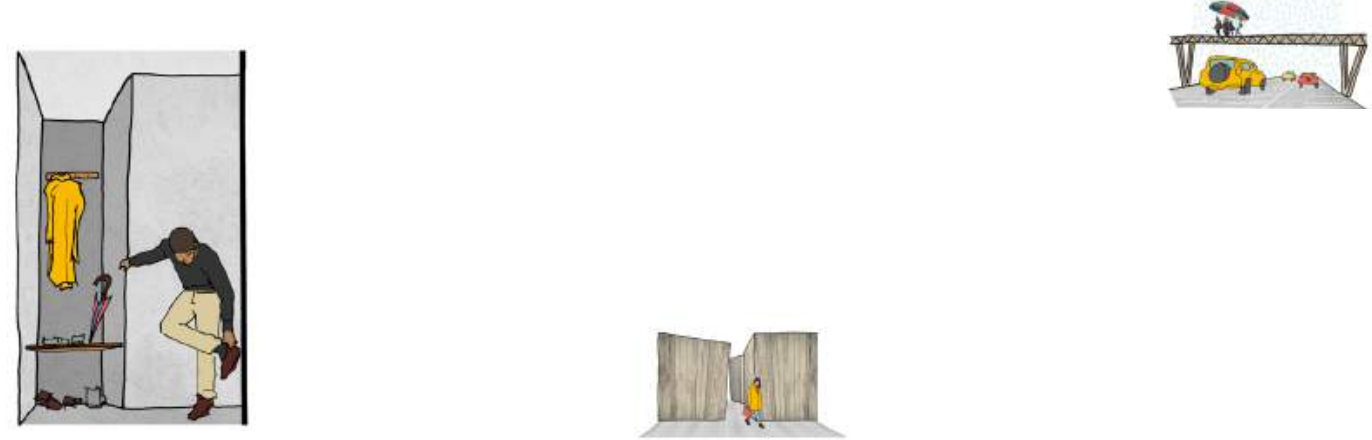

Din

噌

댕․

Cing

E)

a

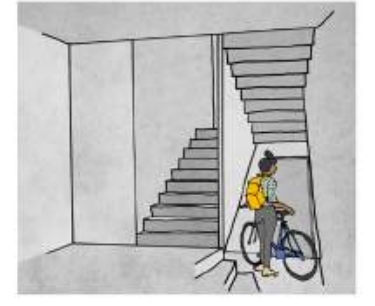

D.

aㅔ 

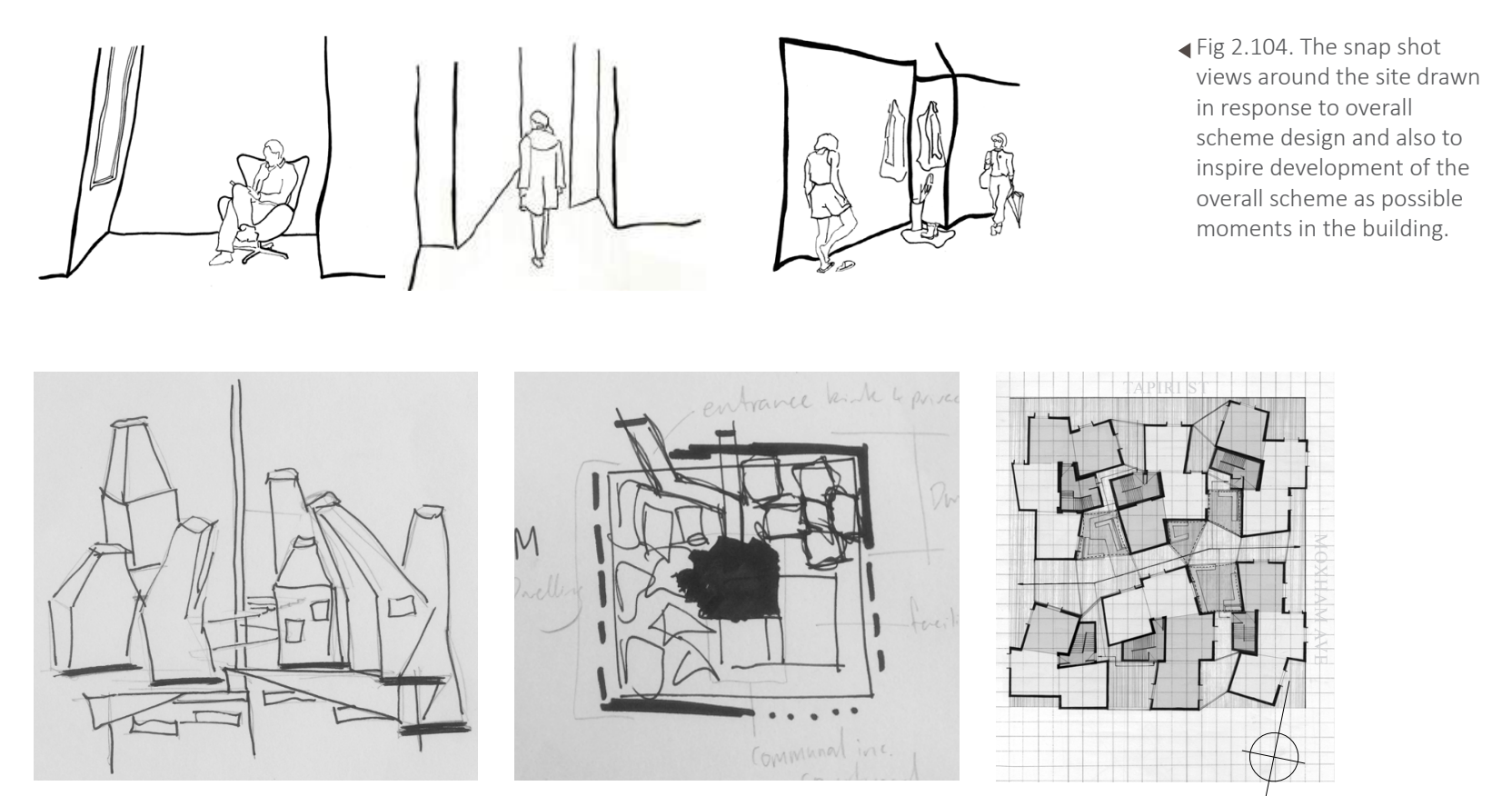

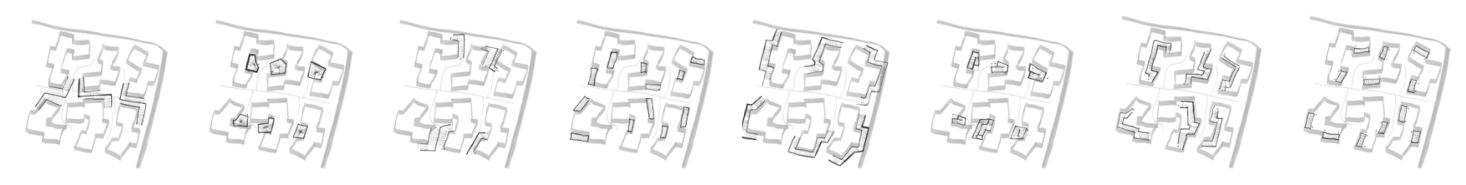

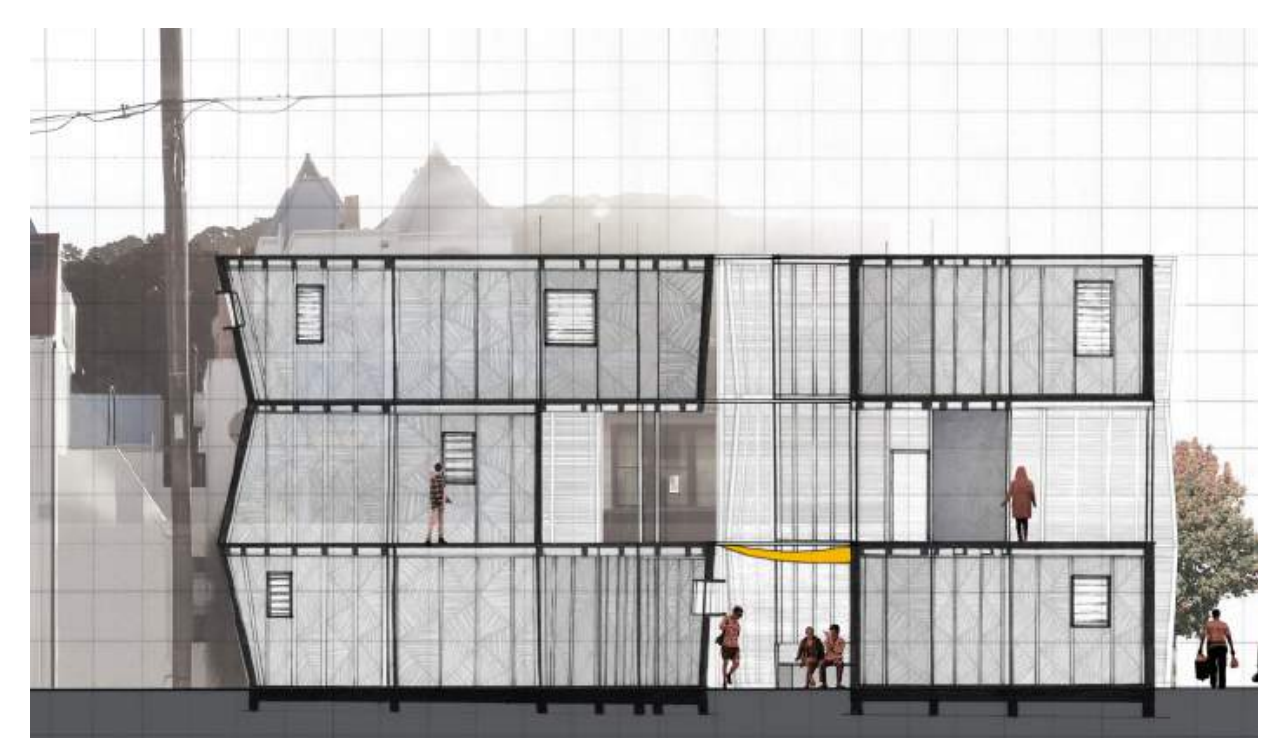

Figs 2.105- 2.122. These images (continued next other design methods thinking hand drawings concept and development of cartoon snapshot spaces or drawn to develop these
spaces in existing concepts spaces in existing concepts
This was part of orbiting This was part of orbiting
between designing from between designing from
the 'human' view and looking at the scheme as a
whole.
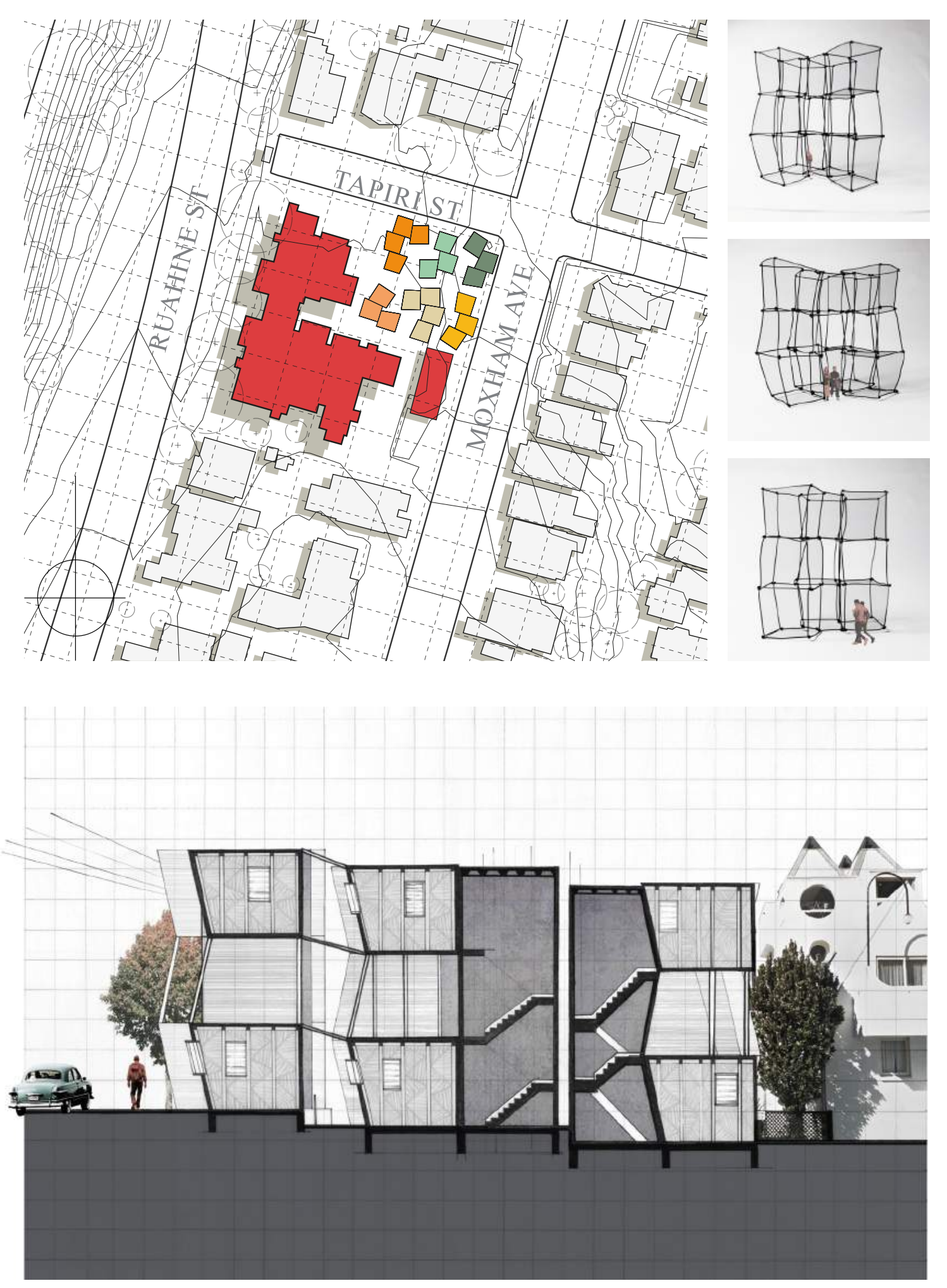



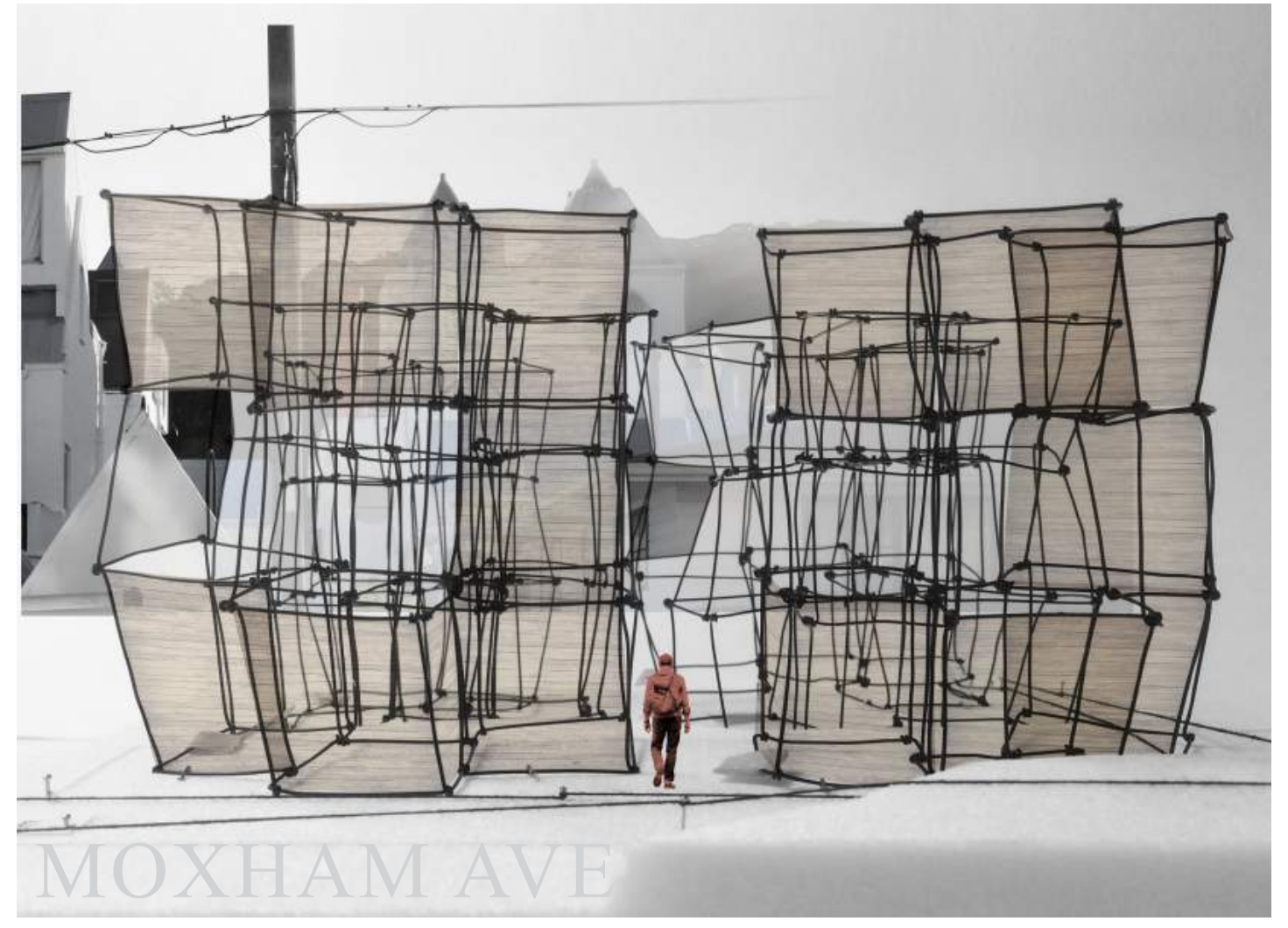

Process:

Breakthrough in Drawing

$2.16 \longmapsto$ Breakthrough in Drawing

The process of perspective cartooning was the context of a

breakthrough in the design research process. Throughout the designing, drew more than 30 of the snapshots. Although a core part of the

process, their relevance waned over the year, but a change in perception

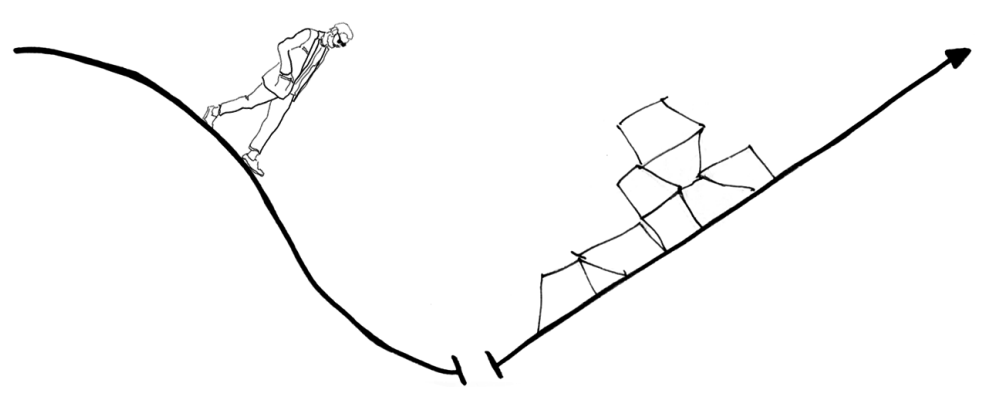

4 rig 2.130. The usefuliness of the cattoons

Peter Cook's conceptual cartoons for personal interactions he wanted to accommodate in the Gold Coast Bond University design firstly inspired the technique (Cook, 2016). Initially, along this vein, I called the drawings 'vibe cartoons,' as I was using them to express human understanding of the spaces, the intimacy, the hygge... the vibe.

While this had value in conceptual stages, prioritising people over the architectural detail was allowing me to linger on the symptom of intimate, complex design not the cause.

was stagnant in facilitating in the vibes I wanted to create as the designer. I was using people to express hygge and intimacy in drawing not architecture.

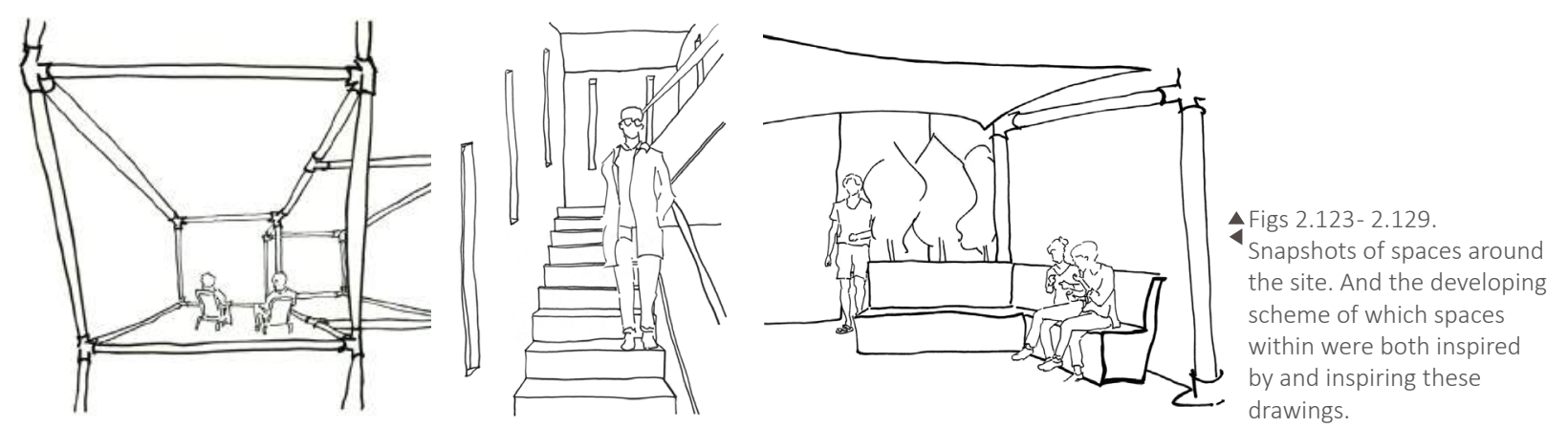

The breakthrough came when I deliberately reversed the focus. I redrew The breakthrough came when I deliberately reversed the focus. I red
existing drawings without the figures, and instead drew over them with ideas of detail, material and craft in each moment. The change in technique related to change in my perception of the design from a social problem to a material problem. A realisation that as a designer the material, craft and detail is what I have control over to generate interaction between users and the building. The change in the use of the thinking hand made it more effecient in processing the architecture. 


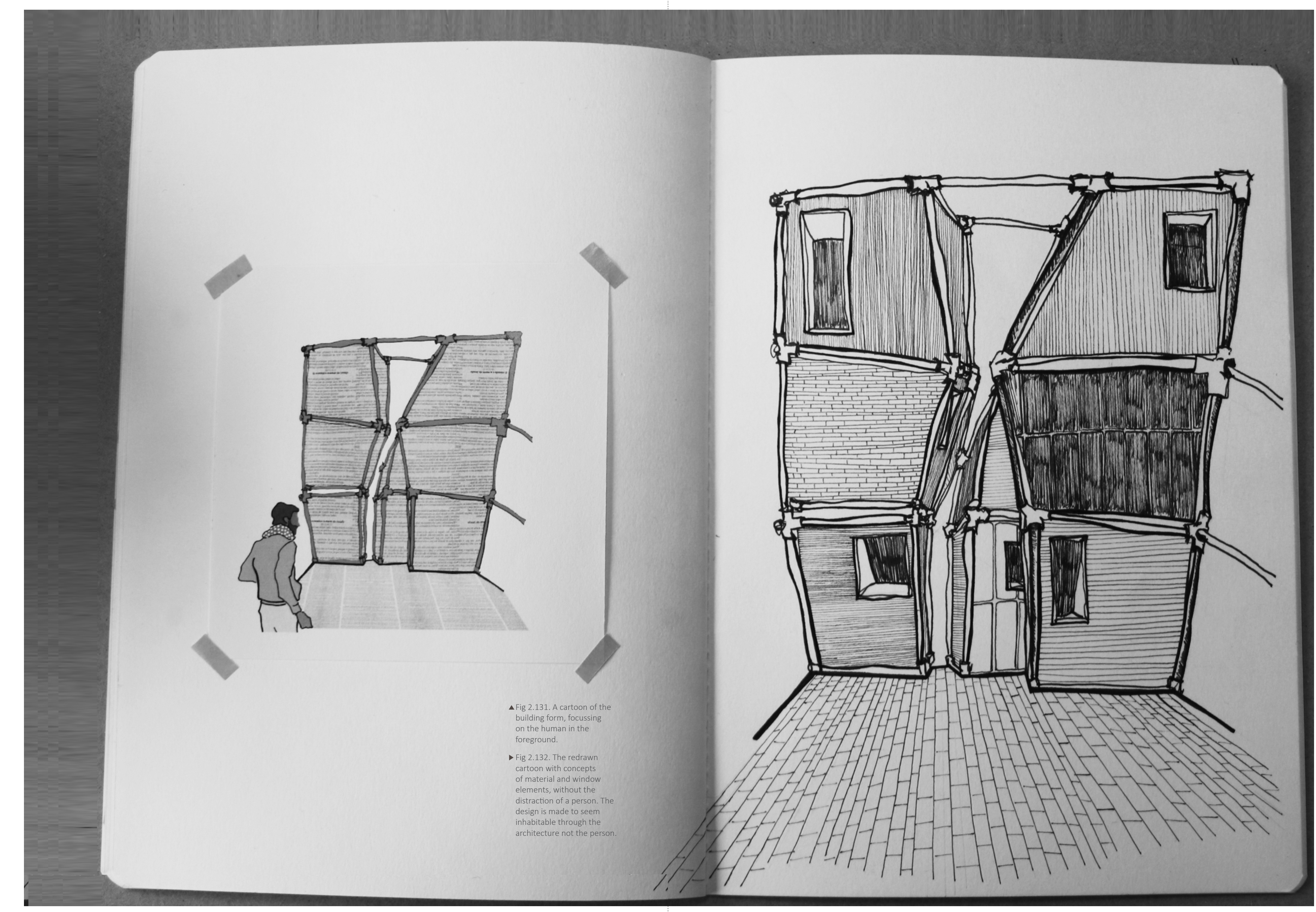




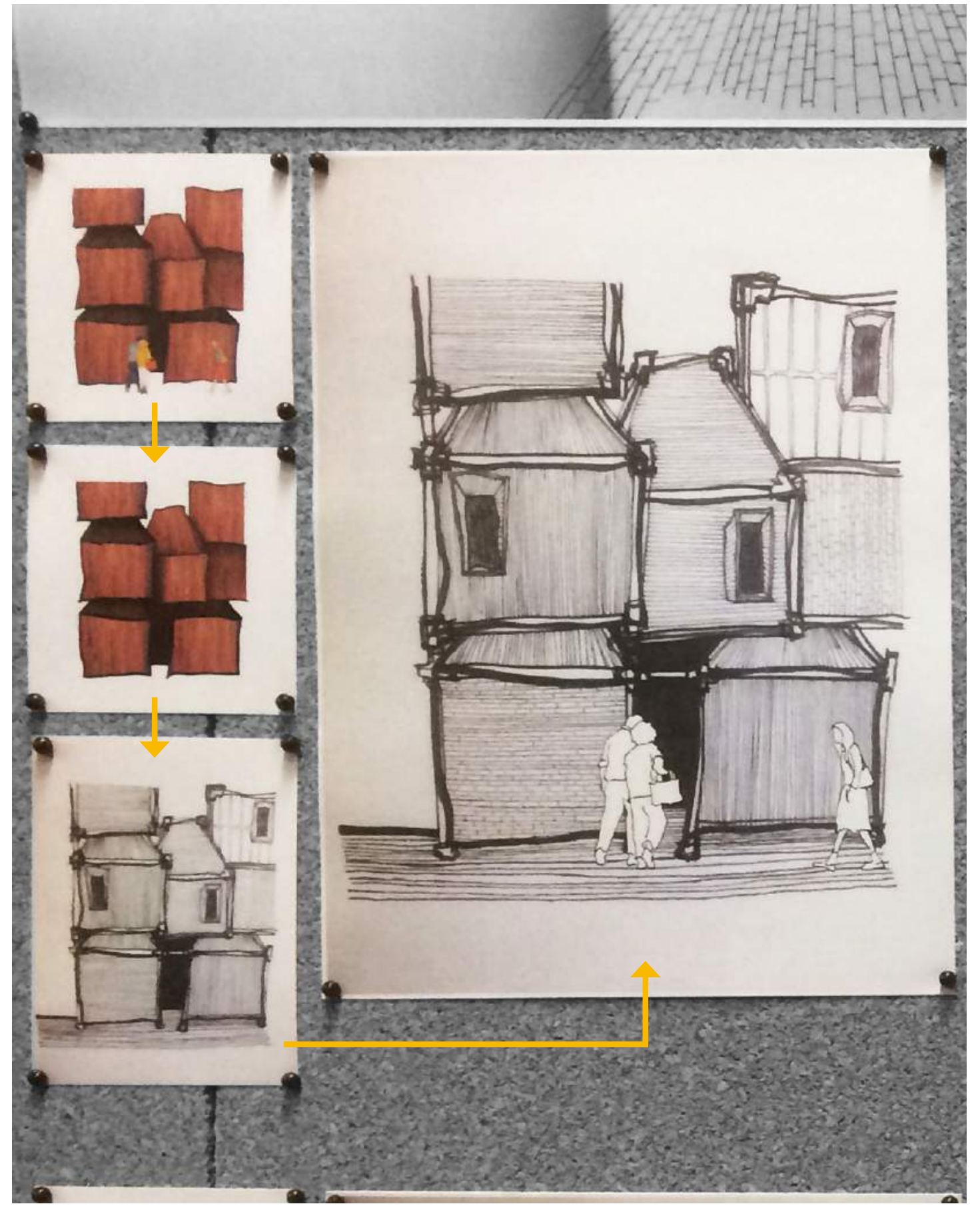

Fig 2.133. Photoshop was used to remove the people from old cartoons.
These were then redrawn with ideas for material and tectonic of the building

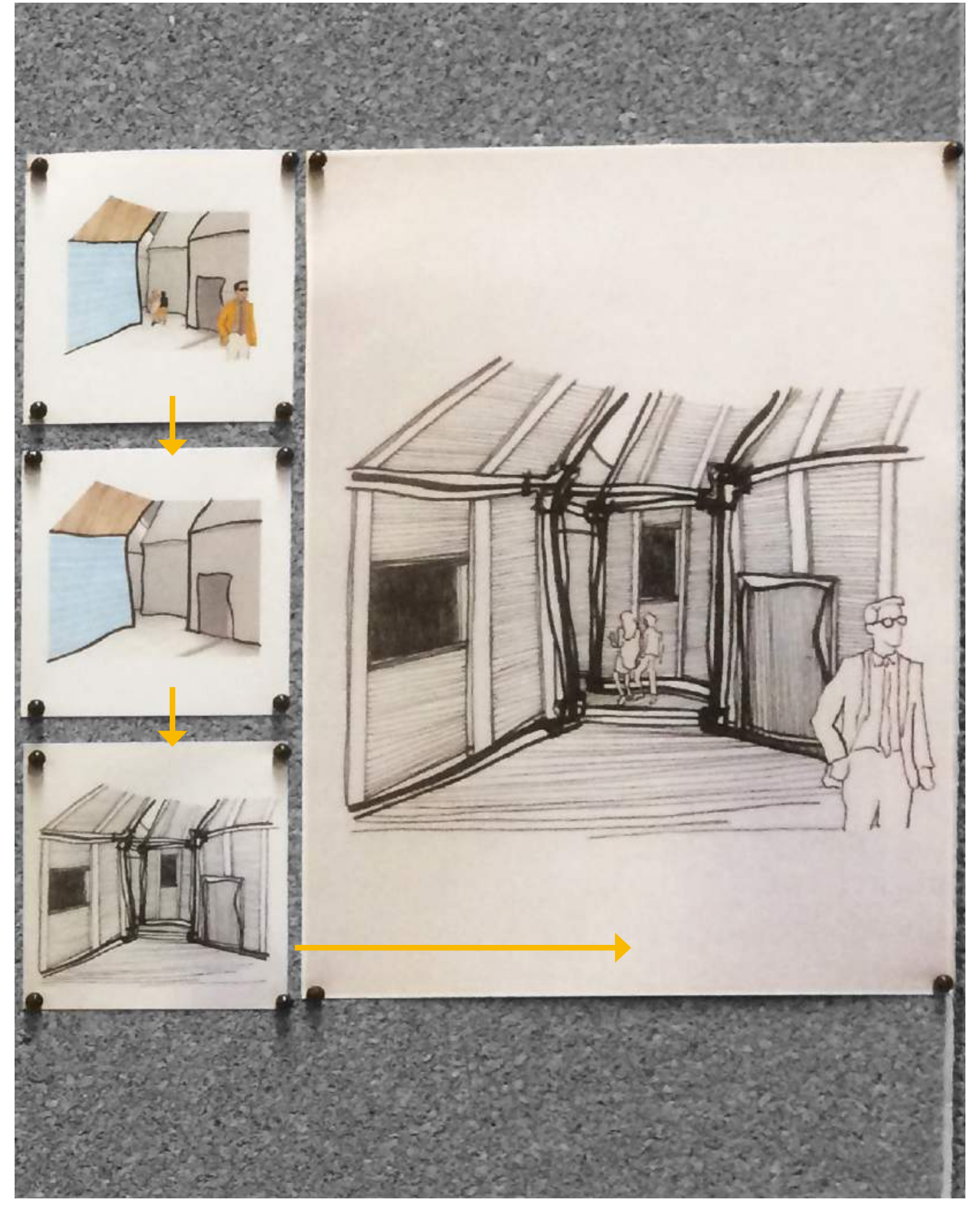

A Fig 2.134. Once the drawings have been developed to push the

The contrast between the final and original drawings shows the value the change in perception gave to my design process. 

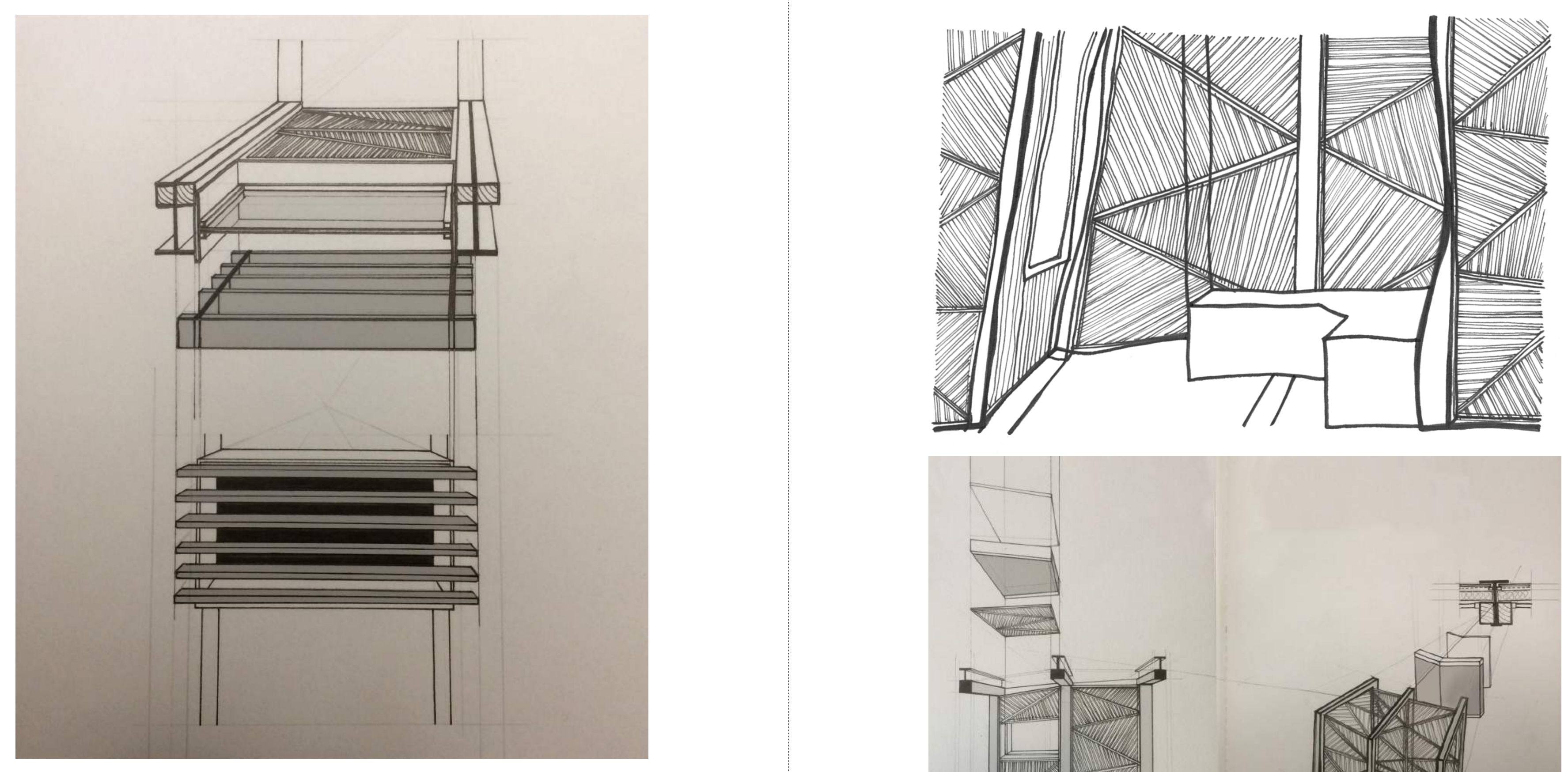

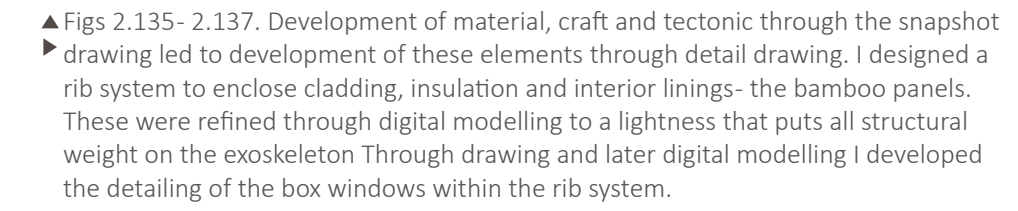

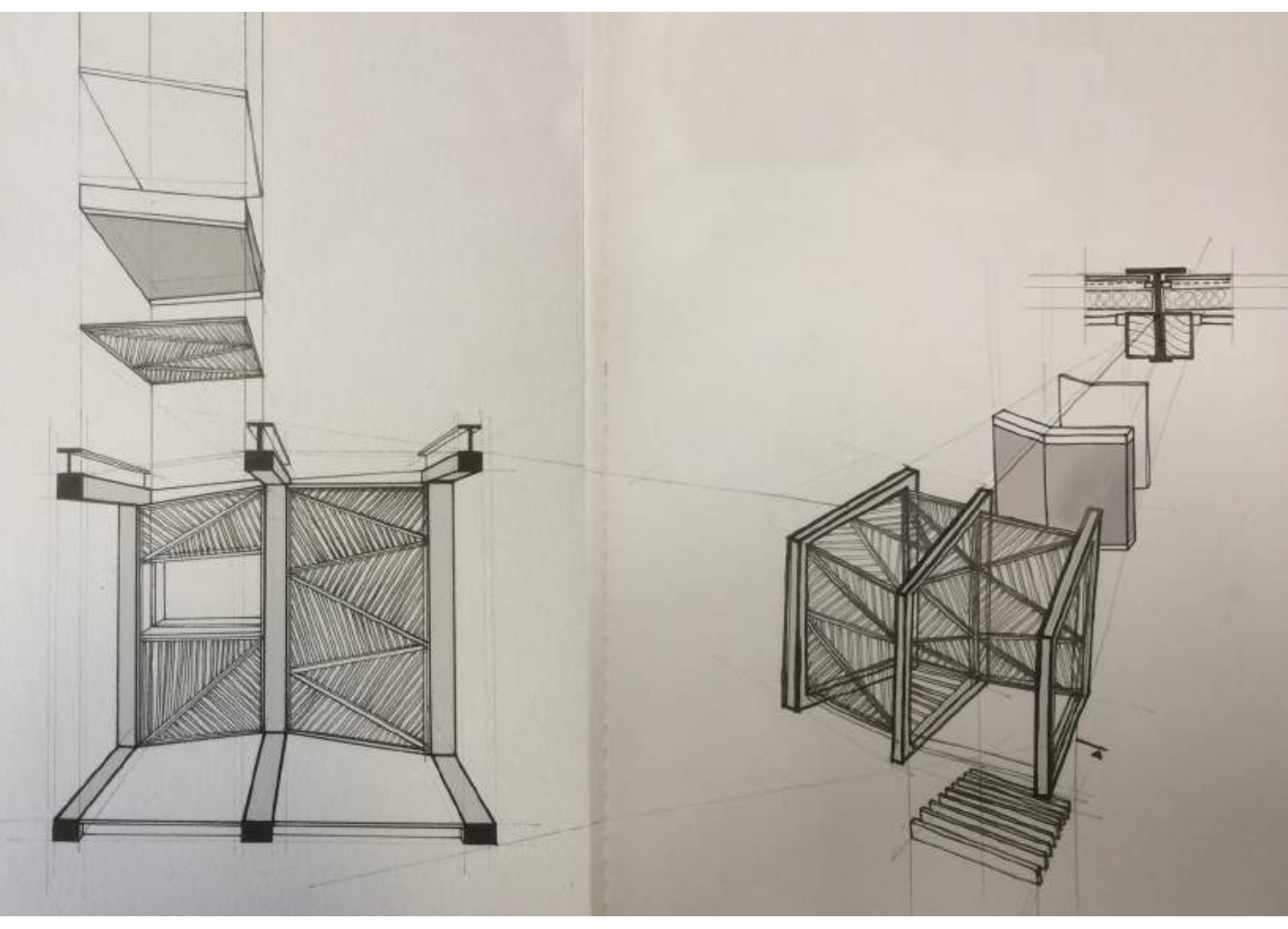




\section{Context: \\ 2.17}

Peter Salter wrote of his work on Walmer Yard, that,

"Bespoke architecture is synonymous with invention of detail" and "Bet when this intention is const is left of the beepote is probably only for

In Walmer Yard, in full invention mode, he developed an intensely bespoke version of architecture generated and bultt through careful handcraft. This produced rich intricate spaces and moments for the inhabitants (page 108). However, it also took more than ten laborious years to design and build. This is a means only possible at the top tie of housing. A tier in which Walmer Yard's wealthy London suburb of Kensington, and ornate design, exists.

This method for generating richoss within a home is unsustainable or midde-of-the-cerve housing. However, changing methods of

construction in the digital realm can bring hope to the idea of a more holistic focus in ordinary house building, to bring intimacy and richnes into the experience of an 'ordinary' hom

When evaluating the state of the city and its preoccupation with the economy, philosopher Georg Simmel wrote,

"Money is concerned only with what is common to all: it asks for the exchange value. It reduces all quality and individuality to the question: How much?" (simmel, 1903)

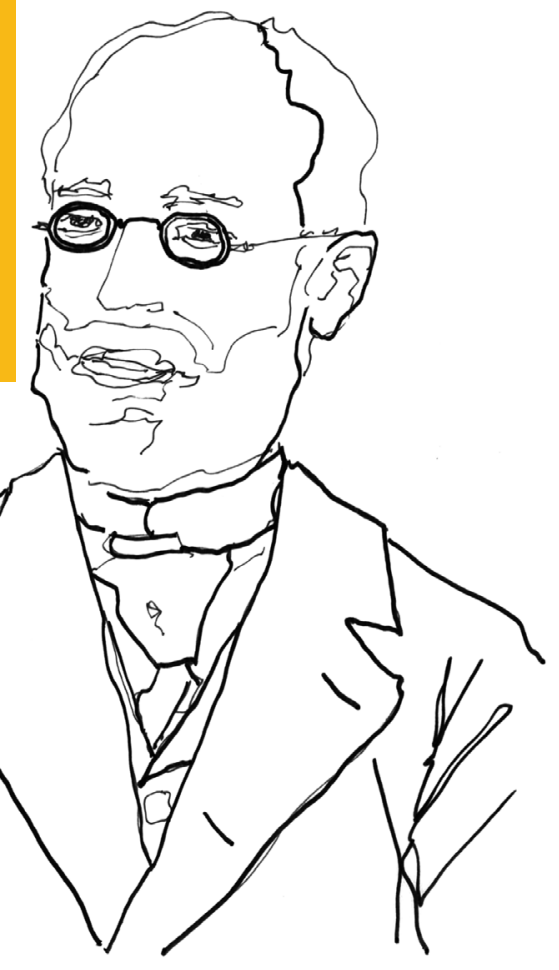

The focus on the economy instead of human centred outcomes in design has led to extremes of banal, regular architecture. Alternatively unsustainable levels of labour danger, or time for construction workers.

Jacinda Ardern stood up at the United Nations and stated that our . economy, but instead holistically.

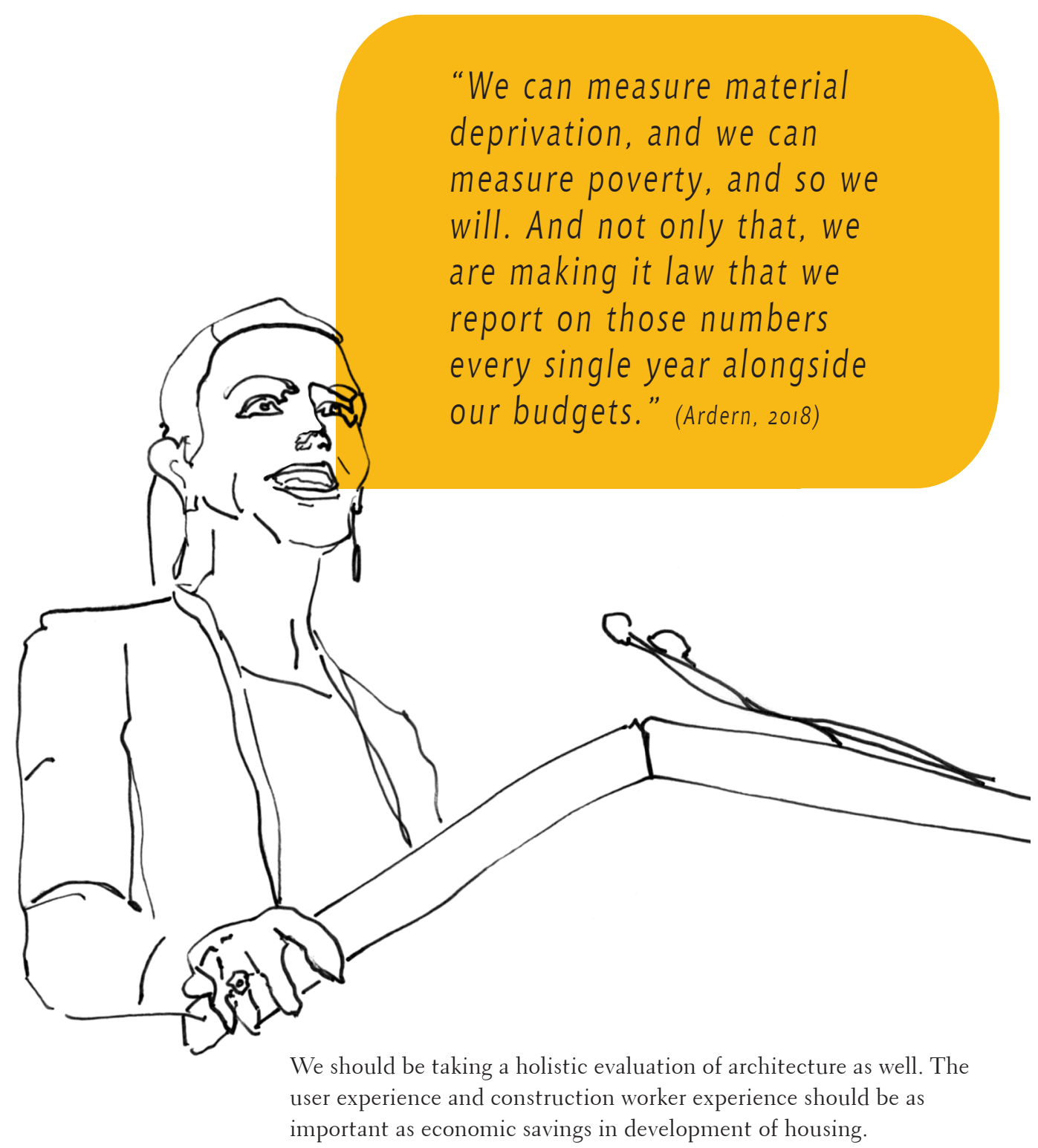




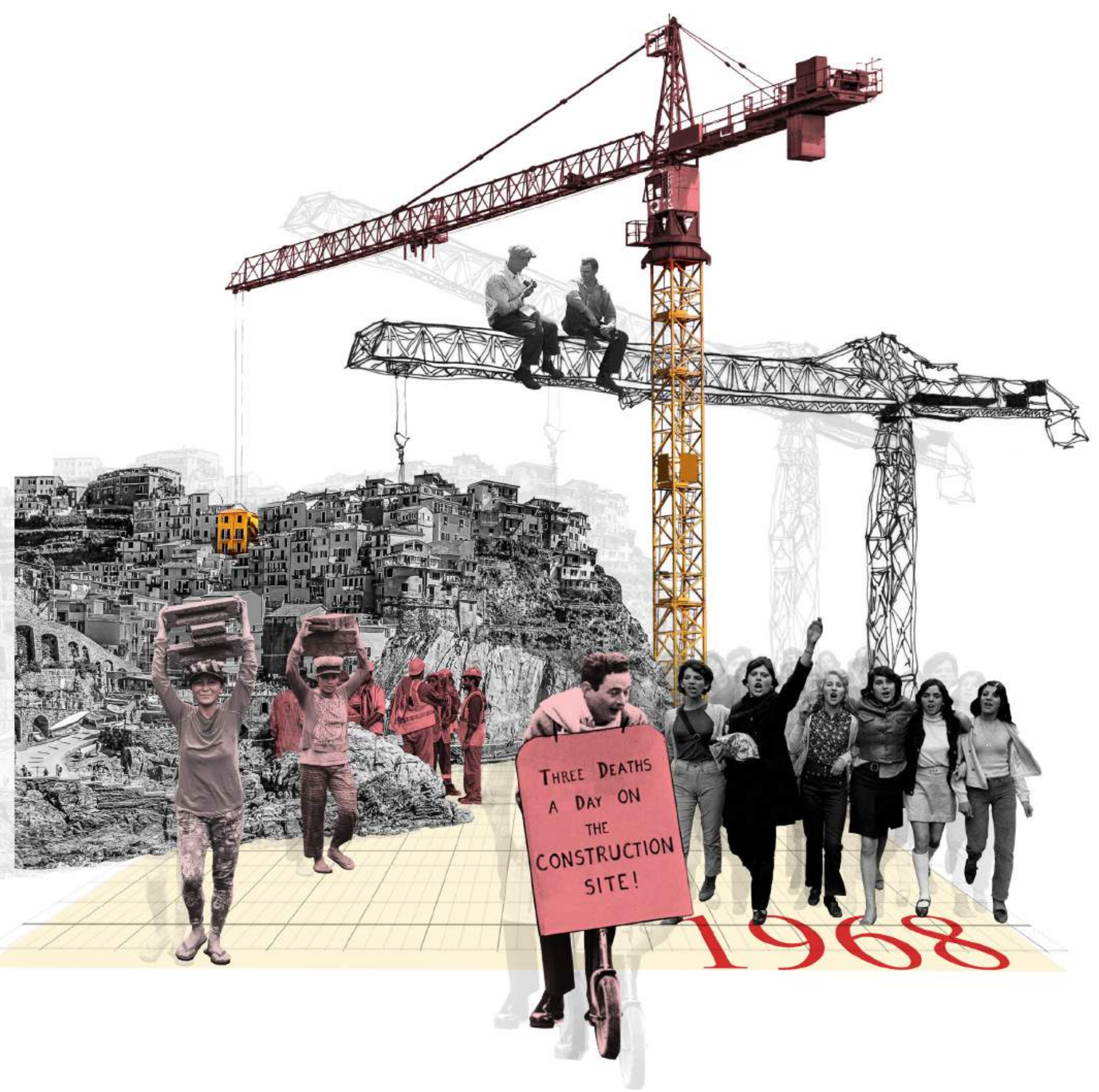

Architects have always had an awareness of their influence over the labour occurring on construction sites. Peggy Deamer writes that

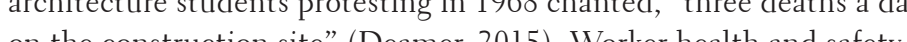
on the constretion site" (Deaner, 2015). Worker health and sate architecture, such as Frank Gehry have recently highlighted this.

Although the scale of building and level of control a designer has on the constuction site of these examps orseas is different to residential construction in New Zeland, the complexity of my design mens on site construction simply from a set of drawings would be confusing time consuming and dangerous. The geometric certainty of angles and sizes that digital fabrication gives can alleviate this.

Using digital fabrication alongside handcraft allows each to bring their own strength to making the construction and final building better for users and contractors. Advancement of digital tools give the opportunity to mitigate dangers of construction through more controlled fabrication methods. However, this does not need to be utilised universally across the construction. The richness of handcraft can remain to generate material complexity and intimacy in spaces requiring engagement and tactility for the user. The efficiency of digital fabrication to make bespoke connections and angles generates the spatial intimacy, as an element that does not require tactile engagement with dwellers, but crucially makes on site construction easier for workers.

In my design, this was the role of the metal 3D printed nodes, fabricated to the same strength as aluminium. They form the

connection points to make the stect exsskelt The angled and irregular. This eases construction of the rest of the building envelope attached to it. From the fundamental steel exoskeleton, it becomes a logical build despite the complex form. Consequently, the envelope, particularly the

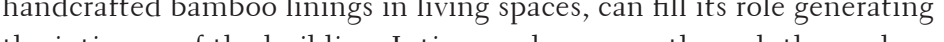
the intimacy of the building. Intimacy also comes through the angles in plan and section facilitated by the nodes, which create nooks and

Although the nooks are time consuming to print and sort, they

convert the labour that would be hazardous, spent up high measuring cont creating a complex form through simpler, safer labour. 
Process:

Labour in Design

2.18

Deamer also writes about the high levels of labour involved in a desig process. Aneclota evere

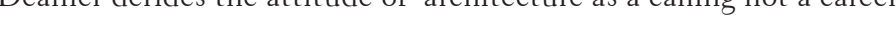

"How could architecture have become so completely deaf to the labor discourse that it could so unselfconsciously subscribe to the honor of labor exploitation?" (Deamer, 2015)

This especially resonated with my own design process, due to the timeconsuming nature of hand drawing.

Within my process for this design, iterative development drawings became an opportunity to augment the labour of drawing with digita tools.

As previously written (page 74), I saved time in development drawing by using screenshots of a wire frame, parametric model as a base to trace over with more detailed hand drawing.

Photoshop as a digital tool also augmented the hand drawing to decrease labour and increase their merit in the design process. I used digital appliction and allowed accurate undestanding of some materis relow a dawing I would have restated, if I did not elit out slips of the per or changing design decisions (figs $2140-2141$ ).

These processes augmented the design hand in labour, but still allowed the creative power of the thinking hand to generate ideas.

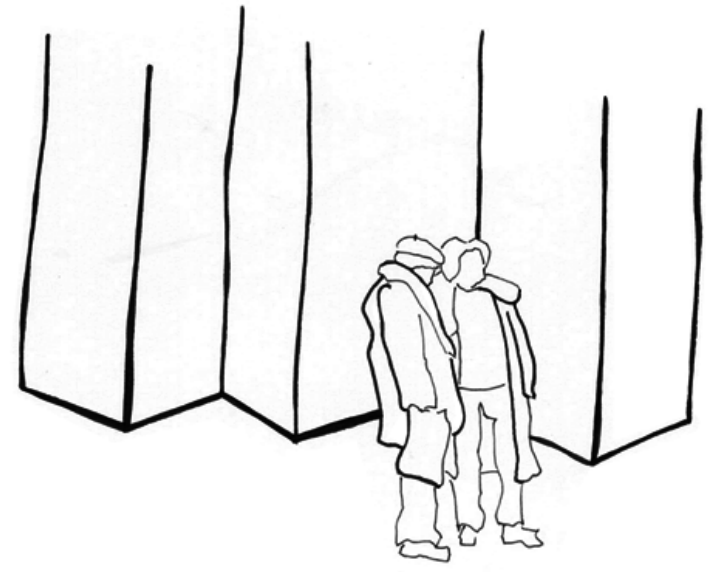
drawing in its edited final

Fig 2.141. A thinking hand drawing in its original state.
It was quickly drawn with no worry of mistakes due to confidence instilled by $\mathrm{my}$ ability to use digital tools to

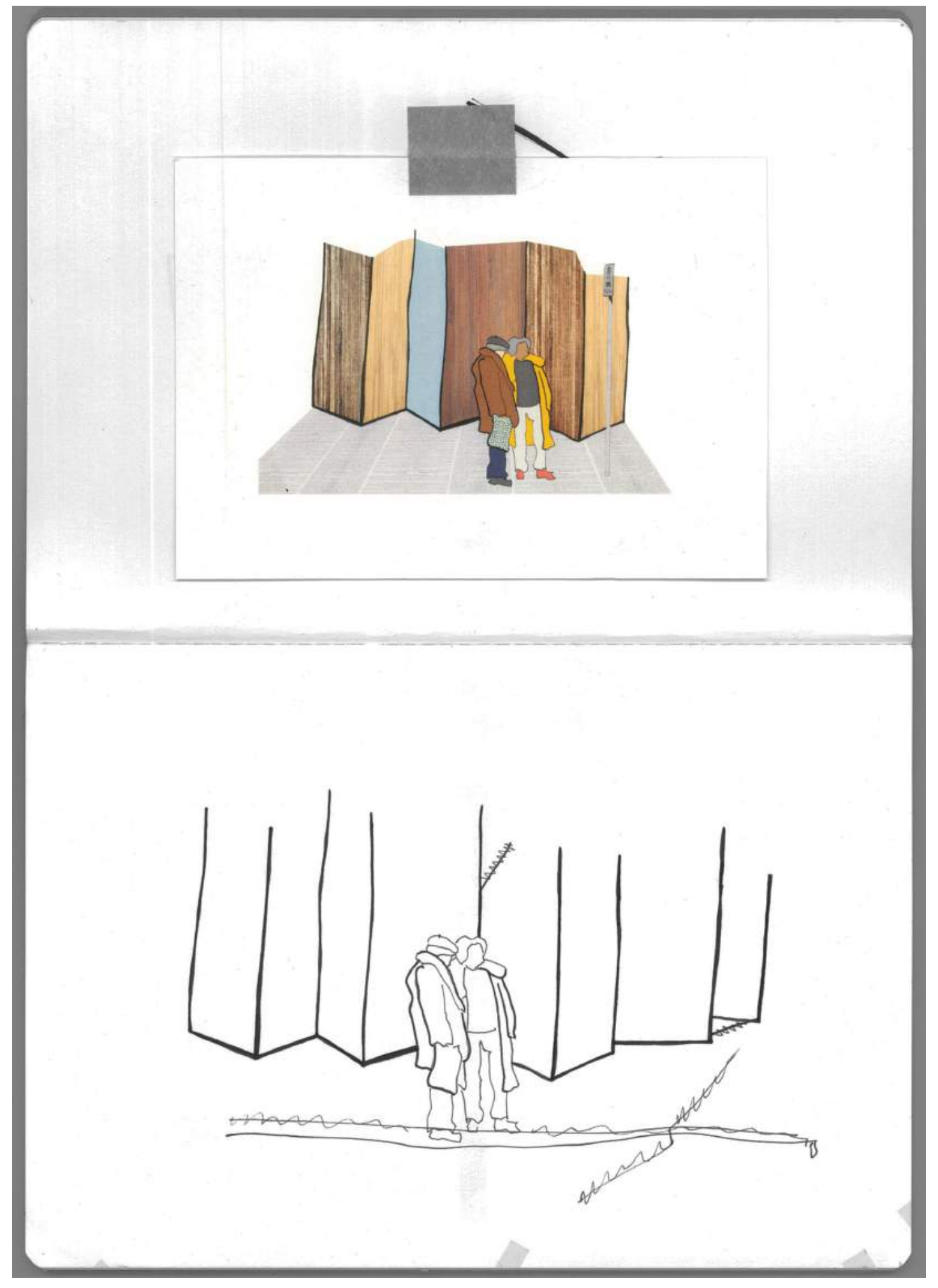




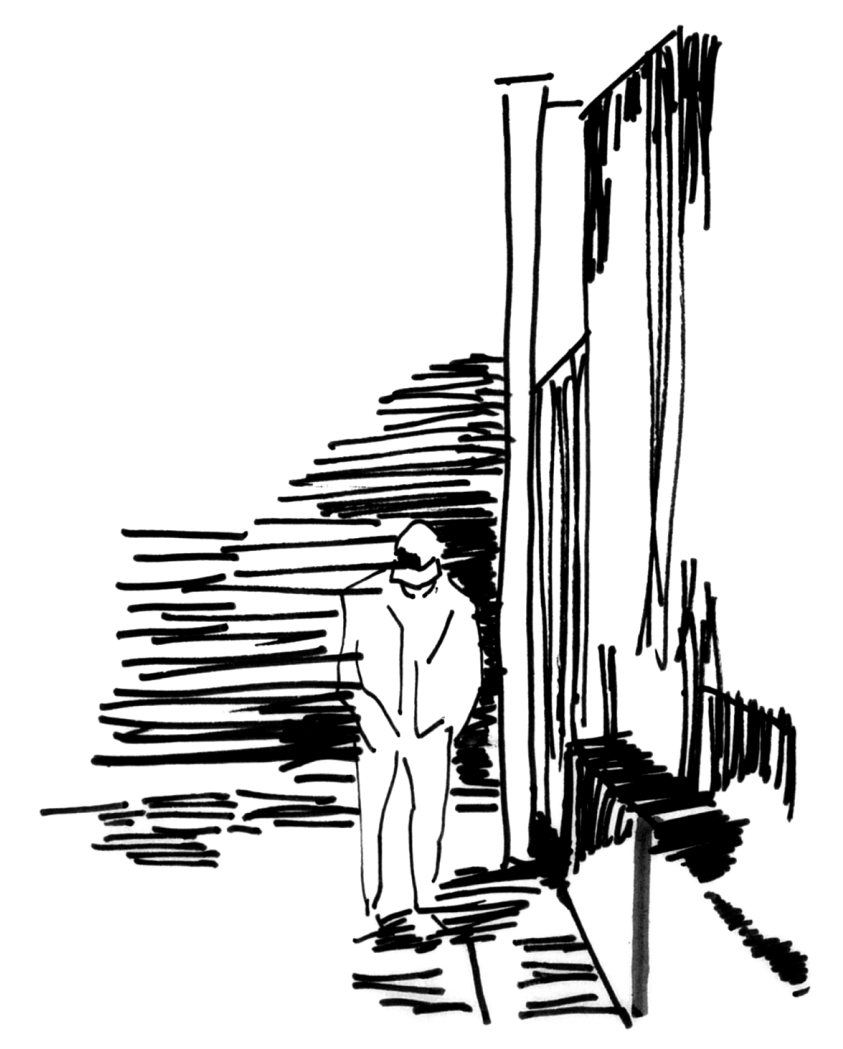

Findings

03. 


\section{Research Findings: \\ Introduction}

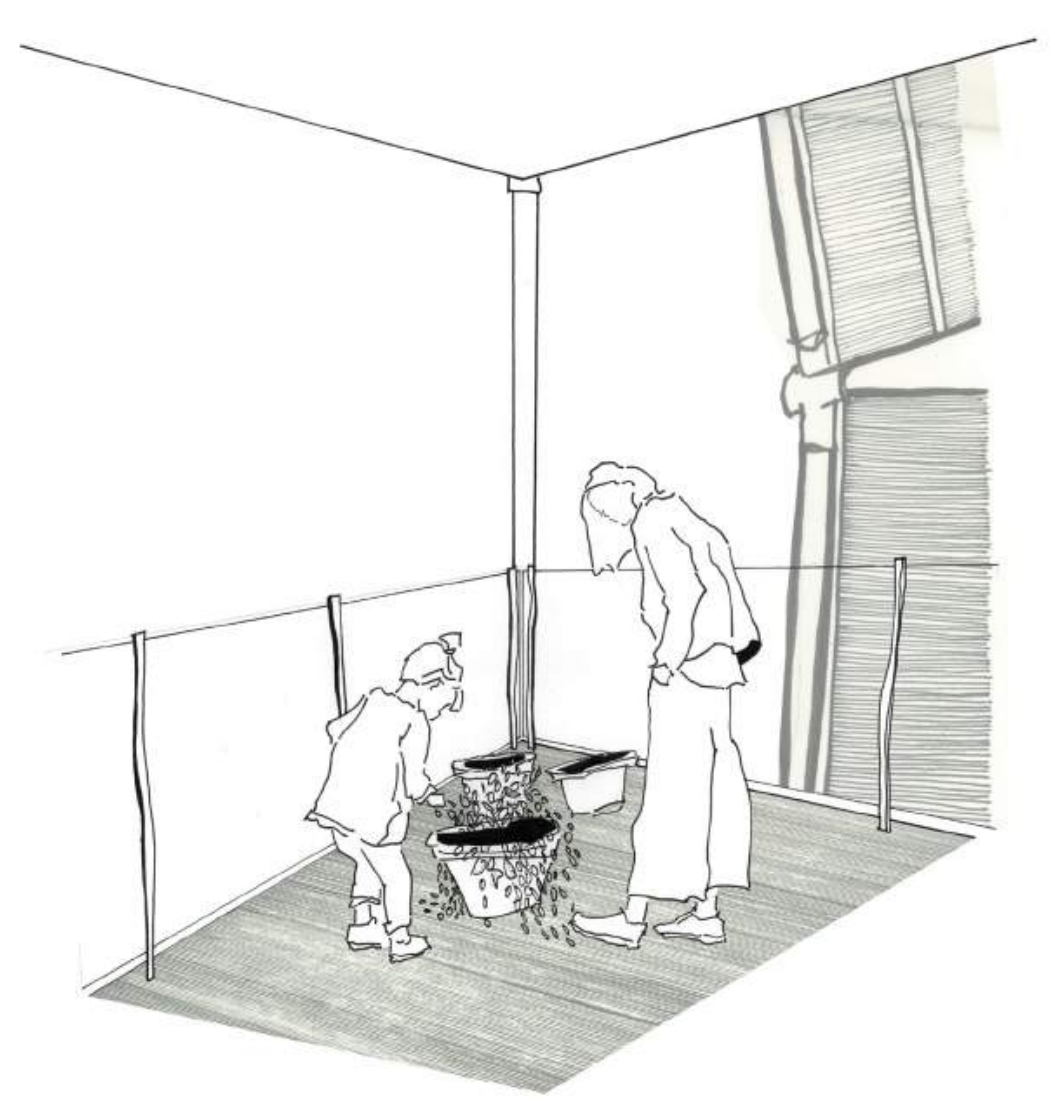

Designing this building, with the understanding of the site and the method of using both sides of the bionic hand. the thinking hand, and the digital machine, has led to five key research findings. These are:

1. The value of a process augmenting both sides of the bionic hand in the form of architecture.

2. The value of a process augmenting both sides of the bionic hand in formation of architecture.

3. The integration of complex design into Hataitai and New Zealand's version of suburbia.

4. The bionic hand as a way of working, in the history of complexity in the architectural discipline.

5. Understanding my own perception of the project and the impact of this on the design process.

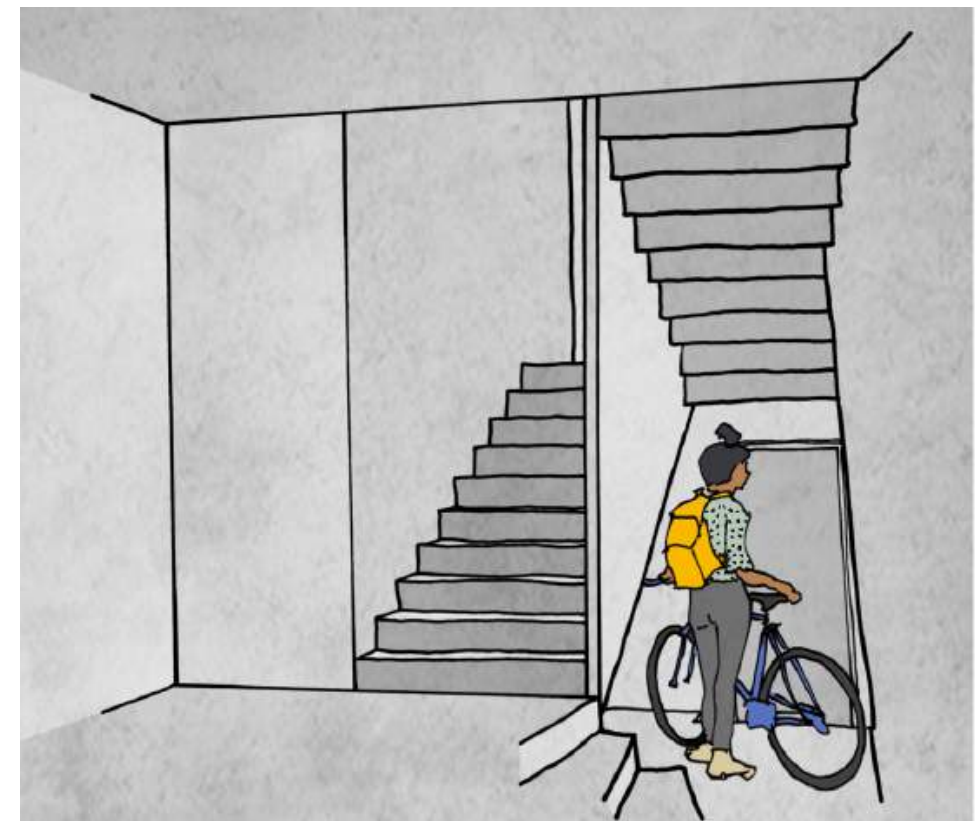

A Fig 3.3. Storage space in
the staircase entrance 
Research Finding !:

The Bionic Hand in the

Form of Architecture

The synergy in augmenting the two sides of the bionic hand mean a built form with complex richness and efficiency of construction. The streng of the bio ic Holistic evaluation of this architecture means judgement over this efficiency in money, but also the experience of hose building it, and of divitaly prefor of digitally pre-fabricated bailding is chasing effciency to the point of Yard or Mirles The

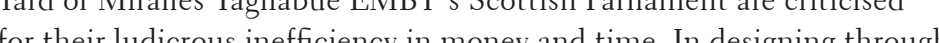
for ther ling

In my design, this came through the overall building language, hand crafted bamboo linings and the digitally fabricated node connections.

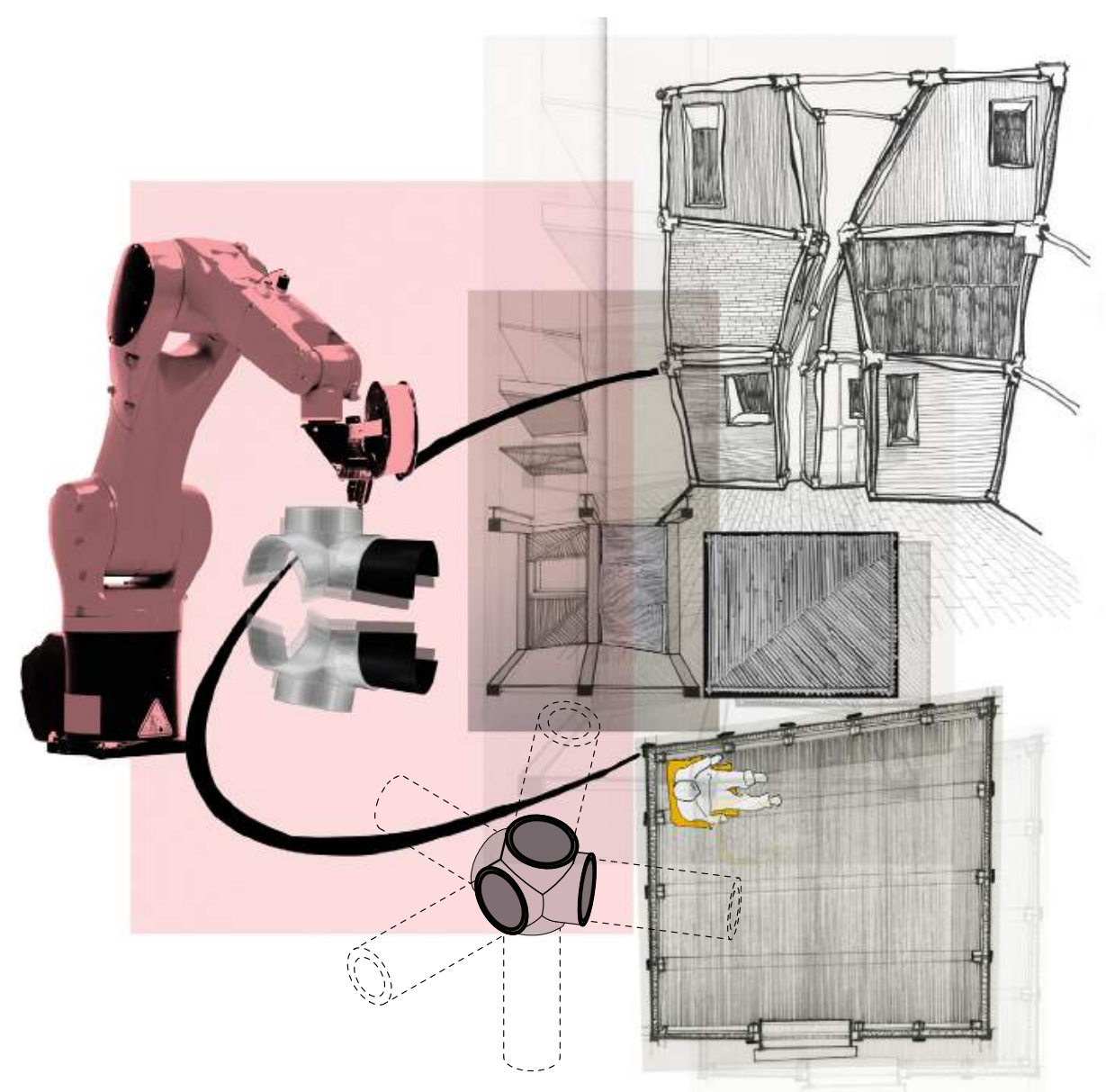

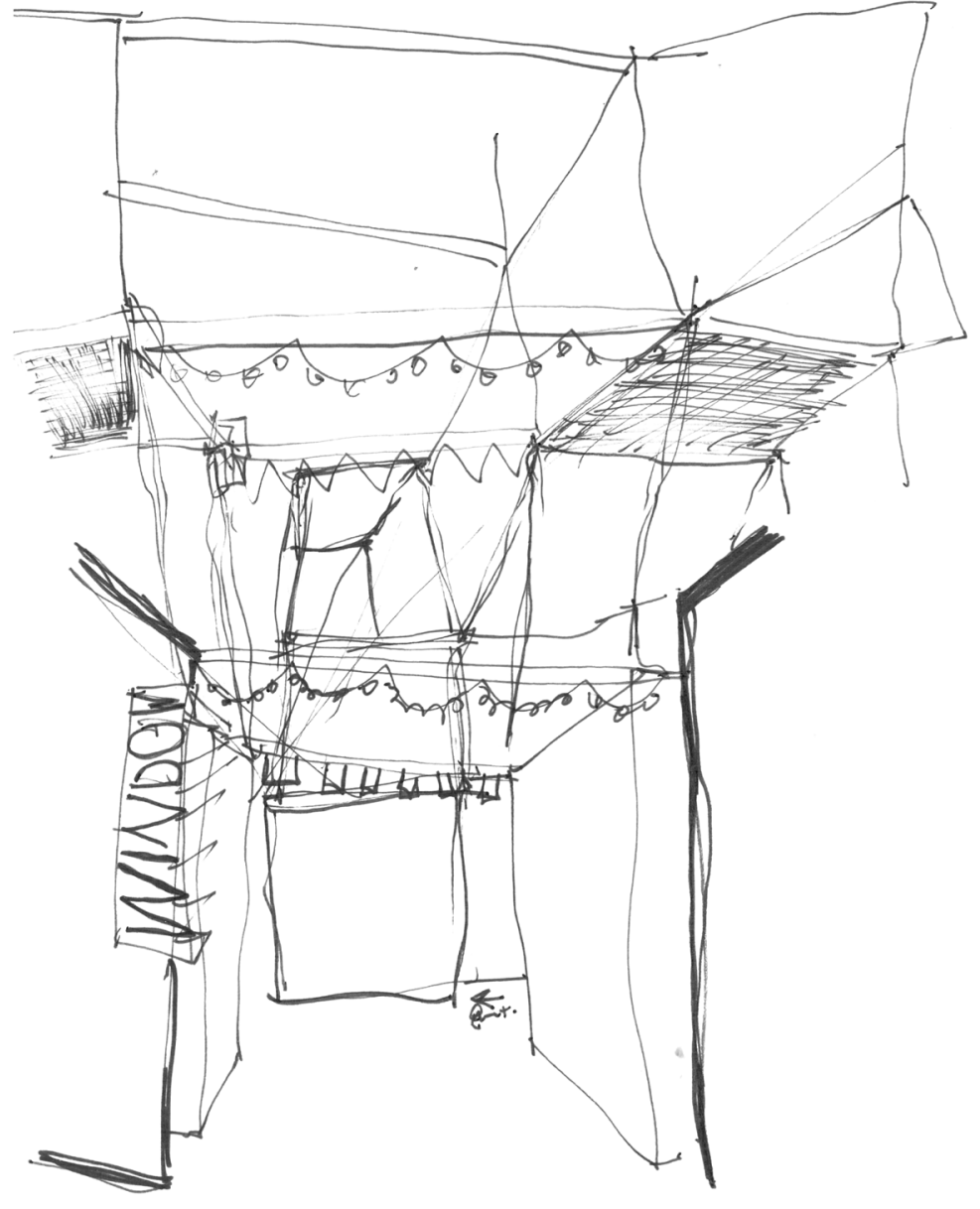

Through the process of orbiting between hand and digital, the language of the building in the sloping walls, irregular structural frame and complex planning is that of the thinking hand. I maintained this language from early conceptual drawings and their 'wonkiness.' The inherent understanding of space by brain and body means the thinking hand is the direct tool to create and express this. Our brains and bodies do not work by Euclidian geometry. Why should our homes be slaves to it? Maintaining this language through the digital / hand flip flop in the design process was deliberate to use the strengths of each side of the eng intimate space. Within the homes, sloped walls give a surface to rest against, and irregular corners into which to crawl. Between the buildings, angled walls give closeness in circulation spaces. These wer not decisions to be made in a computer programme, but through a body's understanding of what inhabiting these spaces would be like. The synergy of the bionic hand in my project was identifying the strengths of each side and applying then. 


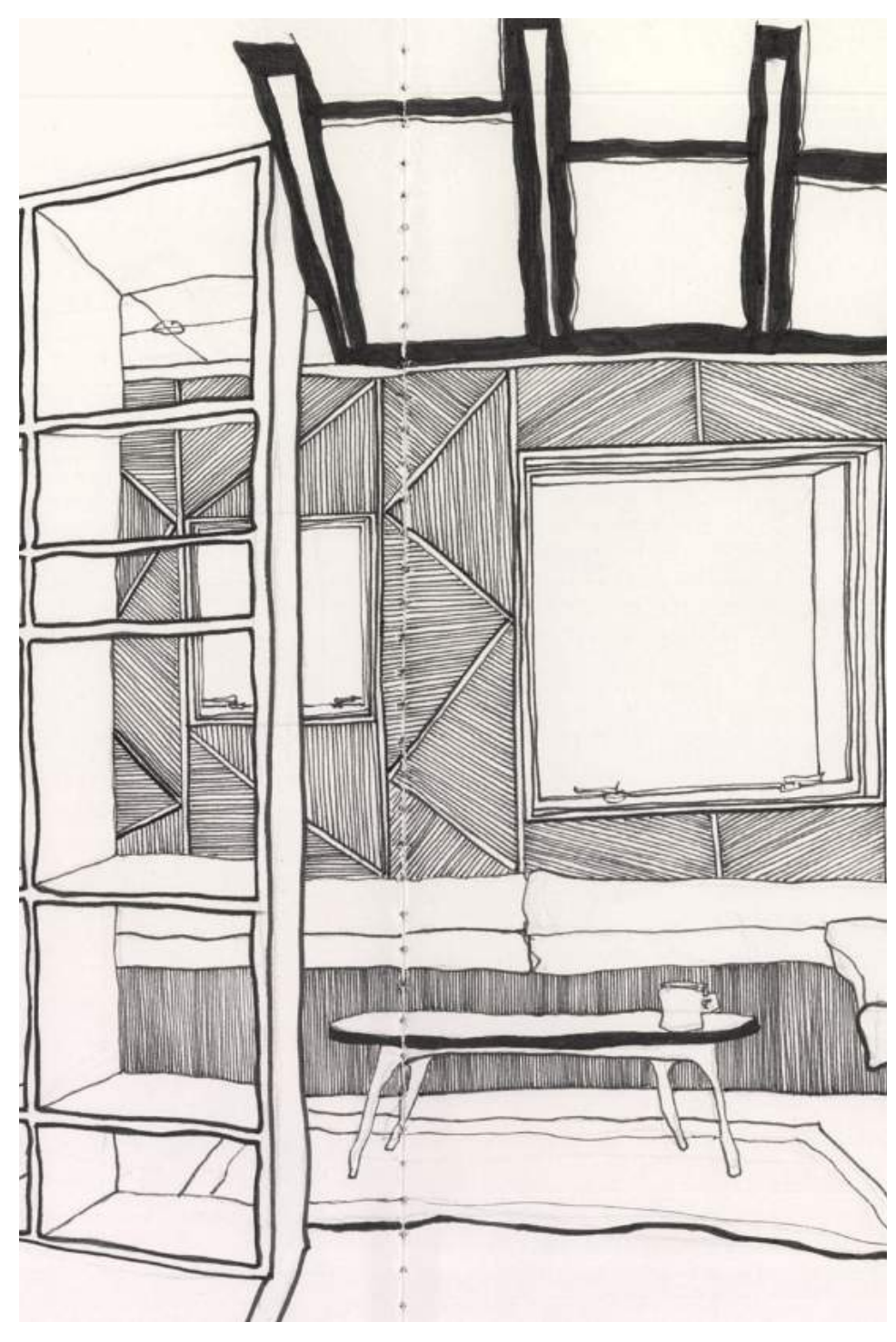

Creating spaces to inhabit with intensity using the thinking hand came through cratt as well as spatial design. The sane wontiness that comes through in thinking hand drawing also comes through in hand-led craft. This is the place of the handcrafted bamboo panels in the building.

This wonkiness gives tangible richness to interior spaces allowing users to inhabit with intensity. In living spaces closest to an inhabiting body in the homes, the rich craft gives a bespoke nature, tactility and visua richness. This brings the strength of the thinking hand to generate richness into the form of the building.
In the same way the bamboo panels bring the strengths of the hand side of the bionic hand into the form of the architecture, the $3 \mathrm{~d}$ printed structural connections bring the strengths of the digital side. The digital tools in both. to a conplex project. This is the role of ho nodes. They are as easy to tabricate bespole, as tha are to fabricategoncirally. Through crre ing the reality. By accol the reall By are

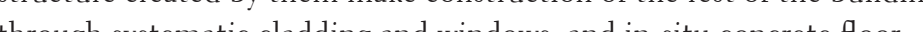
slabs, logical for a complex building.

The node system is not perfect, due to the sorting and refining that would occur post printing However they do transfer the labour from precarious, awkward measuring and welding on site, to in workshop digital fabrication. It is a blue-sky proposal for the potenti impact digital tools could have on making complex design easier for contractors. As Deamer asks,

"How can the architect think all at once material resources, manufacturing technologies, laboring bodies, the fetish of the commodity, and the production of real habitable space?" (Deamer, 2015)

Habitable space is key to the needs of the user. However when evaluating the impact of architecture holistically the construction process is a significant factor. Wellbeing of the workers is at the core of this. This use of the digital does not hugely reduce the work, but replaces dangerous, difficult handwork with smarter tools.

The bionic hand within the form of architecture in this each side. On one side, the inherent ability to gencrate intimacy through hand diawng and cratt. On the other side, the potential for efficiency through digital fabrication

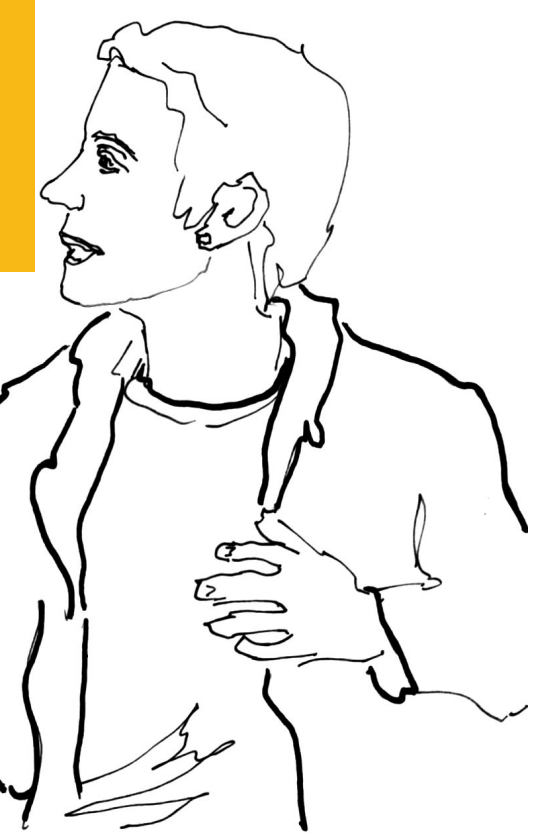


Research Finding 2:

The Bionic Hand in the

Formation of Architecture

The key finding in the design process is the synergy of the two sides of the bionic hand. The intimacy, nisual richness and craft I could not

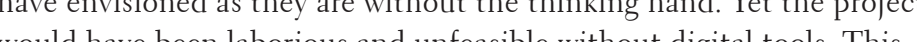
would have been laborious and unfeasible without digital tools. This conctis the two sides of the bionic hand. These haph augmenting drawings and nodell $\mathrm{g}$ photogn

Idea generation in the designing occurred through the thinking hand; using the brain and body's inherent understanding of inhabiting space. As Pallasmaa writes,

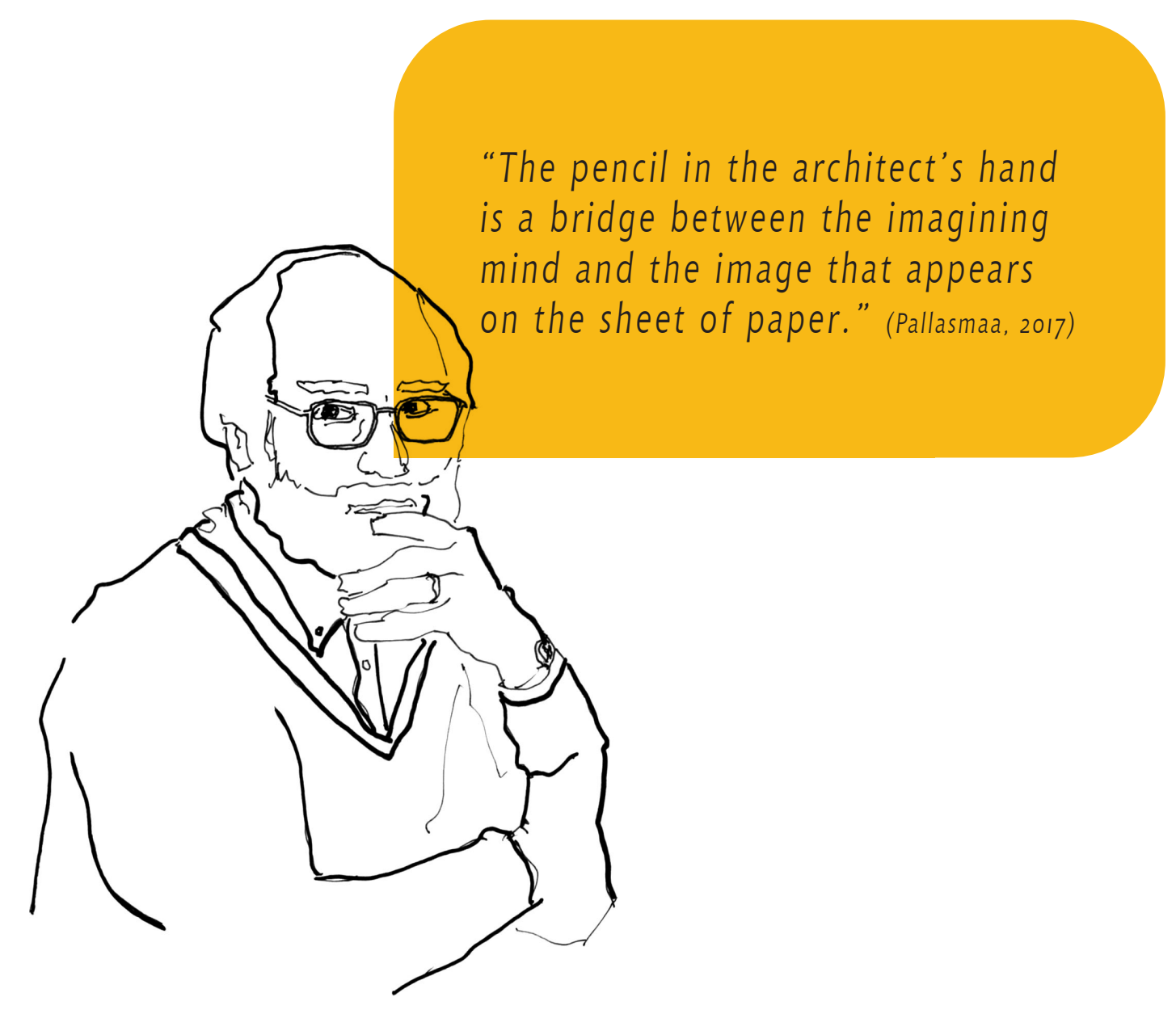

However, it was the inclusion of the digital side of the bionic hand which allowed these ideas to be coherent and flow effectively. Photoshopping drawing and photos of handmade models allowed faster testing of material and intimacy and more confidence to draw quickly.

Being able to edit the drawings and photos to correct mistakes, overlay materials, or insert people relieved pressure in creating perfect images physically. This allowed me to work with a freer hand, and let ideas flow more naturally knowing I could make them more coherent to others later. I was creating, like Aalto wrote, "Childlike compositions" (Aalto \& Schildt, 1998). However, when needed I could edit them toward a broader audience. Or, edit them for a different design test. For example, taking drawings originally testing spatial intimacy, and testing material over the top. This was allowing the strength of the thinking hand to produce ideas organically while using digital tools for their strength of creating efficiency As I was able to draw faster with more confidence and avoid restarting drawings which went wrong.

The main collaboration between the two sides of the bionic hand to generate intimate architecture efficiently was producing a parametric wire frame model to be the base for the thinking hand drawings. Variou number sliders in the dynamo model script meant 1 could control the angles, lengths and heights of walls around the design. This allowed me to test ideas I had begun to generate through hand drawing and modelling quickly. This did not lose the direct connection of brain to pen as the testing was still through hand drawing. I took labour out of the process by not needing to set up the drawings.

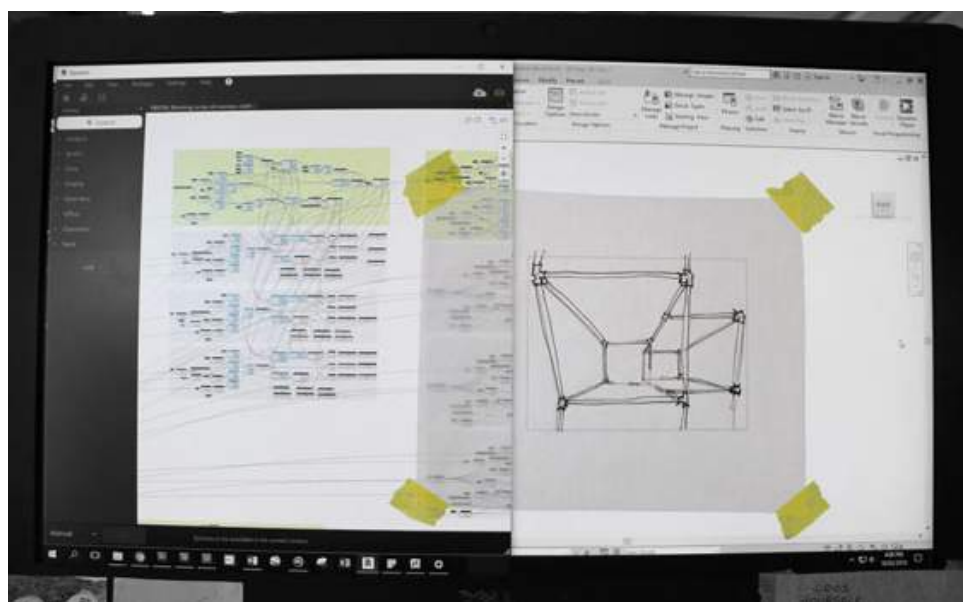

Fig 3.7. The set up of tracing thinking hand
drawings over a changing dynamo model. 
I used prototyping in the design process on both sides of the bionic tools were used to test and iterate the $3 \mathrm{~d}$ printed nodes.

Hand crafted fabrication existed just on the hand side of the bionic hand. It proved to be a process of evaluation and betterment of the drawing process that came before it. When drawing the bambo pancls as generators of richness and intimacy the repetition of lines in sull drawings had implied this without question. However building this full scale proved the sparsity the gaps would give as a lining So furthe iteration at 1:1 allowed me to rectify this.
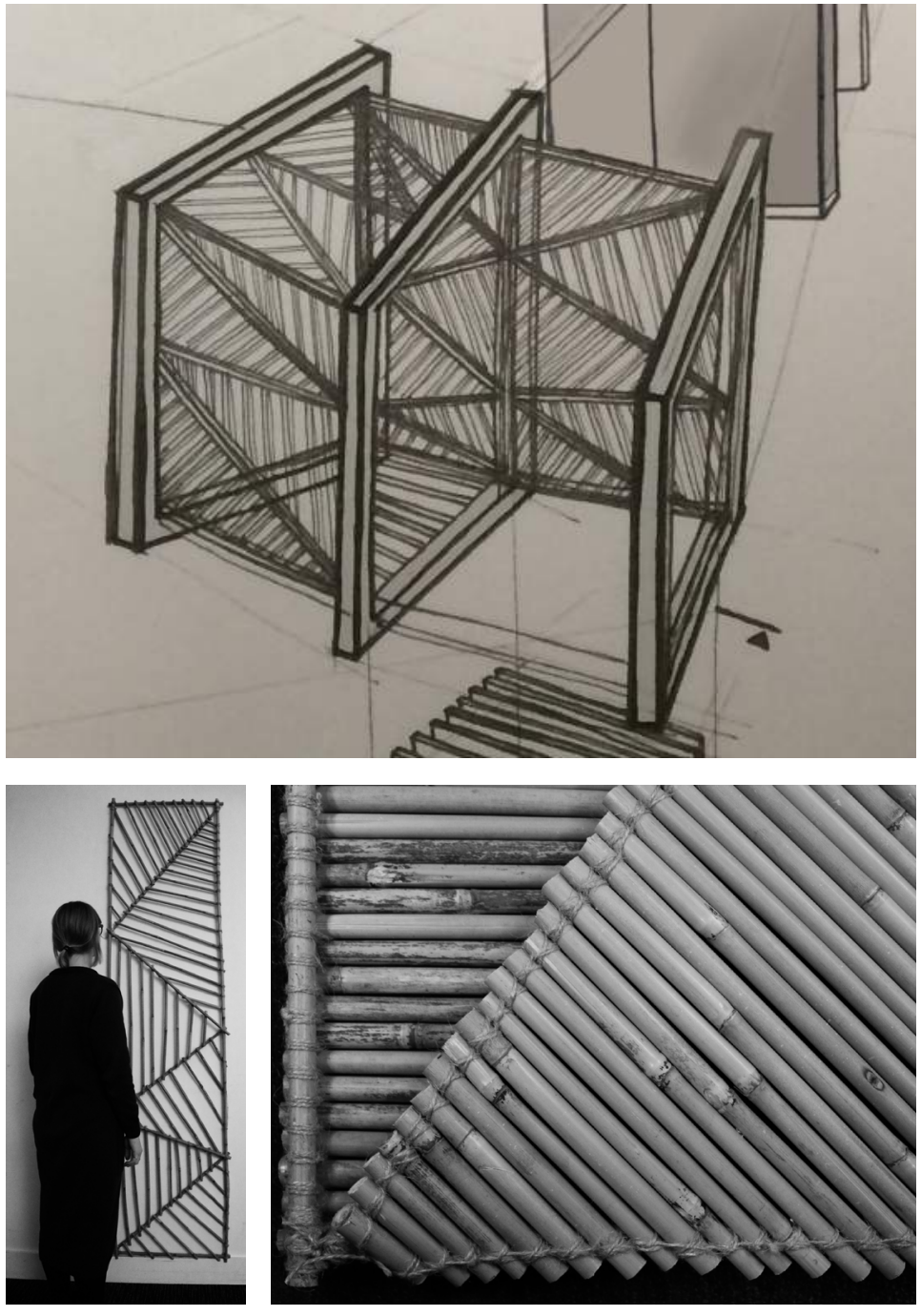

4 Fig 3.8. The formation, designing thinking hand's panels.

4Figs 3.9. 3.10. The two
iterations of the form iterations of the form,
constructing thinking hand's version of the ric bamboo panels.
DFigs 3.11- 3.12. Two of the iterations of the form
constructing digital too version of the $3 d$ printed designing th ther version of the rich digts fabricated 3d nodes.

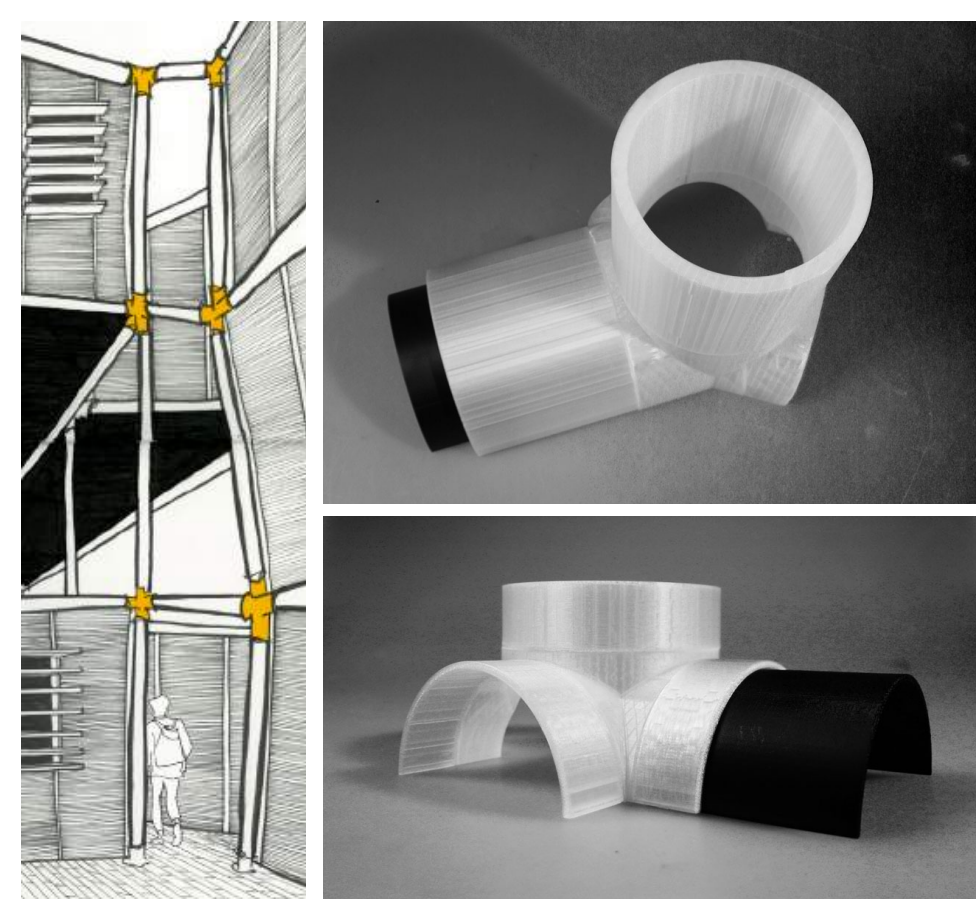

Digital prototyping allowed the process of the bionic hand to come full circle in the development of the nodes. From being originally imagined by the thinking hand, to digital interpretation. The 3d printing allowed them to be understood and evaluated again by the hand.

It was easy to translate the full building form from drawing to computer model, to use as a frame for tracing over. However, translating details to realise their scale and form digitally was more challenging. Especially the nodes as they are so inherently three-dimensional. Understanding them as a two-dimensional image on a screen or even as a drawing was not enough. 3d printing as a tool meant it was as easy to generate the forms at 1:1 as at any other scale. So I could evaluate against the initial drawings to find scale and form of the same subtlety and relationship to the rest of the building and users. The bionic hand worked together according to its strengths. The hand's natural understanding of inhabitation, scale and form, and computer modelling and fabrication as tools to enable this thoroughly and effectively.

It was synergy in the conbination of the hand and digital sides of the bionic hand hat produced and progressed the form and formation of my final design. The use of these sides generated the imaginary world and determined a way for them to bring them into being efficiently, without losing the value of the original lines on the paper. 
Research Finding 3:

The Design as Part of Suburbia

As landscape mainly made up of low density, single, low-rise dwellings, Hataitai exemplifies suburbia in New Zealand.

As previously discussed, these issues go deeper. Suburbia is willing itself away from being an urban landscape at all. This is in its rejectio of the street front towards a people focussed sub-centre for Wellington.

This problem is not just prevalent in the low density, bungalow dwellings with street facing front yards. Park Mews and this version of postmodern complexity as a group can be criticised for its addressing of the street front. While existing as an interesting object within and from afar, on its main elevation, (Moxham Avenue) Park Mews presents garages and then steps back to a car park. The site within the Park Mews block allowed me direct comparison between the two buildings for critique and improvement.

My response has been direct and linear street fronting on both Moxhan Avenue and Tapiri Street. The scope of the design is to be within a densified Hataitai. While the scale of the building is large against the low-density surround, it is a statting point towards denser living around the town centre. The elevation of the houses runs directly along the tootpath edge. This contrasts with Park Mews, which has no living areas on the boundary, favouring service areas on the peripheries instead. In my design, both interior house and balcony spaces on the edges will contribute towards life and activity on the streets. The grid created by the external structural system, the windows and storey heights presen a human scale building. Which, as Jan Gehl promotes, is the key to a (Gehl, 2010).

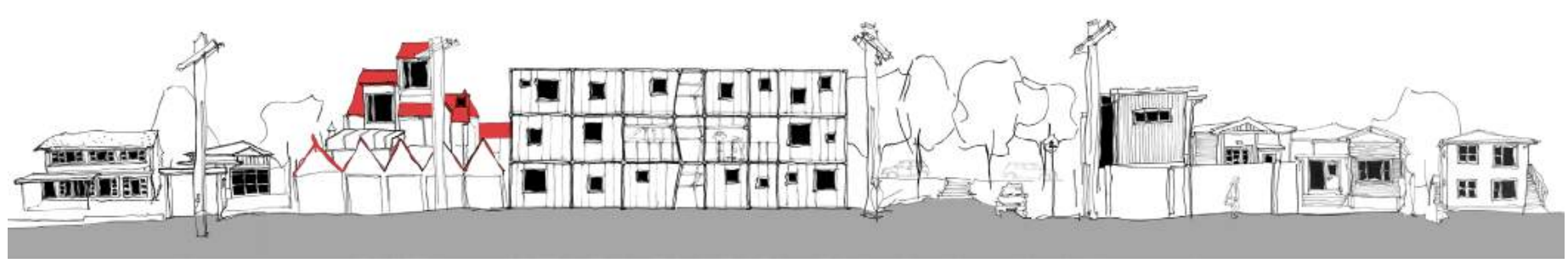

Fig 3.14. The building is a step towards
greater density around Hataitai's centre.

The building language in the sloping walls, irregular planning, and variation in lengths of structural members speaks of its conception by the thing hand. The is informed these formal decisions. The language creates the intimacy

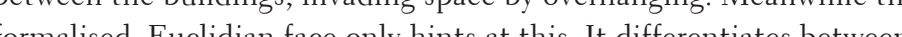
for

This is in contrast to Park Mews. In my design a focus on deliberate interruptions in conventional spatial layout, and intricacy of craft and material makes for a 'simple complexity.' Concentration is on the personal experience in these moments for the intimacy and hyge the Not complexity for the benefit of the external form, like Park Mews. As a spectacle, it is less complex. However, it is complex in ways morc personal to the user. This, as stated previously allows the form to be part of creating a better street.

Despite Park Mews, and other postmodern examples in New Zealand, irregular forms still can and must have a place in creating an engaged and deliberate street front to densify suburbia.

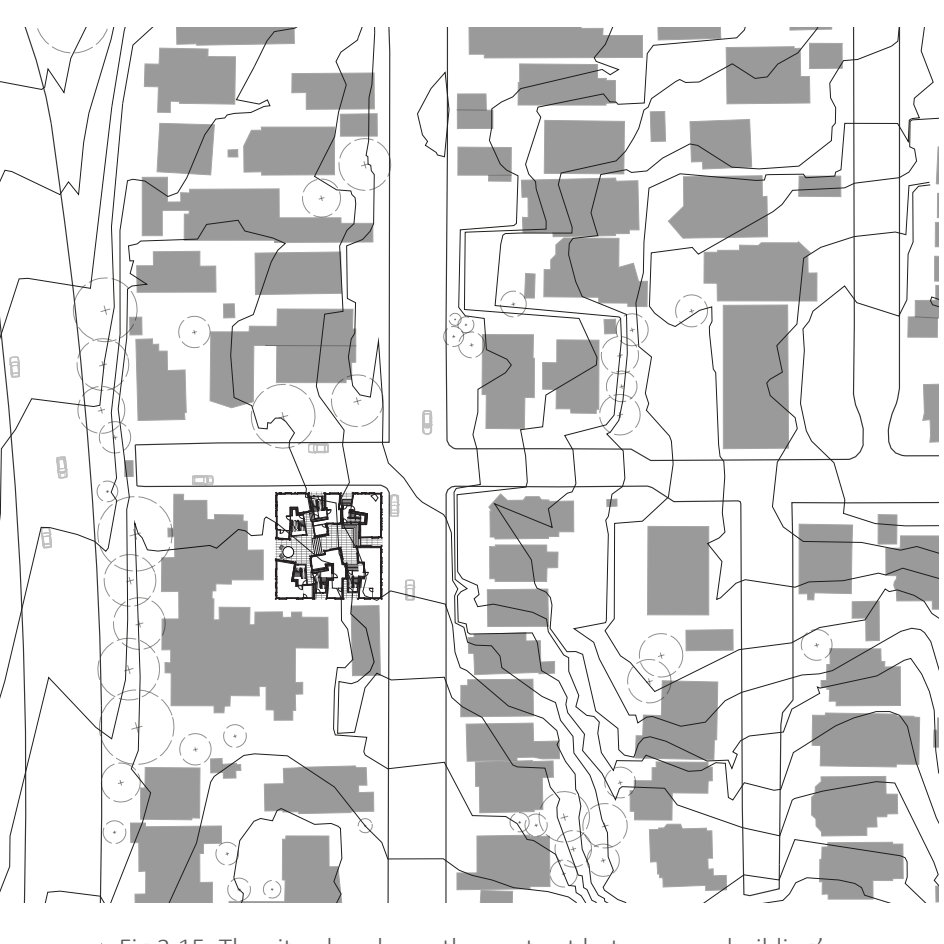

Fig 3.1.15. The site plan shows the contrast between my building's
proximity to the street with Park mews and the single dwellings 
Research Finding 4:

The Design in the Discipline

Direct comparison to Park Mews, as previously written about, also allows for the critical reflection of the work's position within the discipline. Park Mews provides an example of New Zealand's current understanding and relationship with the ideas of 'complexity' and 'irregularity' in architecture.

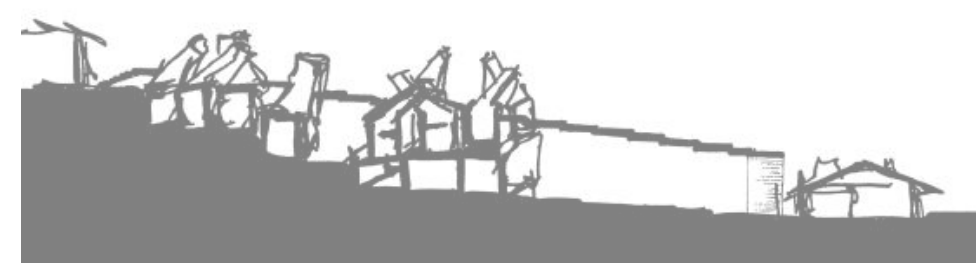

4 Fig 3.16. Example of complexity
generated through the thinking hand

After critical reflection on early drawings, I identified a natural tendency in my drawing towards the contemporary version of complexity. That the experience of tactile spaces for dwelling and moving through. This is the version of complexity exemplified by practitioners such as Salter in Walmer Yard and Miralles Tagliabue EMBT in the Scottish Parliament It is at the contemporary end of the historic thread of complexity exemplifed in New Zealand by post modernists in formal complexity in buildings such as Park Mews and the Athfield house and offices. Through the process of the bionic hand in both the form and formation of the architecture, I position my work at the future end of this thread in architectural history. I used two sides of the bionic hand, firstly to generate the complex and intimate spaces, while also attempting to reduce labour in both the design and construction. This is a documentation of a blue-sky design and construction process that could mitigate the restrictions high levels of labour puts on hand generated bespoke and irregular design, through digital processes in design and construction.

The digital side of the bionic hand is how I aimed to progress this contemporary vession of complexity. As previously written, although Walmer Yard is a rich experience for the user, it was a laborious and time-consuming experience for both Salter as the designer and the contractors over ten years. Gentrating intimate, interesting spaces is attractive to me as a designer, but many contractors would have a hard time sharing this enthusiasm. Using digital fabrication in balance with high labour craft can mitigate either end of the spectrum. The building need neither be unfeasibly expensive and labourious in construction, or sterile and banal in design.

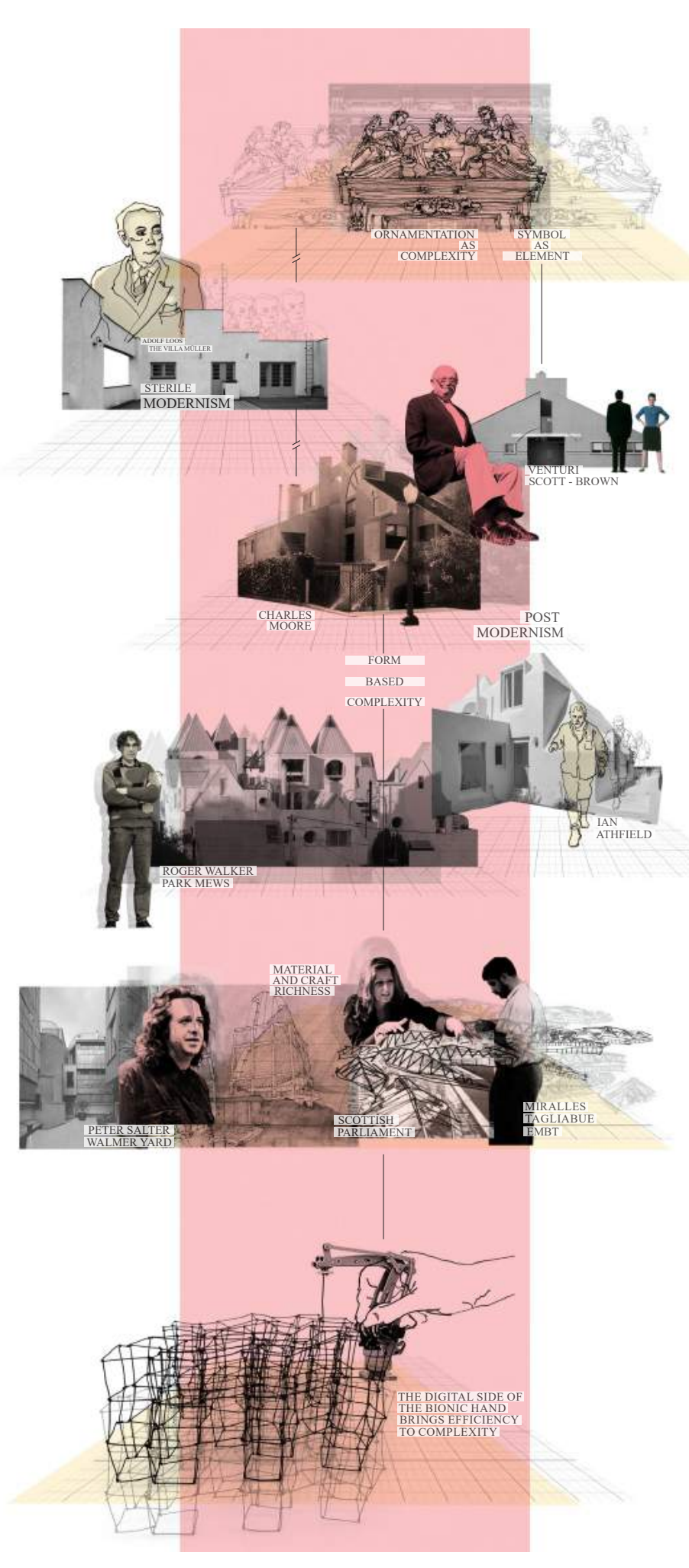

iig 3.17. The selected ime line of complexity
extended to include consideration of efficiency brought by a
bionic hand design and construction process design. 


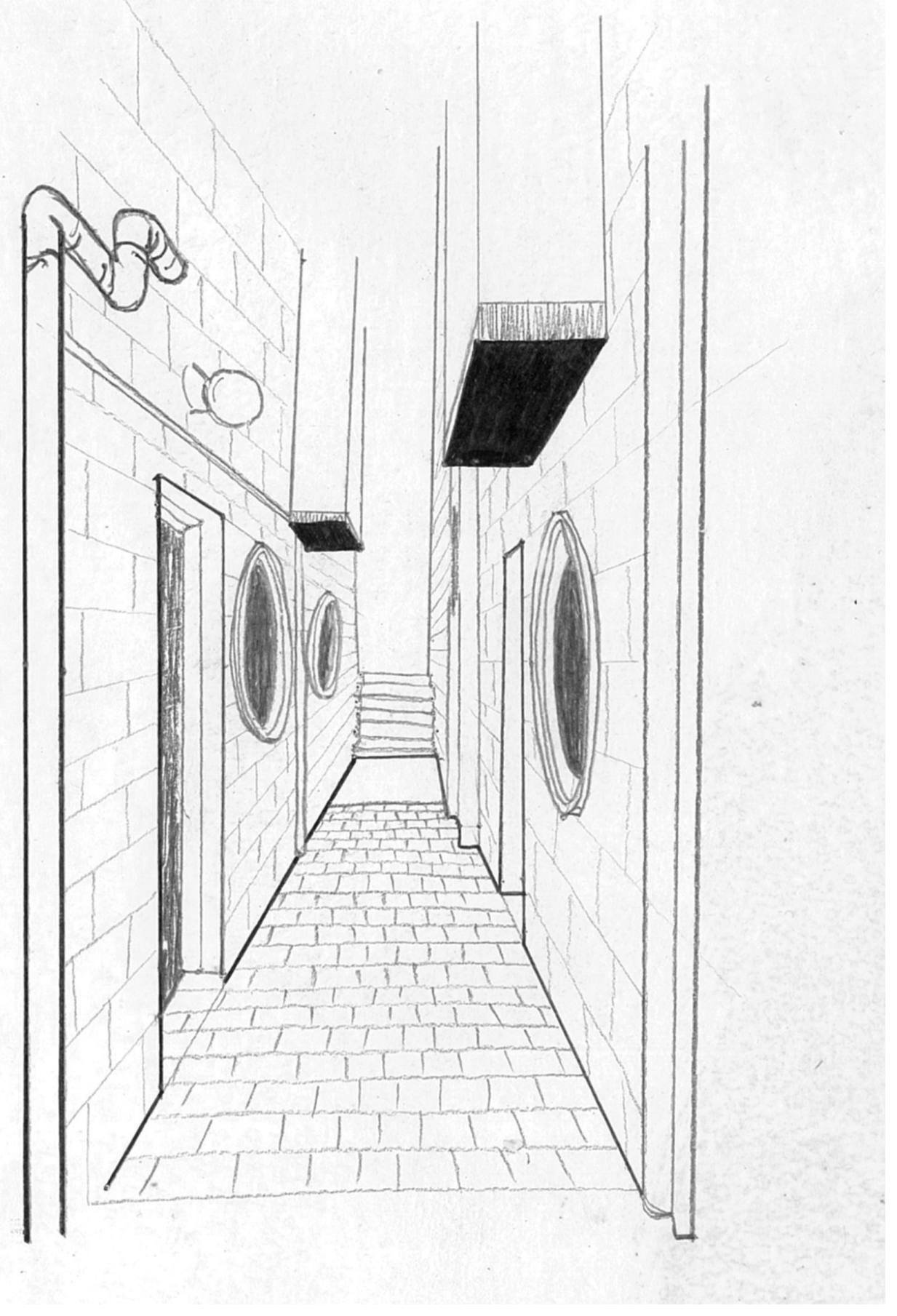

When leading a tour of Park Mews, Roger Walker was asked about his decision to use concrete block. His first answer was the expected: it w a cheap, durable material. Secondly, he showed his tendency toward

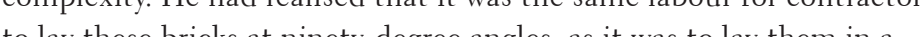
straight line.

Robert Venturi wrote.

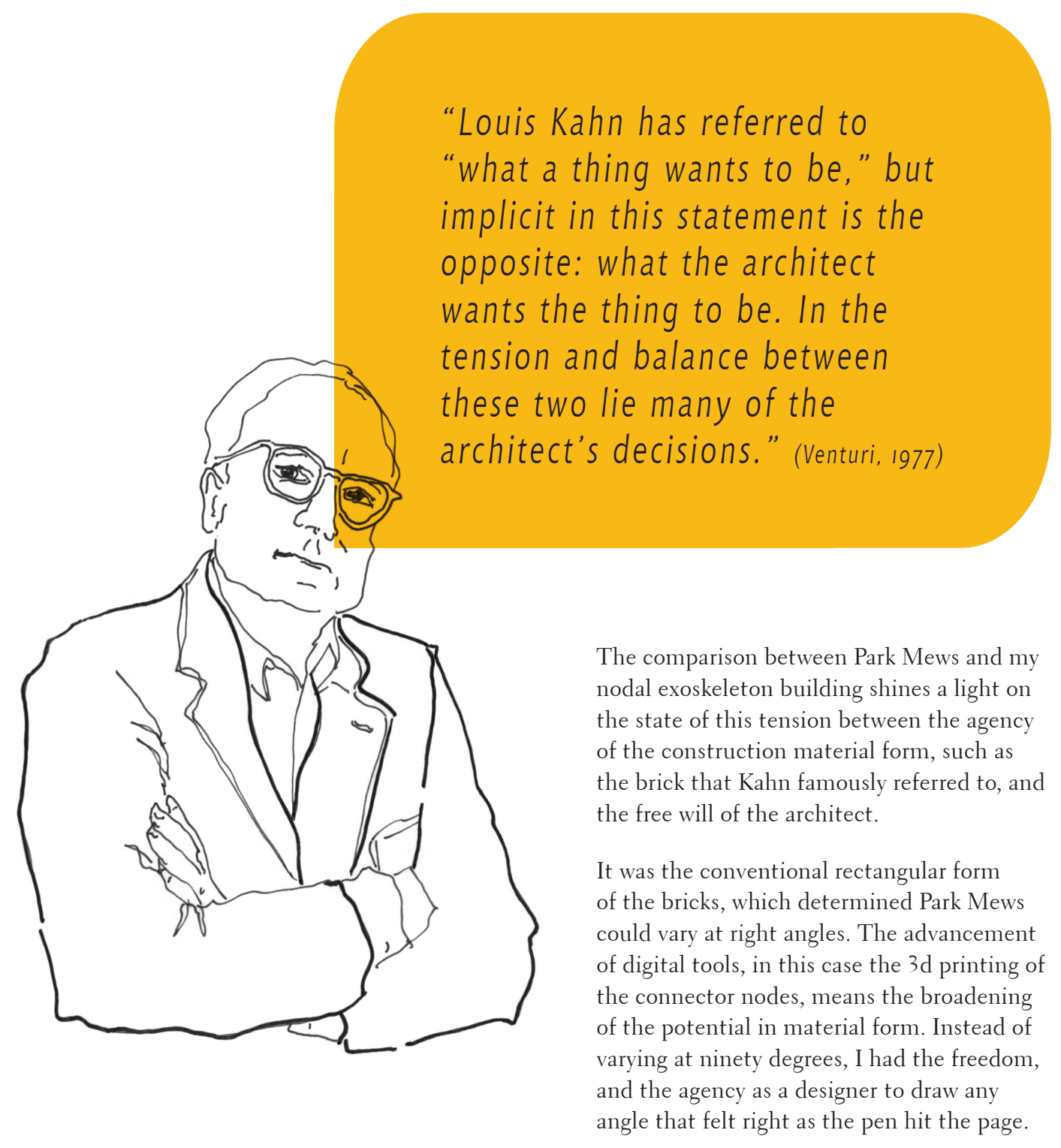


Research Finding 5:

Perception of the Designing

Within the process of the thinking hand, the breakthrough in the development of the detail and materials was a change in focus from people to architecture in the drawings. This was a part of the process of drawing cartoons of snapshots of human perception around the apparent the drawings were assuming feeling of the people in the space without drawing any architecture to evoke this.

Although efficiency is the domain of the digital side of the bionic hand this perception was stagnating development of ideas throug the thinking hand. It was a switch from drawing people, and human activities, to drawing the material craft and structure - what a building really is.

This change came in hand with a change in my perception of the project. The original programme I had started designing for at the beginning of the year was accommodation integrating different sectors of the community. Therefore drawings I did, Peter Cook style, to establish vibes of the programme focussed on interaction between people (Cook, 2016).

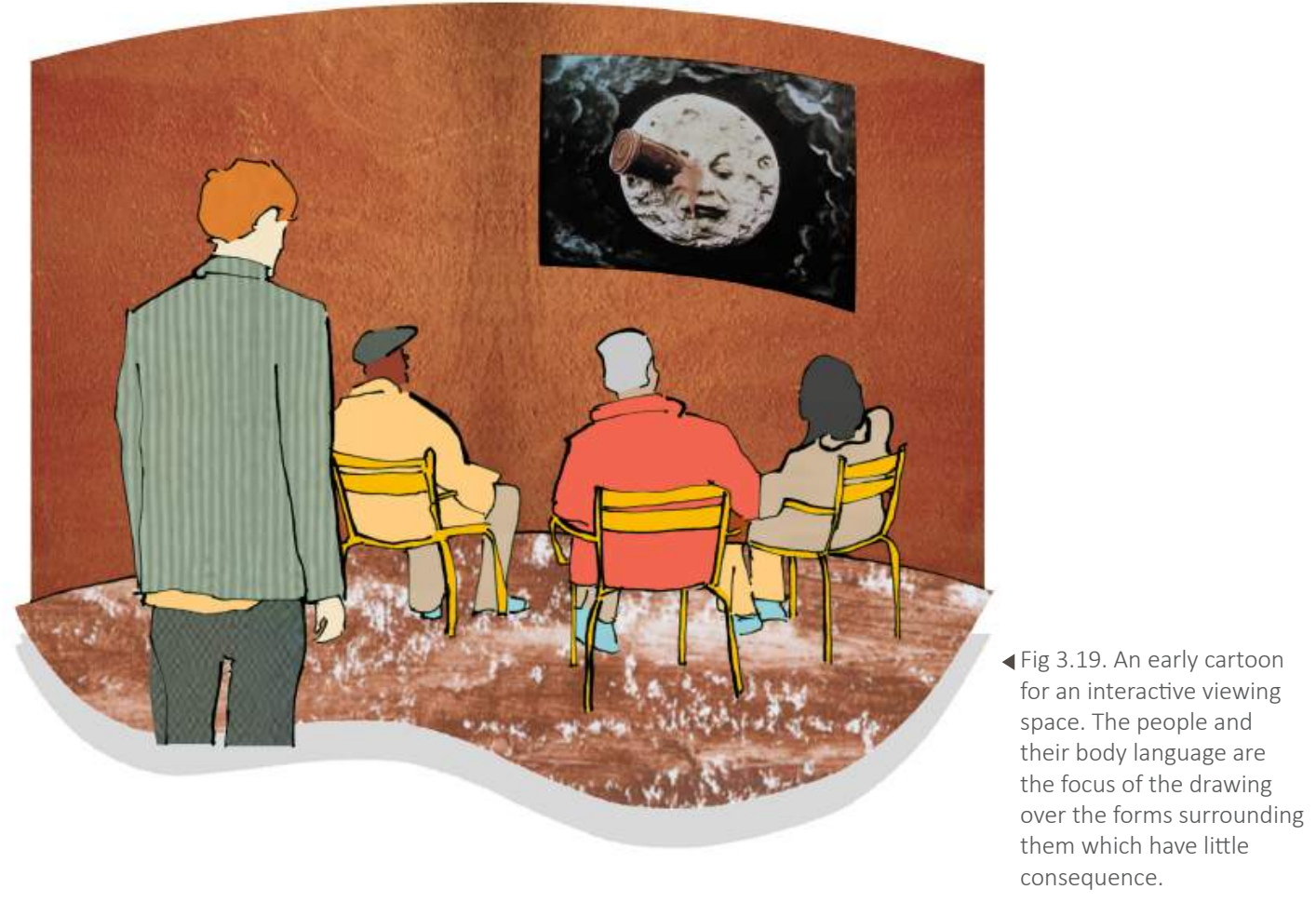

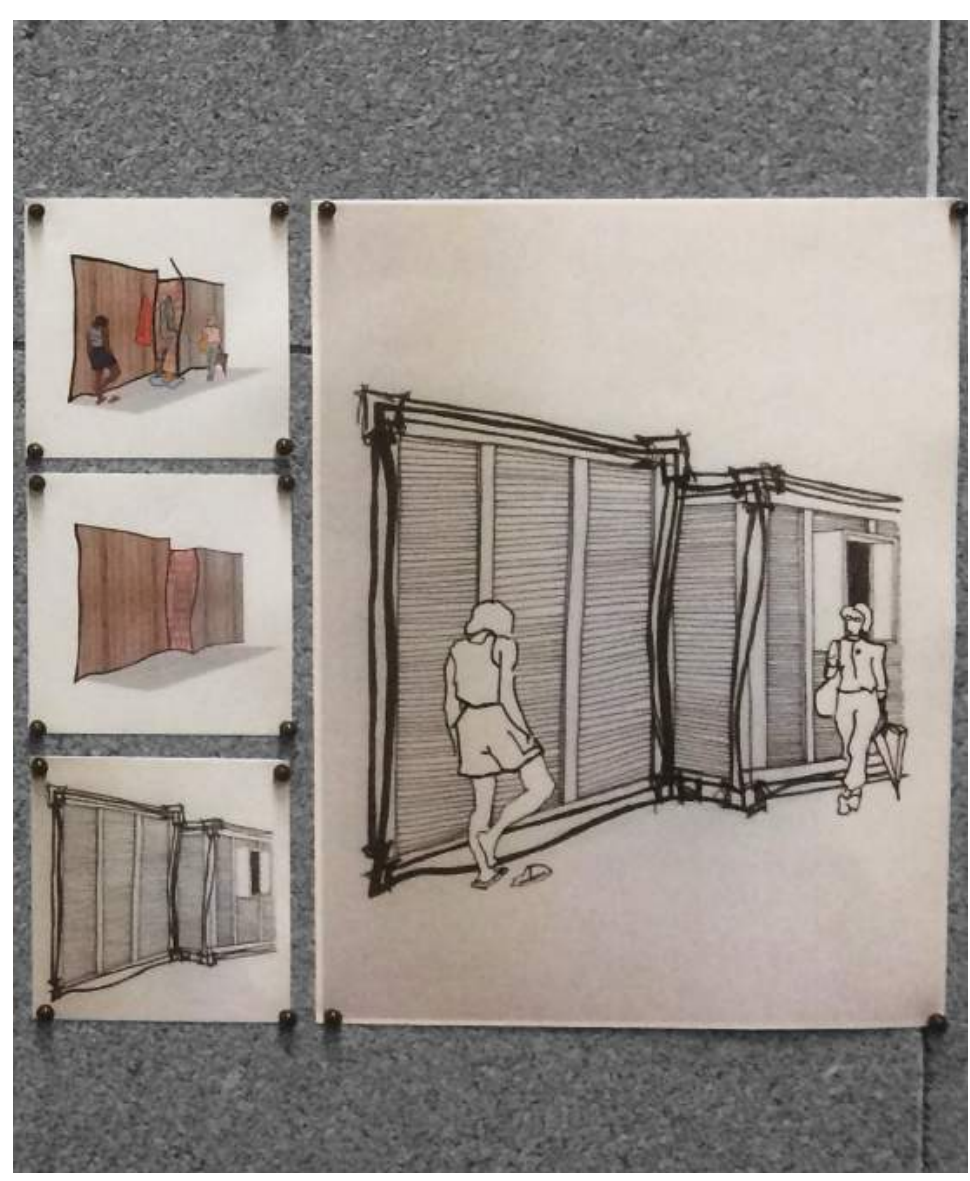

As a series of drawings, this tendency remained past the change of programme. When the change did occur, it was a realisation of the role of architecture, and the role of the designer

Designing for people does not just mean drawing people.

I was drawing the intended outcome instead of the cause. I was focussing on the vibe I wanted to create, instead of the space to facilitate that vibe. Increasing the detail in the cartoon drawing
enhanced the richness of spaces, allowing users to inhabit with

$\Delta$ Fig 3.20. The process of pushed the design forward: digitally removing the people, drawing in ideas for
structure and detail, and reinserting the people to winstead of a drawing depicting them with the assumption they would.

This breakthrough was the change needed for the value of the thinking hand side of the bionic hand coming directly from brain to pen in developing intimacy of space through material, detail and tectonic. 


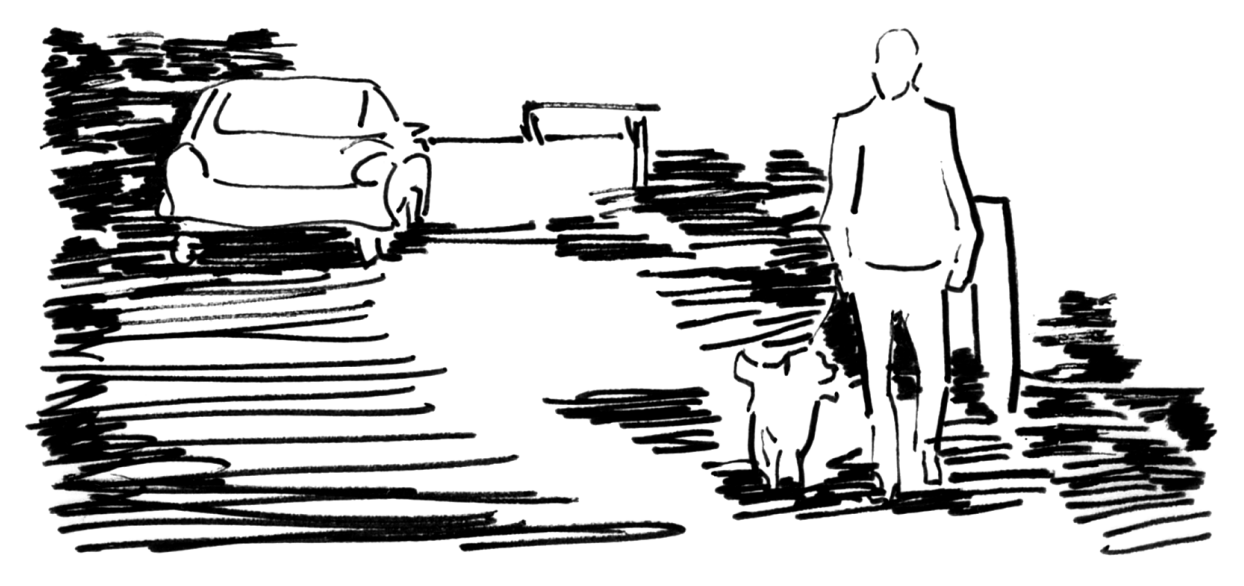

Conclusions 


\section{Conclusion Overview}

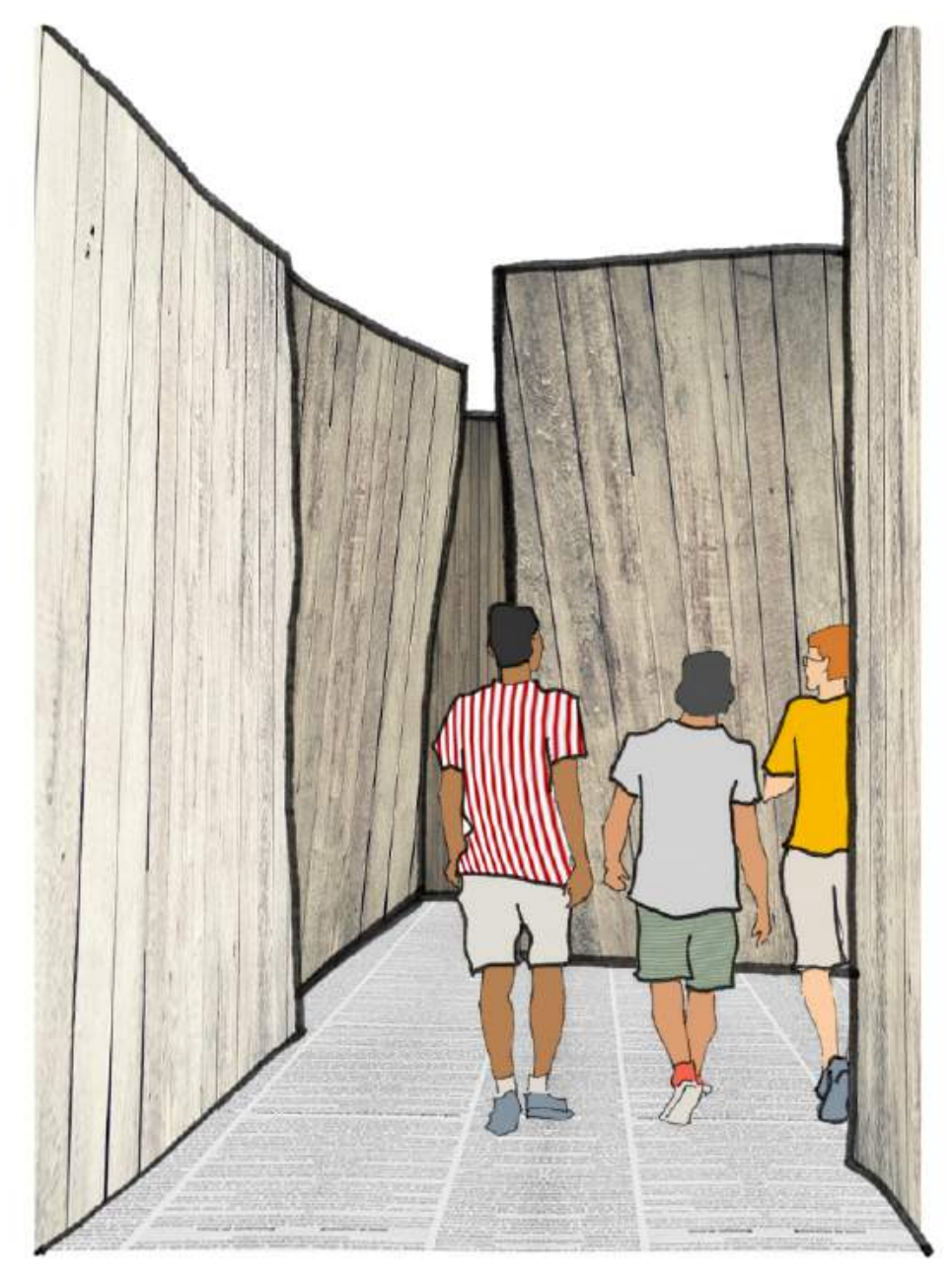

I based my research around the idea of the bionic hand. That is, the way the efficiency of digital tools can work with the inherent connection between imagination and work through the hand. T investigated the role of this within the for
intimate architecture.

Upon reflection of my own tendencies in method, I became interested in the role of hand led design in a world of ever advancing digital technologies. Adjacent to this, analysis of my designing showed an affinity toward spatial and material complexity in creation of intimacy. From the combination of these interests, I asked the question:

How can emerging technologies and 'the thinking hand' augment each other in the design and construction of intimate architecture?

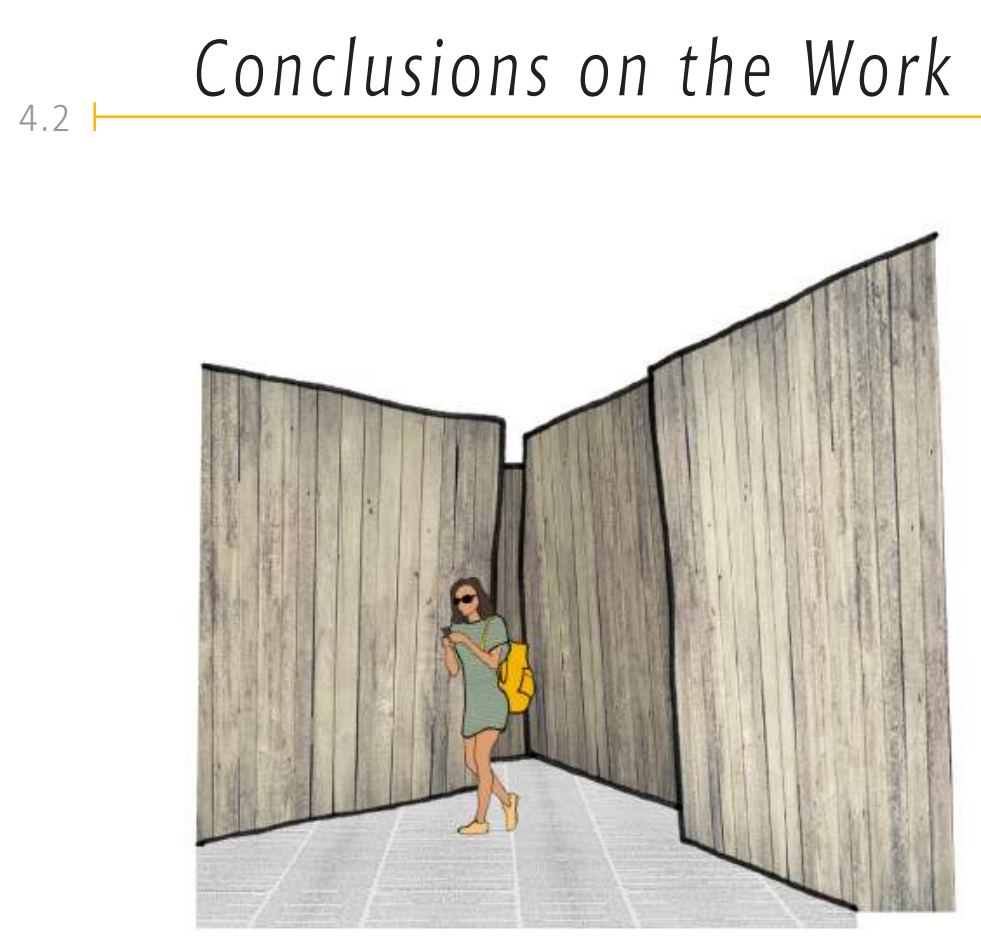

The final building is six town houses within a single site, and the same structural exoskeleton frame. Each house spans three levels including a private balcony. The houses are each unique in irregular planning. the user and the architecture, walls create moments of intimacy between intensity" (Bachelard, 1957). This intimacy is between the buildinos, in shared circulation space under overhanging sloped walls, and 'stoop' spaces to sit. Within the homes, intimacy is in the richly crafted living areas, bespoke furniture and stairway thresholds. Achieving these goals of intimacy and richness was through the bionic hand in the architecture's form and formation.

Part of the identified context of the design was Hataitai as a suburb - and Hataitar as an example of New Zealand suburbia. The goal of the research stream, that this project fits into, is the development of Hataitai as an urban sub-centre for a densifying Wellington. For Hataitai to achieve this it needs to density from the centre outwards, creating active engaged streets as it does. This was an issue to addres in my design. How can complex architecture still contribute to an engaged street front? Early designing in testing shape and angle of the plan resulted in similar issues to Park Mews. In the same way that I was creating nooks in the building interior, I was presenting negative space to the street. Upon reflection, I consciously straightened the street edges. This presents the vibrancy of living to the street, including the entrance to the semi-private social spaces whin the shard circhlation spaces. The Euclidian geometry of the street front hides the private moments and complexity reserved for the dweller within the structure. 
Through the bionic hand I created the complexity and intimacy in the building. As design led research, the intention of this project was documenting and analsing my own design process. This analysis gave rise to understanding bion bic hand. Crical reflection across the designing were through the ous The The The steng of designing.

While I naturally generated ideas through drawing, my designing became most efficient when I used the digital tool of dynamo to augment it. Making changes to the form on dynamo was easy through changing sliders on the script. However, it did not allow me to explore richness and intimacy of material, or visual richness of elements such

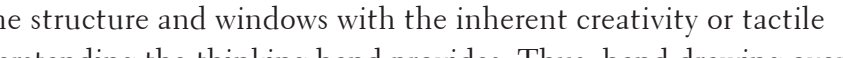
ing the thinking hand provides. Thus, hand drawing over the dynamo frame utilised the strengths of both of these processes.

Digitally editing drawings and model photographs was another way of augmenting the hand and the digital. Knowledge that through photoshop I could fix mistakes, gave me confidence to draw quicker, making the work of the thimking hand more efficient.

Digital tools providing support allowed the thinking hand to be the true driver of the designing. Therefore, understanding and proper use of the thinking hand was parm the drawing and building allowed progression of the thinking hand in designing. Early drawing focussed on human activity in the building. By removing the people and drawing tectonic, material, structure and craft instead, I got back to progressing the actual building design. This realisation made me appreciate my role as a designer of these physica phenomena - not a creator of behaviou

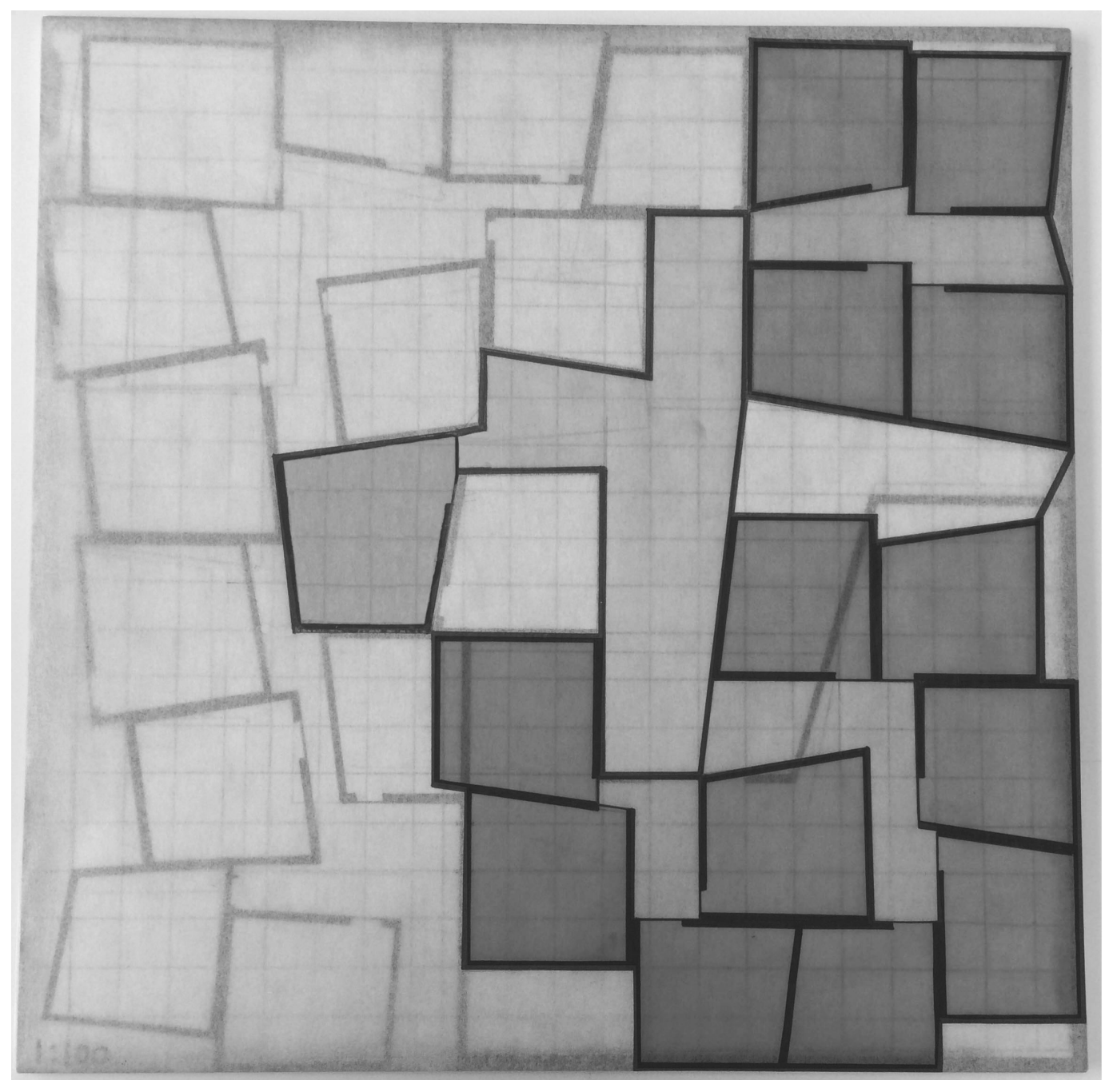




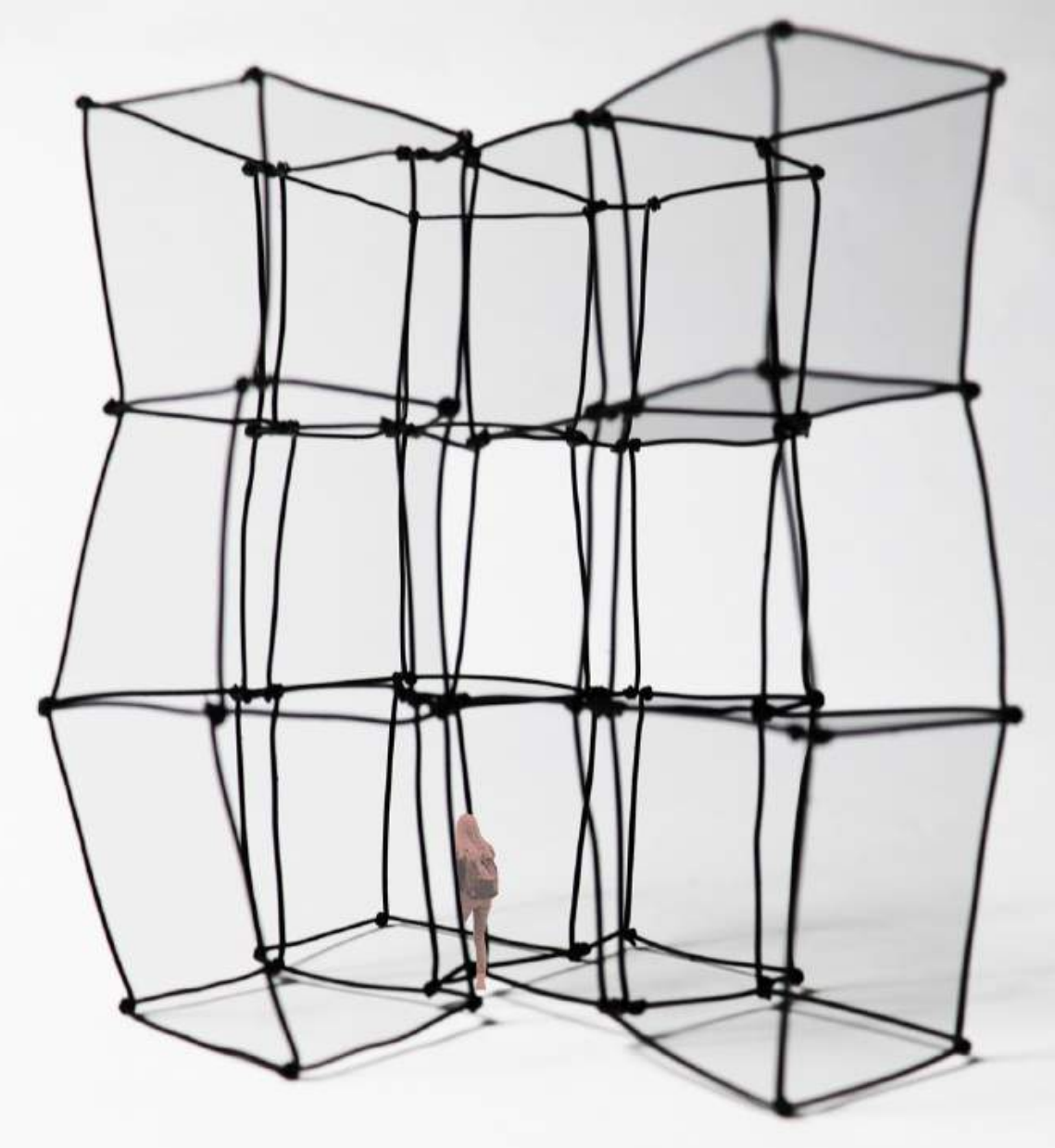

The strengths of each side of the bionic hand in the final form of the architecture accommodate the spatial complexity and richness.

Understanding the thinking hand in designing allowed me to

understand the language and intimacy I had developed in the building form. Inherent wonkiness of hand drawing led to the wonky building language.

The complexity of this language created the opportunity for the efficiency of digital tools to simplify the construction. 3d printed nodes would accommodate the angles of the exoskeleton. While they were intended to save time in the construction, the process of prototyping them proved the printing and sorting process of the high number of nodes would not make them the 'just click print' process they may seem. However, this use of digital tools makes the construction an easier process for the contractor. This therefore begins to address the main hurdle of complex design - it is so difficult to build.

In the same way digital tools make construction of the building easier, hand crafted elements of construction nake building actively more laborious. One role or the thinking hand in the building form is as tactile, rich material for dwelling spaces of the building. The inconsistency of hand making brings wonkiness and irregularity as interest. The inefficiency of this way of making is the reason projects such a Walmer Yard were so challenging to construct. Therefore, the panels, originally intended to line the full interior, were concentrated just to spaces for diclling. living spaces. This gave hichachy to the building for its intention in intimacy, and balanced the high levels of labour with the benefit of the panels.

The intention of the project is bringing intimacy and richness to realistically constructible housing. Use of the bionic hand in designing the building was an efficient design process towards this. Balance bete 


\section{Opportunities for the Future}

The bionic hand is a way of working and building that is only going to become more relevant as digital technologies advance. Therefore, his research tis a stanting point for my method of design in the future. Analysis and critique of my own process gave me understanding of
strengths and weaknesses of design processes to use moving forward.

In the scope of this research, I explored the relevance of the bionic hand in intimate architecture. have a wider relevance than this. Processes such as digital editing of drawing and tracing over easily adaptable digital models are relevant to most building design.

There are opportunities within this project relating to the bionic hand that with more time I would have liked to explore. It is the bionic hand in the final form of my building, which provides the most opportunity for development. In the final form, the digital side of the bionic

hand exists only as the digitally fabricated nodes. The thinking hand manifests as the planning, building language, and bamboo panels. The remaining construction is broadly conventional. More of the building's detailing could harness the potential efficiencies digital fabrication allows. This would change the nature of the construction in the same way the nodes do. Transferring labour from intricate, on site, repetitive work to digitally fabricated work makes the construction easier for contractors and thus a better building when evaluated holistically, as contractors are stakeholders whose experience must be considered.

The research investigates opportunities within the discipline of

designing complexity. High levels of labour in projects such as Walmer Yard, led me to explore ways to address this. The key finding of the role of digital fabrication as a way to build more efficiently is a starting block towards making complex design more feasible. Not only does it make the complexity more constractible, it can push the complexity further as well. In the same way Walker described the concete blocks as giving him freedom to design 90 degreo conners, the 3 dpinted

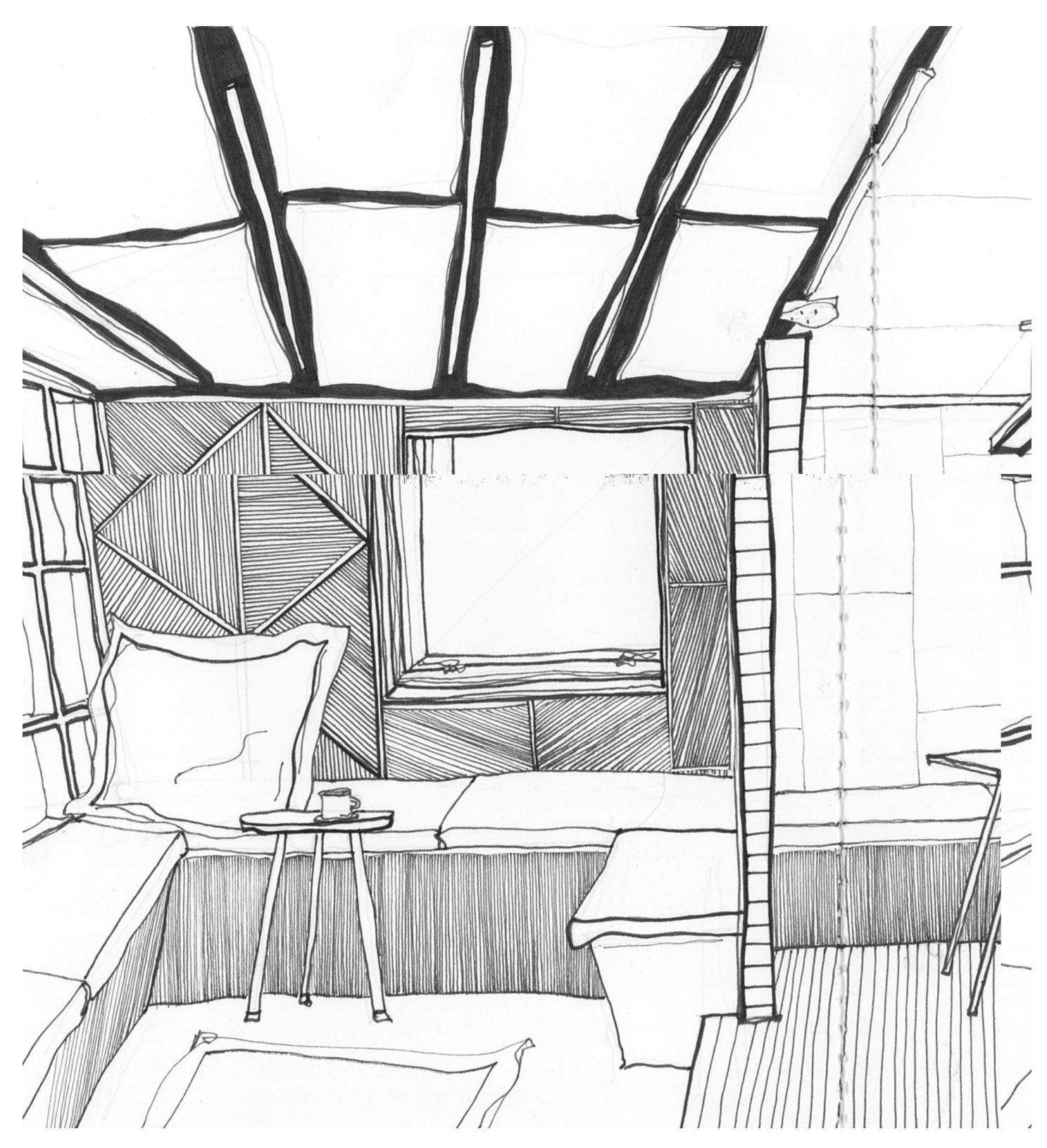

ig 3.6. Intimate dwelling space hand was used to create. 


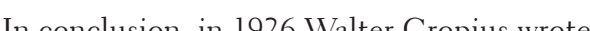

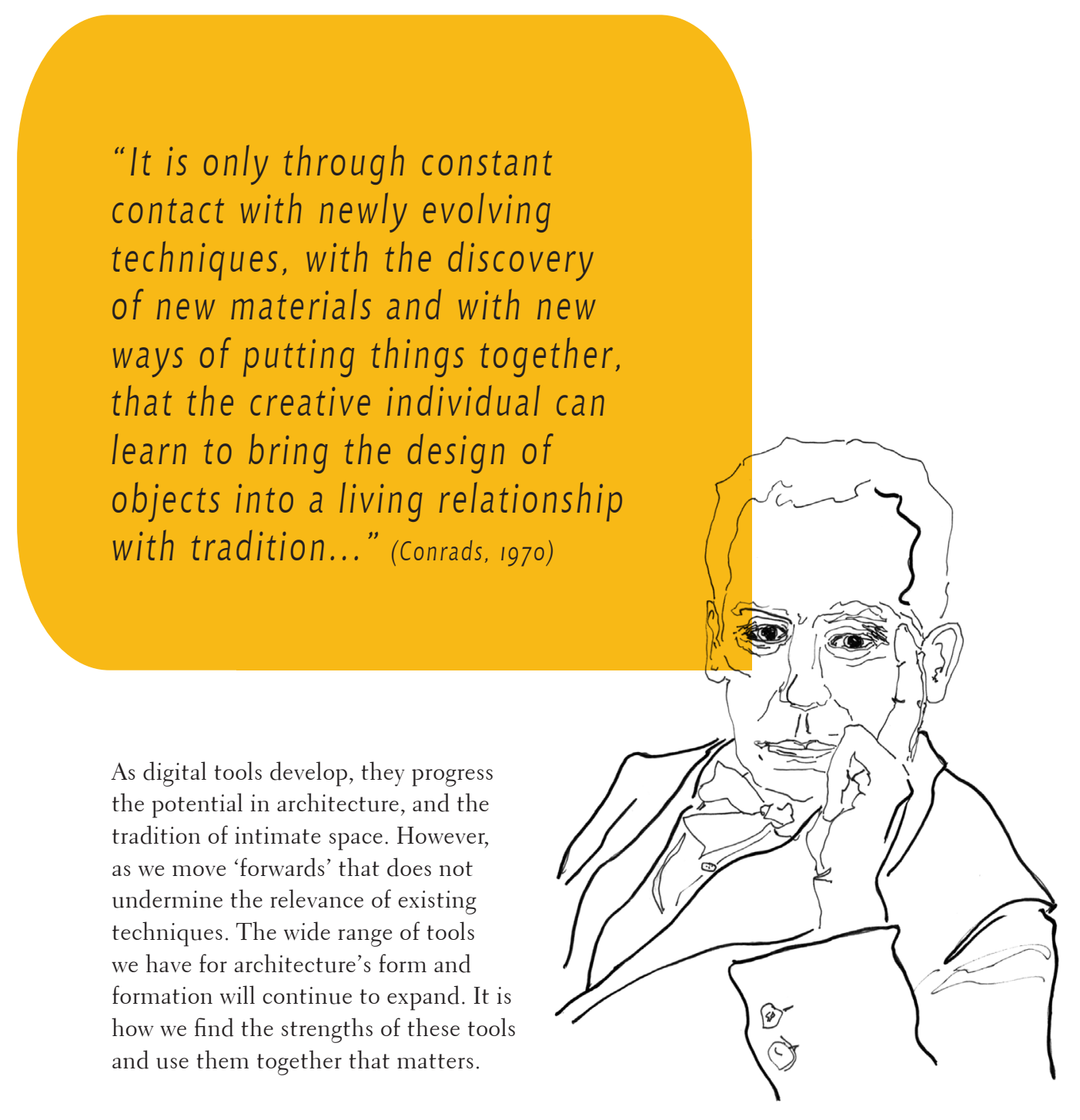

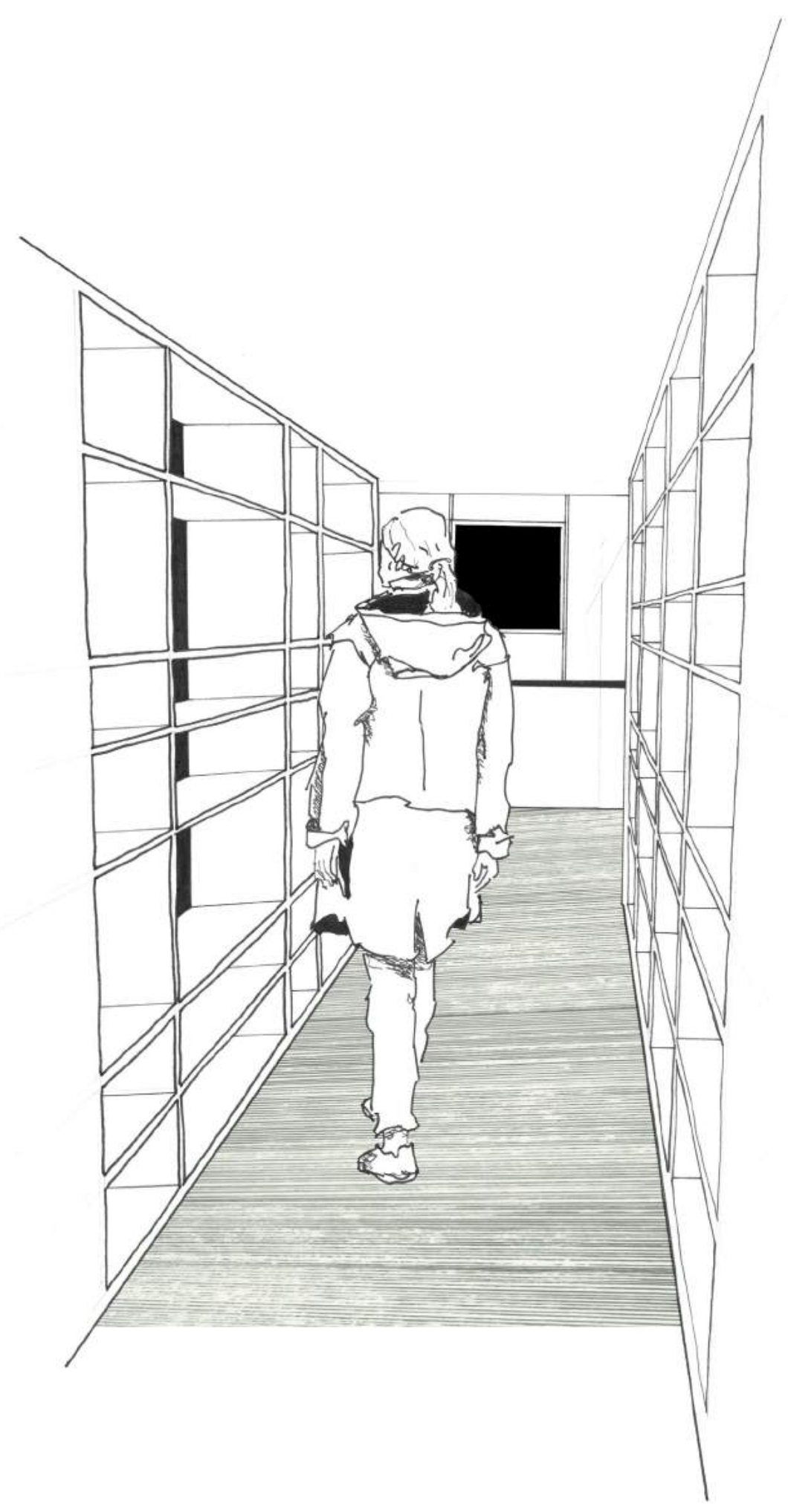


- Aalto, A., \& Schildt, G. (1998). Alvar Aalto in his own words / edited, with introduction by Coran Schildt New York: New York : Rizzoli.

- Ardern, J. (2018). Full text: PM's speech to the United Nations.

- Bachelard, G. (1957). The poetics of space / Gaston Bachelard. Translated from the French by Maria Jolas. Boston: Boston : Beacon Press.

- Conrads, U. (1970). Programmes and manifestoes on 20th-century architecture / translated [trom the German] by Michael Bullock. London: London, Lund Humphries.

- Cook, P. (2016). Architecture Workbook: Design through Motive: United Kingdom: John Wiley \&amp; Sons Inc.

- Deamer, P. (2015). The architect as worker : immaterial labor, the creative class, and the politics of design / edited by Peggy Deamer: London. New York : Bloomsbury Academic.

- Gehl, J. (2010). Cities for people / Jan Gehl. Washington, DC Washington, DC : Island Press.

- Kernohan, D. (1989). Wellington's new buildings : a photographic guide to new buildings in central Wellington / David Kernohan With the assistance of Marilyn McHaffie and Keith Small. Photographs by Gavin Woodward. Sketches by John Gray. Wellington [N.Z.]: Wellington N.Z. : Victoria University Press.

- Kieran, S. (2008). Loblolly House e elements of a new architecture Stephen Kieran, James Timberlake. Preface by Barry Bergdoll. Introduction by Michael Stacey (1st ed.. ed.). New York: New York : Princeton Architectural Press.

- Littlejohn, D. (1984). Architect : the life and work of Charles W. Moore David Littlejohn (1st ed.. ed.). New York: New York : Holt, Rinehart

- London, G. (2003). Houses for the 21st century / Geoffrey London .. [et al.]. Balmain, N.S.W.: Balmain, N.S.W. : Pesaro.

- Melling, G. (1985). Positively architecture! : New Zealand's Roger Walker / by Gerald Melling. Dunedin, N.Z: Dunedin, N.Z. Square
- Moore, C. W. (1978). The work of Charles W. Moore / [editor, Toshi .

- Mullins, C. (2004). Rachel Whiteread/Charlotte Mullins. London: London : Tate Pub.

- Pallasmaa, J. (2012). The Eyes of the Skin: Architecture and the Senses. Somerset: Somerset: John Wiley \& Sons, Incorporated.

- Pallasmaa, J. (2017). Embodied and Existential Wisdom in Architecture: The Thinking Hand. Body \& Society, 23(1), 96-111. doi:10.1177/1357034X16681443

- Sheil, B. (2012). Manufacturing the bespoke : making and prototypin architecture / Bob Sheil. Hoboken, N.J. : Chichester: Hoboken, N.J Chichester : Wiley. John Wiley distributor.

- Simmel, G. (1903). The Metropolis and Mental Life. Gary Bridge and Sophie Watson, eds. The Blackwell City Reader Oxford and Malden, MA. Wilev-Blackwell, 2002.

- Tafuri, M. (1976). Architecture and utopia : design and capitalist development / Manfredo Tifur. Trensted from the Italin by B Bara - Migia La Penta. Ca bridge, Mass: Combridge, Mass. MIT Press.

- Venturi, R. (1977). Complexity and contradiction in architecture Robert Venturi. with an introd. by Vincent Scully (2d ed.. ed.). New York : Boston: New York : Museum of Modern Art. Boston : distributed by New York Graphic Society.

- Walden, R. (1981). The Architectural review. AR, 169. 


\section{List of Figures}

\section{All figures not listed are authors own}

FIG 2.10: Rewi Thompson House. (2016, October 16). Retrieved from http://eyeofthefish.org/rewi-thompson-rip/

FIG 2.17: Aaron, P. (2006). The House at Twilight. Retrieved from https://kierantimberlake com/pages/view/20/oblolly-house/parent 3

FIG 2.40: Gourley, ). (2017, September 17). Untitled (Stairs) Photograph found in London]. Retrieved from hitps://www. theguardian.com/artanddesign/2017/sep/17/rachel-whiteread-tatebritain-review (Originally photographed 2001)

FIG 2.71: Moore-Rogger-Hofflander Condominium Building (n.d.) Retrieved from https://wwwlaconservancy.org/locations/moore-roggerhofflander-condominium-building

FIG 2.72: Condominium One housing. (2018, September 25). Retrieved

architecture-environment-idealism-iennifer-dunlop-fletcher-sfmoma/

FIG 2.73: Sweeping. (2015, January 16). Retrieved from https://www. stuff.co.nz/dominion-post/news/65138113/null

IIG 2.74: Buck House, Havelock North. (2015). Retrieved from https:/ www.thearts.co.nz/artists/sir-ian-athfield

HG 2.75: Large house in Khandallah, Wellington. (n.d.). Retrieved from http://www.rogerwalker.co.nz/rw-houses/

FIG 2.76: Binet, H. (2016, December 06). Walmer Yard Street Retrieved from https://www.archdaily.com/800485/walmer-yard-petersalter (Originally photographed 2016)

\section{FIG 2.77 and FIG 3.17 INCLUDE:}

-Müllerova vila. (n.d.). Retrieved from https://adolfloos.cz/en/ villa-muller

•Buszek, M. (2010, June 02). Vanna Venturi House. Retrieved from https://www.archdaily.com/62743/ad-classics-vanna-venturihouse-robert-venturi

- Venturi, R., \& Scott-Brown, D. (1966). "Brown in the Las Vegas desert with the strip in the background" (1966). Retrieved from https://www.grazia.it//oto-gallery/totogallery-il-postmodernismoin-mostra-al-va-museum-di-londra
- Roger and son and Ferrari (2016). Retrieved from https://www nzia.co.nz/explore/interviews/roger-walker-in-conversation

- Belmont, Lower Hutt, (n.d) Retrieved from https//www professionals.co.nz/property/RED19022/belmont/

- Chris Macdonald and Peter Salter on their Osaka pavilion. (2010, March 26). Retrieved from https://www.bdonline.co.uk/ japanese-lessons/3160780.article

- Enric Miralles. (n.d.). Retrieved from http://www.blogarchkuleuven.be/?filter_department=11/exhibitions recommended-exhibition-enric-miralles-with-time/

•Benedetta Tagliabue. (2012, December 27). Retrieved from https://blog.a-cero.com/benedetta-tagliabue-y-su-granparlament

-Scottish Parliament Skylights. (n.d.). Retrieved December 27, 2012, from Benedetta Tagliabue. (2012, December 27). Retrieved from https://blog.a-cero.com/benedetta-tagliabue-ysu-gran-parlamento/

• Binet, H. (2016, December 06). Walmer Yard Courtyard.

Retrieved from https://www.archdaily.com/800485/walmer-yardpeter-salter

• Salter, P. (2016, December 06). Walmer Yard Sketch. Retrieved from https://www.archdaily.com/800485/walmer-yard-peter-salter

FIG 2.81: Salter, P. (2016, December 06). Walmer Yard Plans. Retrieved from https://www.archdaily.com/800485/walmer-yard-peter-salter

FIG 2.82: Binet, H. (2016, December 06). Walmer Yard Balcony. Retrieved from https://www.archdaily.com/800485/walmer-yard-petersalter (Originally photographed 2016)

FIG 2.84: Binet, H. (2016, December 06). Walmer Yard Office Space. Retrieved from https://www.archdailv.com/800485/walmer-yard-petersalter (Originally photographed 2016)

FIG 2.138: All images CCO liscence sourced trom: www.pexels.con 